Portland State University

PDXScholar

1996

\title{
A Methodology for Regional Seismic Damage Assessment and Retrofit Planning for Existing Buildings
}

Thomas C. McCormack

Portland State University

Follow this and additional works at: https://pdxscholar.library.pdx.edu/open_access_etds Let us know how access to this document benefits you.

\section{Recommended Citation}

McCormack, Thomas C., "A Methodology for Regional Seismic Damage Assessment and Retrofit Planning for Existing Buildings" (1996). Dissertations and Theses. Paper 1239.

https://doi.org/10.15760/etd.1238

This Dissertation is brought to you for free and open access. It has been accepted for inclusion in Dissertations and Theses by an authorized administrator of PDXScholar. Please contact us if we can make this document more accessible: pdxscholar@pdx.edu. 
A methodology for regional seismic damage assessment and retrofit planning for existing buildings McCormack, Thomas Craig

\section{INFORMATION TO USERS}

This manuscript has been reproduced from the microfilm master. UMI films the text directly from the original or copy submitted. Thus, some thesis and dissertation copies are in typewriter face, while others may be from any type of computer printer.

The quality of this reproduction is dependent upon the quality of the copy submitted. Broken or indistinct print, colored or poor quality illustrations and photographs, print bleedthrough, substandard margins, and improper alignment can adversely affect reproduction.

In the unlikely event that the author did not send UMI a complete manuscript and there are missing pages, these will be noted. Also, if unauthorized copyright material had to be removed, a note will indicate the deletion.

Oversize materials (e.g., maps, drawings, charts) are reproduced by sectioning the original, beginning at the upper left-hand corner and continuing from left to right in equal sections with small overlaps. Each original is also photographed in one exposure and is included in reduced form at the back of the book.

Photographs included in the original manuscript have been reproduced xerographically in this copy. Higher quality 6" $\mathrm{x} 9$ " black and white photographic prints are available for any photographs or illustrations appearing in this copy for an additional charge. Contact UMI directly to order.

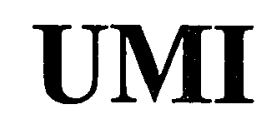

A Bell \& Howell Information Company

300 North Zeeb Road, Ann Arbor MI 48106-1346 USA

$313 / 761-4700 \quad 800 / 521-0600$ 
Reproduced with permission of the copyright owner. Further reproduction prohibited without permission. 
A METHODOLOGY FOR REgIONAL SEISMIC DAMAGE ASSESSMENT AND RETROFIT PLANHING FOR EXISTING BUILDINGS

by

THOMAS MCCORMACK

A dissertation submitted in partial fulfillment of the requirements for the degree of

\author{
DOCTOR OF PHILOSOPHY \\ in \\ SYSTEMS SCIENCE:CIVIL ENGINEERING
}

Portland State University

1996

Reproduced with permission of the copyright owner. Further reproduction prohibited without permission. 
UMI Number: 9635653

UMI Microform 9635653

Copyright 1996, by UMI Company. All rights reserved.

This microform edition is protected against unauthorized copying under Title 17, United States Code.

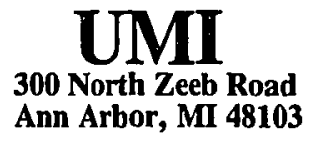

Reproduced with permission of the copyright owner. Further reproduction prohibited without permission. 


\section{DISSERTATION APPROVAL}

The abstract and dissertation of Thomas McCormack for the Doctor of Philosophy in Systems Science:Civil Engineering were presented on June 14, 1996, and accepted by the dissertation committee and the doctoral/program.

COMMITTEE APPROVALS:

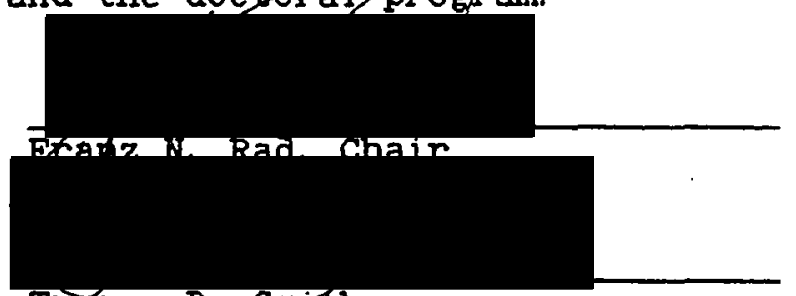

Trevor Di-smith

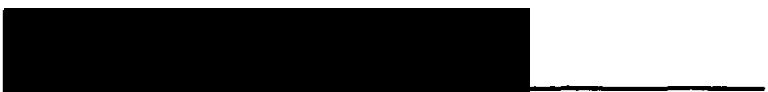

Wende 1 in $H$. Mueller

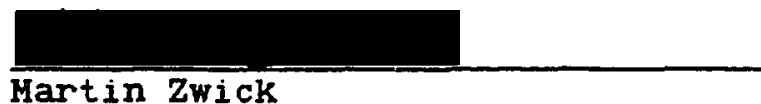

DOCTORAL PROGRAM APPROVAL:

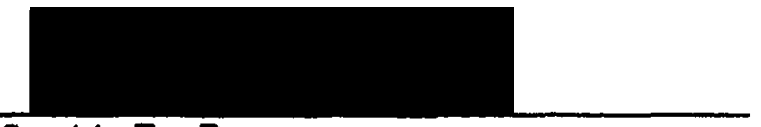

Scott F. Burns

Representative of the Office of Graduate Studies

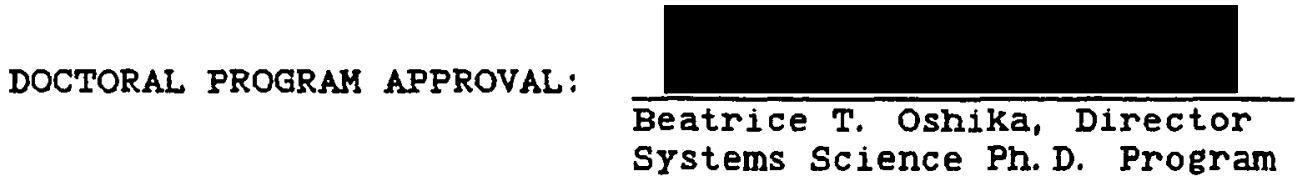

ACCEPTED FOR PORTLAND STATE UNIVERSITY BY THE LIBRARY by

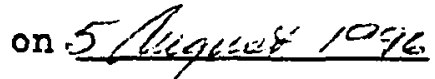




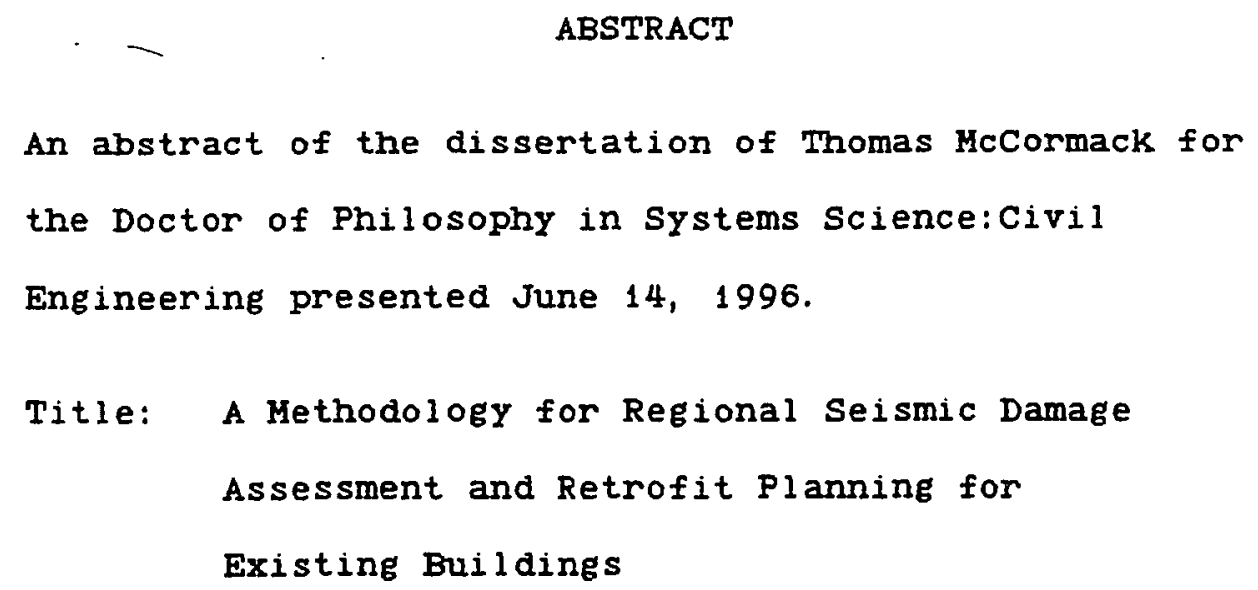


Building inventory data from a rapid visual screening survey of individual buildings form the basis for modeling structural variations. Earthquake Hazard Maps are the basis of modeling the effect on building damage of ground motion amplification, soil liquefaction, and slope instability.

Published retrofit effectiveness estimates and retrofit cost data are used to estimate post-retrofit damage avoided, lives saved, and retrofit cost. A Building Classification System is formulated to aggregate buildings with similar retrofit benefit magnitudes.

A cost-benefit analysis is used as the basis for a retrofit prioritization and efficiency analysis, to establish the cut-off point for an optimal retrofit program. Results from an Expected Value and a Scenario Earthquake Event are compared.

Regional Earthquake Loss and Retrofit Analysis Program (REAL-RAP) software was developed, and used to make a loss estimate for more than 7,500 bulldings inventoried in the 1993 Portland Seismic Hazards Survey. One hundred percent of the loss of life is attributed to only 10-percent of the buildings.

A retrofit analysis is made for a Design Basis Earthquake. Twelve-percent of the building inventory was identified for the optimal retrofit program, wherein 98-percent of the loss of life is avoided at less than 
one-quarter the cost of retrofitting all the buildings.

An alternate optimal retrofit program was determined using an Expected Value Analysis. Most of the buildings in the Design Basis Earthquake optimal retrofit program are also contained in the alternate program. 
DEDICATION

This dissertation is dedicated to my wife,

Susan K. McCormack, for her love, unselfish support, and faith in me, without which the project could not have been completed. 


\section{ACKNOWLEDGEMENTS}

Dr. Franz N. Rad, Chair of Civil Engineering, Portland State University, originally conceptualized the integration of the ATC-13 damage data and the ATC-21 inventory scoring system. The present research fleshes out this concept, and Dr. Rad deserves special thanks for inspiring and supervising this project.

Thanks also to Dr. Gerry Uba of METRo, who administered the Portland Seismic Hazards Survey, which provided the building inventory data for this research.

Thanks to the members of my committee, for providing helpful review and commentary on the dissertation:

Dr. Trevor Smith, Dr. Wendel in Mueller, Dr. Martin Zwick, and Dr. Scott Burns.

Thanks also to Richard McKenzie, PSU Civil Engineering student, for his assistance on the regressions and the graphics presentations. 
TABLE OF CONTENTS

PAGE

ACRNOWLEDGEMENTS . . . . . . . . . . . . . . . . . . iii

LIST OF TABLES . . . . . . . . . . . . . . . . . . . $\mathrm{xi}$

LIST OF FIGURES . . . . . . . . . . . . . . . . . . xviii

CHAPTER

I INTRODUCTION . . . . . . . . . . . . . . . 1

Problem Definition........... . 1

General Nature of the Problem . . . . 4

Systems Approach

System Defined

Multi-Disciplinary Aspects

Complexity

Uncertainty

Decision Theoretic Considerations

II LITERATURE REVIEW . . . . . . . . . . . . 14

ATC-13: Earthquake Damage Evaluation

Data for California . . . . . . . . 14

Earthquake Shaking Characterization

Facility Classifications

Physical Damage Caused by

Ground Shaking

Death and Injury Estimates

Significance and Limitations

ATC-21: Rapid Visual Screening of

Buildings for Potential Seismic

Hazards: A Handbook. . . . . . . . 26

Rapid Screening Procedure

Seismicity

Scoring System

Basis of the Scoring System

Significance and Limitations 
Portland Seismic Hazards Survey . . . 36

Building Inventory Database

Range of Estimated Number of People

Post-Benchmark Year

Significance and Limitations

State of Oregon Seismic Design

Mapping

Earthquake Sources

Seismic Hazard Analysis

Limitations and Significance

Earthquake Hazard Maps of the

Portland Quadrangle . . . . . . . 44

Liquefaction Susceptibility Map

Lateral Spread Displacement Map

Ground Motion Amplification Map

Dynamic Slope Instability Map

Relative Earthquake Hazard Map

Significance and Limitations

FEML-227: A Benefit-Cost Model

for Seismic Rehabilitation

of Buildings. . . . . . . . . . .

Expected Net Present Value Model without the Value of Life

Expected Ket Present Value Model with the Value of Life

Benefit/Cost Ratios

Significance and Limitations

FEMA-156: Typical Costs for Seismic

Rehabilitation of Existing

Buildings, Second Edition . . . .

Significance and Limitations

Limitations of Current Practice . .

Earthquake Loss Modeling

Retrofit Decision Analysis

Outline of the Research . . . . . . . 
IV DEVELOPMENT OF AN EARTHQUAKE LOSS

MODEL FOR EXISTING BUILDINGS . . . . . . . 84

Formats for Expressing Seismic

vulnerability . . . . . . . . . . 85

Ground Motion Characterization

Damage Function Format

Fragility Curve Format

Significance and Limitations

The Basis of the ATC-21 Scoring

System . . . . . . . . . . . 89

The Basic Structural Hazard Score

Extension to Non-California Bldgs

Performance Modification Factors

Development of a Technique to

Derive Damage Factor from

Structural Score........ . 100

Development of Fragility Curves Based

on Performance Modifiers. . . . . 110

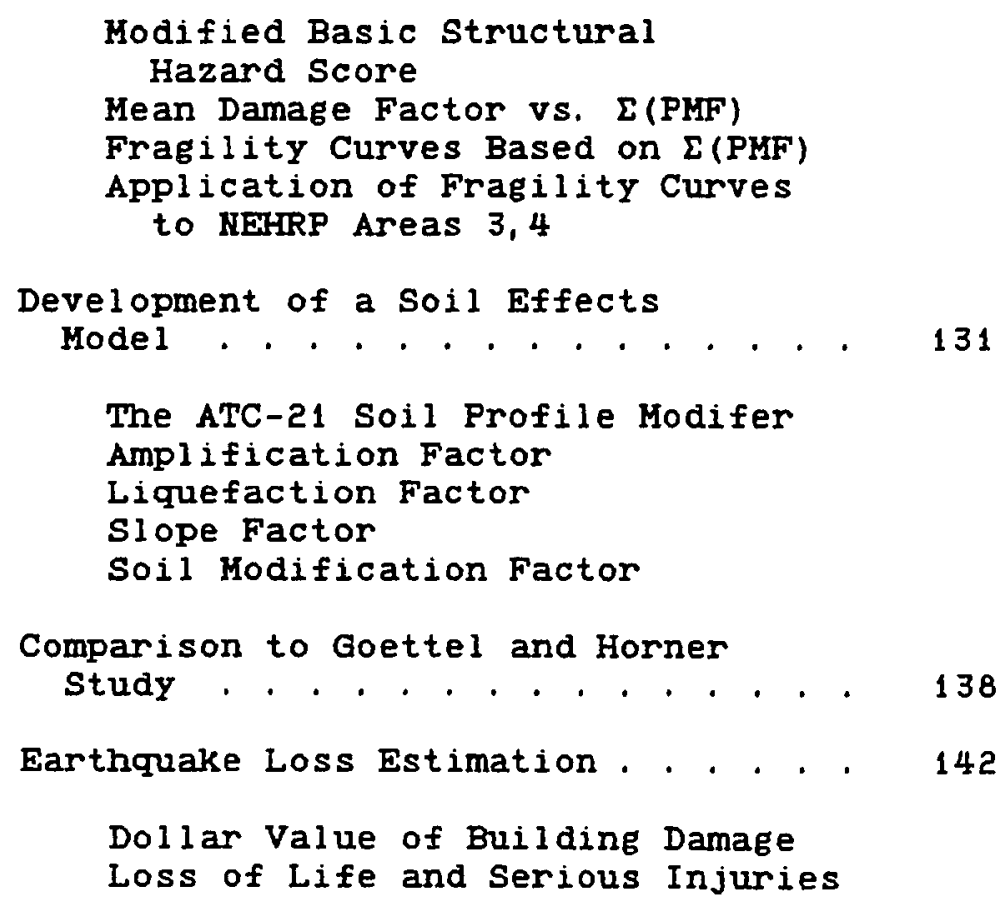


$\mathrm{V}$ DEVELOPMENT OF A RETROFIT DIRECT

BENEFIT AND COST MODEL . . . . . . . . . . 148

Retrofit Effectiveness Model . . . . . 149

Retrofit Direct Benefit Model . . . . 159

Retrofit Cost Model . . . . . . . . 160

VI DEVELOPMENT OF A REGIONAL RETROFIT

PLANNING METHODOLOGY . . . . . . . . . . . 164

Building Classification System . . . . 164

Retrofit Cost-Benefit Analysis . . . 167

Dollar Value of Life-Safety Benefits

Scenario Earthquake Event Analysis

Expected Value Analysis

Retrofit Prioritization and

System Optimization . . . . . . . . 171

VII DEVELOPMENT OF REGIONAL EARTHQUAKE

LOSS AKD RETROFIT AKALYSIS SOFTWARE . . . 173

Earthquake Loss Estimation Modules . . 173

DAM-FACT Module

DAMAGE-\$ Module

LIFELOSS Module

DAM-SUM Module

REGION-L Hodule

Retrofit Direct Benefit and

Cost Modules... . . . . . . . . 180

RETRO-DF Hodule

RETRO-\$D Module

RETRO-LL Module

RFBEN-** Hodule

Regional Retrofit Classification, Prioritization, and Optimization

Modules . . . . . . . . . . . . 185

BCS-RBEN Module

RETRO-BC Hodule

EXP-VAL Module

SORT-BC Module

SYST-EFF Hodule 
VIII EARTHQUARE LOSS ESTIMATE OF THE PORTLAND, OREGON QUADRANGLE . . . . . . . 189

Non-Residential Building Stock

Building Type, Area, and Structural score

Soil Modification Factor

Occupancy Type and Number of Occupants

Loss Estimates for Four Scenario

Earthquake Events... . . . . . 193

Loss Estimates for the Design

Basis Earthquake. . . . . . . . . 198

Damage and Loss of Life by Structure Type

Total Dollar Value of Loss

Loss of Life by Structural Score

Loss of Life by Soil Modification Factor

Loss of Life by Number of People

Damage State by Building Type

Comparison to Kobe City Earthquake of 1994

Losses Attributable to the

Performance Modifiers

IX RETROFIT ANALYSIS OF THE

PORTLAND, OREGON QUADRANGLE . . . . . . . 206

Post-Retrofit Earthquake Loss

Estimates for Four Scenario

Earthquake Events Following

Full Retrofit . . . . . . . . . . . 207

Development of an Optimal Retrofit

Program for the Design

Bas is Earthquake. . . . . . . . . 212

Total Value of Retrofit Benefits

Retrofit Prioritization by

Building Class

System Efficiency

Parameters of the Optimal

Retrofit Program 
Comparison of Optimal Retrofit to Full Retrofit

Building Class Indices in the Optimal Retrofit

Sensitivity Analysis

Development of an Optimal Retrofit

Program Based on an Expected

Value Analysis ...................

Present Value of Full Retrofit

Retrofit Prioritization by Building Class

System Efficiency

Parameters of the Optimal

Retrofit Program

Building Class Indices in the Optimal Retrofit

Comparison of Expected Value and Design Basis Retrofits

CONCLUSIOKS

Earthquake Loss and Retrofit

Modeling . . . . . . . . . . . . 240

Regional Retrofit Planning Model . . . 241

Computer Software Development . . . . 242

Earthquake Loss Estimate of the Portland Quadrangle . . . . . 242

Retrofit Analysis of the Portland Quadrangle . . . . . . . 244

Limitations in Applying this Research . . . . . . . . . . 247

Recommendations for Further Research . . . . . . . . . . 248

REFERENCES CITED . . . . . . . . . . . . . . . . . . 251 
APPENDICES

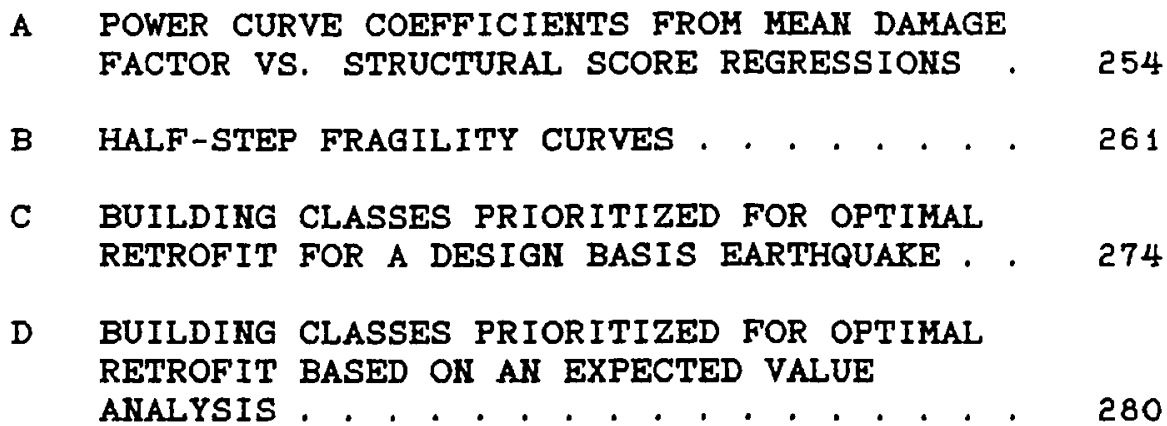




\section{LIST OF TABLES}

PAGE

TABLE

I Modified Mercalli Intensity Scale . . . . 15

II ATC-13 Facility Classes and Numbers . . . 17

II ATC-13 Damage State Descriptions . . . . . 21

IV ATC-13 Injury and Death Rates . . . . . . 23

V ATC-21 Building Types . . . . . . . . . . 27

VI ATC-21 Performance Modifiers . . . . . . . 28

VII ATC-21 Seismicities and Earthquake

Intensities . . . . . . . . . . . 31

VIII ATC-21 Basic Structural Hazard Scores . . 32

IX Ranges of Estimated Number of People used in ATC-21 and PSHS-93 . . . . . . 39

X Post-Benchmark Years used in PSHS-93. . . 40

XI PGA on Rock and Recurrence Intervals for

Portland (Geomatrix Consultants 1995) . 43

XII Liquefaction Susceptibility from

GMS-79 Plate 1 . . . . . . . . . . . . 48

XIII Lateral Spread Displacement from

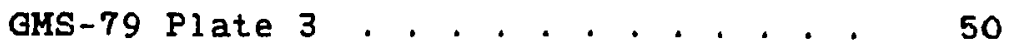

XIV Ground Motion Amplification from

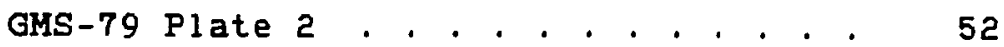


XV Relative Dynamic slope Instability from GMS-79 Plate 3 . . . . . . . . . . 53

XVI FEMA-156 Building Group Mean Cost . . . 70

XVII FEMA-156 Area Adjustment Factors . . . . 71

XVIII FEMA-156 Seismicity/Performance Objective Adjustment Factor . . . . . . . . 71

XIX FEMA-156 Location Adjustment Factor . . . 72

XX FEMA-156 Time Adjustment Factor . . . . 73

XXI Damage Function for Tilt Up Buildings

from ATC-13 Appendix G . . . . . . 86

XXII Weighted Statistics of the Damage Factor

for Tilt-up Buildings from

ATC-13, Appendix G . . . . . . . . 93

XXIII Damage Factor Modification Constants for

Non-California Buildings from

ATC-21-1 Table B3 . . . . . . . . 96

XXIV ATC-21 Seismicity by NEHRP Map Area . . . 97

XXV The Standard Normal Variate vs.

Structural Score . . . . . . . . 102

XXVI Structural Score vs. Mean Damage Factor for

Tilt-up Buildings (PC1) at $P G A=0.22 .104$

XXVII $\Sigma(P M F)$ vs. Mean Damage Factor for Tilt-up

at $\mathrm{PGA}=.22$ with $\mathrm{MC}=1.35 . . . . .113$

XXVIII $\Sigma(P M F)$ vs. Mean Damage Factor for Tilt-up

at $\mathrm{PGA}=.05$ with $\mathrm{MC}=1.35 . . . . .113$ 
XXIX $\Sigma(P H F)$ vs. Mean Damage Factor for Tilt-up at $\mathrm{PGA}=.10$ with $\mathrm{MC}=1.35 . . . . .114$

XXX $\Sigma(P M F)$ vs. Mean Damage Factor for Tilt-up at $\mathrm{PGA}=.47 \mathrm{with} \mathrm{MC}=1.35 . . . . .114$

XXXI $\Sigma(P M F)$ vs. Mean Damage Factor for Tilt-up at $\mathrm{PGA}=1.02 \mathrm{with} \mathrm{MC}=1.35 . . . .115$

XXXII PGA vs. Mean Damage Factor for Tilt-up at $\Sigma($ PMF $)=0$ with $\mathrm{HC}=1.35 . . . .115$

XXXIII ATC-21 Soil Profile and Ground

Amplification. . . . . . . . . . . 133

XXXIV Amplification Factor (AF) . . . . . . . . 134

XXXV Liquefaction Factor . . . . . . . . . . 136

XXXVI Slope Factor . . . . . . . . . . . . 137

XXXVII Unit Replacement Values (URV) . . . . . . 144

XXXVIII Fraction Dead vs. Central Damage Factor

from ATC-13 Table 9.3........ . 145

XXXIX Expected Retrofit Effectiveness (ERE)

for $W_{1}$ s3 Buildings... . . . . . . . 150

XL Expected Retrofit Effectiveness (ERE)

for C1, S1, S2, S4 Buildings . . . . 150

XLI Expected Retrofit Effectiveness (ERE)

for C3/S5, C2, PC2 Buildings . . . . . 151

XIII Expected Retrofit Effectiveness (ERE)

for RM Buildings . . . . . . . . . . . 151 
XLIII Expected Retrofit Effectiveness (ERE)

for URM, PC1 Buildings . . . . . . . . 152

XLIV Total Unit Retrofit costs for

Commercial Buildings, \$/SF . . . . . . 162

XLV Total Unit Retrofit Costs for

Institutional Buildings, \$/SF . . . . . 162

XLVI Total Unit Retrofit Costs for

Industrial Buildings, \$/SF . . . . . . 163

XLVII Number of Buildings, Area, and Average

Score by Building Type . . . . . . . . 190

XLVIII Number of Buildings by Range of

Structural Score (S) . . . . . . . 191

XIIX Number of Buildings by Range of Soil

Modification Factor (SMF) . . . . . . 191

L Lowpoint and Hidpoint of Range of

Number of People and Number of

Buildings by Occupancy Type . . . . . . 192

LI Summary of Losses for the Portland Quad

at $\mathrm{PGA}=.08$ (100 Year Return) . . . 194

LII Summary of Losses for the Portland Quad

at $\mathrm{PGA}=.20$ (500 Year Return) . . . 195

LII Summary of Losses for the Portland Quad

at $P G A=.27$ (1,000 Year Return) . . 196

LIV Summary of Losses for the Portland Quad

at $\mathrm{PGA}=.39(2,500$ Year Return $) . .197$ 
IV Loss of Life by Range of

Structural Score . . . . . . . . 200

LVI Loss of Life by Range of Soil

Modification Factor (SMF) . . . . . . . 201

LVII Loss of Life by Lowpoint and Midpoint

of Number of People Range,

by Occupancy Type... . . . . . . . 202

LVIII Number of Buildings in 2 Damage States

by Building TYpe . . . . . . . . . . 203

LIX Damage State Comparison to Kobe City

1995 Earthquake . . . . . . . . . . 204

LX Building Damage and Loss of Life

Attributable to Performance Modifiers . 205

LXI Summary of Losses for the Portland Quad

if All Bldgs are Retrofit

at $P G A=.08$ (100 Year Return) . . . 208

LXII Summary of Losses for the Portland Quad

if All Bldgs are Retrofit

at $P G A=.20$ (500 Year Return) . . . 209

LXIII Summary of Losses for the Portland Quad

if All Bldgs are Retrofit

at $\mathrm{PGA}=.27(1,000$ Year Return $) . .210$

LXIV Summary of Losses for the Portland Quad

if All Bldgs are Retrofit

at PGA $=.39(2,500$ Year Return $) .. \quad 211$ 
LXV Effect of Retrofitting All Buildings . . . 213

LXVI SYstem Parameters of Optimal Retrofit

Investment for a Scenario Earthquake

Event of PGA $=.20 . . . . . . . . . .217$

LXVII Comparison Between Complete Retrofit

and Optimal Retrofit . . . . . . . . 220

LXVIII Summary of Building Types and Occupancy

Groups Included in the Optimal

Retrofit Program . . . . . . . . . 221

LXIX Percentage of Building Types Included

in Optimal Retrofit Program . . . . . . 222

LXX Percentage of Occupancy TYpe Groups

Included in Optimal Retrofit Program . 223

LXXI Sensitivity Analysis Results . . . . . . . 225

LXXII Annual Expected Value of Full Retrofit. . 229

IXXIII System Parameters of Optimal Retrofit

Investment Based on an

Expected Value Analysis... . . . . 234

LXXIV Sumary of Building Types and Occupancy

Groups Included in the Optimal Retrofit

Program Based on an Expected

Value Analysis . . . . . . . . . 234

LXXV Percentage of Building Types Included in

Optimal Retrofit Program Based on

an Expected Value Analysis . . . . . 235 
xvii

LXXVI Percentage of Occupancy Type Groups
Included in Optimal Retrofit Program
Based on an Expected Value Analysis. . 236
LXXVII Comparison of System Parameters of
Expected Value vs. Design Basis
Optimal Retrofit Programs........ 238




\section{LIST OF FIGURES}

PAGE

\section{FIGURE}

1. NEHRP Map Areas of the United States

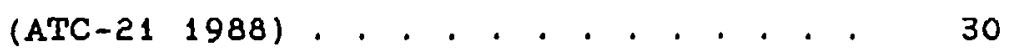

2. A Sample Page from the 1993 Portland

$$
\text { Seismic Hazards Survey Database. . . . } 38
$$

3. Liquefaction Susceptibility Map

$$
\text { (GMS-79, Plate 1) . . . . . . . . . } 45
$$

4. Ground Motion Amplification Map

$$
\text { (GMS-79, Plate 2) . . . . . . . . . } 46
$$

5. Lateral Spread Displacement and Dynamic

$$
\text { Slope Instability Map (GMS-79 Plate 3). } 47
$$

6. Earthquake Loss Modeling Flowchart. . . . 82

7. Fragility Curve for TILT UP Buildings

Derived from Table XXI . . . . . . . . 87

8. Lognormal Distribution of Estimated DF

at $P G A=.22$ for Average California

TILT UP bldgs . . . . . . . . . . . . . 94

9. Normal Distribution of $\ln (\mathrm{DF})$ at

$P G A=.22$ for Average Claifornia

TILT-UP buildings. . . . . . . . . . . 95 
10. Determining the Mean Damage Factor (MDF) from the structural score (S) and the Normally Distributed ln(DF) . . . . . 103

11. Mean Damage Factor vs. Structural Score for TILT UP (PC1) buildings, for $P G A=.05 . . . . . . . .4105$

12. Mean Damage Factor vs. Structural Score for TILT UP (PC1) buildings, for $P G A=.10 . ., . . ., 106$

13. Mean Damage Factor vs. Structural Score for TILT UP (PC1) buildings, for $P G A=.22 . . . . . . . . .4107$

14. Mean Damage Factor vs, Structural Score for TILT UP (PC1) buildings, for $\mathrm{PGA}=.47 . . . . . . . . . . .108$

15. Mean Damage Factor vs, Structural Score for TILT UP (PC1) buildings, for $P G A=1.02 . . . . . . . . .4109$

16. Mean Damage Factor vs. Structural Score for TILT-UP at PGA $=.22$, Showing coordinates for $\Sigma(P M F)=0$ and $\Sigma(P M F)=-1 . . .112$

17. PC1 - TILT UP fragility curve for $\Sigma(P M F)=0 . . . . . . . . . . .$. 
18. PC1 - TILT UP fragility curves for

$$
\text { integer } \Sigma \text { (PMF) steps . . . . . . . . . } 119
$$

19. W - WOOD fragility curves for

$$
\text { integer } \Sigma \text { (PHF) steps . . . . . . . . . } 120
$$

20. S1 - STEEL MRF fragility curves for

$$
\text { integer } \Sigma(P M F) \text { steps . . . . . . . . . }
$$

21. S2 - BR STL FRAME fragility curves for

$$
\text { integer } \mathbf{\Sigma} \text { (PHF) steps . . . . . . . . . } 122
$$

22. S3 - LIGHT MEOTAL fragility curves for

$$
\text { integer } \mathbf{\Sigma} \text { (PHF) steps . . . . . . . . . } 123
$$

23. S4 - STL FRAME w/ CONC SHEARWALLS fragility

$$
\text { curves for integer } \Sigma \text { (PMF) steps . . . . } 124
$$

24. C1 - REINF CONC MRF fragility curves for integer $\Sigma(\mathrm{PMF})$ steps . . . . . . . . 125

25. C2 - REINF CONC SHEARWALL fragility curves for integer $\Sigma($ PMF) steps . . . . . . . 126

26. C3/S5 - URM INFILL fragility curves for integer $\Sigma$ (PMF) steps . . . . . . . . . 127

27. PCE - PRECAST CONC FRAME fragility curves for integer $\Sigma(P M F)$ steps . . . . . . . 128

28. RH - REINF MASONRY fragility curves for integer $\Sigma($ PHF) steps . . . . . . . . 129

29. URH - UNREINF MASONRY fragility curves for integer $\Sigma($ PMF) steps . . . . . . . . 130 
30. Comparison of URM Fragility Curve for "Average" Buildings with

Goettel \& Horner (1995)

Damage Factor Estimates... . . . . 140

31. Comparison of C3/S5 Fragility Curve

for "Average" Buildings with

Goettel \& Horner (1995)

Damage Factor Estimates . . . . . . . 141

32. Fraction Dead vs. Damage Factor

Relationship Derived from

ATC-13 (1985) Table 9.3........ . 146

33. Retrofit Effectiveness for

W and S3 Buildings . . . . . . . . . . 153

34. Retrofit Effectiveness for

C1, S1, S2, and S4 Buildings . . . . . 154

35. Retrofit Effectiveness for

C3/S5, $\mathrm{C} 2$, and PC2 Buildings . . . . . 155

36. Retrofit Effectiveness for

RM Buildings . . . . . . . . . . . . 156

37. Retrofit Effectiveness for

URM and PC1 Buildings. . . . . . . . 157

38. Example of DAH-FACT Module output file . . 176

39. Example of DAMAGE-\$ Module output file. . 177

40. Example of LIFELOSS Module output file . . 178

41. Example of RETRO-DF Module output file.. 182 
42. Example of RETRO-\$D Module output file . . 183

43. Example of RETRO-LL Module output file . . 184

44. System Efficiency Curves for Retrofit for DBE (PGA $=.20)$ for the Portland Quad. 216

45. Lives Saved vs. Retrofit Investment for Retrofit for DBE (PGA =.20), . . . 218

46. Building Damage Avoided vs, Retrofit

Investment for Retrofit for

$\mathrm{DBE}(\mathrm{PGA}=.20) . . . . . . .2 .219$

47. System Efficiency Curves for Retrofit for

DBE (PGA $=.20)$ for the Portland Quad,

Using the Lowpoint of NP Range . . . . 226

48. System Efficiency Curves for Retrofit for

$D B E(P G A=.20)$ for the Portland Quad,

Using VOL $=\$ 500,000$. . . . . . 227

49. System Efficiency Curves for Retrofit for

Expected Value Analysis for

the Portland Quad . . . . . . . . . 233 
CHAPTER I

INTRODUCTION

PROBLEM DEFINITION

Newly discovered geologic evidence shows that the entire Pacific Northwest, including Portland, is subject to periodic large earthquakes (Geomatrix Consultants 1995). Unlike the plate tectonic mechanisms in California, which generate large earthquakes every decade or so, the geomechanics of the Pacific Northwest produce large events on the order of hundreds of years apart. Very recent studies have shown that the average interval between occurrances of the large events is 450 years, with a $90 \%$ confidence interval of 200 years; the last event occurred about 300 years ago (Geomatrix Consultants 1995). Since our historical record is less than two hundred years old, comparison to the active faults in california had previously led the scientific and engineering community to assume Portland is in a region of low to moderate seismicity. Prior to the 1994 edition of the Uniform Building Code (International Conference of Building Officials 1994), buildings in Portland were only required to resist lateral forces equal to two-thirds of that now required for design. Further, prior to the early 
$1970^{\prime} \mathrm{s}$, much less was known about seismic design, so that al construction in the first two-thirds of this century is non-seismic resistant construction, i.e., without special attention given to seismic resistance.

Portland is home to thousands of existing buildings which have not been designed to resist the larger earthquakes which are now expected. Since we have rarely had earthquakes producing even slight damage, the problem is made worse in that grossly deficient old buildings have not been automatically "culled out" (as they are in California) by moderate quakes, and in addition public awareness of the risk potential is lacking. Many structural engineers now feel that we are sitting on a powder Keg; sometime in the future, Portland will experience a large earthquake, and the damage and loss of life will be much greater than seen during a similar event in California, because of our deficient building stock.

A responsible public safety policy, in view of current risk awareness, should require many buildings in Portland to be strengthened in an effort to reduce damage and casualties. However, retroactively requiring improvements in a community's existing building stock is among the most conflictual and difficult types of public policy decisions, requiring careful engineering and economic analysis and consideration of societal 
priorities. In most cases, the value of life is the principal motivation for implementing seismic retrofit programs, while in some instances property protection or continued function may be the driving force.

The basic problem, from a city manager or decision-maker viewpoint, is to decide which buildings "should" be retrofit, which should not be retrofit, how much a retrofit program will cost, and how should it be financed.

"Should be retrofit" refers to sufficiently high benefits from retrofit --- savings in life and property -- to warrant the expense. Some buildings should not be retrofit, either because the risk is low, or because the risk is so high that retrofit will not be effective in making them safe, or because the cost is too high to justify the expected benefits. Clearly, some form of benefit-cost analysis is needed to make rational choices. Sufficiently accurate modeling of earthquake losses, avoided losses (benefits) resulting from retrofitting, and the cost of retrofit must precede and provide the input to the benefit-cost analysis. The required modeling is probabilistic, complex, and multi-disciplinary.

It will be desirable to optimize the sequence of buildings to be strengthened in a retrofit program. The first dollars spent should go to retrofit those buildings 
where savings of life will be greatest. An efficient prioritization of buildings earmarked for retrofit, based on benefit-cost analysis, should be established. If constraints in available resources -.- time and money -.dictate a staged retrofit program over time, the prioritization becomes very meaningful indeed.

\section{GENERAL NATURE OF THE PROBLEM}

This research focuses on assessing and avoiding potential seismic damage and casualties (losses) to non-residential buildings in a region or metropolitan area. Methodologies for creating a detailed inventory of data on the buildings, accurately modeling losses, modeling reduced losses anticpated from retrofitting, establishing costs, prioritizing buildings for retrofit, and planning resource allocation are multi-disciplinary, complex, and uncertain in nature. High-quality decision making will require a decision maker to "see through" the complexities of the problem. These characteristics of the nature of the problem point toward utilizing a systems problem solving approach.

\section{Systems Approach}

A "system" is defined as a time-varying configuration of people, hardware, and procedures organized for the purpose of accomplishing certain 
functions (Robertshaw, Mecca and Rerick 1978).

Inherent in this functional definition of system is the idea that there are many alternative system descriptions of the same "reality," and that the system description selected is a representation of reality, not reality itself. The choice of system description is made by the analyst, based on the problem to be solved.

In assessing regional earthquake damage, it has become customary to classify losses as belonging to one of three general categories (National Institute of Building Sciences 1995), as follows:

Buildings: residential, non-residential.

Transportation Systems: highways, railways, light rail, bus, ports and harbors, ferry, and airports.

Lifeline Utility systems: potable water supply, waste water, oil, natural gas, electric power, communications.

Decisions regarding loss mitigation are likely to be made by individual government agencies responsible for each category: city/county building departments, state transportation departments, and individual utilities. Clearly, the above categories are system descriptions designed to facilitate earthquake hazard mitigation decision-making. The present research follows this current practice by considering one category of loss: non-residential buildings in a region. 
Inter-dependence between the NIBS loss categories is a potential topic for further research, to explore "cross-category" loss synergisms and consequent potential changes in retrofit priorities.

\section{System Defined}

The system description selected for use in the present research is defined as follows:
SYSTEM:
Non-residential buildings of a region.
SUB-SYSTEKS:
Building owners.
Building occupants.
ENVIRONMENT: Earthquake magnitudes and probabilities. soil conditions at building sites.
DECISION-MAKER: Municipal Managers; State Legislature.

\section{Multi-Disiplinary Aspects}

Although earthquake rehabilitation seems at first glance to be essentially a structural engineering problem, it is actually a task that crosses a number of traditional technical discipline boundaries, including the following:

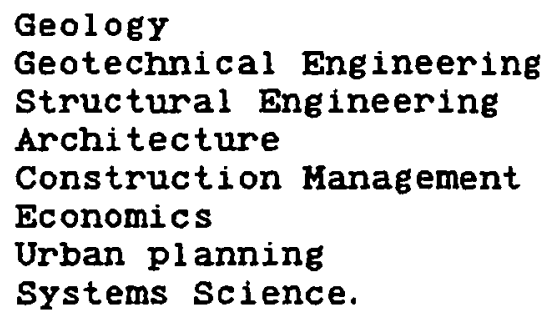

Geologists are depended upon to provide estimates of magnitude and expected frequency of occurrance for seismic 
events; indeed, as previously discussed, new geologic information about the Pacific Northwest is the genesis of the increased local interest in this subject. Geotechnical engineering addresses the response of subsurface soils, which often significantly increases the damaging effect of the ground shaking. Structural engineering is of course the "center-stage" discipline: structural engineers are the group providing estimates of damage and techniques for rehabilitation of existing buildings. Architects address issues of building occupancies and building finishes which must be removed and/or restored as part of the retrofit process. Construction managers provide input on the cost required for seismic rehabilitation, and carry out the work of retrofitting the buildings. Economic theories of benefit-cost analysis are used to determine where retrofits are and are not justified, and provide tools to analyze the efficiency of a retrofit program. Urban planners and municipal authorities are the professionals who must make recommendations and implement a retrofit program.

The multi-disciplinary nature of a seismic rehabilitation program may impose difficulties in current practice. The professionals in the various technical disciplines described are problem solving specialists, adept in their own disipline but not necessarily adept at 
cross-disciplinary problem solving. A general problem solving approach is needed to put the whole package together. Systems science is that general problem solving approach, and can form the backbone to synthesize the various disciplines. A systems approach would provide tools to safeguard against leaving out important elements of the problem, plus tools to bring the diverse elements to a solution.

\section{Complexity}

Complexity can be defined as a state that involves uncertainty, indescribability, intangibles, and many interactions (Robertshaw, Mecca and Rerick, 1978). The losses sustained by a building in an earthquake depend on the combined effect of the interactions between many parameters of the SYSTEY and of the ENYIRONIENT.

The SYSTEM parameters (attributes belonging to the non-residential buildings of a region) used in the present research are:

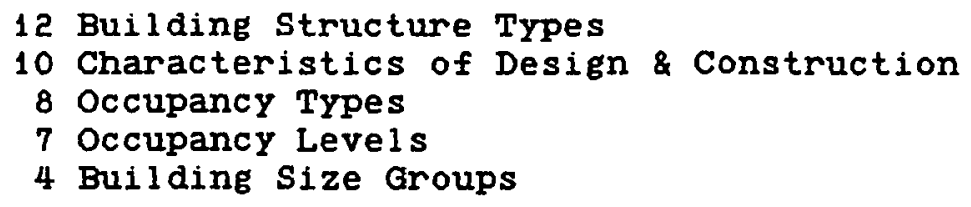

The number of possible subsets of building performance categories created by combinations of these attributes are:

$$
12 \times 210 \times 8 \times 7 \times 4=2,752,512 \text { combinations. }
$$


The proposed ENVIRONMENTAL parameters are:

3 Soil Profile Characteristics

6 Ground Motion/Probability values.

The environmental parameters generates the following number of scenarios for consideration.

$6 \times 2^{3}=48$

Finally, the total number of possible combinations of system and environment parameters is a staggering:

$$
2,752,512 \times 48=132,120,576 .
$$

The number of combinations of attributes creates difficulties at two levels in optimizing retrofit priorities. First, it makes the analysis of losses and retrofit effectiveness more difficult. Second, it makes a practical scheme to classify the results without losing the detail of the analysis more difficult as well.

A major intangible in retrofit benefit-cost analysis is the value of loss of life. It becomes necessary to compare the value of human life (intangible) to the value of building damages and retrofit costs (tangibles). Additionally, cost data on the buildings and the retrofits, and a method for rating retrofit effectiveness, are required. These items contribute greatly to the complexity of establishing a retrofit program.

\section{Uncertainty}

As an engineering community, in the USA we are 
successful at designing new structures to withstand earthquakes. For example, consider two earthquakes of similar magnitude that took place in 1988 and 89: in the Loma Prieta (San Francisco) earthquake, approximately 60 people were killed (Benuska 1990), while in the Armenian earthquake the dead numbered approximately 25,000 (Wyllie and Filson 1989).

However, modeling earthquake loss estimates for a large number of existing buildings is not the same thing as designing new buildings to withstand earthquakes. The loss modeling discipline is in its infancy. As demonstrated above, loss modeling is complex, and complexity leads to uncertainty.

At the present time, existing methodologies generaliy address the probability of average damage for a given group of similar structures, and do not apply to individual, specific buildings. This failure to address the complexity of the problem increases the uncertainty. Additionally, the magnitude and return period of earthquakes is a highly probabilistic science, with large uncertainties. For example, the earthquakes now being predicted for Portland and the Pacific Northwest have not occurred in historic times, but are postulated based on geologic evidence and probabilistic modeling.

The uncertainties are clearly compounded. For 
specified earthquake characteristics (magnitude, type, and location), the response of a given building is uncertain. However, the magnitude of the earthquake cannot be specified without its own contribution of uncertainty. Furthermore, there is the uncertainty of how closely the entire regional system of real buildings fits the model of damage for the "average" building.

\section{Decision Theoretic Considerations}

Establishing a retrofit program will involve decision making under conditions of uncertainty. There are two primary categories of "decision rule" which are typically considered in making decisions under uncertainty (Robertshaw, Mecca and Rerick 1978):

1. Maximum Expected Value, and

2. Maximin.

These two decision rules may produce opposite results, which leads to more uncertainty about the decision.

Maximum Expected Value weights the expected utility of outcomes according to the probability of occurance of a particular state of nature. Maximin ignores probabilities, and pessimistically chooses the alternative which minimizes the maximum possible loss.

As a simplified example, suppose a hypothetical building stands to cause its owner a loss of $\$ 10$. M if a "design basis" earthquake occurs (a design basis 
earthquake has a 10-percent probability of occurrance in the 50 year "life" of the building). Suppose also that if the building is retrofit, at a cost of $\$ 1$. $M_{1}$ the earthquake losses are reduced from $\$ 10$. M to $\$ 4$. M.

If the owner decides to retrofit, there are two possibilities for his losses, which are:

a) If the earthquake occurs $(p=.1)$ :

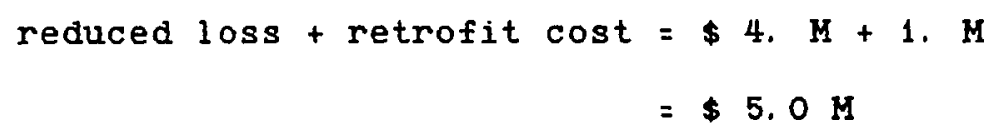

b) If the earthquake does not occur $(p=.9)$ : retrofit cost only $=\$ 1.0 \mathrm{M}$

On the other hand, if he does not retrofit, his two possible losses are:

c) If the earthquake occurs $(p=.1)$ : total earthquake loss $=\$ 10$. H

d) If the earthquake does not occur $(p=.9)$ : loss $=0$.

If the maximum expected value decision rule is used, the expected loss if the owner chooses to retrofit is found by multiplying the losses from a) and b) by their corresponding probabilities:

$$
(.1 * \$ 5.0 \mathrm{M})+(.9 * \$ 1.0 \mathrm{M})=\$ 1.4 \mathrm{M}
$$

The expected loss of choosing to not retrofit is found similarly, from c) and d):

$$
(.1 * \$ 10 \mathrm{M})+(.9 * \$ 0 .)=\$ 1.0 \mathrm{M}
$$


Since the expected loss of retrofitting is 40 -percent greater than the expected loss of not retrofitting, the maximum expected value decision rule indicates that the building owner should not retrofit.

However, the maximin decision rule seeks to insure avoidance of the worst outcome, pessimistically assuming the worst state of nature (the earthquake occurs). This means choosing between a) and c) above; clearly, the decision is to retrofit, to avoid the $\$ 10$. M loss. If maximum expected value and maximin produce paradoxical results, as in this example, selecting the correct decision rule will be a major point of debate in retrofit decision making. 


\section{CHAPTER I I}

\section{LITERATURE REVIEW}

\section{ATC-13: EARTHQUARE DAMAGE EVALUATION DATA FOR CALIFORNIA}

ATC-13 (1985) was developed by the Applied

Technology Council (ATC), funded by the Federal Emergency Management Agency (FEMA), to estimate the economic impact of a major California earthquake. ATC-13 presents expert-opinion earthquake damage and loss estimates for existing industrial, commercial, residential, utility and transportation facilities in California.

ATC-13 is a crucial landmark study, establishing the basic methodology of earthquake loss estimation, and setting the stage for many research projects to follow. It is still the most complete source of earthquake damage and loss estimating information available for a wide variety of structure types. Three tasks in the study of particular importance to the present research are:

1. Identification of the earthquake shaking characterization most appropriate for damage and loss estimation.

2. Development of facility classification schemes.

3. Development of earthquake damage and loss 


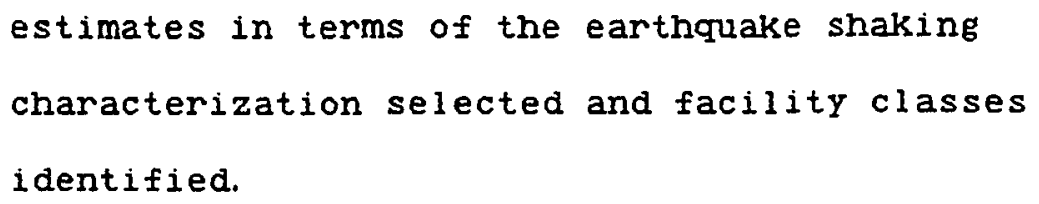

\section{Earthquake Shaking Characterization}

The Modified Mercalli Intensity (MMI) Scale (Wood and Newmann 1931) was selected as the most appropriate earthquake shaking characterization, because most expert knowledge and existing motion-damage data for earthquakes in the USA exists in that form. The upper portion of the MMI scale is summarized in Table $I$, following:

\section{TABLE I}

MODIFIED MERCALLI INTENSITY SCALE

vI. Felt by all, many frightened and run outdoors.

Some heavy furniture moved; a few instances of fallen plaster or damaged chimneys; damage slight.

VII. Everybody runs outdoors. Damage slight to moderate in we11-built ordinary structures; some chimneys broken. Noticed by persons driving cars.

VIII. Alarm approaches panic. Damage considerable in ordinary substantial buildings with partial 
collapse. Fall of chimneys, factory stacks, columns, monuments, walls. Heavy furniture overturned; disturbing to persons driving cars.

IX. Panic general. Damage great in substantial buildings, with partial collapse. Well designed frame structures thrown out of plumb. Buildings shifted off foundations. Ground cracked conspicuously.

$\mathrm{x}$. Some well-built wooden structures destroyed; most masonry and frame structures destroyed. Ground badly cracked. Landslides considerable from river banks and steep slopes.

XI. Few if any masonry structures remain standing. Bridges destroyed. Broad fissures in ground. Earth slumps and land slips in soft ground. XII. Damage total. Waves seen on ground surface. Lines of sight and level distorted. Objects thrown upward into the air.

\section{Facility Classifications}

The step of classifying facilities was fundamental to the ATC-13 study, because earthquake-induced physical damage is dependent upon structural properties. The classification developed contains 78 classes of structures, 40 of which are buildings and 38 of which are 
other structure types, such as bridges, pipelines, dams, tunnels, etc. The classes were selected on the basis of expected uniqueness in seismic performance. The facility classes were assigned Facility Numbers to which the data developed is referred. The facility numbers are not consecutive, because facility classifications were added after the expert questionnaire process was started, and numbers assigned initially were maintained to preclude error. The ATC-13 Facility Numbers for buildings only are presented in Table II, following.

PABLE II

ATC-13 FACILITY CLASSES AND NUMBERS

FACILITY CLASS

Wood Frame (Low Rise)

Light Metal (Low Rise)

Unreinforced Masonry (Bearing Wall)

a) Low Rise (1-3 Stories)

b) Medium Rise (4-7 Stories)

Unreinforced Masonry (with Load Bearing Frame)

a) Low Rise

78

b) Medium Rise

c) High Rise (8+ Stories)

2

76

79

80
FACILITY NUMBER 
Reinforced Concrete Shear Wall

(with Moment-Resisting Frame)

a) Low Rise 3

b) Medium Rise

c) High Rise 5

Reinforced Concrete Shear Wall

(without Homent-Resisting Frame)

a) Low Rise 6

b) Medium Rise $\quad 7$

c) High Rise 8

Reinforced Masonry Shear Wall

(without Moment-Resisting Frame)

a) Low Rise 9

b) Medium Rise 10

c) High Rise i1

Reinforced Masonry Shear Wall

(with Moment-Resisting Frame)
a) Low Rise
84
b) Medium Rise
85
c) High Rise
86

Braced Steel Frame

a) Low Rise 12

b) Medium Rise 13

c) High Rise 14 
Moment-Resisting Steel Frame (Perimeter Frame)

a) Low Rise $\quad 15$

b) Medium Rise 16

c) High Rise 17

Moment-Resisting Steel Frame (Distributed Frame)

a) Low Rise 72

b) Medium Rise $\quad 73$

c) High Rise $\quad 74$

Moment-Resisting Ductile Concrete Frame

(Distributed Frame)

a) Low Rise 18

b) Medium Rise 19

c) High Rise 20

Moment-Resisting Non-Ductile Concrete Frame

(Distributed Frame)

a) Low Rise $\quad 87$

b) Medium Rise $\quad 88$

c) High Rise $\quad 89$

Precast Concrete (other than Tilt-up)

a) Low Rise 81

b) Medium Rise $\quad 82$

c) High Rise 83

Long Span (Low Rise) 91

Tilt-up (Low Rise) 21

Mobile Homes 23 
Physical Damage Caused by Ground Shaking

To express earthquake damage, ATC-13 introduced an expression for Damage Factor (DF), the percentage of dollar loss to buildings:

Damage Factor (DF) Dollar Loss

Replacement value

Expected damage (\$Damage) for a given facility is then calculated as follows:

$\$$ Damage $=$ DF $\times$ (Replacement Value)

Damage Factor is useful and flexible; other types of earthquake loss can be rationally deduced from it. Ranges of DF were correlated to Damage States; Central Damage Factor (CDF) is defined as the midpoint of the DF range, as shown in Table III, following. 
TABLE III

ATC-13 DAMAGE STATE DESCRIPTIONS

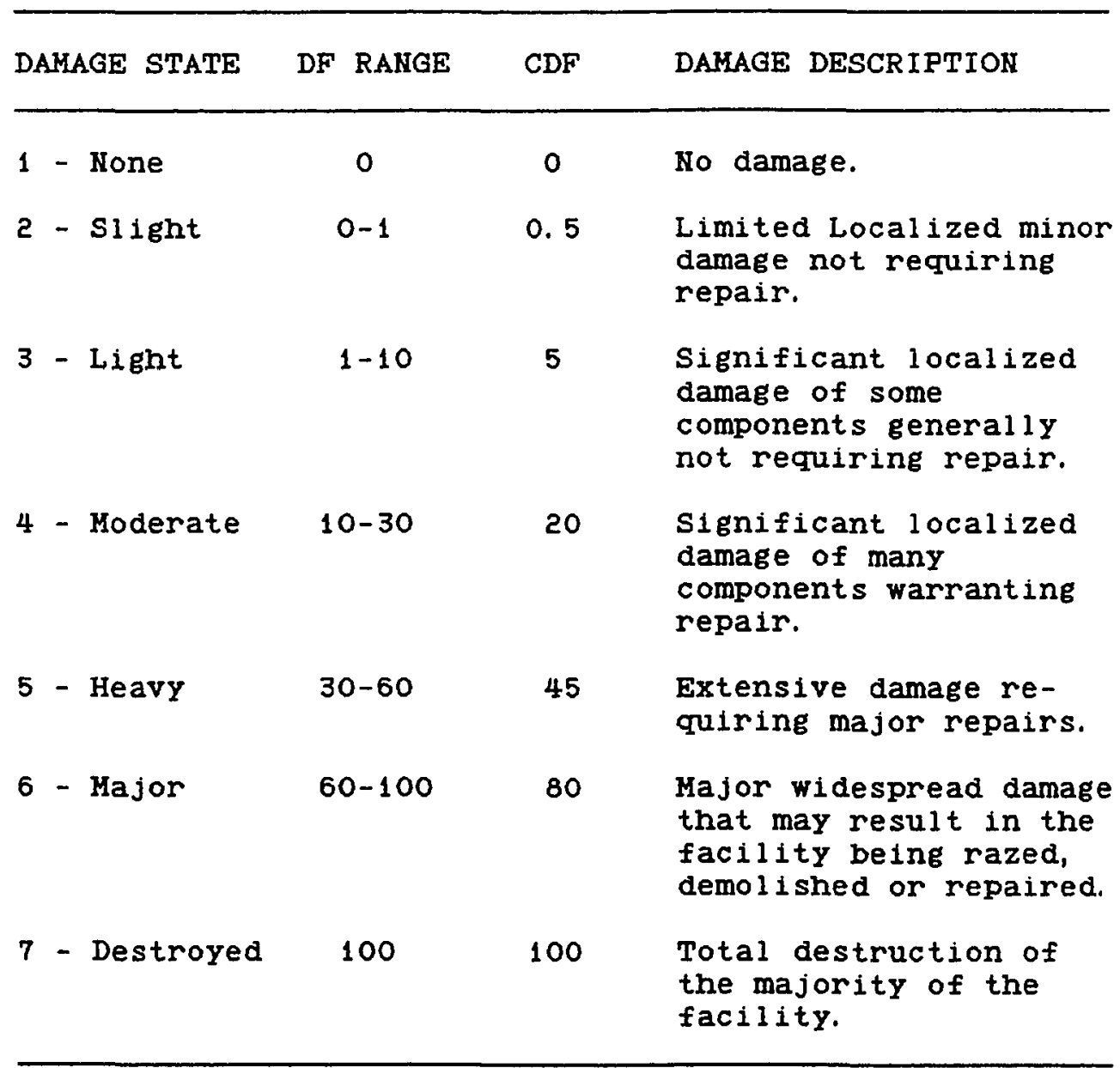

Estimates of DF versus MMI were developed for all 78 facility classes, through a multiple questionnaire process involving a Project Engineering Panel of 13 senior-level specialists in earthquake engineering, plus 58 other selected earthquake engineering experts. The questionnaire process was modeled after the Delphi method for expert 
opinion solicitation, developed for the Air Force by the Rand Corporation in the 1950 's. The procedure as used in ATC-13 consisted of formulating and obtaining individual answers to questionnaires from experts, iterating the questionnaires two or three times while carefully controlling the information feedback between rounds, and finally aggregating the responses by statistical operations.

One of the most important aspects of the Delphi method is the selection of the experts. The experts were carefully chosen by the Project Engineering Panel. As a further safeguard each expert was asked to respond only on the facility classes with which they had extensive familiarity. This resulted in, out of a total of 71 selected experts, at most only eight experts giving answers for any given facility class.

For each facility class, the experts were asked to provide a low, best, and high estimate of DF at seven shaking intensities, from MMI VI through XII. The low and high estimates were defined to be the $90 \%$ probability bounds of the DF distribution, while the best estimate was defined for the experts as the DF most likely to be observed for a given MMI and facility class. Each expert was also asked to evaluate his level of experience in the facility class being evaluated and to provide a 
self-evaluated degree of certainty in the low, best, and high estimates, which were used as weighting factors in the statistical compilation of the results.

Appendix G of ATC-13, "Weighted Statistics of Damage Factor," is a complete listing of the expert opinion data, including the weighted means of the experts' low, best, \& high DF estimates for the 78 facility classes, subjected to each of the 7 levels of shaking intensity.

\section{Death and Injury Estimates}

ATC-13 reviewed the existing literature to determine the rates of deaths and injuries as a function of damage to various facilities. On the basis of this information, death and injury rates were developed as a function of Central Damage Factor (CDF), shown in Table IV, following.

TABLE IV

ATC-13 INJURY AND DEATH RATES

\begin{tabular}{lccl}
\hline $\begin{array}{l}\text { DAMAGE } \\
\text { STATE }\end{array}$ & $\begin{array}{c}\text { CDF } \\
(\%)\end{array}$ & SERIOUS IMJURIES & \multicolumn{1}{c}{$\begin{array}{c}\text { FRACTION } \\
\text { DEAD }\end{array}$} \\
\hline & & \multicolumn{1}{c}{0} & \multicolumn{1}{c}{0} \\
1 & 0 & $1 / 250,000$ & $1 / 1,000,000$ \\
2 & 0.5 & $1 / 25,000$ & $1 / 100,000$ \\
3 & 5 & $1 / 2,500$ & $1 / 10,000$ \\
4 & 20 & $1 / 250$ & $1 / 1,000$ \\
5 & 45 & $1 / 25$ & $1 / 100$ \\
6 & 80 & $2 / 5$ & $1 / 5$ \\
7 & 100 & &
\end{tabular}


These estimates are for all types of construction except light steel construction and wood-frame construction. For light steel construction and wood-frame construction, multiply all numerators by 0.1 .

\section{Significance and Limitations}

Earthquake loss estimation is more an art than a science, because there is not sufficient observational data on earthquake losses to characterize it as a hard science. The ATC-13 loss estimates are based on judgment, subject to the following limitations:

1. Damage estimates represent "average" conditions.

2. Damage estimates provided are for California.

3. Great amounts of experimental data from actual earthquakes would be needed to verify or improve these estimates.

Because the MMI scale was selected to characterize the earthquake intensities used in the ATC-13 expert opinions, the shaking intensity reference is not specific to California. However, the building response is specific to California, because building codes in California have for many years required a higher level of seismic resistant design than in most regions. This specificity of the design basis of California bulldings must be adjusted to apply the results of ATC-13 to other regions. 
Although the expert loss estimates were weighted and statistically analyzed in a scientific manner, the loss estimates themselves are not experimentally verifiable. Despite its limitations, the ATC-13 loss estimates reflect the best judgement of a group of highly prominent earthquake engineers and represent the only available information for a wide variety of structure types. The seventy plus participants in the project represent more than a thousand man-years of professional experience in earthquake engineering; thus the judgement evaluations made are of significance. 
ATC-21: RAPID VISUAL SCREENING OF BUILDINGS FOR POTENTIAL SEISMIC HAZARDS: A HANDBOOK

\begin{abstract}
ATC-21 (1988) was developed to provide a standard rapid visual screening procedure (RSP) to identify those buildings that might pose a potentially serious risk of loss of life and injury, or of severe curtailment of community services, in case of a damaging earthquake. ATC-21 extends the loss estimating results of ATC-13, and presents :

1. A Rapid Screening Procedure (RSP), based on visual observation, to classify the building as to structural type and identify significant seismic-related defects in each building.

2. A Scoring System, based on the field survey data, which relates to the probability of each building sustaining major life-threatening structural damage during a major earthquake.
\end{abstract}

\title{
Rapid Screening Procedure
}

ATC-21 utilizes a methodology based on a "sidewalk survey" of a building using a Data Collection Form, which an inspector completes based on visual observation of the building. Three versions of Data Collection Form are employed, for Low, Moderate and High Seismicity areas. The methodology begins by collapsing the 40 building classes of ATC-13 into 12 Building Types, based on the 


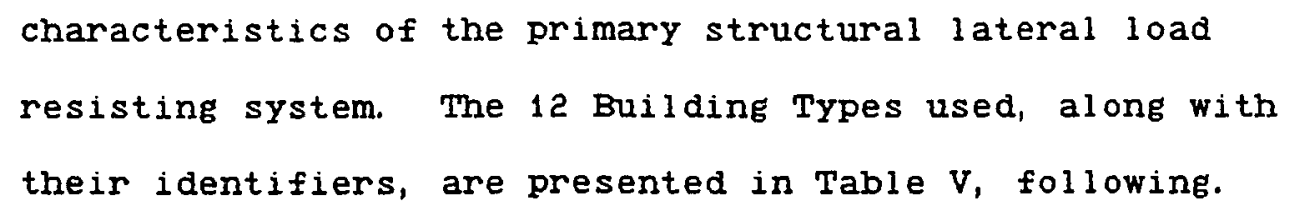

TABLE V

ATC-21 BUILDING TYPES

\begin{tabular}{ll}
$\begin{array}{l}\text { BUILDING } \\
\text { IDENTIFIER }\end{array}$ & \multicolumn{1}{c}{ DESCIPTION } \\
W & Wood buildings of all types. \\
S1 & Steel moment resisting frames. \\
S2 & Braced steel frames. \\
S3 & Light metal buildings. \\
S4 & Steel frame with concrete shear walls. \\
C1 & Concrete moment resisting frames. \\
C2 & Concrete shear wall buildings. \\
C3/S5 & Concrete or steel frame w/URM infill walls. \\
PC1 & Tilt-up concrete buildings. \\
PC2 & Precast concrete frame buildings. \\
RH & Reinforced masonry. \\
URM & Unreinforced masonry.
\end{tabular}

Eleven Performance Modifiers are identified as being present or absent in each building. This is a significant advance, making ATC-21 the first of the earthquake loss estimation procedures to include the characteristics of 
design and construction of individual buildings into the estimates. The Performance Modifiers are presented in Table VI, following.

TABLE VI

ATC-21 PERFORMANCE MODIFIERS

\begin{tabular}{ll} 
HR & High rise \\
PC & Poor condition \\
VI & Vertical irregularity \\
SS & Soft story \\
T & Torsion \\
PI & Plan irregularity \\
P & Pounding \\
LH & Large heavy cladding \\
SC & Short columns \\
PB & Post benchmark year \\
SL & Soil profile \\
\hline
\end{tabular}

Foundation type (deep vs. shallow foundations) has not been included as a performance modifier because it is impractical to include it as part of a "sidewalk" survey. Also included on the Data Collection Form are number of stories, square footage, year built, occupancy, number of occupants, and non-structural falling hazards. 
Seismicity

It has been necessary to correlate MMI intensity to horizontal acceleration, which has become the commonly accepted scientific measure of ground motion. Peak Ground Acceleration (PGA) is defined as the maximum acceleration recorded from an accelerogram on rock during an earthquake. Efrective Peak Acceleration (EPA) can be thought of as the maximum acceleration after high frequency accelerations (that do not affect sizeable structures) have been discounted. ATC-21-1 uses the following correlations between MMI, PGA, and EPA:

$$
\begin{aligned}
& \text { PGA }\left(\mathrm{cm} / \sec ^{2}\right)=10(M M I-1) / 3 \\
& E P A=0.75 \times \mathrm{PGA}
\end{aligned}
$$

The United States has been divided into 7 "NEHRP Map Areas," corresponding to estimated maximum EPA levels likely to occur during the life of a building. ATC-21 uses the NEHRP Map Areas to define it's Low, Moderate, and High Seismicities, as shown on the map in Figure 1. Table VII, following, shows the NEHRP Map Areas, the defining EPA, and corresponding back-calculated PGA and MMI values. 


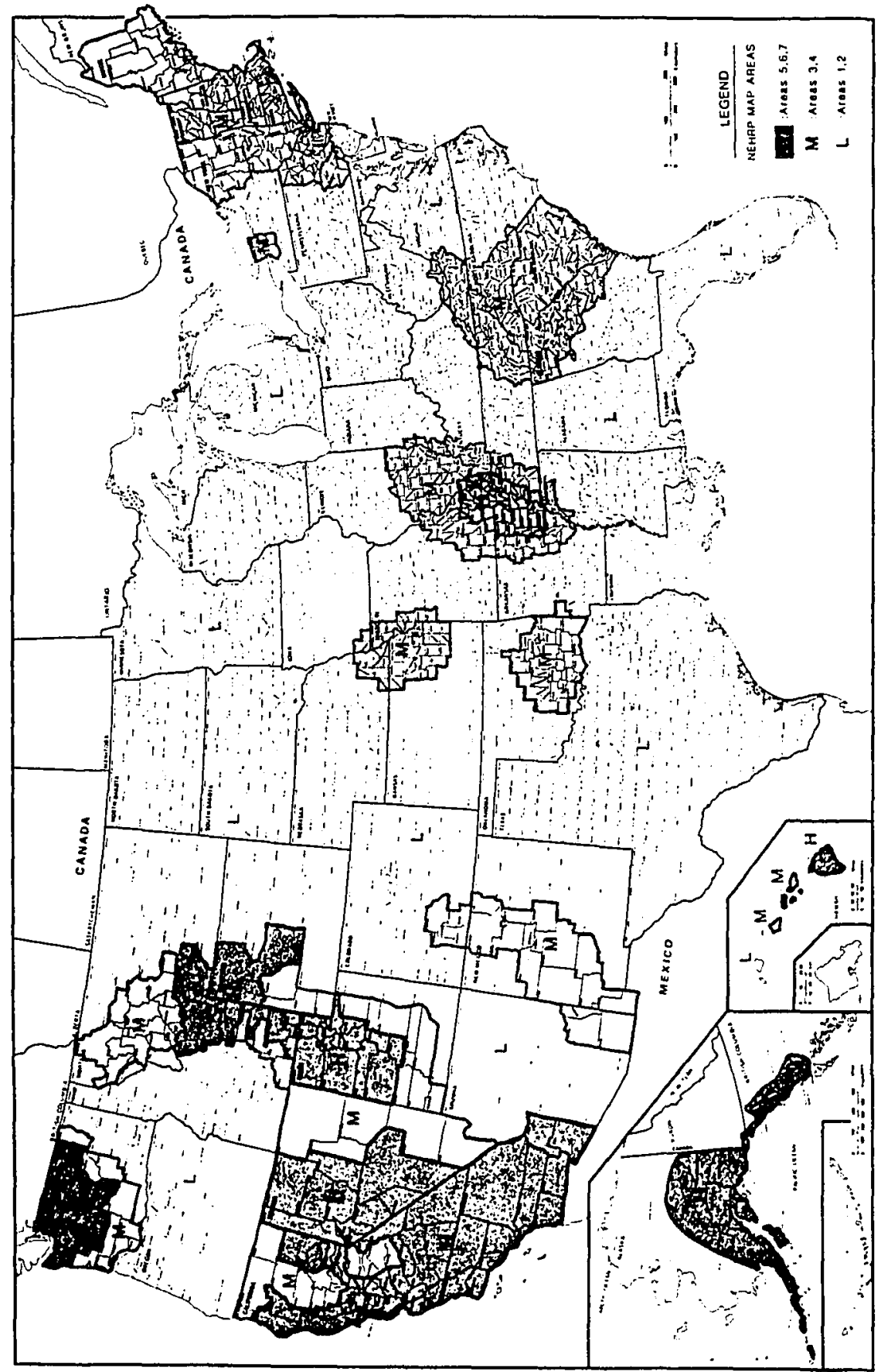

Figure 1. NEHRP Map Areas of the United States (ATC-21, 1988). 
TABLE VII

ATC-21 SEISMICITIES AND EARTHQUAKE INTENSITIES

\begin{tabular}{lcccc}
\hline $\begin{array}{l}\text { ATC-21 } \\
\text { SEISMICITY }\end{array}$ & $\begin{array}{l}\text { MEHRP } \\
\text { MAP AREA }\end{array}$ & EPA & PGA & MMI \\
\hline Low & 1 & .05 & .07 & 6.4 \\
Low & 2 & .05 & .07 & 6.4 \\
Moderate & 3 & .10 & .13 & 7.4 \\
Moderate & 4 & .15 & .20 & 7.9 \\
High & 5 & .20 & .27 & 8.3 \\
High & 6 & .30 & .40 & 8.78 \\
High & 7 & .40 & .53 & 9.2 \\
\hline
\end{tabular}

\section{Scoring System}

After identifying the NEHRP Map area and Seismicity,

a Basic Structural Hazard (BSH) score, ranging from 1 to

8. 5, is assigned to each bullding, depending on the Building Type and the NEHRP Map Area (high BSH values reflect good seismic performance, and low BSH values reflect a seismically hazardous building). The Basic Structural Hazard Scores are presented in Table VIII, following. 
TABLE VIII

ATC-21 BASIC STRUCTURAL HAZARD SCORES

\begin{tabular}{llccc}
\hline & & \multicolumn{3}{c}{ NEHRP MAP AREAS } \\
\cline { 3 - 5 } & & $\begin{array}{c}\text { LOW } \\
(1,2)\end{array}$ & $\begin{array}{c}\text { Moderate } \\
(3,4)\end{array}$ & $\begin{array}{c}\text { High } \\
(5,6,7)\end{array}$ \\
\hline BUILDING IDENTIFIER & WOOD FRAME & 8.5 & 6.0 & 4.5 \\
S1 & STEEL MRF & 3.5 & 4.0 & 4.5 \\
S2 & BRACED STEEL FRAME & 2.5 & 3.0 & 3.0 \\
S3 & LIGHT METAL & 6.5 & 6.0 & 5.5 \\
S4 & STEEL FRAME W/CONC SW & 4.5 & 4.0 & 3.5 \\
C1 & RC MRF & 4.0 & 3.0 & 2.0 \\
C2 & RCSW NO MRF & 4.0 & 3.5 & 3.0 \\
C3/S5 & URM INFILL & 3.0 & 2.0 & 1.5 \\
PC1 & TILT UP & 3.5 & 3.5 & 2.0 \\
PC2 & PC FRAME & 2.5 & 2.0 & 1.5 \\
RM & REINFORCED MASONRY & 4.0 & 3.5 & 3.0 \\
URM & UNREINFORCED MASONRY & 2.5 & 2.0 & 1.0 \\
\hline
\end{tabular}

Each of the Performance Modifiers present in a building is assigned a Performance Modification Factor $(P M F)$, from -2.5 to +2.0 , depending on the specific Performance Modifier, Building Type, and NEHRP Map Area (most PMF's are "detractors," indicating a reduction in the seismic performance of a building, and are therefore 
negative values).

Final $1 y$, each building is assigned a structural Score (S), equal to the BSH score plus the sum of all the PMF values for the building:

$$
S=B S H+\Sigma(P M F)
$$

The Structural Score $S$ is a "performance score" (higher numbers mean better seismic resistance), measuring the $11 \mathrm{kl}$ ihood of building resistance to major damage during a large earthquake.

ATC-21 recommends a structural score of 2 as a "cut-off"; that is, buildings with an $S$ of 2 or less should be flagged for detailed investigation by a professional engineer experienced in seismic design. The cut-off score is a cost-benefit division between the costs of detailed engineering investigation versus the benefits of increased seismic safety. The cut-off of $S=2$ recommended by ATC-21 is a preliminary value, which could be adjusted by a particular community based on its own cost-benefit analysis of seismic safety.

\section{Basis of the Scoring system}

ATC-21's Structural score $s$ was developed from the Damage Factor DF established in ATC-13. The Structural Score $S$ is defined as the negative of the logarithm (base 10) of the probability of damage (DF) exceeding 60-percent of the building value for a specified NEHRP Effective Peak 
Acceleration (EPA) loading, as:

Structural score $S=\log [\mathrm{Pr}(\mathrm{DF}\rangle=60 \%)]$

Sixty percent damage was selected as the generally accepted threshold of major damage, roughly the point at which many structures are a "total loss," and the approximate lower bound at which there begins to be a significant potential for building collapse and significant life-safety threat.

ATC-21's development of $S$ from DF was accomplished by treating ATC-13's DF as a random variable, and modeling it with a lognormal probability distribution. From ATC-13's Appendix G (The Weighted Statistics of the Damage Factor), the mean low and mean high estimates of the DF were taken as the $90 \%$ probability bounds on the damage factor distribution, while the mean best estimate was interpreted as the median DF. The value of the mean best estimate of DF was multiplied by a Modification constant to adjust for differences in building practices for non-California buildings. The probability of the DF being greater than 60 percent was then calculated from a polynomial approximation. MMI intensities were transformed to EPA values, so the resulting structural scores could be applied to NEHRP Map Areas.

Where several ATC-13 building types correspond to one in ATC-21, the results were averaged. Inconsistencies 
were smoothed and adjusted on the basis of judgment, and the final BSH score $S$ rounded to the nearest 0.5 .

\section{Significance and Limitations}

The landmark achievement of ATC-21 is the development of the first methodology that rates the performance of individual buildings, accounting for structural type, expected seismicity, and combinations of individual variations in bullding design and construction characteristics.

However, ATC-21/RSP is by definition an approximate procedure. The goal is to broadly identify most of the potentially seismically hazardous buildings, at a relatively modest expenditure of time and effort, and to eliminate most of the relatively adequate buildings from further review. It is intended for rapidly evaluating the hundreds or thousands of buildings in a community, and is definitely not intended for the full determination of the seismic safety of individual buildings.

ATC-21's structural Score $S$ was designed to be a cutoff score for builaings with a potential life-safety risk during major earthquakes. Despite utilizing the Damage Factor of ATC-13 in developing S, ATC-21 does not model damage. A continuous function does not exist, allowing DF to be calculated from $S$, structure type, and earthquake intensity. 
PORTLAND SEISMIC HAZARDS SURVEY (PSHS)

In 1993, Portland State University's Department of Civil Engineering, funded by METRO, conducted a survey of the seismic hazards of 4,500 non-residential buildings in the USGS Portland Quadrangle (Rad and McCormack 1994). Eight sections in the SE part of the quadrangle --sections $1 \mathrm{N1E33}, 34,35,36$ and $151 \mathrm{E0} 1,02,03,04 \ldots$ were inventoried by the Bureau of Buildings, City of Portland, bringing the total number of buildings surveyed in the Portland Quadrangle to about 10,000. In 1995, an additional 12,000 buildings were surveyed by the PSU/CE team in the Ht. Tabor, Gladstone, Lake Oswego, and Linnton Quadrangles. This may be the largest survey of its kind made anywhere to date.

About a dozen civil engineering graduate and upper-division students were trained and supervised by PSU faculty conducting the survey, utilizing ATC-21's Rapid Screening Procedure (RSP). In the 1995 phase of the work, about twice that many students were employed.

\section{Building Inventory Database}

The PSU team created an inventory of the survey data on the database ACCESS, wherein one data-line is used for each building. Each data-line contains the map section number, survey sequence number, tax lot parcel (R) number, 
address, year built, area, city use code, number of stories, building name, use, occupancy, estimated range of number of people, state occupancies (special, major, essential, and hazardous), non-structural falling hazards, RSP building type, and RSP performance modifiers. A sample database spreadsheet page is shown in Figure 2 (with no R-number, address nor building name, but with the three soil modifers added).

In the database, the Building Type (using the symbols indicated previously) was recorded, and the Performance Modifiers were identified as either present (Y) or absent (blank). The survey did not record the ATC-21 Soil Profile (SL) modifer for soil effects. Three performance modifiers specific to soil profiles in Portland, based on the Oregon DOGAMI Earthquake Hazard Haps (GMS-79 1993), were developed as part of the present study. These were matched to the specific building sites and added to the database.

\section{Range of Estimated Number of People}

The ATC-21 estimated ranges of Number of Persons was expanded for use in the Portland Seismic Hazards Survey, as shown in Table IX, following. 
TABLE IX

\section{RANGES OF ESTIMATED NUMBER OF PEOPLE \\ USED IN ATC-21 AND PSHS-93}

\begin{tabular}{ll}
\hline ATC-21 & PSHS-93 \\
\hline $0-10$ & $0-10$ \\
$11-100$ & $11-30$ \\
$100+$ & $31-100$ \\
& $100-500$ \\
& $500-2000$ \\
& $2000-5000$ \\
& $5000+$ \\
\hline
\end{tabular}

The range of number of people was based on the field surveyors estimate of the building occupant load while the building is in "full use." This occupant load would, for most of the buildings surveyed, occur during regular business hours, 9:00 AM - 5:00 PM Monday through Friday.

\section{Post-Benchmark Year}

The Post Benchmark Year for each building type used in the survey are presented in Table $X_{1}$ following. The post benchmark years were determined in consultation with the City of Portland Bureau of Buildings. 
TABLE $X$

POST-BENCHMARK YEARS USED IN PSHS-93

\begin{tabular}{ll}
\hline $\begin{array}{c}\text { BUILDING } \\
\text { TYPE }\end{array}$ & POST $\begin{array}{l}\text { BENCHMARR } \\
\text { YEAR }\end{array}$ \\
\hline & \\
$W$ & 1965 \\
S1 & 1978 \\
S2 & 1990 \\
S3 & N/A \\
S4 & 1978 \\
C1 & 1978 \\
C2 & 1978 \\
C3/S5 & N/A \\
PC1 & 1975 \\
PC2 & N/A \\
RH & 1978 \\
URM & N/A \\
\hline
\end{tabular}

\section{Significance and Limitations}

This is probably the 1argest ATC-21/RSP survey completed to date. The earthquake loss estimates and retrofit programming in the present research are, therefore, based on the most complete and detailed building inventory data available.

This work refers to a scoring system that has a probabilistic basis. Therefore, it should not be used to tag specific buildings as hazardous or safe. It is intended for use in estimating losses for categories or classes of buildings. 
STATE OF OREGON SEISMIC DESIGN MAPPIHG

Geomatrix Consultants (1995) of San Francisco, California, presented to the Oregon Department of Transportation a probabilistic assessment of seismic hazard in the state of Oregon. The probabilistic approach to mapping earthquake hazards is a standard approach and is used by the U.S. Geological Survey to prepare national seismic hazard maps that form the basis for setting seismic design levels in most building codes. The Geomatrix report is the best currently avallable summary of the seismicity of Oregon, applicable to any type of facility, and includes:

1. A detailed desciption of the characterization of earthquake sources throughout oregon.

2. A set of seismic hazard maps showing contours of peak ground acceleration (PGA) with 500, 1,000, and 2,500 year returns.

3. Detailed seismic hazard analyses for fifteen locations in Oregon (including Portland).

\section{Earthquake Sources}

The principal tectonic feature of the Pacific Northwest is the active subduction zone formed by the Juan de Fuca Plate subducting beneath the North American Plate along the Cascadia margin, the western coast of North 
America stretching from northern California to central

Vancouver Island. In 1987, evidence was discovered for what appear to have been repeated large magnitude earthquakes along the coast of oregon, Washington, and northern California in the recent geological past (Atwater 1987). These large earthquakes are now attributed to the subduction zone.

Three possible earthquake source zones that could affect the Portland are outlined in the Geomatrix report (1995):

1. Cascadia subduction zone earthquakes which can occur on the interface between the Juan de Fuca Plate and the North American Plate, called "interplate" sources.

2. Deep earthquakes which can occur within the subducting plate, called "intraplate" sources.

3. Earthquakes that occur on shallow crustal faults within the North American Plate, called "crustal" sources.

\section{Seismic Hazard Analysis}

The seismic hazard maps and detailed hazard analyses determine annual exceedance probabilities based on combining the probabilities of occurrance from the three earthquake sources. The PGA on rock for 100,500, 1,000, and 2,500 year return periods for Portland are presented 
in Table XI, following.

TABLE XI

PGA ON ROCK AND RECURRENCE INTERVALS FOR PORTLAND (GEOMATRIX CONSULTANTS 1995)

\begin{tabular}{cc}
\hline $\begin{array}{c}\text { RECURRENCE } \\
\text { INTERVAL } \\
\text { (Years) }\end{array}$ & $\begin{array}{c}\text { PEAK GROUND } \\
\text { ACCELERATION ON ROCK } \\
\text { (PGA as \% of g) }\end{array}$ \\
\hline 100 & .08 \\
500 & .20 \\
1,000 & .27 \\
2,500 & .39 \\
\hline
\end{tabular}

Limitations and Significance

Characterization of the magnitude of ground motion and corresponding recurrence intervals is a fundamental first step in any earthquake loss estimation methodology. The Geomatrix report (1995) is the best currently available summary of the probabilistic seismology of Oregon. 
EARTHQUAKE HAZARD MAPS OF THE PORTLAND QUADRANGLE

The Oregon Department of Geology and Mineral Industries (1993) published an earthquake hazard map series, designated GMS-79, consisting of 4 maps of the USGS Portland Quadrangle, as follows:

1. Liquefaction Susceptibility Map (Plate 1)

2. Ground Motion Amplification Map (Plate 2)

3. Lateral Spread Displacement and Dynamic Slope Instability Map (Plate 3)

4. Relative Earthquake Hazard Map

These maps delineate hazards due to site-specific soil conditions derived from a three-dimensional digital geologic model coupled with borehole records, geotechnical properties, and shear-wave velocity data collected from purpose-drilled boreholes at 20 locations. Each map is color-coded for gradations in the severity of hazards depicted, as shown in Figures 3, 4, and 5, following.

\section{Liquefaction Susceptibility Map}

Liquefaction-induced ground failure is a major cause of earthquake damage. Liquefaction is a phenomenon during which ground shaking causes a complete loss of shear strength in loose, water-saturated granular solls, typically fine sands and silty sands near river channels. Foundations supported on liquefied soils may sink or be 


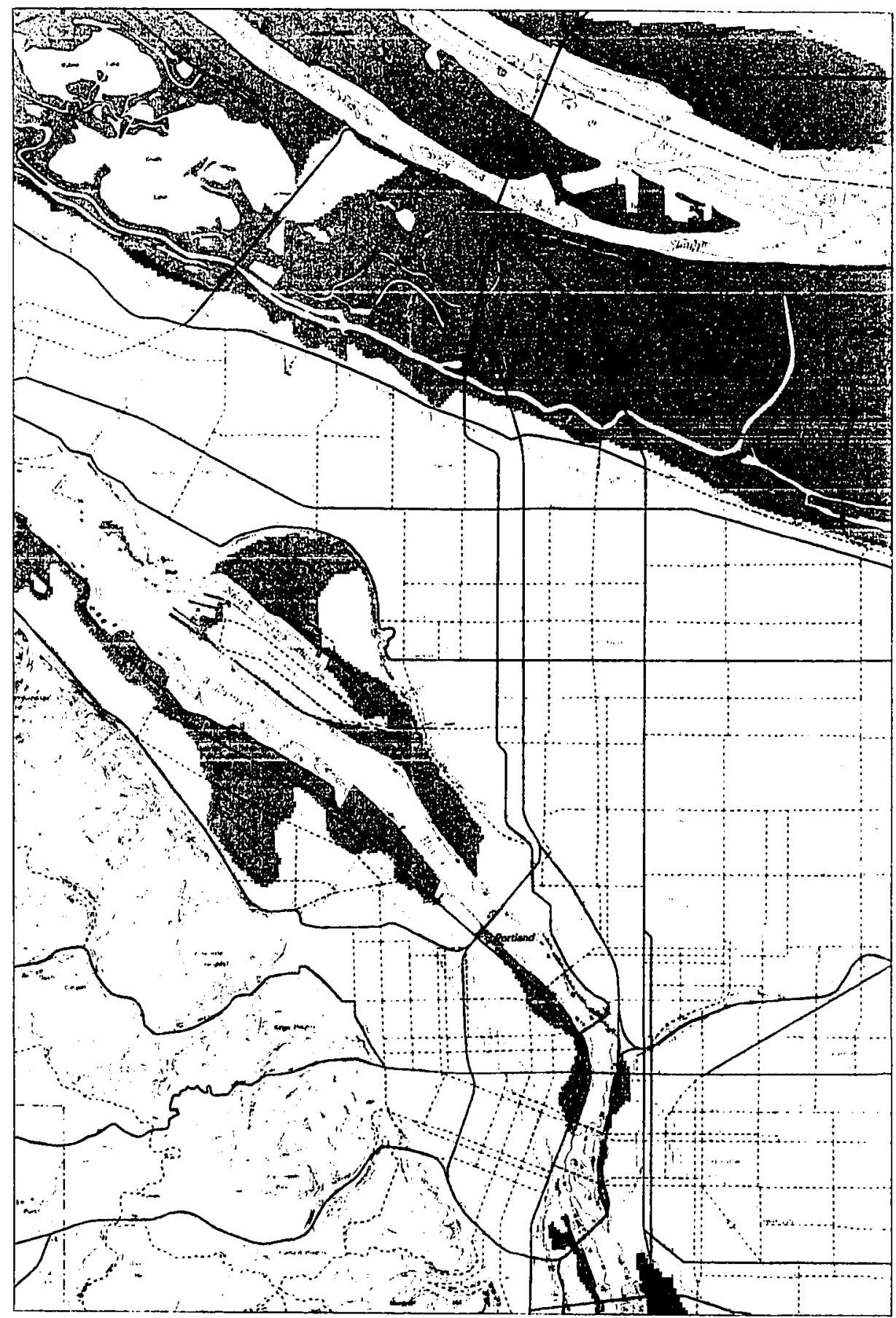

Figure 3. Liquefaction Susceptibility Map (GMS-79, Plate 1). 


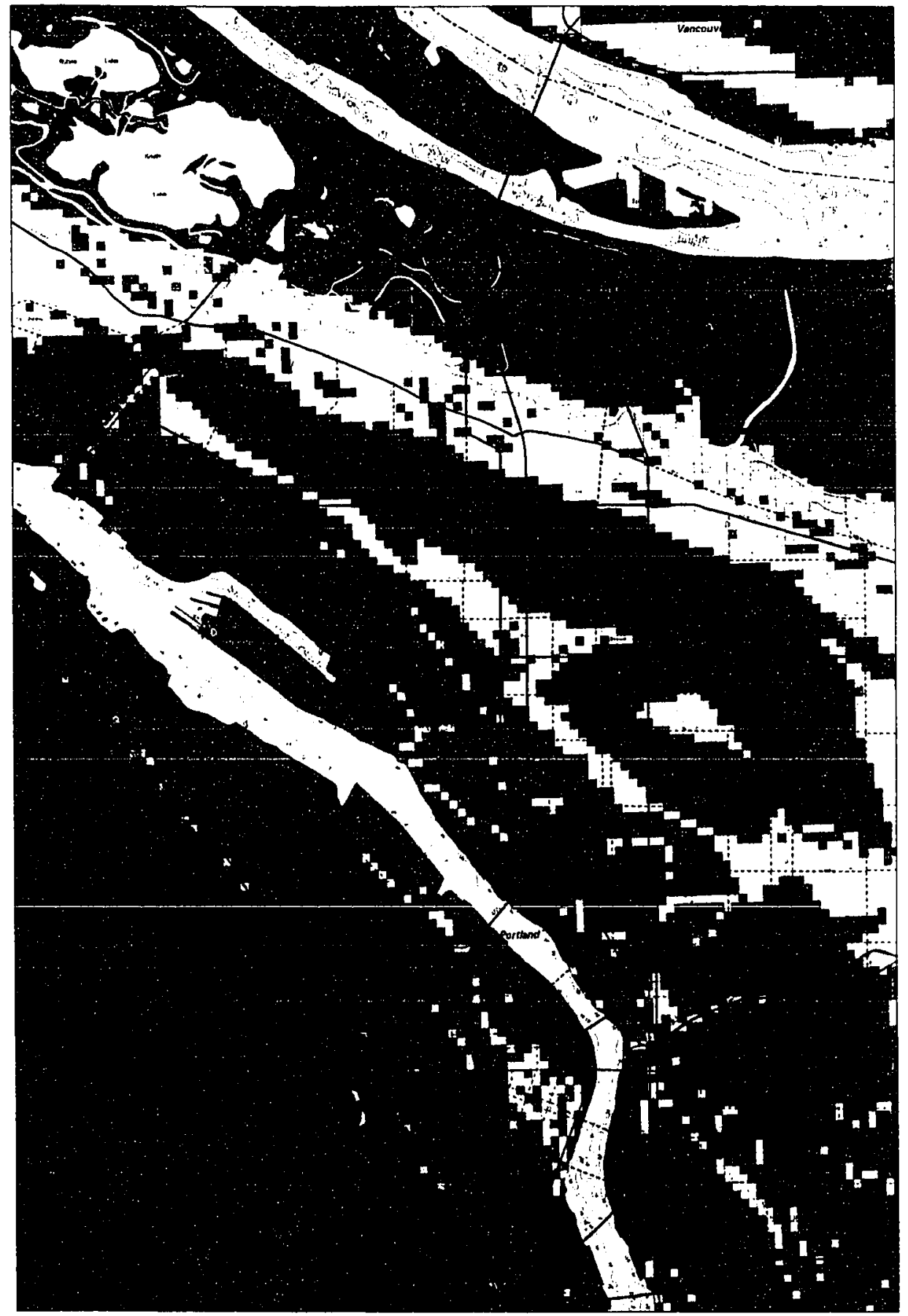

Figure 4. Ground Motion Amplification Map (GKS-79, Plate 2). 


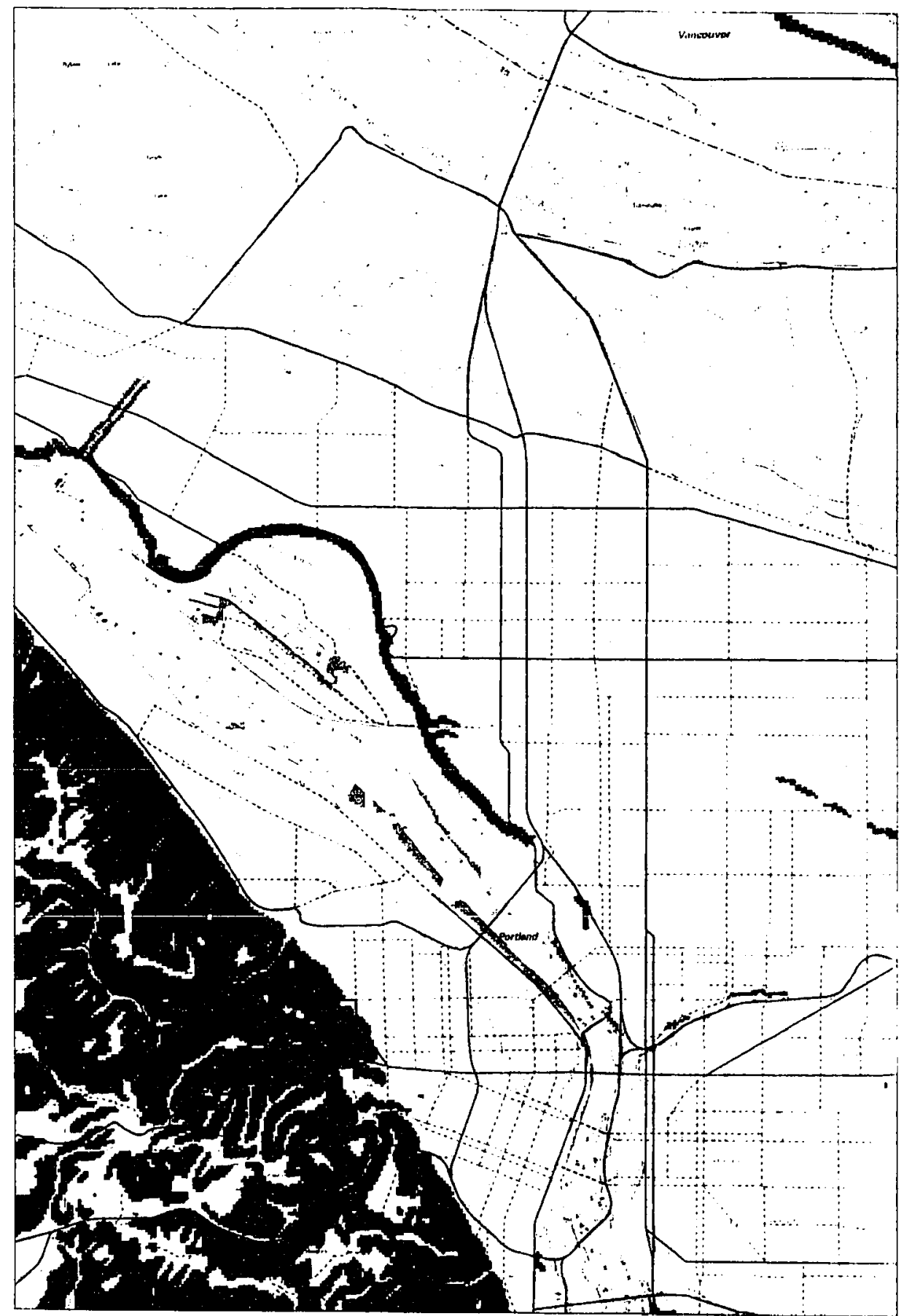

Figure 5. Lateral Spread Displacement and Dynamic Slope Instability Map (GMS-79 plate 3 ). 
pulled apart laterally. The amount of permanent ground displacement resulting from liquefaction is a function of the thickness of the liquefiable layer. The thickest and most liquefiable deposits in the Portland Quadrangle lie beneath the extended flood plains of the Columbia and Willamette Rivers and generally conform to the lowlands along those rivers.

The purpose of the Liquefaction Susceptibility Map (Plate 1) is to show the areas likely to be underlain by liquefiable deposits. Plate 1 indicates liquefaction susceptibility by showing color codes indicating combinations of thickness of liquefiable sediment and depth to water table, as shown in Table XII, following.

TABLE XII

LIQUEFACTION SUSCEPTIBILITY FROM GMS-79 PLATE 1

\begin{tabular}{|c|c|c|}
\hline $\begin{array}{l}\text { MAP } \\
\text { COLOR }\end{array}$ & $\begin{array}{l}\text { THICKNESS OF } \\
\text { L IQUEF IABLE SEDIMENT }\end{array}$ & $\begin{array}{l}\text { DEPTH TO } \\
\text { WATER TABLE }\end{array}$ \\
\hline Red & More than $30-f t$ & Less than $15-f t$ \\
\hline Pink & More than $30-f t$ & $15-f t$ to $30-f t$ \\
\hline Orange & $10-f t$ to $20-f t$ & Less than $15-f t$ \\
\hline Yellow & $10-f t$ to $20-f t$ & $15-f t$ to $30-f t$ \\
\hline Dark Green & Less than $10-f t$ & Less than $15-\mathrm{ft}$ \\
\hline Light Green & Less than $10-f t$ & $15-f t$ to $30-f t$ \\
\hline
\end{tabular}


The order shown in Table XII is roughly from worst to decreasing liquefaction hazard. Liquefaction seldom occurs in areas where the depth to the water table exceeds 30-feet.

\section{Lateral Spread Displacement Map}

Lateral spread is one of the most widespread and devastating forms of ground failure triggered by liquefaction. These failures are characterized by surface soils underlain by liquefied soils that slide laterally down mild slopes or toward a free face, such as a river channel bank. Differential movements within the spreading mass usually create such features as fissures, scarps, and grabens. Lateral displacements may range from a few centimeters to several meters, and differential vertical movements (settlements) may be up to about half of the horizontal movement. These displacements commonly inflict severe damage to structures built on the unstable terrain.

Lateral spread displacements are driven by a combination of static gravitational and dynamic seismic forces. Localities most vulnerable to lateral spread lie near river channels or on gently sloping ground underlain by loose, water-saturated granular sediments.

The purpose of the Lateral Spread Displacement Map (Plate 3) is to quantitatively estimate maximum lateral ground displacements, by combining ground slope and/or 
proximity to a free face with the liquefaction hazard data, utilizing a technique developed by Bartlett and Youd (1992). Bartlett and Youd formed empirical regression models relating ground displacement to seismic, topographic, and geotechnical factors with data compiled from more than 450 sites where lateral spread has occurred. Plate 3 color-codes estimated maximum lateral displacement, as shown in Table XIII, following.

TABLE XIII

LATERAL SPREAD DISPLACEMENT FROM GMS-79 PLATE 3

\begin{tabular}{ll}
\hline MAP COLOR & GROUND DISPLACEMENT \\
\hline White & $\begin{array}{l}0 \\
\text { Light Green to } 2 \text { feet } \\
\text { Yellow } \\
\text { Orange } \\
\text { Red }\end{array}$ \\
\hline
\end{tabular}

\section{Ground Motion Amplification Map}

Recent earthquakes have shown the effect of local ground shaking amplification on the distribution of major damage. Unconsolidated geologic materials tend to amplify the ground shaking from earthquakes, as much as 2 to 3 times the accelerations of underlying bedrock (AKi 1988). 
The amount of amplification depends primarily on the thickness and shear-wave velocity of the unconsolidated materials overlying bedrock.

The Ground Motion Amplification Map (Plate 2) was developed by combining information on the thickness and distribution of geologic units with measurements of the physical properties of the units. The shear modulus is one of the most critical properties and was determined directly by down-hole measurements of the shear-wave velocity in twenty boreholes throughout the quadrangle.

The degree of ground shaking amplification that might occur in future earthquakes was estimated using the computer program SHAKE (Schnable and others 1972). Version SHAKE88 was selected because $1 t$ is widely used and accepted for this type of modeling. In order to account for both the variation of shaking from one earthquake to another and to account for the three distinct types of seismic sources in the region, Plate 2 was created by taking the maximum amplification from the SHARE analysis of five time histories of bedrock acceleration.

Plate 2 uses a color-coded map to depict the ground motion amplification of the Portland Quadrangle. The Amplification is defined as the ratio of the peak ground surface acceleration to the peak bedrock acceleration, as shown in Table XIV, following. 
TABLE XIV

GROUND MOTION AMPLIFICATION FROM GMS-79 PLATE 2

\begin{tabular}{ll}
\hline MAP COLOR & AMPLIFICATION \\
\hline Dark Blue & 1 or less \\
Dark Green & 1.4 to 1.4 \\
Light Green & 1.8 to 2.2 \\
Yellow & 2.2 to 2.5 \\
Orange & 2.5 or more
\end{tabular}

Dynamic Slope Instability Map

The dynamic loading imposed by earthquakes tends to destabilize steep slopes that are stable under static conditions. The objective of the Dynamic slope Instability Map (also on Plate 3 ) is to identify areas likely to experience dynamic instability. The only significant area of steep slopes is in the West Hills, which are covered by a varying thickness of the loessial Portland Hills Silt. The map was developed by analyzing slope steepness, thickness of unconsolidated material overlying bedrock, and potential seismic loading.

The steepness of slopes was derived from UsGS elevation data. The thickness of unconsolidated material, which is all loess, was interpreted from boreholes in the 
area and seismic refraction profiling done for this purpose. The strength properties of the loess were based on extensive laboratory testing done for the west-side light-rail project. A soil friction angle of 33-degrees and a moist unit weight of 115 pcf were used in the stability analysis, based on Tri-Met (1993).

The dynamic slope stability was evaluated with a pseudo-static infinite slope model, comparing the results obtained from four seismic coefficients: $0.05,0.15$, and 0. 25. Factors of safety were assigned to map areas derived from the seismic coefficient of 0.15 , which was judged to most realistically represent the shaking likely to be experienced. Four hazard zones are identified by color-code on the map, as shown in Table XV, following.

TABLE XV

RELATIVE DYNAMIC SLOPE INSTABILITY FROM GMS-79 PLATE 3

MAP COLOR RELATIVE DYNAMIC SLOPE INSTABILITY

\begin{tabular}{ll}
\hline White & None \\
Dark Green & Slope = $15 \%$ or greater \\
Blue & Factor of Safety $=1.25$ to 2.0 \\
Dark Purple & Factor of Safety less than 1.25 \\
Light Purple & Existing Landslide
\end{tabular}


The dark green merely represents areas with steep slopes, which could experience some instability just because of their steepness. Blue represents areas that should be suspect during earthquakes. Dark purple represents areas with the greatest hazard based on the stability modeling, with factors of safety less than 1.25; these areas are likely to experience instability during earthquakes with a rock PGA $0.20 \mathrm{~g}$, or less. The light purple represents existing landslides, which are likely to be reactivated in an earthquake.

Plate 3 combines two seismic hazards on one map: lateral spread displacement and dynamic slope instability. These two seismic hazards involve ground slopes that are different by an order of magnitude, and always occur in mutualiy exclusive map areas. Therefore, the two hazards have been logically combined on one map, to reduce the total number of maps required.

\section{Relative Earthquake Hazard Map}

This is a composite map developed to show which areas have the greatest tendency to experience damage due to any one, or any combination of three different earthquake-related hazards. The map was developed by combining the single hazard maps for ground motion amplification, liquefaction, and slope instablity. The objective is to generalize the hazards in a way useful to 
a non-technical audience such as planners, lenders, and emergency responders, and for hazard mitigation response planning.

The three individual hazards were categorized as zones $0,1,2$, or 3 , with 3 being the greatest hazard, as foll ows:

For ground motion amplification:

1) Amplification Factor less than 1.25

2) Amplification factor 1.25 to 1.50

3) Amplification factor greater than 1.50

For liquefaction susceptibility:

1) Materials liquefiable when they are intermittently saturated.

2) Liquefiable material less than 20-ft thick, with a water table 15 to $30-f t$ deep.

3) Liquefiable material more than 30-ft thick, with a water table 15 to $30-f t$ deep, or when the water table is less than 15-feet deep. For dynamic slope instability:

1) Slopes steeper than 15-percent.

2) Dynamic safety factor from 2.0 to 1.25

3) Dynamic safety factor less than 1.25, or the vicinity of an existing landslide.

The relative hazard map methodology takes a "vector sum," or square root of the sum of the squares, of the 
three individual hazard categories, rounding the result to the nearest whole number. The result is assigned to hazard categories, as follows:

VECTOR SUM

4

3

2

1

\section{RELATIVE HAZARD MAP ZONE}

Zone A - Greatest Hazard

Zone B

Zone $C$

Zone D - Least Hazard

The result of this system is that areas with a high hazard from a single local effect are assigned the rating of Zone $B$, as well as areas with a combination of lesser single ratings. The rating of A represents a combination of high ratings. The hazard zone $B$ should not be underrated, since it can result from the great severity of a single hazard.

\section{Significance and Limitations}

The quantitative data provided by these maps is the best currently available information on probabilistic seismic soil hazards in Portland.

The most severe damage done by an earthquake is sometimes concentrated in areas which respond adversely due to the subsurface soil conditions. Clearly, improvements in regionally defining and quantifying the soil strata response to earthquake shaking is important in modeling the total damage to structures. 
The earthquake hazard maps are intended to provide an estimate of regional variations in the geologic earthquake hazards, but were not intended for use as the basis for earthquake resistant design of individual structures. Additional site-specific investigations and analyses are generally required for such purposes. 
FEMA-227: A BENEFIT-COST MODEL FOR SEISMIC REHABILITATION OF BUILDINGS

\begin{abstract}
FEMA-227 (1992) presents the results of a two year experimental research project undertaken to establish a benefit-cost model for seismic rehabilitation of buildings. The objective of the project was to encourage local decision makers, the design professions, and other interested groups to undertake a program of mitigating the risks posed by future earthquakes.

The intended application of the model is to provide quick and preliminary estimates of whether a prospective seismic retrofit program is economically justifiable. The benefit-cost model presented produces three indices for judging whether the rehabilitation of a building or group of buildings is economically justified:
\end{abstract}

1. The expected net present value of the retrofit without the value of life.

2. The expected net present value of the retrofit with the value of life.

3. The benefit/cost ratio of the retrofit.

When expected benefits exceed costs, the net present value is positive and the rehabilitation investment is economically justified. When expected benefits are less than costs, the net present value is negative and the rehabilitation investment is not economically justified. 
Expected Net Present Value Model without the Value of Life

The expected net present value (NPV) of a seismic rehabilitation investment is the sum of the present value of benefits expected to accrue each year (probabilistically) over the planning period, plus the present value of the salvage value of the rehabilitation investment at the end of the planning period, minus the initial cost of the rehabilitation. FEMA-227 presents the following equation for NPV:

$$
N P V=B t\left[\frac{1-(1+i)-t}{i}\right]+\frac{V t}{(1+i) t}-I N V
$$

where:

Bt = the expected annual benefit attributed to the retrofit in year $t$;

Vt = any change that the retrofit will have on the salvage value of the building in the terminal year $t$;

$t=$ the length of the planning horizon which should reflect the effective life of the retrofit of the buildings;

$i=$ the discount rate; and

INV = the cost (engineering/construction) of the retrofit. In the NPV equation above, the term in brackets is the Uniform Series - Present Worth Factor (PWF), which discounts each years benefit over the planning horizon to its present value. The choice of an appropriate discount rate, $i$, is one of the most difficult aspects of 
benefit-cost analysis. Increasing the discount rate lowers the present value of future benefits and lowers Benefit/Cost (B/C) ratios. FEMA-227 recommends using a discount rate between $3 \%$ and $6 \%$; for public sector considerations, the lower end of the range is appropriate, whereas for private sector, the higher end is more appropriate. The planning horizon also significantly impacts benefit-cost results. Longer planning horizons capture more future benefits, resulting in higher present value of benefits. Typical planning horizons suggested by FEMA-227 are 20 or 30 years.

Cost records of renovated buildings rarely indicate what would have been the cost of seismic retrofit alone, separate from other kinds of renovation that generally occurs concurrently. In estimating the cost of seismic retrofit, a decision must be made whether to use the estimated cost of seismic retrofit as if it were the only building improvement, or a share of costs that occur in conjunction with other improvements. The retrofit cost question is covered in more detail under the discussion of FEMA-156, to follow.

Typically, the net present value of the salvage value of the retrofit investment is only a few percent of retrofit costs and, thus, has only a minor impact on $B / C$ ratios. 
The expected annual benefit which accrues from the retrofit (Bt) is the sum of expected avoided losses, both direct and indirect, accounting for the expected annual probability of damaging earthquakes, as follows:

$$
B t=\Sigma\left[\begin{array}{ll}
\left(E A E^{m}\right) & \left(B D^{m}+I D\right)
\end{array}\right]
$$

where:

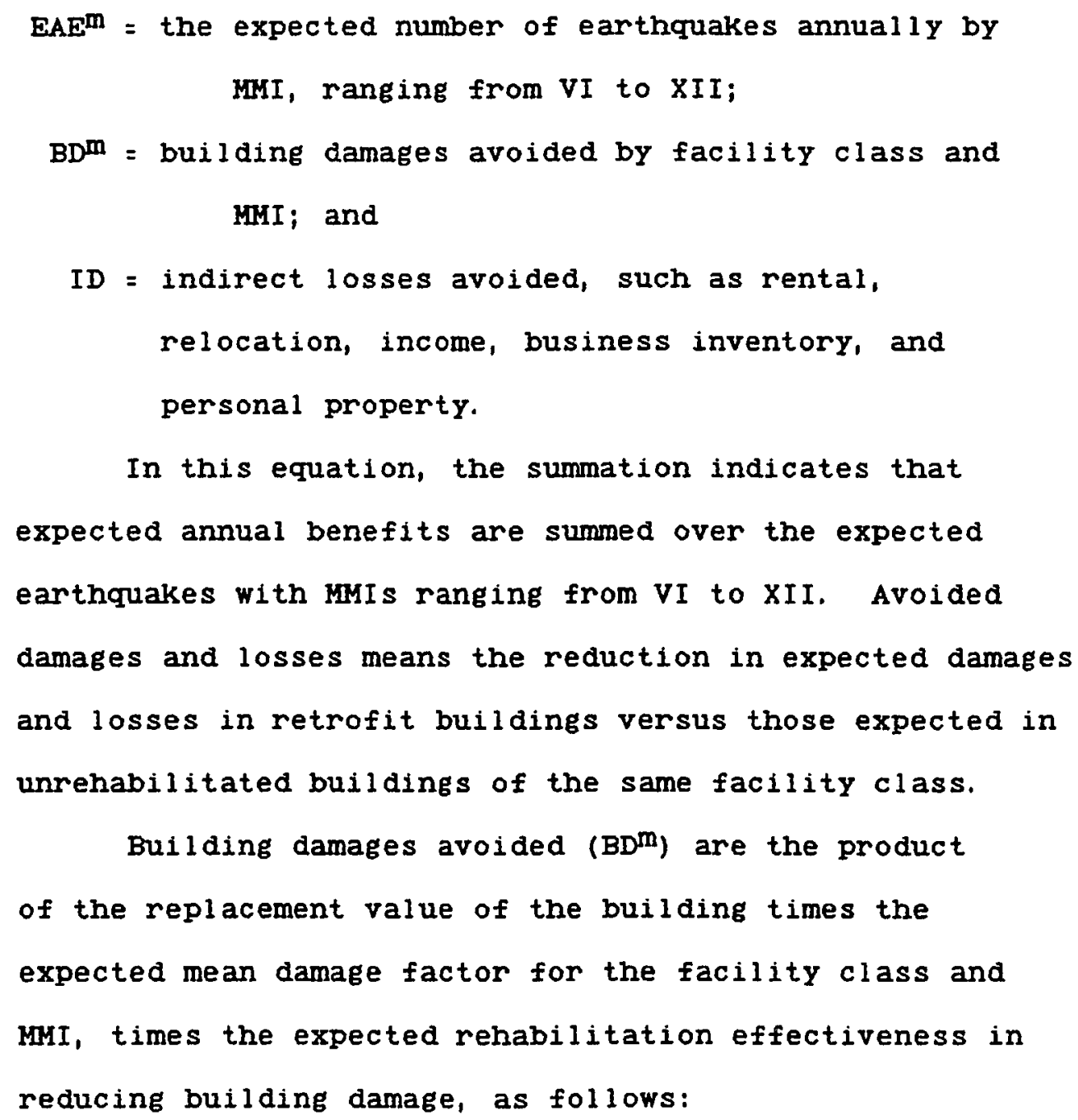




$$
B D^{m}=(B V A L)\left(M^{m} F^{m}\right) \quad\left(E R E^{m}\right)
$$

where:

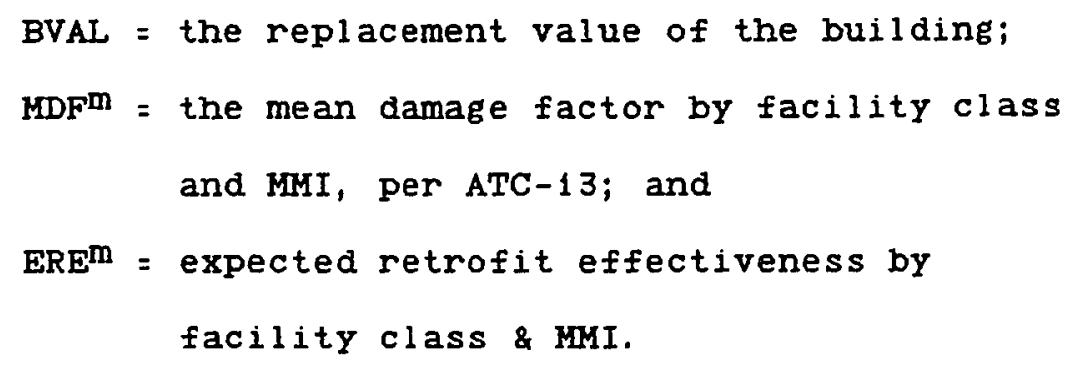

To account roughly for the greater damage expected at poor soil sites, the model adjusts the mean damage factor upward by one MMI level for sites on "soft" soils. The retrofit effectiveness, EREm, is defined as the percent reduction in expected damages in the strengthened facility compared to the expected damages in the unstrengthened facility. This factor was determined as part of FEMA-227. These estimates were based on engineering experience and judgement, assuming life-safety as the objective of the retrofit.

"Life-Safety" retrofits provide the minimum strengthening to prevent building collapse, other objectives are "Damage Control," for additional reduction in damage, and "Immediate Occupancy," appropriate for emergency service facilities. FEMA-227 invites users to adjust the retrofit effectiveness estimates for alternate performance objectives. 
Expected Net Present Value Model with the Value of Life

The model discussed above does not include the value of life. When the value of life is included, the value of avoided deaths is frequently one of the principal factors in producing high $B / C$ ratios for prospective strengthening programs, especially for high occupancy facilities.

The expected net present value including the value of life (NPVVol) is the expected net present value without the value of life, plus the present value of expected deaths avoided by seismic retrofit, as follows:

$$
\mathrm{NPVVO}=\mathrm{NPV}+\left[\begin{array}{ll}
\text { (VDAt) } & (\mathrm{PWF})
\end{array}\right]
$$

where:

MPV = the expected net present value without the value of life;

VDAt = the annual value of expected deaths avoided by retrofitting buildings to life-safety standards.

PWF = the Uniform Series - Present Worth Factor, as previously defined.

The annual value of avoided earthquake death loss is assumed to be the product of the building occupancy times the difference in expected death rates between unretrofit and retrofit buildings, times the dollar value of one human life, as follows: 
VDAt $=\Sigma\left[\begin{array}{lll}\left(E A E^{m}\right) & (O C C) & \left(D R^{m}-D R R^{m}\right)\end{array}\right]($ VOL $)$

where:

OCC = the average occupancy of the building, number of people;

$D R^{m}=$ the expected death rate by central damage factor, according to ATC-13 Table 3-9

$D R^{m}=$ is the expected death rate for rehabilitated buildings by central damage factor; and

VOL = the dollar value of one human life.

The summation symbol indicates that the expected deaths avoided must be summed over the range of MMI earthquakes for each facility. The occupancy OCC is determined from local occupancy data, or by applying ATC-13 Table 4.12 to the building area.

The expected death rate for the rehabilitated buildings, $D R^{m}$, are estimated based on engineering experience and judgement, assuming that the death rates are lowered to those that would be expected if the building damage states were three states lower. For most damage states, this assumption is equivalent to reducing deaths by a factor of 1,000. This benefit-cost model did not include as a benefit the economic value of injuries avoided by retrofitting, concluding that this benefit was insignificant compared with the dollar value of 11 fe. 
The value of one human 1 ife, Vol, has been the subject of much study, with values ranging from $\$ 1,100,000$ to $\$ 8,000,000$ per 1 ife. FEMA-227 recommends a consensus value obtained from a review of 25 updated studies for the FAA, of $\$ 1,740,000$.

\section{Benefit/Cost Ratios}

Benefit/cost (B/C) ratios are an alternative way of viewing net present value results, which may make it easier to compare and prioritize prospective rehabilitation projects. $B / C$ ratios are the expected present value of future benefits divided by retrofit cost. $B / C$ ratios greater than one correspond to positive expected net present values, indicating that a prospective retrofit is economicaliy justified, while ratios less than one correspond to negative expected net present values and a prospective retrofit that is not justified on the basis of the assumptions in the model. The extent to which $\mathrm{B} / \mathrm{C}$ ratios are greater or less than one provides important guidance as to the relative economic justification of prospective retrofit projects.

\section{Significance and Limitations}

Benefit-cost analysis is a widely-used economic tool for helping to make economic decisions. The central economic question about retrofitting earthquake-hazardous 
buildings is whether the benefits which accrue from retrofit are sufficiently valuable to warrant the expense. FEMA-227 was an important step in establishing a model to answer this question.

Since the benefit-cost analysis is based on the ATC-13 loss model, the limitations of ATC-13 are carried into this model, namely, that loss estimates are based on "average" buildings of each class, with the characteristics of individual buildings not accounted for; additionally, important soil profile effects, often an important component of earthquake losses, are only roughly accounted for.

Two other areas add uncertainty to the model. The first is uncertainty in the evaluation of retrofit effectiveness. Estimating the effectiveness of retrofit would be difficult even if clear and well-defined seismic strengthening standards were avallable. Currently, some of the facility classes considered do not have well defined standards, and very few buildings that have received seismic improvements have ever been tested by earthquakes strong enough to demonstrate their effectiveness.

A second fundamental limitation with the model is imposed by the expected value methodology used. For Portland, the return period for damaging earthquakes (the 
inverse of the annual exceedance probability) is far

greater than any reasonable planning horizon. This

results in total losses, and hence total benefits from

retrofit, being significantly less than the losses and

retrofit benefits from a moderate earthquake. At constant

retrofit cost, the resulting net present value and $B / C$

ratios could produce misleading conclusions regarding the

cost effectiveness of retrofit. 
FEMA-156: TYPICAL COSTS FOR SEISHIC REHABILITATION OF EXISTING BUILDINGS, SECOND EDITION

FEMA-156 (1994) presents a methodology to estimate typical costs for seismic retrofit of buildings. The methodology was derived from a computerized database of 2,088 retrofit costs.

Each retrofit cost data point is from either an actual retrofit project or the estimated cost of retrofit of a building subjected to a detailed analysis by an experienced design professional. Cost estimates based on studies were excluded, as were cost estimates that lacked certain critical information. Consistency was achieved by weighting the quality of the data and the source. Therefore, the resulting database is extensive, objective, reliable, and consistent.

FEMA-156 provides three methods of retrofit cost estimation. Option 1 requires a minimum of input information, and is intended for rough preliminary estimates. Option 3 uses raw cost data from the computerized database, and is the most accurate for costing individual buildings, but contains gaps that make it less suitable for use in regional studies. Option 2 is the most suitable for the present research, because it provides values in tables that are derived using a smoothing of the cost data to provide values for all 
variable combinations, and to provide logical relationships between changes in variables and changes in costs. Option 2 requires the following input:

Building Group

Building Area (size)

State

Year of Retrofit Construction

NEHRP Seismic Map Area

Performance Objective

The typical structural cost per square foot of retrofit (C), using option 2 , is calculated according to the following formula:

$$
C=\left(C_{1}\right)\left(C_{2}\right)\left(C_{3}\right)\left(C_{L}\right)\left(C_{T}\right)
$$

where:

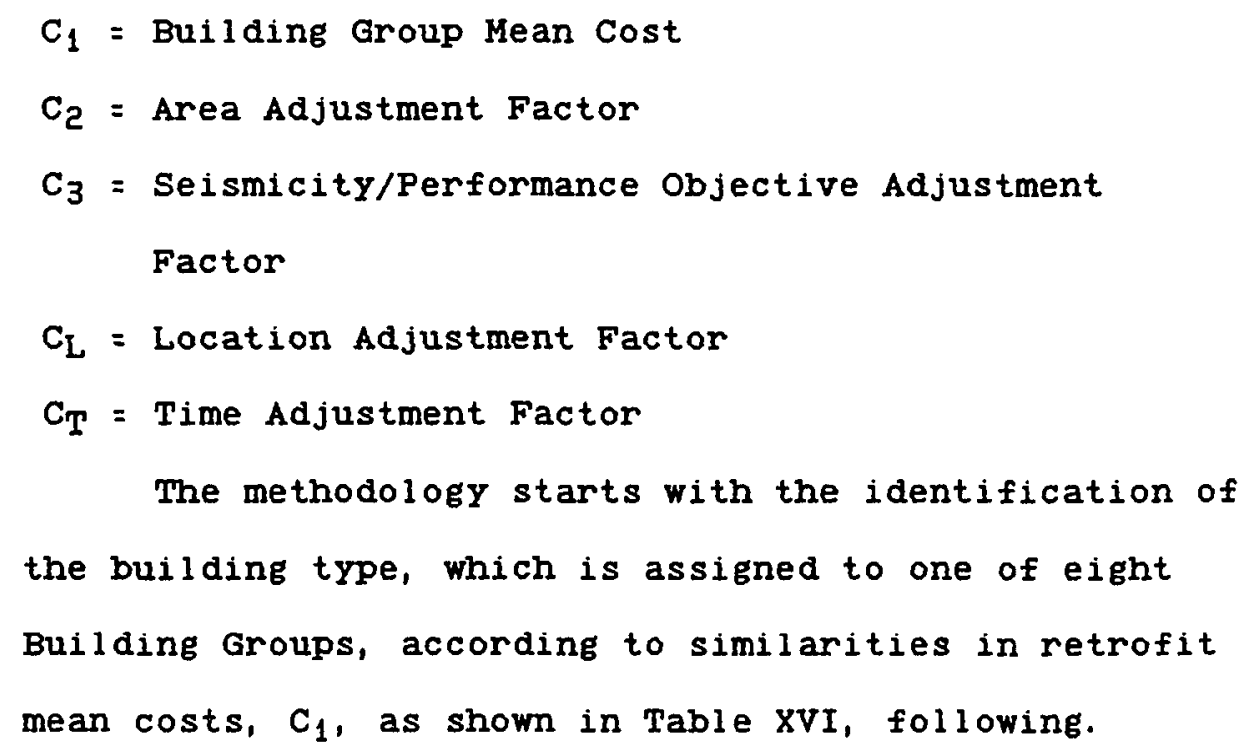


TABLE XVI

FEMA-156 BUILDING GROUP MEAN COST

\begin{tabular}{clc}
\hline $\begin{array}{c}\text { BUIIDING } \\
\text { GROUP }\end{array}$ & $\begin{array}{c}\text { ATC-21 } \\
\text { BUILDING TYPE }\end{array}$ & $\begin{array}{c}\text { GROUP MEAN COST } \\
(\$ / \text { sq. } \text { ft. })\end{array}$ \\
\hline 1 & URM & 15.29 \\
2 & W1, W2 & 12.29 \\
3 & PC1, RM1 & 14.02 \\
4 & C1, C3 & 20.02 \\
5 & S1 & 18.86 \\
6 & S2, S3 & 7.23 \\
7 & S5 & 24.01 \\
8 & C2, PC2, RM2, S4 & 17.31 \\
\hline
\end{tabular}

The size (area) of a building affects its typical cost per square foot. The buildings are assigned to an area group, as follows:

Smal1 Less than 10,000 sq. ft.

Medium $\quad 10,000$ to 49,999 sq. ft.

Large $\quad 50,000$ to 99,999 sq. ft.

Very Large 100,000 sq. ft. or more

The Area Adjustment Factor, $C_{2}$, is a function of the area group and the building group, as shown in Table XVII, following. 
TABLE XVII

FEMA-156 AREA ADJUSTMENT FACTORS

\begin{tabular}{lccccccccc}
\hline \multicolumn{10}{c}{ BUILDING GROUP } \\
& 1 & 2 & 3 & 4 & 5 & 6 & 7 & 8 \\
\hline Sma11 & 1.01 & 0.97 & 1.13 & 1.09 & 1.16 & 1.18 & 1.04 & 1.11 \\
Medium & 1.00 & 1.02 & 1.07 & 1.06 & 1.14 & 1.12 & 1.03 & 1.08 \\
Large & 0.95 & 1.28 & 0.92 & 1.01 & 1.09 & 0.90 & 0.99 & 1.02 \\
V. Lrg & 0.80 & 1.64 & 0.57 & 0.84 & 0.83 & 0.51 & 0.87 & 0.83 \\
\hline
\end{tabular}

The Seismicity/Performance Objective Adjustment Factor, $C_{3}$, incorporates the the seismicity and the desired performance objective, as shown in Table XVIII.

TABLE XVIII

FEMA-156 SEISMICITY/PERFORMANCE OBJECTIVE ADJUSTMENT FACTOR

\begin{tabular}{llll}
\hline SEISMICITY & $\begin{array}{c}\text { LIFE } \\
\text { SAFETY }\end{array}$ & $\begin{array}{l}\text { DAMAGE } \\
\text { CONTROL }\end{array}$ & $\begin{array}{l}\text { IMMEDIATE } \\
\text { OCCUPANCY }\end{array}$ \\
\hline Low & 0.61 & 0.71 & 1.21 \\
Moderate & 0.70 & 0.85 & 1.40 \\
High & 0.89 & 1.09 & 1.69 \\
Very High & 1.18 & 1.43 & 2.08 \\
\hline
\end{tabular}


The seismicity is identified by the NEHRP seismicity Map Areas: map areas 1 \& 2 are Low, 3 \& 4 are Moderate, 5 \& 6 are High, and 7 is Very High. Life Safety allows for unrepairable damage as long as life is not jeopardized and egress routes are not blocked. Damage Control protects some feature or function of the building beyond life-safety, such as protecting building contents or preventing the release of toxic material. Immediate Occupancy allows only minimal post-earthquake damage and disruption, with some nonstructural repairs and cleanup done while the building remains occupied and safe.

The location adjustment factor, $C_{L}$, compares the purchasing power in each state as compared to Missouri; Missouri was chosen as the base because of its central geographic location. A factor for all 50 states is given; of interest in the proposed research is oregon, and perhaps several western states, as shown in Table XIX.

TABLE XIX

FEHA-156 LOCATION ADJUSTMENT FACTOR

$\begin{array}{ll}\text { Missouri } & 1.00 \\ \text { Oregon } & 0.99 \\ \text { California } & 1.12 \\ \text { Washington } & 1.02 \\ \text { Idaho } & 0.91 \\ \text { Utah } & 0.89 \\ \text { Montana } & 0.90 \\ \text { Mevada } & 1.03\end{array}$


The Time Adjustment Factor, $C_{T}$, projects costs beyond the 1993 cost database assuming various rates of inflation. A selection of years vs, inflation rates is shown in Table $x x$.

TABLE XX

FEMA-156 TIME ADJUSTMENT FACTOR

\begin{tabular}{llllll}
\hline YEAR & $0 \%$ & $2 \%$ & $4 \%$ & $6 \%$ & $8 \%$ \\
\hline 1996 & 1.00 & 1.06 & 1.12 & 1.19 & 1.26 \\
2000 & 1.00 & 1.15 & 1.32 & 1.50 & 1.71 \\
2004 & 1.00 & 1.24 & 1.54 & 1.90 & 2.33 \\
\hline
\end{tabular}

Volume 2 of FEMA-156 presents unit costs related to seismic retrofit, including restoration of architectural finishes, non-structural retrofit, design fees, permits, management, insurance, and occupant relocation.

\section{Significance and Limitations}

The FEMA-156 methodology for estimating typical seismic retrofit costs is the most authoritaive study currently available, based on ATC-21 building types. The scientifically and carefully compiled cost database upon which it is based is the backbone of the study. This is the best source of retrofit cost information for use in the benefit-cost analysis portion of the present research. 


\section{CHAPTER I I I}

FOCUS OF RESEARCH

\section{LIMITATIONS OF CURRENT PRACTICE}

Current methods of earthquake loss analysis (Goettel and Horner 1995) are based only on "average" buildings of a given structural type, ignoring individual variations in design and construction, while incompletely modeling the effect on damage of site-specific soil characteristics. Decision analysis for retrofit is currently based on a probabilistic expected value approach (Goettel and Horner 1995; FEMA-227 1992), which computes losses far less than the losses that would be seen in an actual deterministic scenario earthquake event, leading to uncertainty about whether the most appropriate decision rule is being used. Current cost-benefit methods for retrofit decision analysis look at buildings one at a time (FEMA-227 1992), and do not prioritize an entire system of buildings, to insure that the greatest savings in life and property are obtained per dollar spent. Furthermore, the combinations of attributes contributing to seismic performance are so numerous that a workable system to classify the buildings for retrofit has yet to emerge. 
There does not currently exist a comprehensive systems approach to finding the optimal way to proceed with seismic rehabilitation of the buildings in a large city. The preceding review of the current methodologies point to shortcomings in two fundamental areas: 1) earthquake loss modeling, and 2) retrofit decision making.

\section{Earthquake Loss Modeling}

Damage Estimation. Current methodologies of earthquake loss modeling do not utilize data on the actual buildings being analyzed. FEMA-227, for example, follows the lead of ATC-13, basing its loss estimates on damage factors for "average" buildings of a given structural type. The only modification made to "average" building losses is an approximate adjustment in shaking intensity to account for amplified ground motion due to "poor soils". Individual buildings are often different from "average", and commonly exhibit characteristics of design and construction that may modify their earthquake losses to a level well above or below the average for its class. Examples of such characteristics are building height, maintenance condition, irregularities in configuration and stiffness, proximity to adjacent structures, heavy cladding, column stiffness variations, and age. Because of the large number of possible combinations of characteristics, a model based only on typical response for 
a given structural type may be very incorrect. For example, in work on the Portland Seismic Hazards Survey (PSHS), which catalogues these characteristics, the author has seen many examples of structural performance scores reflecting damage of only half of what is considered "average" for the structural type; he has also seen even more instances of scores indicating damage that is double, triple, or more than what is "average" for the structure type.

Clearly, it would be a major improvement if, in addition to the effect of the structure type, an earthquake loss model accounted for and combined the effect of variations in design, construction, and soil condition hazards.

Soil Profile Effects. It is well known that the subsurface soil profile at a building site may have an important effect on building response and consequent losses. However, the existing models of this aspect of seismic response relative to building losses are incomplete. As noted, FEMA-227 includes a very approximate model for ground motion amplification due to "poor soils." None of the current loss estimation models include the most catastrophic of all selsmic soll hazards: liquefaction potential and dynamic slope instability. Additionally, these hazards may have a combined effect with 
ground motion amplification. A better model would develop a method to include the effect of all three of these soil profile effects.

\section{Retrofit Decision Analysis}

Expected Value vs. Scenario Event. FEMA-227 uses an "expected value" approach to compute net benefits and B/C ratios to determine whether retrofit is economically justified. In this method, avoided losses from retrofit for a range of possible earthquake magnitudes are multiplied by the annual probability of each magnitude. The resulting annual benefit is summed over a planning horizon by applying a Present Worth Factor to determine the present value of the benefit.

Because there are orders of magnitude differences between the earthquake return periods and any reasonable planning horizon used for bulldings, the value of beneficial avoided losses using the expected value method are far less than the value of avoided loss that would be computed in a deterministic analysis for a single "scenario earthquake event," such as a Design Basis Earthquake (usually considered as an event with a 10-percent chance of exceedance in 50 years).

Since the retrofit cost is a constant, whether the expected value or the scenario event approach is used makes a big difference in calculation of net benefit and $B / C$ 
ratio. The retrofit plans resulting from using one decision rule versus the other can lead to paradoxical conclusions, as discussed in Chapter I.

This anomalous situation -.- which in decision theoretic terms is the difference between a "maximum expected value" and a "maximin" decision rule -.- is a major point of debate in current retrofit decision analysis.

The Need for a Systems Approach. FEMA-227, the most current benefit-cost methodology for retrofit decision analysis, computes a retrofit $\mathrm{B} / \mathrm{C}$ ratio one building at a time. If the $B / C$ ratio for a particular building exceeds one, retrofit is deemed economically justified.

A systems approach would look at establishing priorities of retrofit for a group of buildings, in order to maximize benefits and optimize investment from a regional viewpoint.

Effective decision analysis must be defined with respect to a decision maker. The decision maker in regional seismic retrofit is the city, county or state government legislating the retrofits. Currently (1995-96), the City of Portland and state of Oregon are searching for criteria by which to establish legislation to encourage or require retrofit. The methods that presently exist would be enhanced by integrating the 
systems approach.

Bullding Classification. Currently, buildings are classified according to their structural types, i.e., wood frame, steel frame, etc. However, structural type is one of a number of attributes that contribute to earthquake loss. As previously discussed, other attributes are various characteristics of design and construction, the site-specific soil profile, occupancy type, and occupant load. Currently, no classification system exists which captures the combinations of these attributes.

\section{OUTLINE OF THE RESEARCH}

The present research formulates a seismic loss estimation and retrofit planning methodology for buildings, to estimate regional earthquake losses and determine retrofit priorities and budgets.

The methodology utilizes seismologic ground motion data, soil hazard maps, and ATC-21/RSP inventory data as input to a soil effects model, an earthquake loss model, and a retrofit direct benefit model. A building classification system was formulated to aggregate buildings which share similar loss and retrofit direct benefit magnitudes.

A benefit-cost model is used as the basis for a retrofit prioritization model and efficiency analysis. 
Results are compared from an Expected value and an Earthquake Scenario Event retrofit analysis. The goal is to obtain the maximum system (regional) benefit (reduced loss) for each retrofit dollar spent. Retrofit prioritization also enables the scope of a regional retrofit program to be established: at what point does the decision-maker opt to "cut-off" the retrofit plan -.. the point of optimum benefit-cost efficiency --- and what is the estimated budgets for the optimal retrofit program.

The research consists of the following sequence:

1. Development of an improved Earthquake Loss Mode1:

a) Seismic vulnerability model for buildings.

b) Soll effects model for buildings.

c) Building damage and loss of life models.

2. Development of a retrofit direct benefit model.

a) Retrofit effectiveness model.

b) Retrofit direct benefit and cost models.

3. Development of a Retrofit Planning methodology:

a) Building Classification System.

b) Retrofit cost-benefit analysis models.

c) Retrofit prioritization model.

d) Retrofit system optimization model.

3. Utilizing the methodologies developed, computer software was developed to estimate earthquake losses and plan a retrofit program for a region. 
4. Losses were estimated for 7,500 non-residential buildings in the Portland, Oregon Quadrangle, for four earthquake scenario events, with emphasis on the Design Basis Earthquake event (a magnitude with a $10 \%$ chance of exceedance in 50 years).

5. A retrofit analysis was made of 7,500 nonresidential buildings in the Portland Quadrangle. Results from a Design Basis Earthquake Scenario are compared to an Expected Value Analysis.

A flowchart depicting the components and general process in the earthquake loss model is shown in the first page of Figure 6, following.

A flowchart depicting the components and general process in the retrofit planning methodology is shown in the second page of Figure 6, following. 


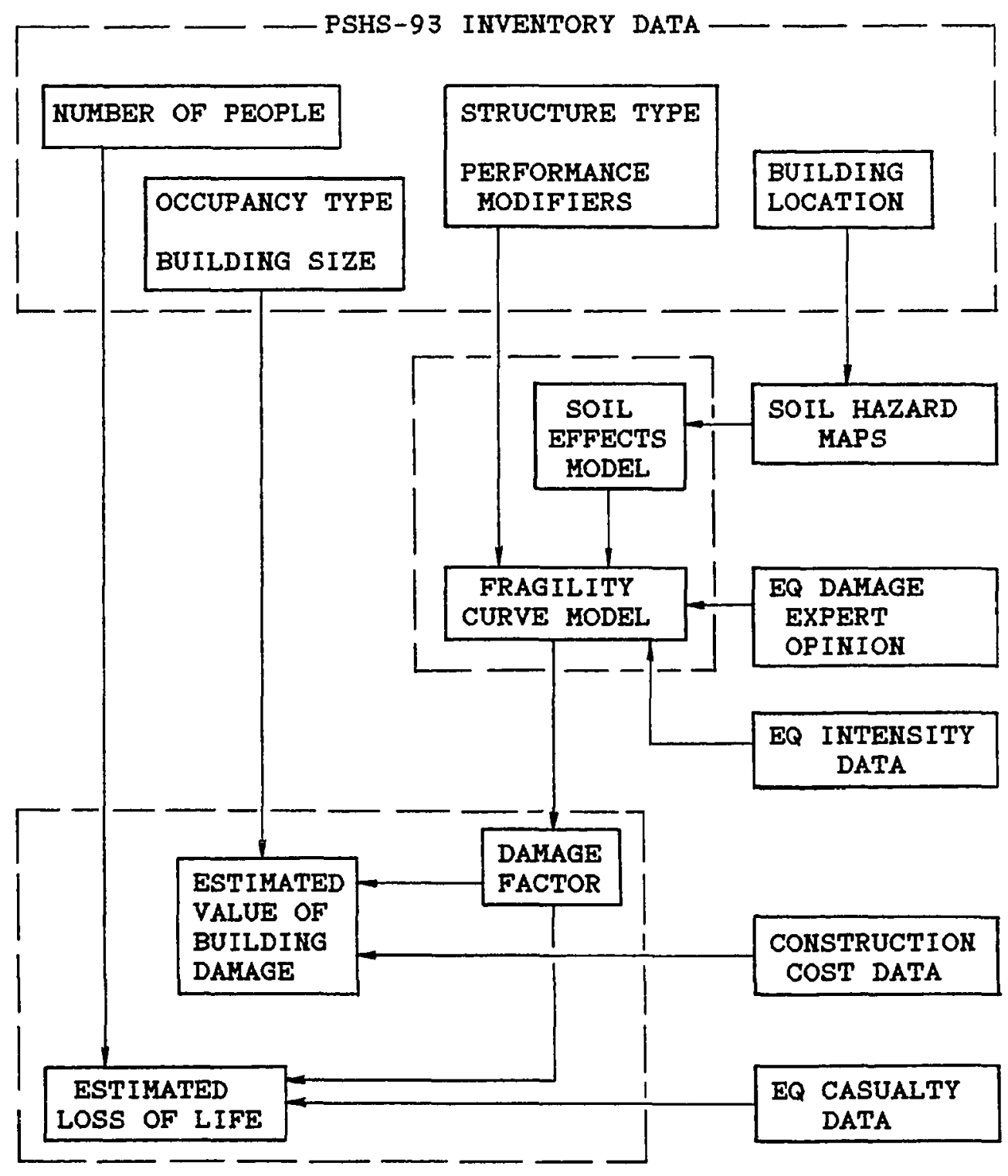

Figure 6. Earthquake loss modeling flowchart. 


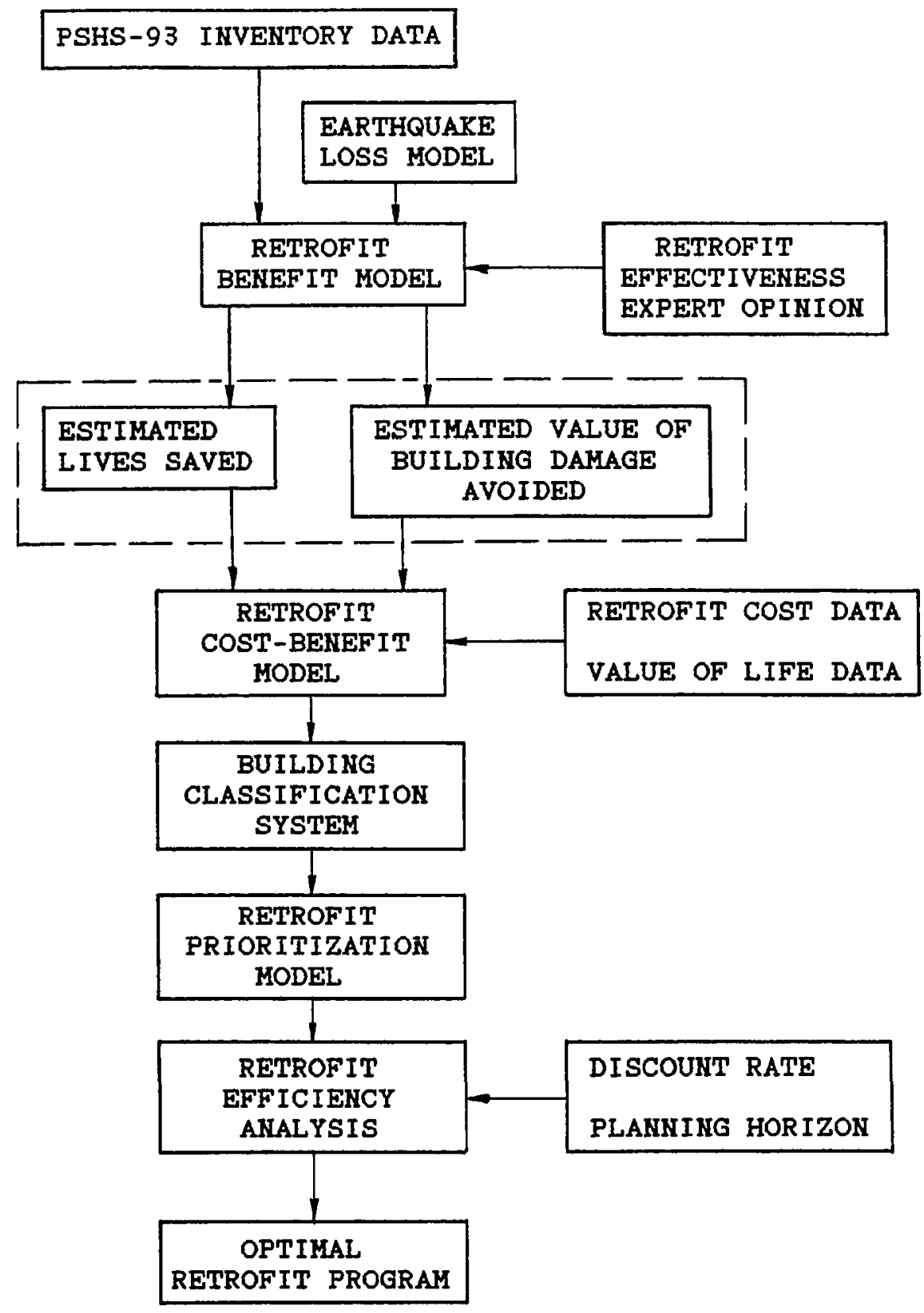

Figure 6, continued. 
CHAPTER IV

DEVELOPMENT OF AN EARTHQUAKE LOSS MODEL FOR EXISTING BUILDINGS

An Earthquake Loss Model was developed to estimate earthquake losses for existing buildings.

Model inputs are:

1. Building Inventory: ATC-21 Rapid Survey Data.

2. Earthquake Hazard Map indices.

The model outputs are estimates, for 6 values of Peak Ground Acceleration (PGA), of the following:

1. Damage Factor.

2. Dollar value of damage.

3. Loss of life \& serious injuries to occupants.

The loss model extends current loss estimation methodologies by including the effect of the following attributes of each individual building and site in the inventory:

1. 12 Structural Types, per ATC-21.

2. 10 Structural Attributes, per ATC-21.

3. 3 Soil Attributes, from GMS-79.

4. 9 Occupancy Types, per ATC-21.

5. 7 Occupancy Levels, per PSHS-93, 
The Damage Factor estimate is based on correlations between ATC-21's Structural Score and ATC-13's Hean Best Damage Factor. Dollar value of damage is estimated from Damage Factor, building area, and occupancy type. Loss of life and serious injury estimates were derived from occupancy level, damage factor, and ATC-13's Table 9.3.

FORMATS FOR EXPRESSING SEISKIC VULNERABILITY

The expert opinion estimates of Damage Factor summarized in ATC-13's Appendix $G$ is an expression of building seismic vulnerability in "damage function" format, giving damage estimates for discrete steps of earthquake intensity. An alternative expression of seismic vulnerability is the "fragility curve" format, wherein the damage factor is modeled as a continuous function of seismic intensity.

\section{Ground Motion Characterization}

In ATC-13, the Damage Factor (DF) is given at seven discrete steps, for seven levels of Modified Mercalli Intensity (MMI). The MMI levels summarized in Appendix $G$ are VI through XII. MMI was used to characterize earthquake intensity in ATC-13 because, as previously noted, most expert knowledge of building damage from earthquakes exists in that form. However, to relate the shaking intensity to currently available seismologic data, 
it will be helpful to base both the damage function and fragility curves on Peak Ground Acceleration (PGA). ATC-21 suggests the relationship developed by Richter (1958) to convert HMI to PGA, as follows:

$$
\text { PGA }\left(\mathrm{cm} / \mathrm{s}^{2}\right) \approx 10(\text { MMI }-1) / 3
$$

More commonly, PGA is expressed as a decimal fraction of the acceleration of gravity, $\left(32.2 \mathrm{ft} / \mathrm{s}^{2}\right)$ :

$$
P G A(E) \approx 0.00102 \times 10^{(M M I-1) / 3} \quad \text { (4.1a) }
$$

\section{Damage Function Format}

An example of a damage function is shown in Table XXI for TILT-UP buildings (ATC-13 Facility Class 21). In Table XXI, the discrete steps of seismic intensity are given in both MMI and PGA, versus ATC-13's Mean Best Estimate (MB) of Damage Factor.

TABLE XXI

DAMAGE FUNCTION FOR TILT UP BUILDINGS FROM ATC-13 APPENDIX $G$

\begin{tabular}{lrr}
\hline MIMI & PGA & \multicolumn{1}{c}{ MB } \\
\hline VI & .05 & 1.50 \\
VII & .10 & 4.20 \\
VIII & .22 & 10.60 \\
IX & .47 & 18.50 \\
$X$ & 1.02 & 28.70 \\
\hline
\end{tabular}


Fragility Curve Format

As an example of a fragility curve, the TILT-UP

damage function in Table XXI is transformed to a fragility curve by regressing $M B$ against $P G A$, resulting in a cubic polynomial,

$$
M B=b_{0}+b_{1}(P G A)+b_{2}(P G A)^{2}+b_{3}(P G A)^{3}
$$

where $b_{0}, b_{1}, b_{2}$, and $b_{3}$ are the polynomial coefficients. This fragility curve and its polynomial coefficients are shown in Fig. 7 .

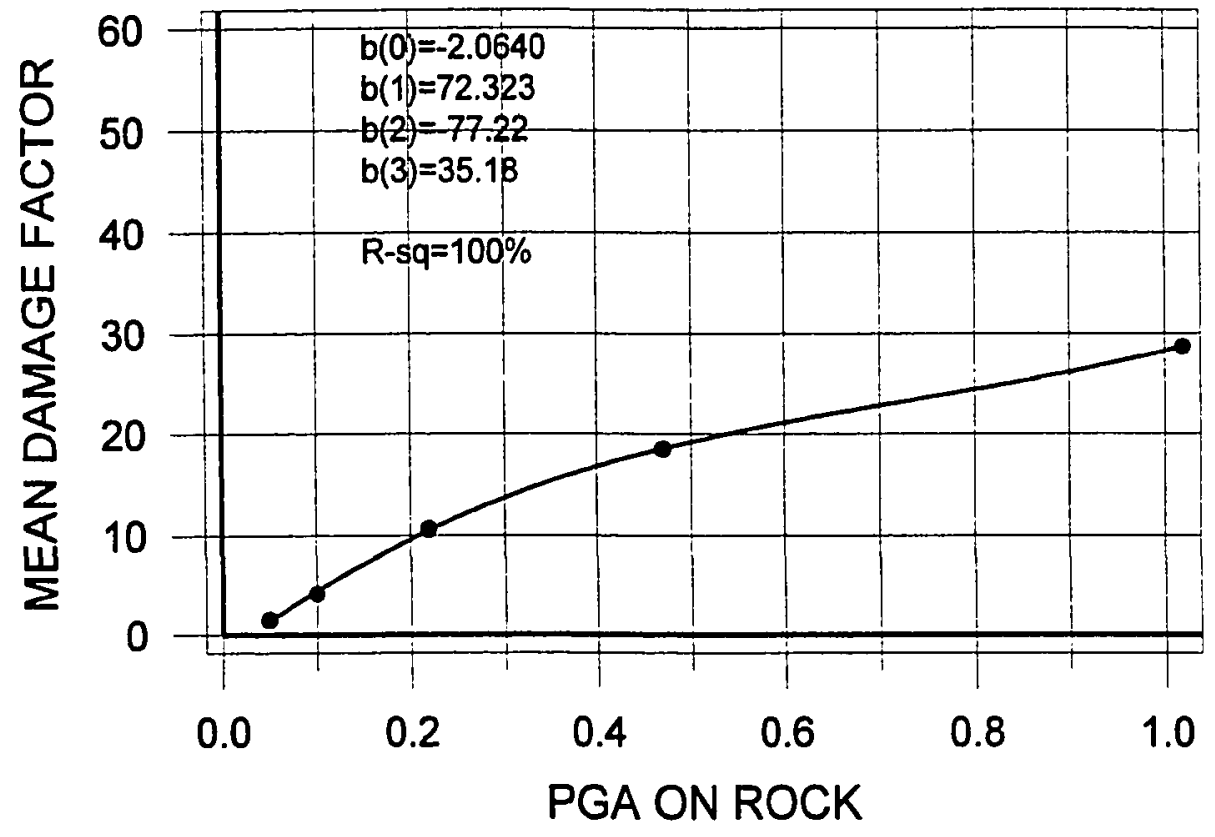

Figure 7. Fragility curve for TILT UP buildings derived from Table XXI. 
Significance and Limitations

The fragility curve format was chosen for this

research, because it provides a continuous estimate of damage vs. seismic intensity. This is helpful in making regional damage estimates based on probabilistic estimates for a range of potential ground motions.

The fragility curve developed here for TILT-UP is subject to the same serious limitations inherent in all the ATC-13 damage estimates, as follows:

1) The damage estimates apply to "average" buildings of the given structural type (in this case, TILTUP). The characteristics of design, construction, and site conditions of specific buildings are not taken into account. Such individual variations can and frequently do result in damages much different from "average" for the building type.

2) The damage estimates apply to buildings designed and constructed in California. Since earthquakes have been recognized and designed for in California long in advance of other localities, it can be expected that the same building type in a different locality will typically suffer more damage than a "California" building. 
THE BASIS OF THE ATC-21 SCORING SYSTEM

ATC-21 is the only peer-reviewed research effort to date which utilizes the extensive estimated damage data from ATC-13, while addressing the two limitations discussed above: 1) accounting for the impact of estimated damage caused by characteristics of design, construction, and site conditions in specific buildings, while 2) taking into account the expected increase in damage for "non-California" buildings.

The purpose of ATC-21 was not to formulate enhanced fragility curves, but rather to separate the buildings in a regional inventory into those which are likely to be a seismic life-safety risk from those which are not. To accomplish this, ATC-21 formulated the concept of a Structural Score (S), and then determined a value of $S$ to use as a "cut-off" between seismic high-risk versus non-high-risk buildings.

The Structural Score $S$ is defined in ATC-21 as the negative of the logarithm (base 10) of the probability of the Damage Factor (DF) exceeding 60-percent (major damage ) :

$$
S=-\log _{10}[\operatorname{Pr}(D F>=60 \%)]
$$

The structural score $s$ has a straightforward interpretation: if $S$ equals 1 , the probability of major damage is 1 in 10 ; if $S$ equals 2 , the probability of major 
damage is 1 in 100, and so on. $S$ can also be visualized as a "performance rating" -.- the higher the score, the better the estimated seismic performance and the less the damage.

Incorporated within $S$ for a specific building are the effects of:

1) a specified seismic intensity,

2) the building type, and

3) characteristics of design, construction, and site conditions of the specific bullding.

$S$ is determined for a specific bullding by adding the Basic Structural Hazard (BSH) score to the sum of the Performance Modification Factors (PMF, as defined in Chapter II), 1. e. ,

$$
S=B S H+\Sigma(P M F)
$$

The BSH is a generic score for an "average" building of its type, at a specified seismic intensity. The BSH score is modified for a specific building by the PHFs, reflecting the characteristics of design, construction, and site conditions of that specific building, that cause its seismic response to differ from "average."

Clearly, $\Sigma(P M F)=0$ reflects a building that does not have characteristics that are different from the average building of its type. This is reflected in Eq. 4, 4, which shows that when $\Sigma(P M F)=0, S=B S H$. Therefore, the BSH is 
the score for an "average" building of its type.

\section{The Basic Structural Hazard Score}

ATC-21, recognizing the inherent variability in structural response to seismic motion, treats the DF as a random variable. To determine the BSH scores, the uncertainty in the DF at a given ground motion was estimated from the expert opinion damage estimates of ATC-13 (this is appropriate, since both the DF estimates in ATC-13 and the BSH are for "average" buildings\}. Appendix G of ATC-13 contains weighted statistics of the DF. The weights reflect the experience level and confidence of the individual experts, who provided low, best, and high estimates of the DF for the facility classes at 6 levels of MMI.

The BSH score was developed by taking ATC-13's mean low (ML) and mean high (MH) estimates of the DF as the 90-percent probability bounds of the DF distribution. The mean best (MB) estimate was interpreted as the median DF (the DF most likely to be observed for a given MMI and facility class). The uncertainty about the mean was examined and found to be acceptably modeled by either a Beta or a lognormal distribution. For convenience, ATC-21 selected the lognormal distribution, primarily because it offers the advantage of easier calculations using well-known ploynomial approximations. 
The lognormally distributed random variable DF has a related random variable, in(DF), which is normally distributed. The mean, $\alpha$, of the normally distributed random variable is related to the median of the lognormally distributed random variable by:

$$
\alpha=\ln (\mathrm{MB})
$$

The standard deviation, $B$, of the normally distributed random variable $\ln (\mathrm{DF})$ can be found by taking ML and MH as the 90-percent probability bounds of the DF distribution. Thus approximately 95-percent of the distribution lies below MH. From tables of the cumulative standard normal distribution, $F(z=1.64)=0.95$, where $z$ is the number of standard deviations from the mean (the wel 1-known "z-transform") and $F(z)$ is the cumulative probability distribution below $z$. The standard deviation may then be calculated from $\beta=[\ln (M H)-\alpha] / 1.64$. Similarly, $95 \%$ of the DF distribution lies above ML, and $F(z=-1.64)=.05$, therefore if $\ln (\mathrm{DF})$ was perfectly normal1y distributed, $\beta=[\alpha-\ln (M L)] / 1.64$. The average of these equations was used to approximate the standard deviation of the normal distribution, as follows:

$$
B=[\ln (M H)-\ln (M L)] / 3.28
$$

Once the parameters, $\alpha$ and $\beta$, of the normal distribution of $\ln (\mathrm{DF})$ are found, the probability of the DF being greater than 60 is calculated from a polynomial 
approximation. This is necessary because frequently the probabilities are very low, and beyond the range of published cumulative standard normal distribution tables. A polynomial approximation from NBS 55 (1964) was used in ATC-21, as follows, where $Q(z)=\operatorname{Pr}(D F>60)$ :

$$
Q(z)=z(z) *\left[b_{1} t+b_{2} t^{2}+b_{3} t^{3}+b_{4} t^{4}+b_{5} t^{5}\right] \text { (4.7) }
$$

where: $\quad z(z)=(2 \pi)-.5 * \exp \left(-z^{2} / 2\right)$

$z=[\ln (60)-\alpha] / \beta$

$t=1 /(1+p z)$

$p=.2316419$

$b_{1}=.319381530$

$b_{2}=-.356563782$

$b_{3}=1.781477937$

$b_{4}=-1.821255978$

$b_{5}=1.330274429$

To illustrate the calculation of $\mathrm{BSH}$, in the

following example the BSH score is calculated for

California TILT-UP buildings at $P G A=.22$ (MMI $=$ VIII).

The weighted statistics of the damage factor from ATC-13

for TILT-UP buildings are shown here in Table XXII.

TABLE XXII

WEIGHTED STATISTICS OF THE DAMAGE FACTOR

FOR TILT-UP BUILDINGS FROM

ATC-13, APPENDIX G

\begin{tabular}{lrrrr}
\hline MIMI & PGA & MI & MB & MH \\
\hline VI & .05 & 0.40 & 1.50 & 4.20 \\
VII & .10 & 1.80 & 4.20 & 9.60 \\
VIII & .22 & 4.00 & 10.60 & 18.20 \\
IX & .47 & 9.10 & 18.50 & 31.60 \\
$X$ & 1.02 & 15.20 & 28.70 & 49.20 \\
\hline
\end{tabular}


The lognormal distribution of the estimated DF at PGA $=.22$ for TILT-UP buildings is 11lustrated in Fig. 8., following.

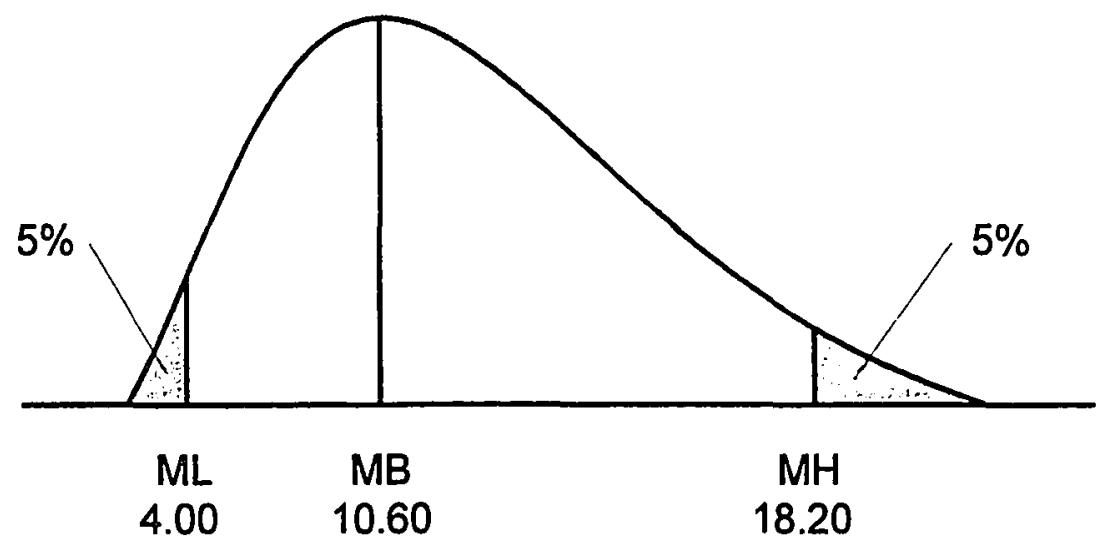

Figure 8. Lognormal distribution of estimated DF at $P G A=.22$ for average California TILT-UP bldgs.

Assuming the DF is lognormally distributed, the standard deviation $\beta_{1}$ and the mean $\alpha_{1}$ of the related normally distrubuted $\ln (\mathrm{DF})$, are:

$$
\begin{aligned}
& \beta=[\ln (18.20)-\ln (4.00)] / 3.28=0.461929 \\
& \alpha=\ln (10.60)=2.3608540
\end{aligned}
$$

The standard normal variate, $z$, is:

$$
z=[\ln (60)-2.3608540] / 0.461929=3.75272
$$

From the polynomial approximation, the probability of the $D F$ exceeding 60-percent, $Q(z)$, is:

$Q(z)=.00008749054$

The Basic Structural Hazard score is:

$\mathrm{BSH}=-\log _{10}(.00008749054)=4.05$ 
The normally distributed $\ln (\mathrm{DF})$ is illustrated in Fig. 9, following.

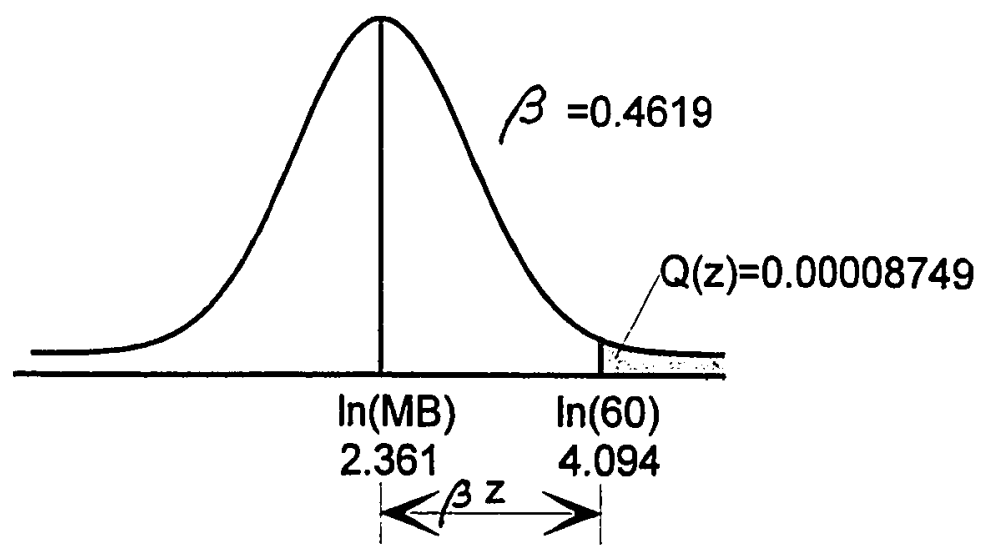

Figure 9. Normal distribution of in(DF) at $\overline{P G A}=.22$ for average California TILT-UP buildings.

\section{Extension to non-California Buildings}

As previously noted, ATC-21 addresses damage in regions where building design and construction practices differ from California. It is expected that in regions where seismic loading has historically had less influence in structural design, damage would be greater (and Structural score lower) for a given seismic intensity. ATC-21 solicited expert opinions from experienced engineers in NEHRP Map Areas 1 to 6 , asking them to compare the performance of specific building types in their regions to "California" buildings of the same type. As expected, for the same level of seismic intensity the 
experts predicted higher damage for buildings in their regions than for similar California bulldings.

From the results of the expert opinions, ATC-21 determined that the non-California DF differed from the California buildings DF by a constant multiple, and developed a table of Modification Constants (MC), which vary with NEHRP Map Area and Bullding Type. The values of $M C$ are summarized in Table XXIII, following, taken from Table B3 in ATC-21-1.

TABLE XXIII

DAMAGE FACTOR MODIFICATION CONSTANTS FOR NON-CAIIFORNIA BUILDINGS

FROM ATC-21-1 TABLE B3

\begin{tabular}{lccccc}
\hline \multicolumn{7}{c}{ NEHRP MaP Area } \\
& 1.2 & 3 & 4 & 5 & 6 \\
\cline { 2 - 6 } & & & & & \\
W & 1.0 & 1.3 & 1.3 & 1.2 & 1.0 \\
S2, S4 & 1.9 & 1.2 & 1.4 & 1.3 & 1.0 \\
S3 & 1.9 & 1.2 & 1.4 & 1.1 & 1.1 \\
C3/S5 & 1.1 & 1.1 & 1.3 & 1.3 & 1.2 \\
C1 & 1.2 & 1.2 & 1.3 & 1.3 & 1.2 \\
C2 & 2.2 & 1.3 & 1.5 & 1.2 & 1.0 \\
PC1 & 1.7 & 1.3 & 1.5 & 1.1 & 1.0 \\
PC2 & 2.0 & 1.2 & 1.5 & 1.3 & 1.4 \\
RM & 2.9 & 1.1 & 1.8 & 1.2 & 1.3 \\
URM & 2.9 & 1.1 & 1.3 & 1.1 & 1.0 \\
& 1.1 & 1.2 & 1.0 & 1.0 & 1.0 \\
\hline
\end{tabular}

In developing the BSH scores for non-California regions, the MC was used to change the value $M B$ from 
ATC-13 to a Best Estimate for each NEHRP Map Area (BENA) according to the following:

$$
\text { BENA }=\text { MC } * \text { MB }
$$

The procedure used bY ATC-21 to calculate the BSH score for non-California buildings is to hold the standard deviation $\beta$ constant, and calculate the mean of $\ln (\mathrm{DF})$ by using BENA in lieu of $\mathrm{KB}$ in Eq. 4.5, 1. e.,

$$
\alpha=\ln (\text { BENA) }
$$

A comparison of resulting scores for different NEHRP Map Areas showed little difference in BSH scores for certain levels of seismicity. Therefore, the BSH scores were simplified by grouping and averaging the calculated scores for three levels of "Selsmicity:" High, Moderate, and Low. The NEHRP Map Areas grouped together and the corresponding seismic intensities are shown in Table XXIV.

TABLE XXIV

ATC-21 SEISMICITY BY NEHRP MAP AREA

\begin{tabular}{lccc}
\hline Seismicity & Map Area & EPA & PGA \\
\hline LOW & 1 & .05 & .07 \\
LOW & 2 & .05 & .07 \\
HODERATE & 3 & .10 & .13 \\
MODERATE & 4 & .15 & .20 \\
HIGH & & .20 & .27 \\
HIGH & 5 & .30 & .40 \\
HIGH & 6 & .40 & .53 \\
\hline
\end{tabular}


By grouping and averaging the BSH scores into the three seismicities, ATC-21 produced 3 sets of BSH scores. For the example of TILT-UP (PC1), after rounding, the BSH scores used in ATC-21 were:

$\begin{array}{ll}\text { LOW } & 3.5 \\ \text { MODERATE } & 3.5 \\ \text { HIGH } & 2.0\end{array}$

To illustrate the effect of the MC on BSH score, in the following example the BSH score will be re-calculated for a TILT-UP building in a MODERATE Selsmicity zone. From Table XXIV, the NEHRP Map Areas corresponaing to MODERATE are Areas 3 and 4. From Table XXIII, the MC values for PC1 for Map Areas 3 and 4 are 1.2 and 1.5, respectively; the average MC is 1.35. BENA is calculated from Eq. 4.8:

$$
\text { BENA }=1.35 *(10.60)=14.30
$$

The rest of the calculations are adjusted as follows:

$$
\alpha=\ln (14.30)=2.6602595
$$

The standard normal variate, $z$, is:

$$
z=[\ln (60)-2.6602595] / 0.4619291=3.1045566
$$

From the polynomial approximation, the probability of the DF exceeding 60-percent, $Q(z)$, is:

$$
Q(z)=.000952892
$$

The Basic Structural Hazard score is:

$$
\mathrm{BSH}=-\log _{10}(.000952892)=3.02
$$

As expected, the increase in damage from the MC results in a reduced BSH score (now 3.02, reduced from 4.05 using $M B$ ). 
In computing the BSH score for a different PGA, the ATC-21 procedure described above re-starts with new ML, MB, and MH values corresponding to that level of ground motion. Additionally, values of the MC consistent with the NEHRP Map Areas corresponding to the PGA being considered are used. In the preceding example of TILT-UP, the BSH score for MODERATE seismicity used a MC $=1.35$. In computing the BSH score for TILT-UP for a LOW seismicity Map Area, a MC = 2. O would be used; for HIGH seismicity, the average for Map Areas 5, 6 again results in $\mathrm{MC}=1,35$. The MC is used differently in developing fragility curves, described in the next section.

\section{Performance Modification Factors}

The BSH score was not created to stand alone, but was designed to be modifed for specific buildings. A number of characteristics of design, construction, and site conditions can modify the seismic performance of a specific building, causing the damage to differ from "average."

Performance Modiflcation Factors (PMFs) were developed by the ATC-21 experts to be added to the BSH score, so the resulting structural score (S) would approximately reflect the probability of major damage, given the presence of that factor. Reversing Eq. 4. 3, it can be shown that for the structural score $s$, the 
probability of the DF exceeding 60-percent is:

$$
[\operatorname{Pr}(D F>=60 \%)]=10^{-S}
$$

Continuing with our illustration using TILT-UP, suppose that at $P G A=.22$, a building in a MODERATE Seismicity zone (for which we calculated a probability of major damage of .000952892, and a BSH score of 3.02) had the performance modifier of "Torsion." The PMF for torsion is -1.0 ; Eq. 4.9 gives us the structural score:

$$
S=3.02-1.0=2.02
$$

Applying Eq. 4.8 provides the revised probability of major damage:

$$
[\operatorname{Pr}(D F)=60 \%)]=10-(2.02)=.0095499
$$

This 10-fold increase in the liklihood of major damage is very significant. Torsion is one of the most common performance modifiers, hence this example illustrates that many buildings will differ significantly in their seismic performance from the "average" reflected by the BSH score.

\section{DEVELOPMENT OF A TECHNIQUE TO DERIVE DAMAGE FACTOR FROM STRUCUTRAL SCORE}

Given that individual characteristics of design and construction for specific buildings may cause significant differences in seismic damage compared to "average" buildings, it is clear that regional damage estimates would be improved if they reflected the characteristics of 
specific buildings. However, although ATC-21 presents a methodology for inventorying and scoring buildings based on specific characteristics, it does not provide a method to modify the DF itself. Clearly, if the probability of major damage $(D F=60)$ increases, the value of the median damage should also increase.

Development of modified damage estimates reflecting the presence of Performance Modifiers is one of the primary objectives of the present research.

The Mean Damage Factor (MDF) is the DF with a 50-percent probability of exceedance, the DF most likely to be observed. The In(MDF) is, in general, the mean $\alpha$ of the normally distributed In(DF). The MDF = BEIL only for "average" buildings, wherein $\Sigma(P M F)=0$ and $S=B S H$. when $S$ differs from BSH (aue to the presence of PMFs), then the MDF differs from BENA, and $\alpha$ differs from in(BENA). The MDF is related to $S$ by the standard deviation of the normally distributed $\ln (\mathrm{DF}), B$, which is determined from the MI and MH estimates of the DF, by Eq. 4.6.

For any value of structural score $s$, the probability that the DF exceeds 60-percent, $Q(z)$, can be determined from:

$$
Q(z)=10^{-S}
$$

The polynomial Eq. 4.7 was "solved" in reverse (the standard normal variate $z$ was determined for specified 
values of $Q(z)$ ) with a BASIC computer program which solved the equation in small increments of $z$, and tabulated $z$ vs. $Q(z)$. Part of this solution is presented in Table XXV, following.

TABLE XXV

THE STAYDARD NORMAL VARIATE VS. STRUCTURAL SCORE

\begin{tabular}{lll}
\hline$s$ & $Q(z)$ & $z$ \\
\hline 0.30 & .50 & 0 \\
1 & .10 & 1.281 \\
2 & .01 & 2.326 \\
3 & .001 & 3.090 \\
4 & .0001 & 3.719 \\
5 & .00001 & 4.265 \\
6 & .000001 & 4.753 \\
7 & .0000001 & 5.199 \\
8 & .00000001 & 5.612 \\
\hline
\end{tabular}

With the standard normal variate $z$ determined from Table XXV, and the standard deviation $B$ of the normal distribution of $\ln (\mathrm{DF})$, the Mean Damage Factor (MDF) corresponoing to any structural score (S) can be determined with Eqs. 4.10 and 4.10a, as shown in Fig. 10.

$$
\begin{aligned}
& \ln (M D F)=\alpha=\ln (60)-z * \beta \\
& M D F=\exp (\alpha)=\exp (\ln (60)-z * B) \quad \text { (4.10) }
\end{aligned}
$$

Note that in Eqs. 4.10 that $\alpha$ is, in general, not the $\ln (B E N A)$. 


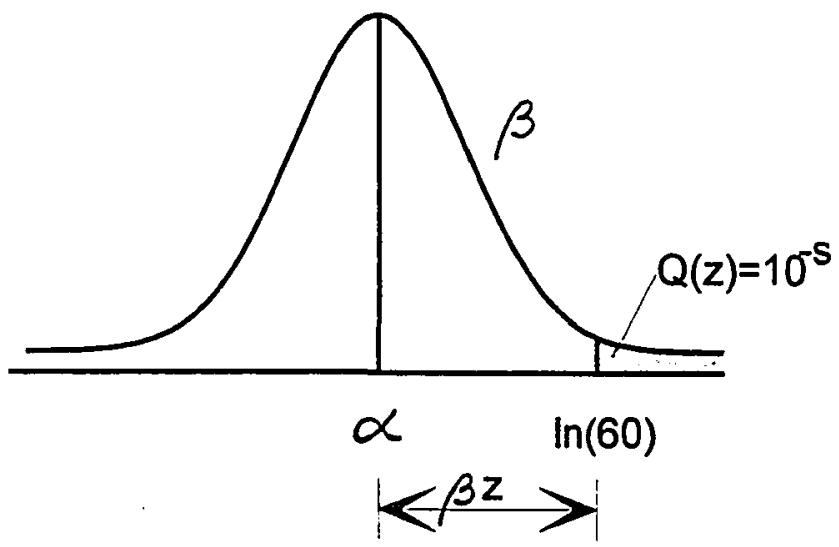

Figure 10. Determining the Mean Damage Factor (MDF) from the structural score (S) and the normally distributed $\ln (\mathrm{DF})$.

Next, a continuous relationship between MDF and $S$ was determined by regressing MDF as determined from Eqs.

4. 10, corresponding to values of of $S=0.3,1,2,3$, and 4. After experimenting with several forms of regression, a good fit was found by using a Power Function, of the form:

$$
\mathrm{MDF}=\mathrm{b}_{0} * \mathrm{~S}_{1}^{\mathrm{b}}
$$

where $b_{0}$ and $b_{1}$ are the regression coefficients.

Returning to the example of the TILT-UP building to illustrate this methodology, Table XXV is utilized to calculate discrete values of $S$ vs, HDF, with $B=.461929$ as previously determined. The results of this step are shown in Table XXVI, following: 
TABLE XXVI

STRUCTURAL SCORE VS. MEAN DAMAGE FACTOR FOR

TILT-UP BUILDINGS (PC1) AT PGA $=0.22$

\begin{tabular}{lllll}
\hline$S$ & $Q(z)$ & $z$ & $\alpha$ & MDF \\
\hline 0.30 & .50 & 0 & 4.09434 & 60.00 \\
1 & .10 & 1.281 & 3.50261 & 33.20 \\
2 & .01 & 2.326 & 3.01990 & 20.49 \\
3 & .001 & 3.090 & 2.66698 & 14.40 \\
4 & .0001 & 3.719 & 2.37643 & 10.77 \\
\hline
\end{tabular}

As expected, as the Score (S) increases, the mean DF decreases; this is consistent with the design of $S$ as a "seismic performance" score.

Next, the five values of MDF were regressed against $S$ from Table XXVI. The resulting Power Function coefficients, which produce a coefficient of correlation of 0.986 , are:

$$
\begin{aligned}
& b_{0}=29.66478 \\
& b_{1}=-.652952
\end{aligned}
$$

This procedure was followed for a total of five levels of ground acceleration: PGA $=.05, .10, .22, .47$, and 1.02 (corresponding to MHI from VI to $x$ ). This resulted in 5 regressed curves of MDF on $S$, as shown in Fig. 11 to 15 , following.

This procedure was repeated for each of the other twelve ATC-21 Structure Types, resulting in a total of 60 curves. 


\section{PC1 - TILT UP \\ $\mathrm{PGA}=0.05 \quad \mathrm{BSH}=5.98$}

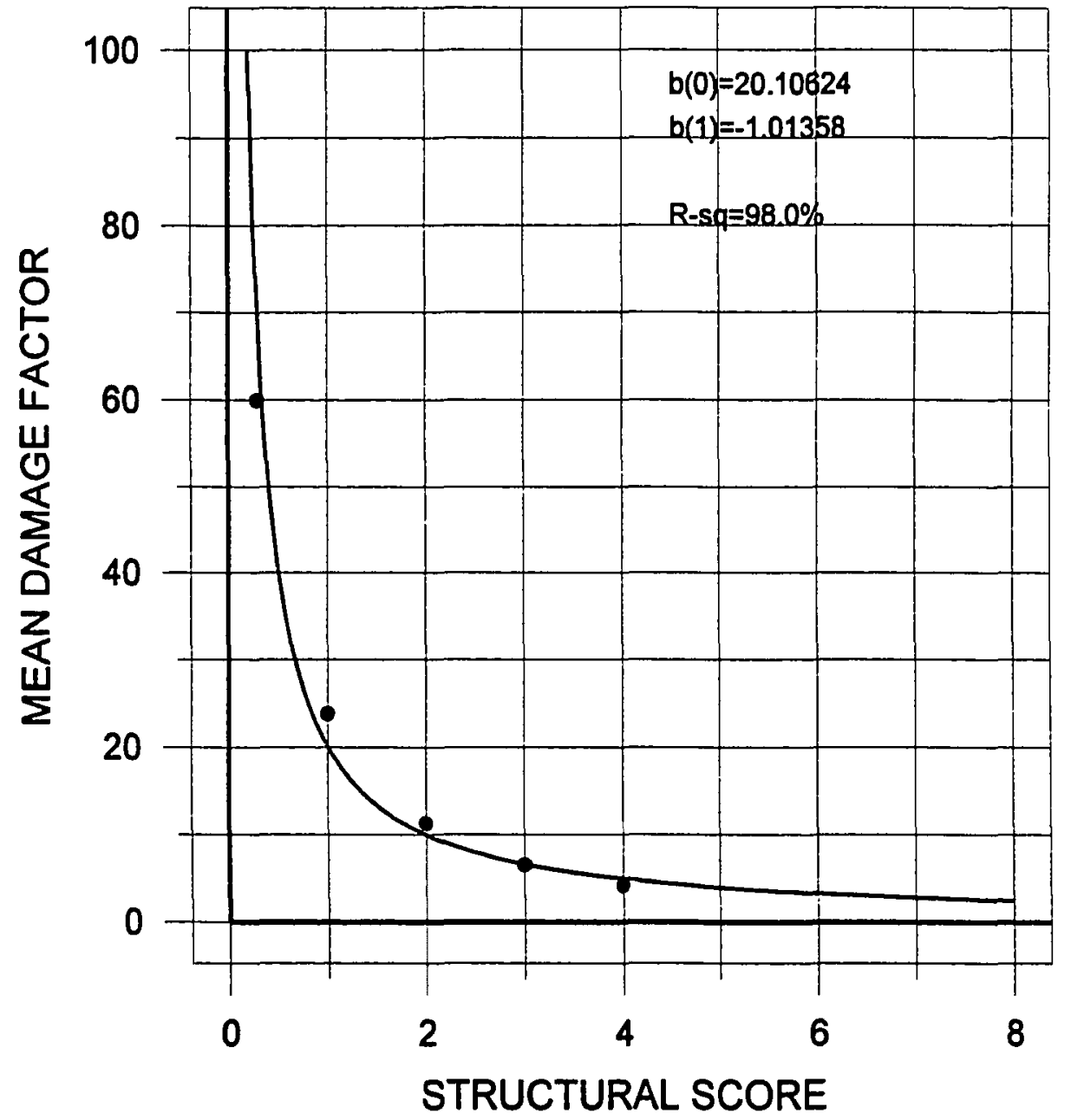

Figure 11. Mean Damage Factor vs. Structural Score for TILT UP (PC1) buildings, for PGA $=.05$. 


\section{PC1 - TILT UP \\ $P G A=0.10 \quad B S H=5.7$}

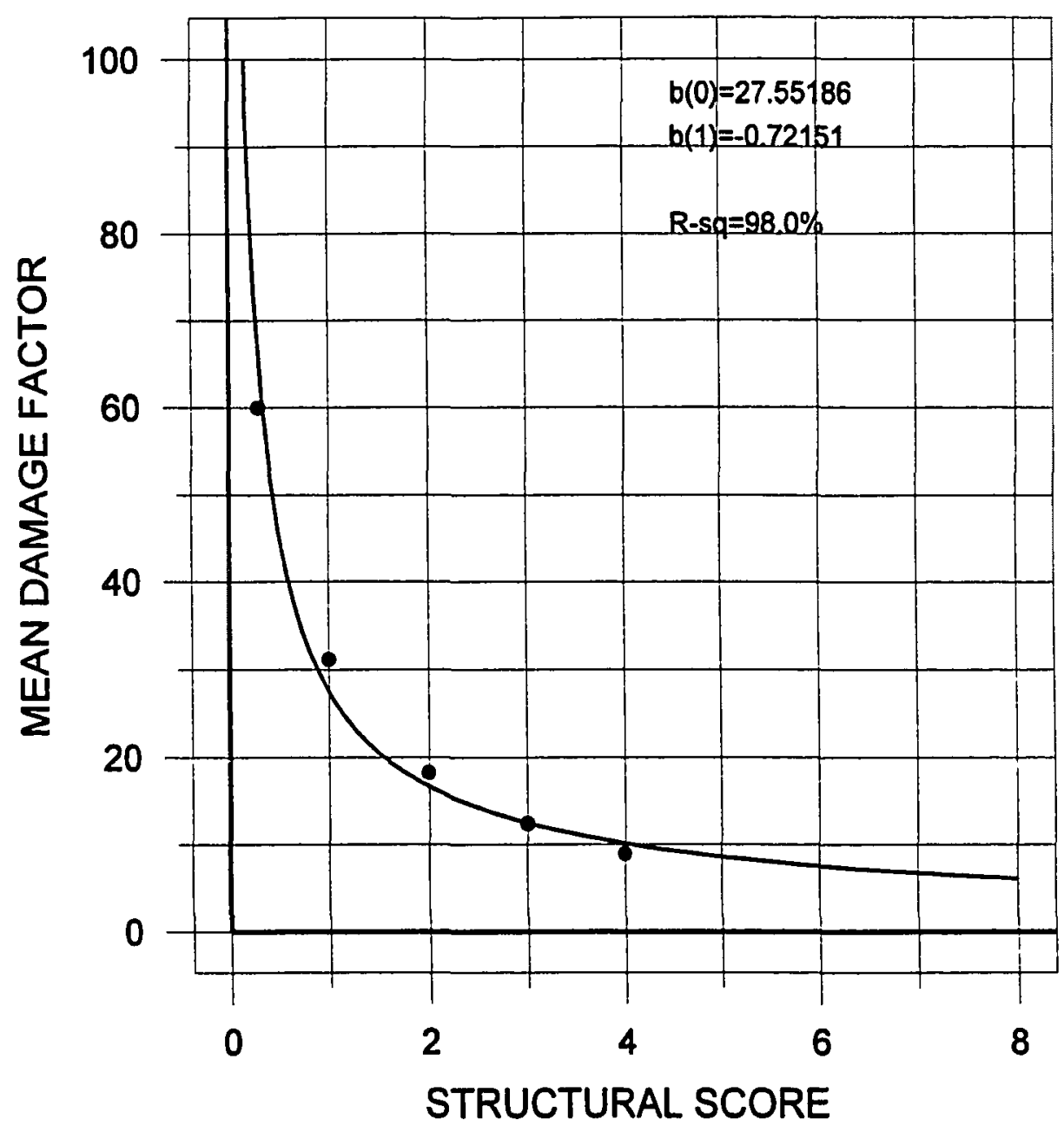

Figure 12. Mean Damage Factor vs. Structural Score for TILT UP (PC1) buildings, for PGA $=.10$. 


\section{PC1 - TILT UP \\ $P G A=0.22 \quad B S H=3.02$}

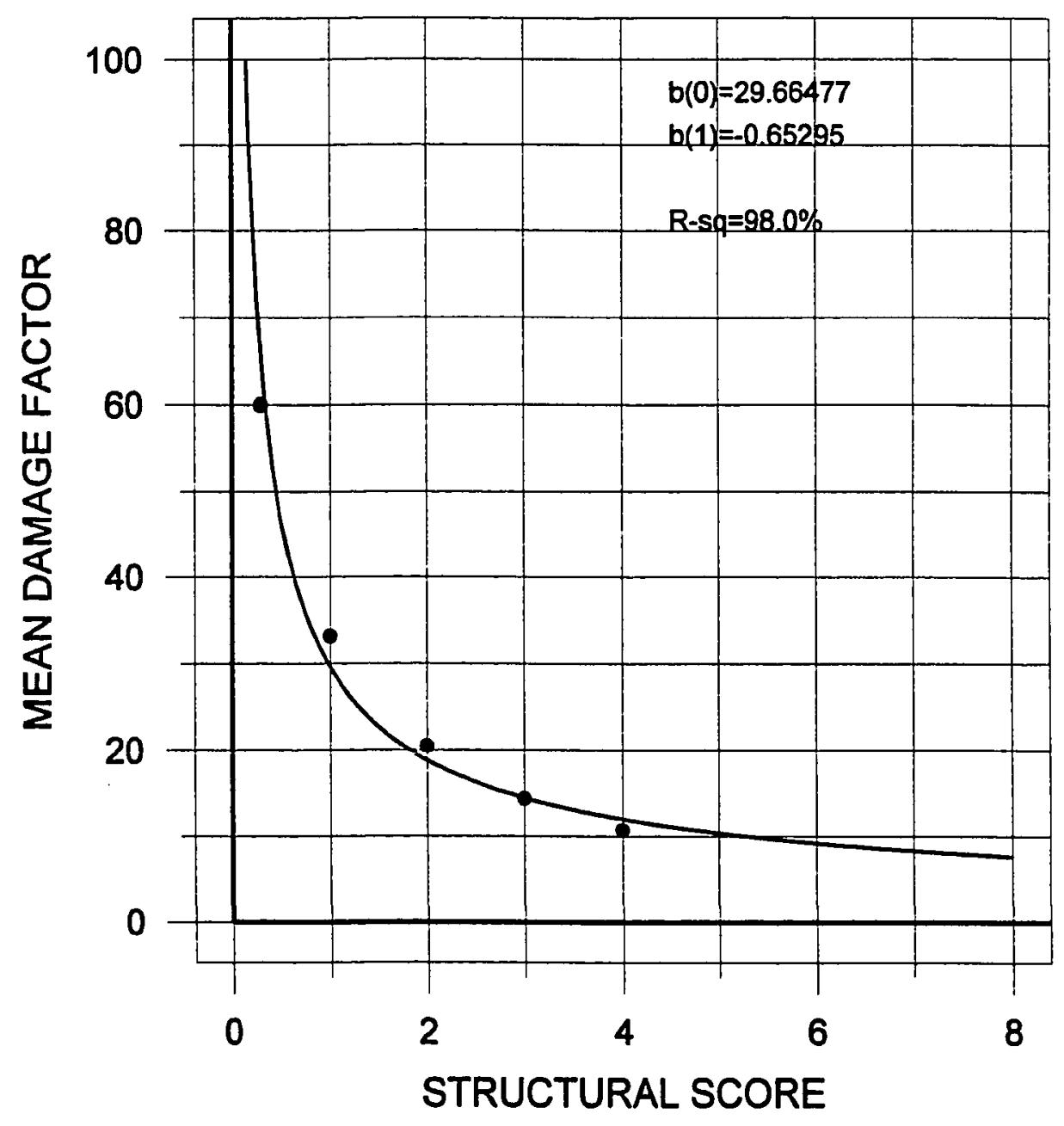

Figure 13. Mean Damage Factor vs. Structural Score for TILT UP (PC1) buildings, for PGA $=.22$. 


\section{PC1 - TILT UP \\ $P G A=0.47 \quad B S H=1.97$}

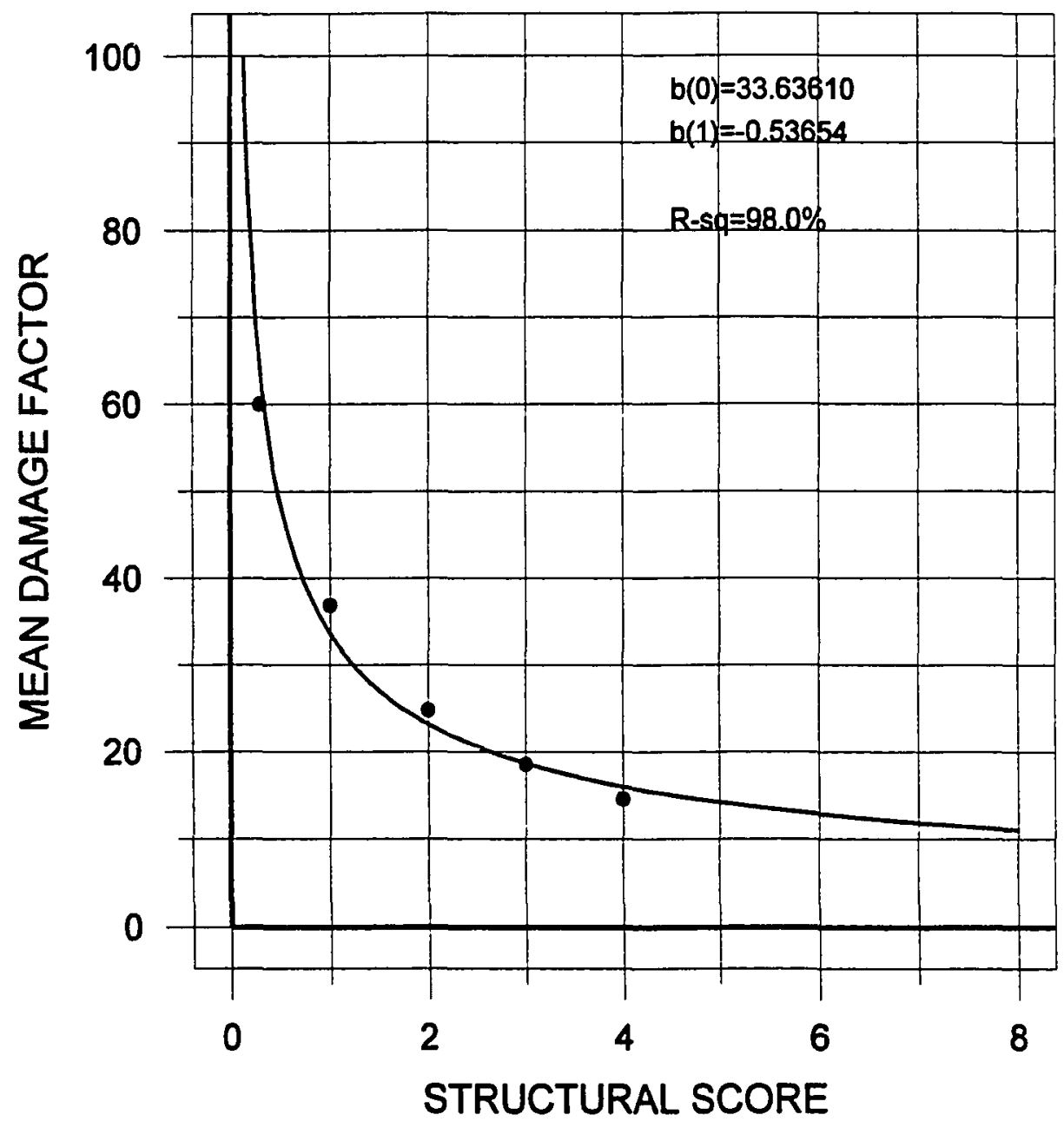

Figure 14. Mean Damage Factor vs. Structural Score for TILT UP (PC1) buildings, for PGA $=.47$. 


\section{PC1 - TILT UP \\ $\mathrm{PGA}=1.02 \quad \mathrm{BSH}=0.95$}

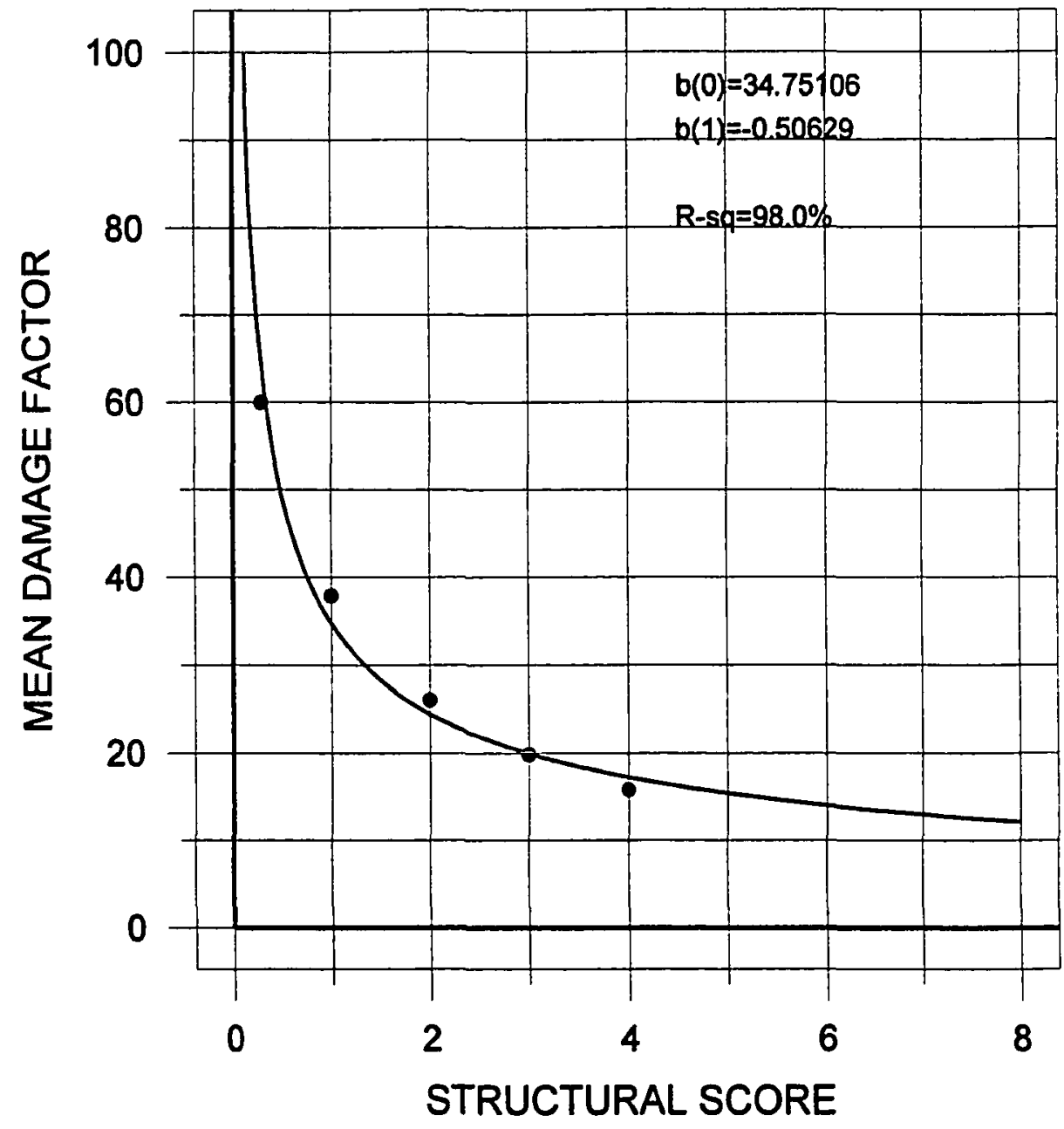

Figure 15. Hean Damage Factor vs. Structural Score for TILT UP (PC1) buildings, for PGA $=1.02$. 
DEVELOPHENT OF FRAGILITY CURVES BASED ON PERFORMANCE MODIFIERS

\section{Modified Basic Structural Hazard Score}

The Basic Structural Hazard (BSH) score is shown at the top of each of the MDF vs. S curves in Figs. 11 to 15. The BSH for each structure Type and each PGA was determined as described previously, with $\beta$ derived from $\mathrm{ML}$ and $\mathrm{MH}, \propto$ derived from BENA, where BENA $=\mathrm{MB} * \mathrm{MC}$.

The BSH score has been modified from ATC-21 in two ways. First, ATC-21 converts PGA to EPA, then regresses $B$ against EPA, and uses this "smoothed" version of $\beta$ to calculate the BSH at even increments of EPA. In the present research the BSH is computed for discrete values of PGA only, without smoothing.

Second, the present study uses the Modification Constant (MC) in a different way than in ATC-21. In ATC-21, the MC's "step up" along with the EPA values; each NEHRP Map Area is assigned both an EPA and MC value, and these are kept consistent so the resulting BSH will reflect the expected seismicity and the construction standard of the Map Area. However, the objective of the present research is to develop fragility curves which express damage across the entire range of possible PGAs, for a single Hap Area. Therefore, as the PGA takes five steps up, from. 05 to 1.02 , a single MC value is used, to 
reflect the design and construction standards of one area. All the BSH values developed herein use the average values of MC for NEHRP Map Areas 3 and 4, for use in Portland.

Mean Damage Factor vs. $\Sigma$ (PMF)

The BSH score, modified as described above, represents an "average" building for its Structure Type. That is, when there are no characteristics of design, construction, nor site conditions that would alter the seismic performance of the building from "average, "there are no Performance Modifiers; $\Sigma(P M F)=0$, and $S=B S H$. The value of MDF corresponding to this average building can be found from the MDF vs, $S$ curves, using $S=B S H$. For the TILT-UP (PGA $=.22)$ illustration, the coordinates on the MDF vs, $S$ curve (Fig. 13) for $\Sigma(P M F)=0$ are $(3.02,14.42)$.

When Performance Modifiers are present, the value of $\Sigma(P M F)$ moves these coordinates along the curve. For example, if Torsion is present as the only Performance Modifier, then $\Sigma(P M F)=-1$, and:

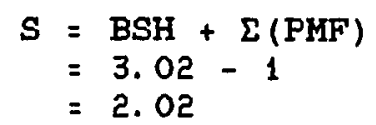

From the power formula regression equation, the MDF for $S=2.02$ is found to be 18.74 , and the coordinates corresponding to $\Sigma(P M F)=-1$ are $(2.02,18.74)$. This is illustrated on Fig. 16, following. 


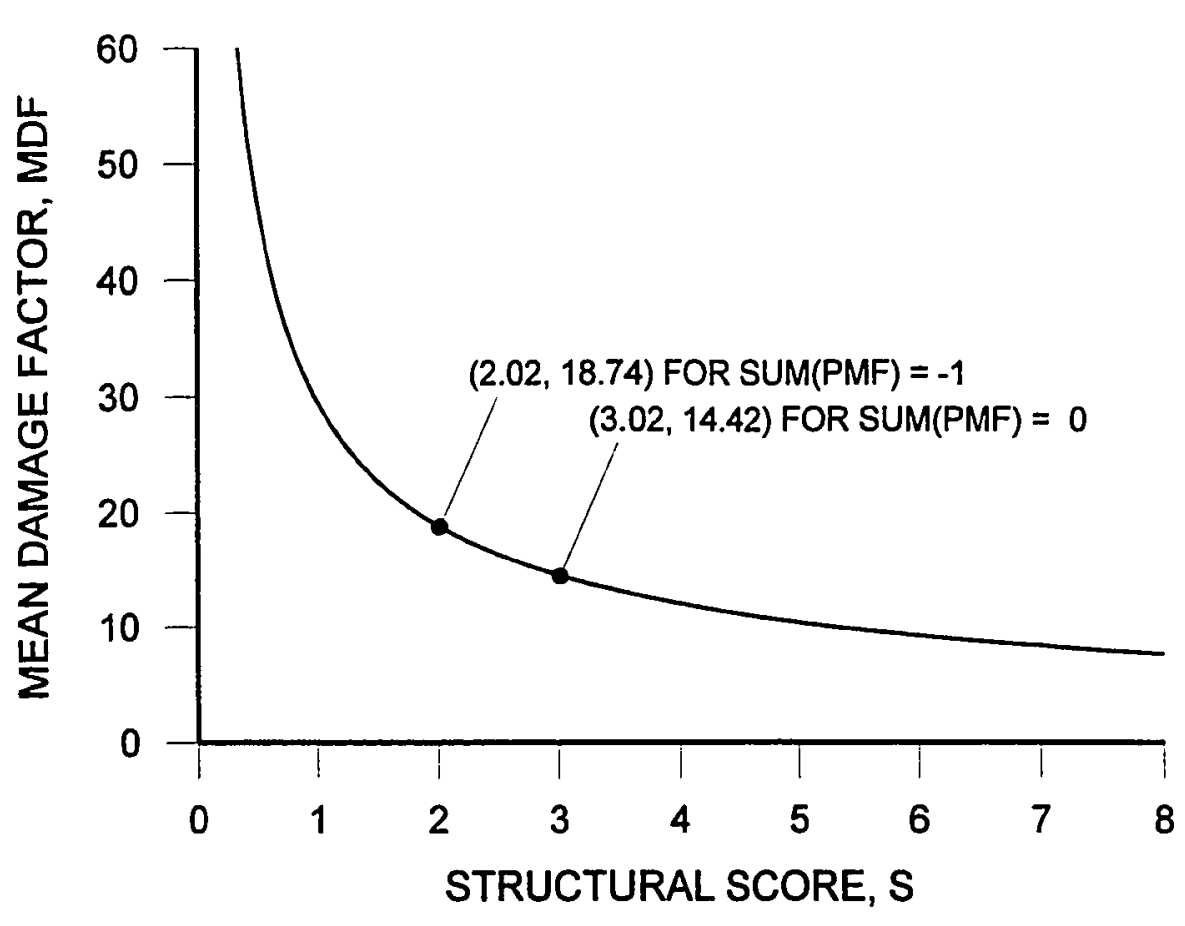

Figure 16. Mean Damage Factor vs. Structural score for TILT-UP at $P G A=.22$, showing coordinates for $\Sigma(P H F)=0$ and $\Sigma(P H F)=-1$.

From the foregoing, it is clear that the BSH score becomes the "starting point" on the MDF vs. S curve. The value of $\Sigma(P M F)$ "moves" the building along the curve, increasing damage for negative and decreasing damage for positive values of $\Sigma(P M F)$.

Therefore, the MDF may be calculated for any value of $\Sigma$ (PMF). For the TILT-UP example, this has been done for $\Sigma(P M F)=-2$ to +2 , and is tabulated in Table XXVII, fol lowing. 
TABLE XXVII

$\Sigma$ (PMF) VS. MEAN DAMAGE FACTOR FOR TILT-UP AT PGA $=.22$ WITH $\mathrm{MC}=1.35$

\begin{tabular}{ccc}
\hline$\Sigma($ PMF $)$ & $S$ & MDF \\
\hline+2 & 5.02 & 10.34 \\
+1 & 4.02 & 11.96 \\
0 & 3.02 & 14.42 \\
-1 & 2.02 & 18.74 \\
-2 & 1.02 & 29.28 \\
-3 & $<0$ & $>60$ \\
\hline
\end{tabular}

Fragility Curves based on $\Sigma$ (PMF)

To create a family of fragility curves for each building type, the preceding steps were taken for five intensities $(\mathrm{PGA}=.05, .10, .22, .47$, and 1.02), creating five Tables of $\Sigma$ (PMF) vs. MDF, similar to Table XXVII. For TILT-UP, these are shown in Tables XXVIII to XXXI.

TABLE XXVIII

$\Sigma$ (PMF) VS. MEAN DAMAGE FACTOR FOR TILT-UP AT $P G A=.05 \mathrm{WITH}$ MC $=1.35$

\begin{tabular}{rll}
\hline$\Sigma($ PMF $)$ & $S$ & MDF \\
\hline+2 & 7.98 & 2.45 \\
+1 & 6.98 & 2.81 \\
0 & 5.98 & 3.28 \\
-1 & 4.98 & 3.95 \\
-2 & 3.98 & 4.96 \\
-3 & 2.98 & 6.65 \\
\hline
\end{tabular}


TABLE XXIX

$\Sigma$ (PMF) VS. MEAN DAMAGE FACTOR FOR TILT-UP

AT PGA $=.10 \mathrm{WITH}$ HC $=1.35$

\begin{tabular}{rrr}
\hline$\Sigma(P M F)$ & $S$ & MDF \\
\hline+2 & 7.70 & 6.32 \\
+1 & 6.70 & 6.98 \\
0 & 5.70 & 7.85 \\
-1 & 4.70 & 9.02 \\
-2 & 3.70 & 10.72 \\
-3 & 2.70 & 13.46 \\
\hline
\end{tabular}

TABLE XXX

$\Sigma$ (PMF) VS. MEAN DAYAGE FACTOR FOR TILT-UP

AT PGA $=.47$ WITH MC $=1.35$

\begin{tabular}{ccc}
\hline$\Sigma$ (PMF) & $S$ & MDF \\
\hline+2 & 3.97 & 16.05 \\
+1 & 2.97 & 18.76 \\
0 & 1.97 & 23.38 \\
-1 & 0.97 & 34.19 \\
-2 & $<0$ & $>60$ \\
-3 & $<0$ & $>60$ \\
\hline
\end{tabular}


TABLE $X X X I$

$\Sigma$ (PMF) VS. MEAN DAMAGE FACTOR FOR TILT-UP AT PGA $=1.02$ WITH MC $=1.35$

\begin{tabular}{rlr}
\hline$\Sigma($ PMF $)$ & $S$ & MDF \\
\hline+2 & 2.95 & 20.10 \\
+1 & 1.95 & 24.78 \\
0 & 0.95 & 35.67 \\
-1 & $<0$ & $>60$ \\
-2 & $<0$ & $>60$ \\
-3 & $<0$ & $>60$ \\
\hline
\end{tabular}

The next step in the methodology was to "dismantle" these five tables of $\Sigma$ (PMF) vs. KDF (one for each PGA intensity) and "reassemble" them into six tables of MDF vs. PGA (one for each integer value of $\Sigma$ (PKF): $-3,-2,-1,0$, $+1,+2)$. For example, the values of MDF vs PGA for $\Sigma(P M F)$ $=0$ for TILT UP are shown in Table XXXII, following (five more tables, for other $\Sigma$ (PMF) values, were also developed).

TABLE XXXII

PGA VS. MEAN DAMAGE FACTOR FOR TILT-UP AT $\Sigma(P M F)=0 W I T H ~ M C=1.35$

\begin{tabular}{rr}
\hline PGA & MDF \\
\hline .05 & 3.28 \\
.10 & 7.85 \\
.22 & 14.42 \\
.47 & 23.38 \\
1.02 & 35.67 \\
\hline
\end{tabular}


Each of the six tables of PGA vs. MDF constitutes a "damage function" for an integer value of $\Sigma$ (PMF). To create a fragility curve, a regression of MDF against PGA was made for each damage function. The best fits were attained with a third-degree polynomial, as follows:

$$
M D F=b_{0}+b_{1}(P G A)+b_{2}(P G A)^{2}+b_{3}(P G A)^{3}
$$

where $b_{0}, b_{1}, b_{2}$, and $b_{3}$ are the regression coefficients. The resulting fragility curve for $\Sigma(P M F)=0$ for TILT-UP, along with the polynomial coefficients, is shown in Fig. 17. following.

Similar curves were established for $\Sigma(P M F)=+2,+1$, $-1,-2$, and -3 , resulting in a family of fragility curves based on $\Sigma$ (PMF) for the TILT UP (PC1) Structure Type, as shown in Fig. 18.

This methodology was repeated for the other eleven building types of ATC-21. The resulting fragility curve families are presented in Figs. 19 to 29.

To provide more resolution of MDF, another set of "half-step" fragility curves was developed, for $\Sigma($ PMF) = $+1.5,+.5,-.5,-1,5$, and -2.5 . These families of fragility curves are presented in the Appendix.

In developing these curves from the ATC-13 expert opinion damage estimates, where several ATC-13 facility 
PC1 - TILT UP PMF $=0$

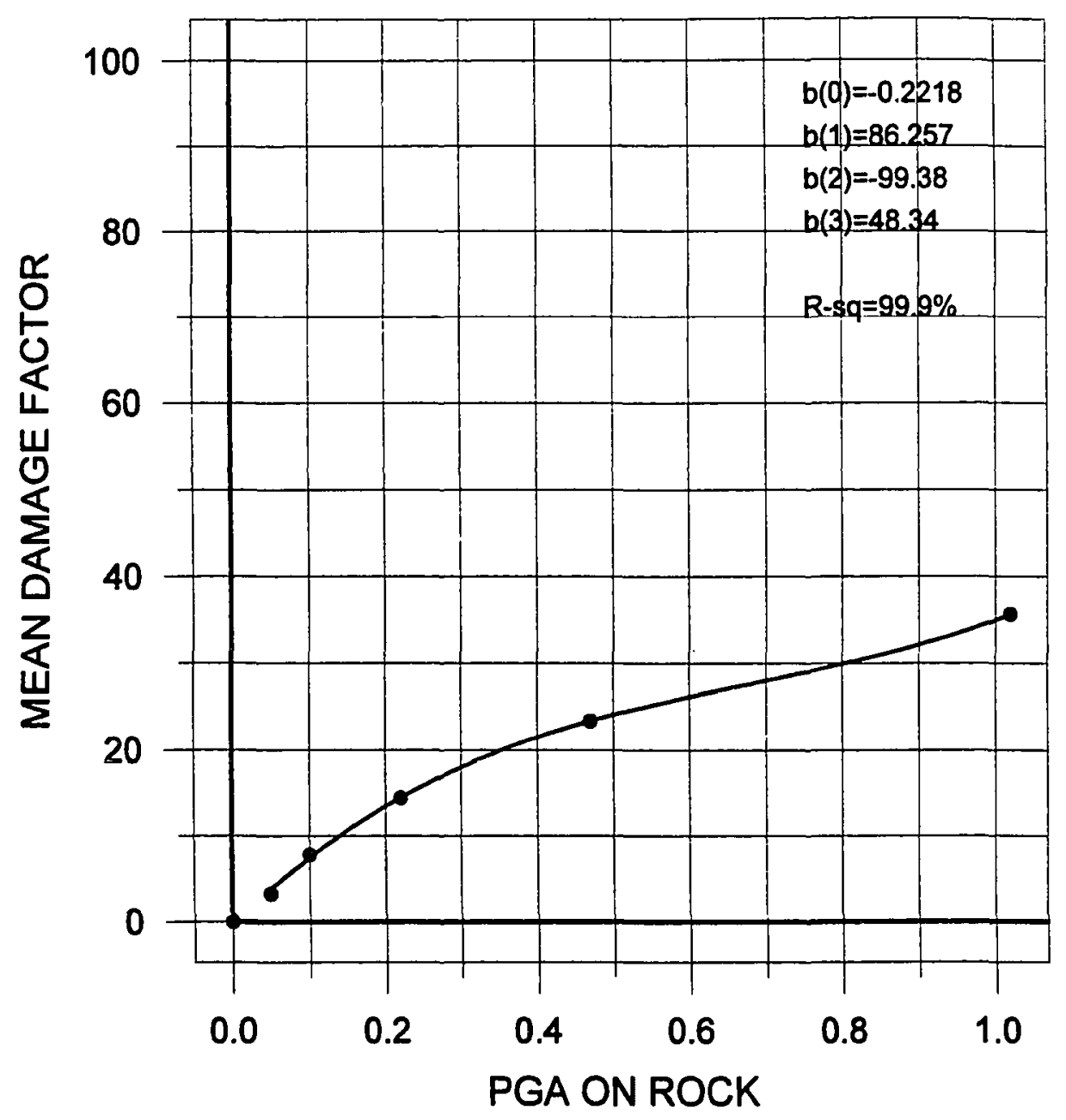

Figure 17. PC1 - TILT UP fragility curve for $\Sigma(P H F)=0$. 
classes correspond to one ATC-21 building type, the values of ML, MB, and MH were averaged at the beginning of the methodology. Where an ATC-13 facility class designated HR (high-rise) was given, this was not included in the damage averages, because ATC-21 includes a PMF for high-rise.

\section{Application of Fragility Curves to NEHRP Areas 3,4}

The fragility curve families presented in Figures 18 to 29 reflect a "non-California" standard of design and construction found in NEHRP Map Areas 3 and 4 (by use of the Modification Constant, as discussed on pp. 110-111). In applying these curves, it is important to note that this reference to NEHRP Areas refers to the quality of seismic resistance of the buildings, and not to the level of seismicity.

Therefore, a different set of fragility curve families would be required for NEHRP Map Areas 1, 2, 5, 6, or 7 , to reflect the Modification Constant (MC) appropriate for those areas. 
PC1 - TILT UP

NEHRP AREAS 3,4

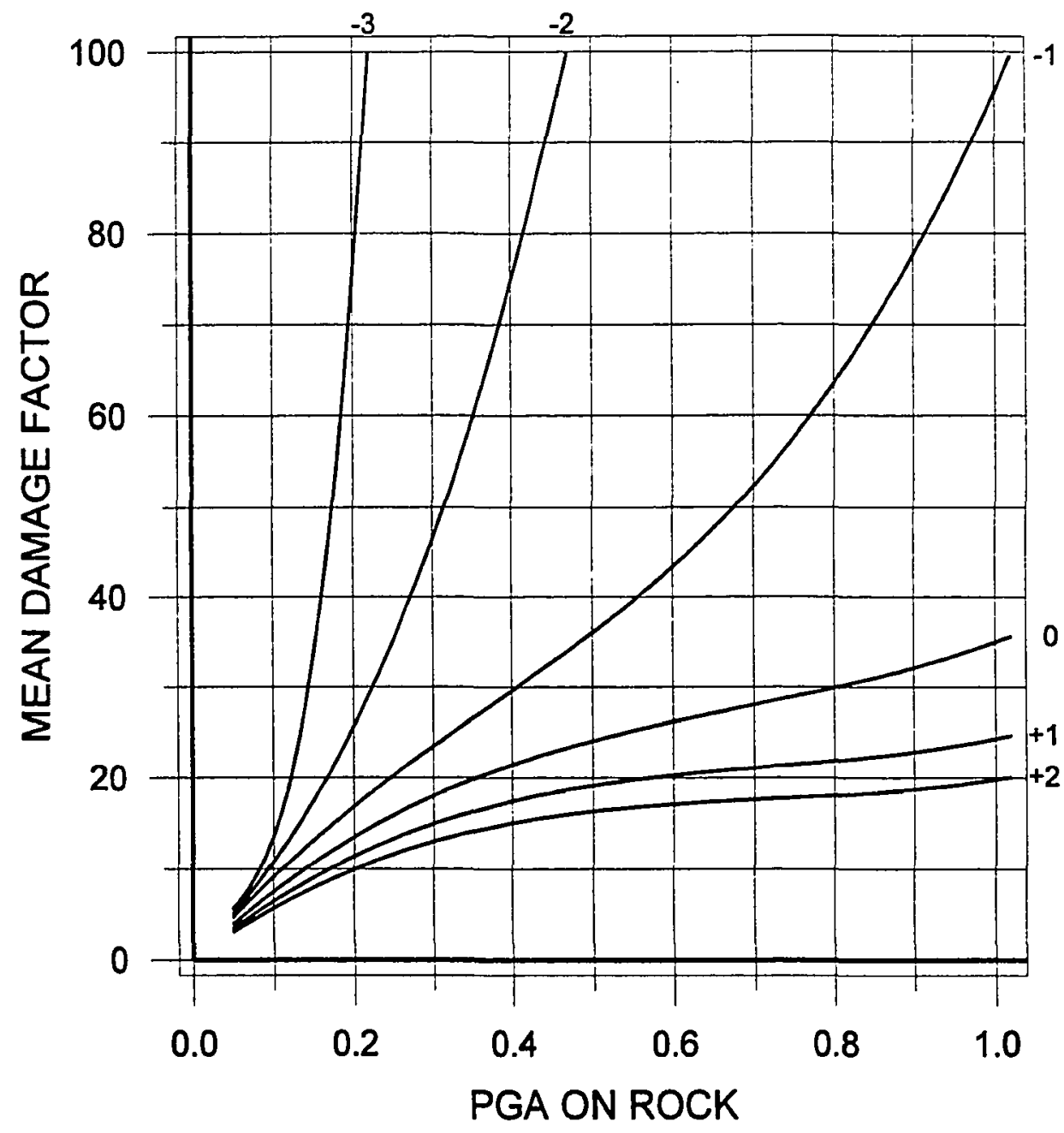

Figure 18. PC1 - TILT UP fragility curve for integer $\Sigma$ (PMF) steps. 


\section{WOOD - WOOD FRAME}

NEHRP AREAS 3,4

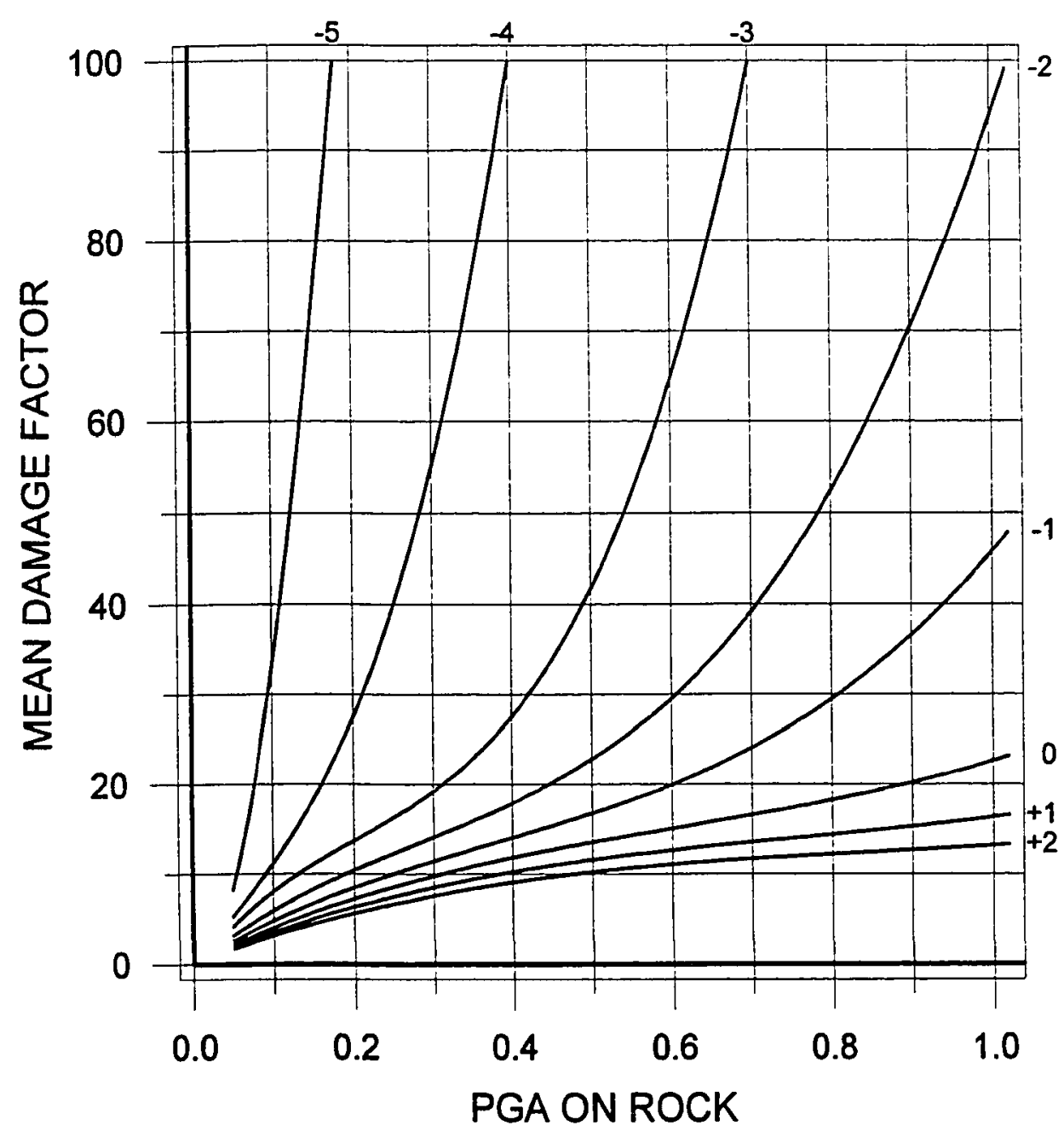

Figure 19. W - WOOD fragility curves for integer $\overline{\Sigma(P M F)}$ steps. 


\section{S1 - STEEL MRF}

\section{NEHRP AREAS 3,4}

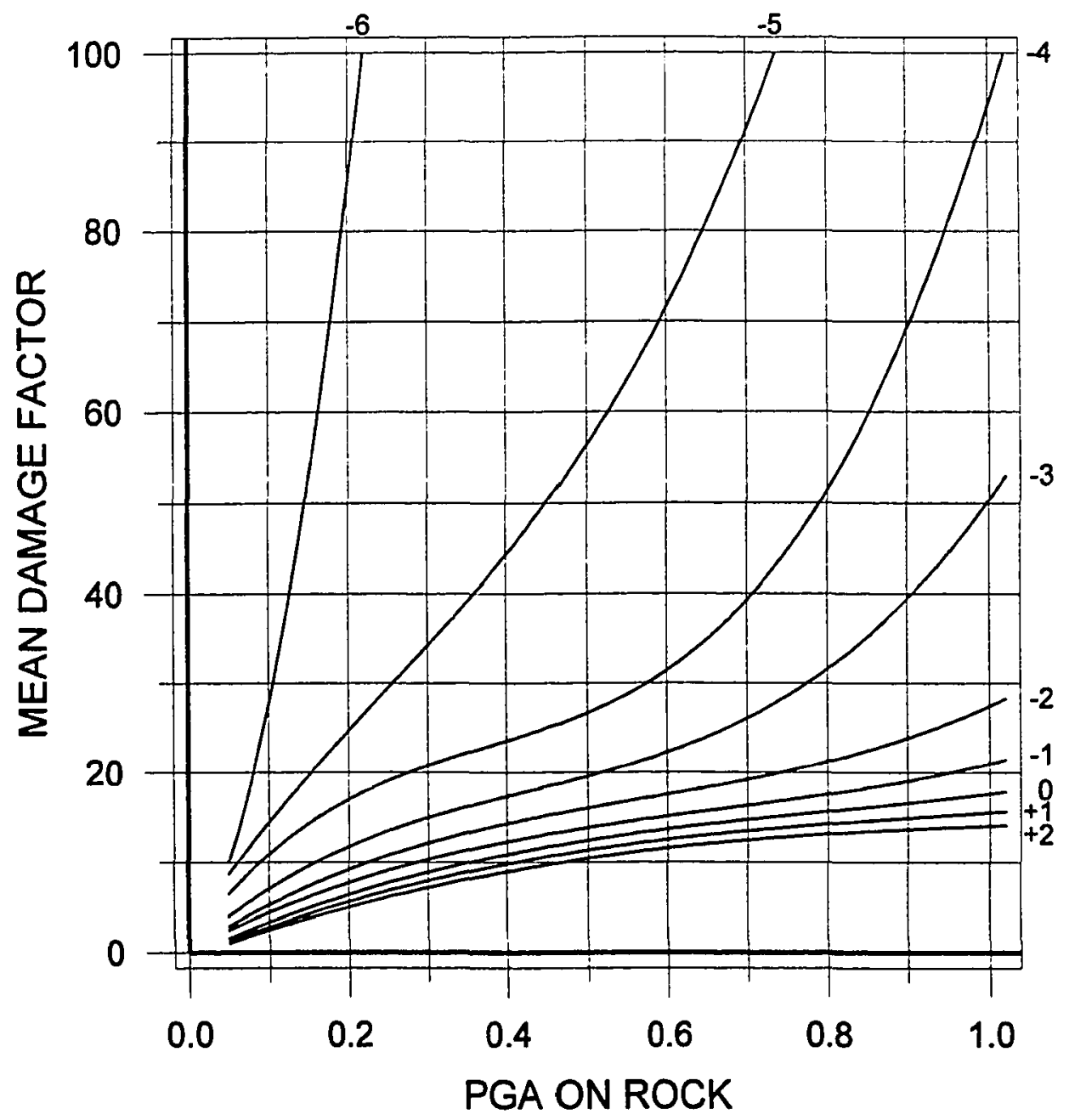

Figure 20. S1 - STEEL MRF fragility curves for integer $\Sigma$ (PMF) steps. 


\section{S2 - BRACED STEEL FRAME NEHRP AREAS 3,4}

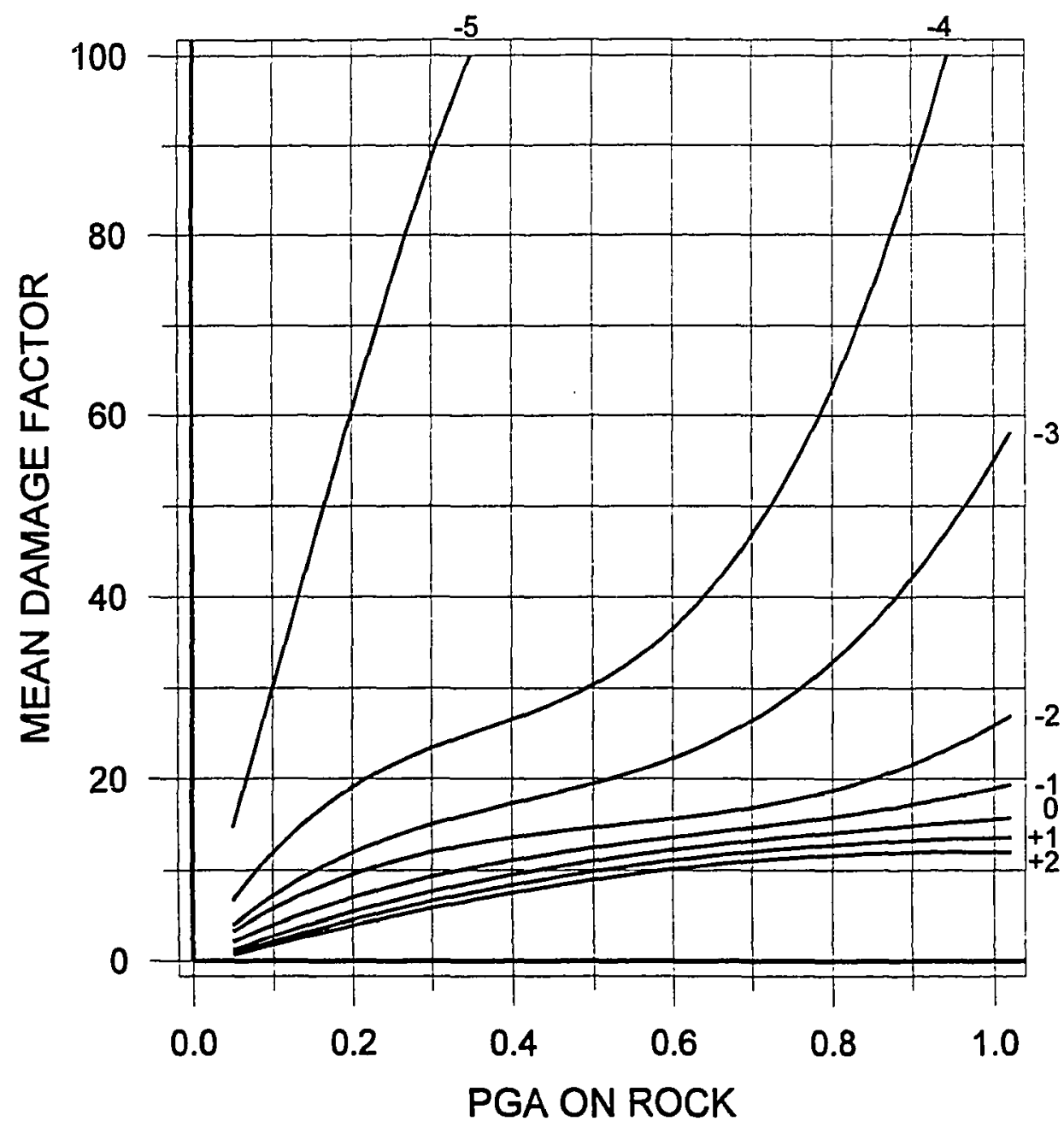

Figure 21. S2 - BR STL FRAME fragility curves for integer $\Sigma$ (PMF) steps. 


\section{S3 - LIGHT METAL}

\section{NEHRP AREAS 3,4}

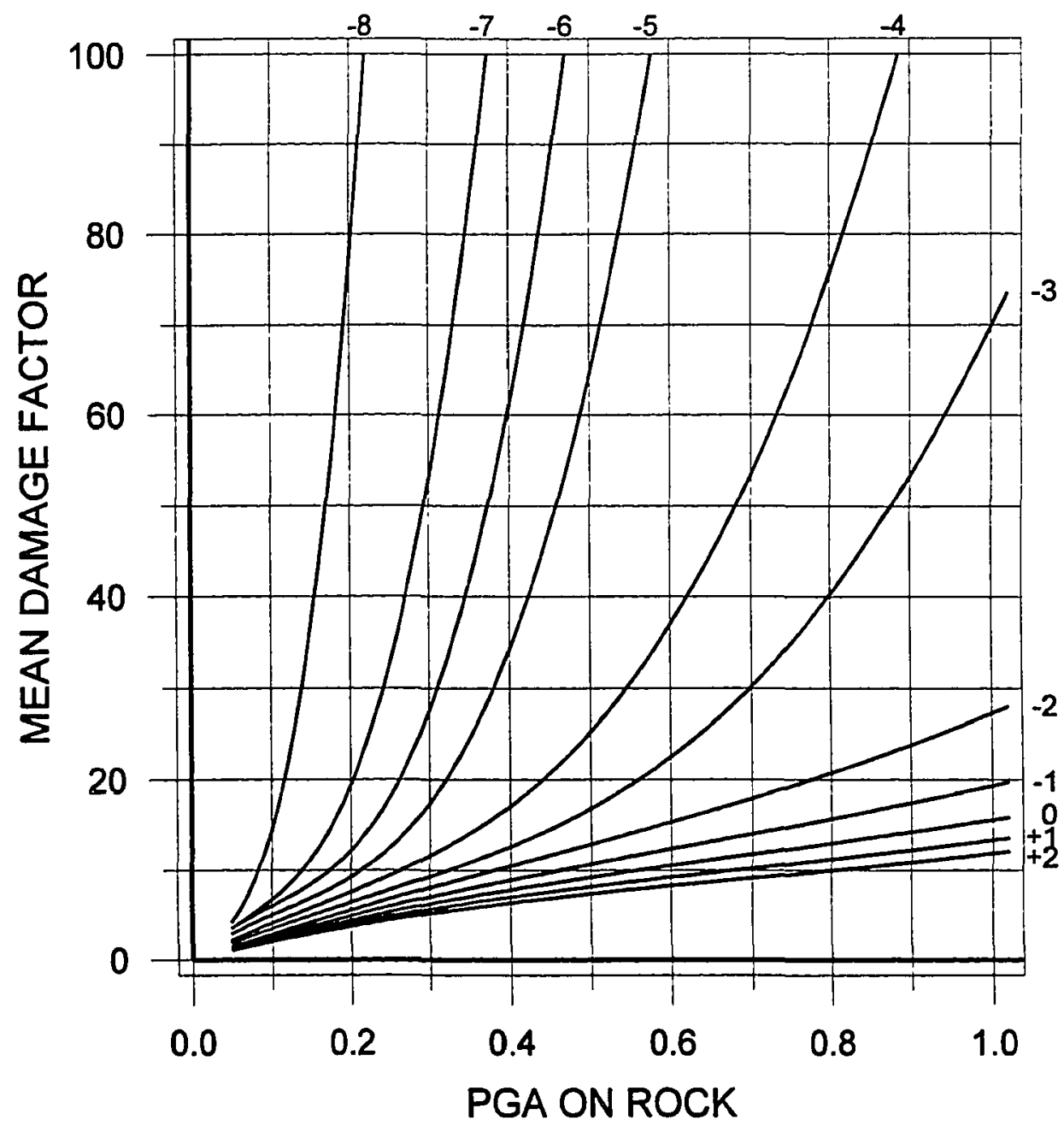

Figure 22. S3 - LIGHT METAL fragility curves for integer $\Sigma$ (PMF) steps. 


\section{S4 - STEEL FRAME W/ CONC SHEARWALLS NEHRP AREAS 3,4}

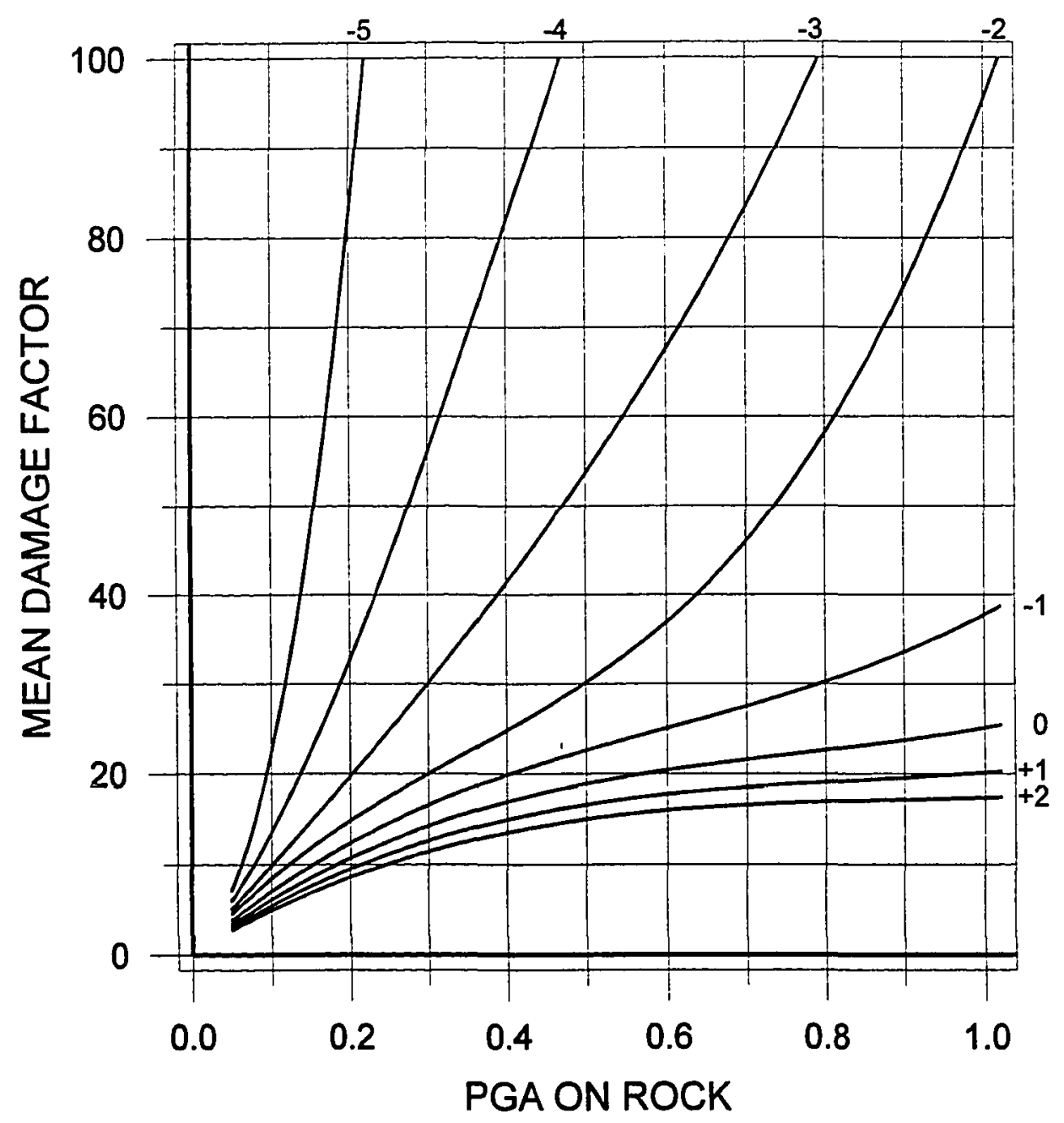

Figure 23. S4 - STL FRAME w/ CONC SHEARWALLS fragility curves for integer $\Sigma$ (PMF) steps. 


\section{C1 - REINF CONC MRF NEHRP AREAS 3,4}

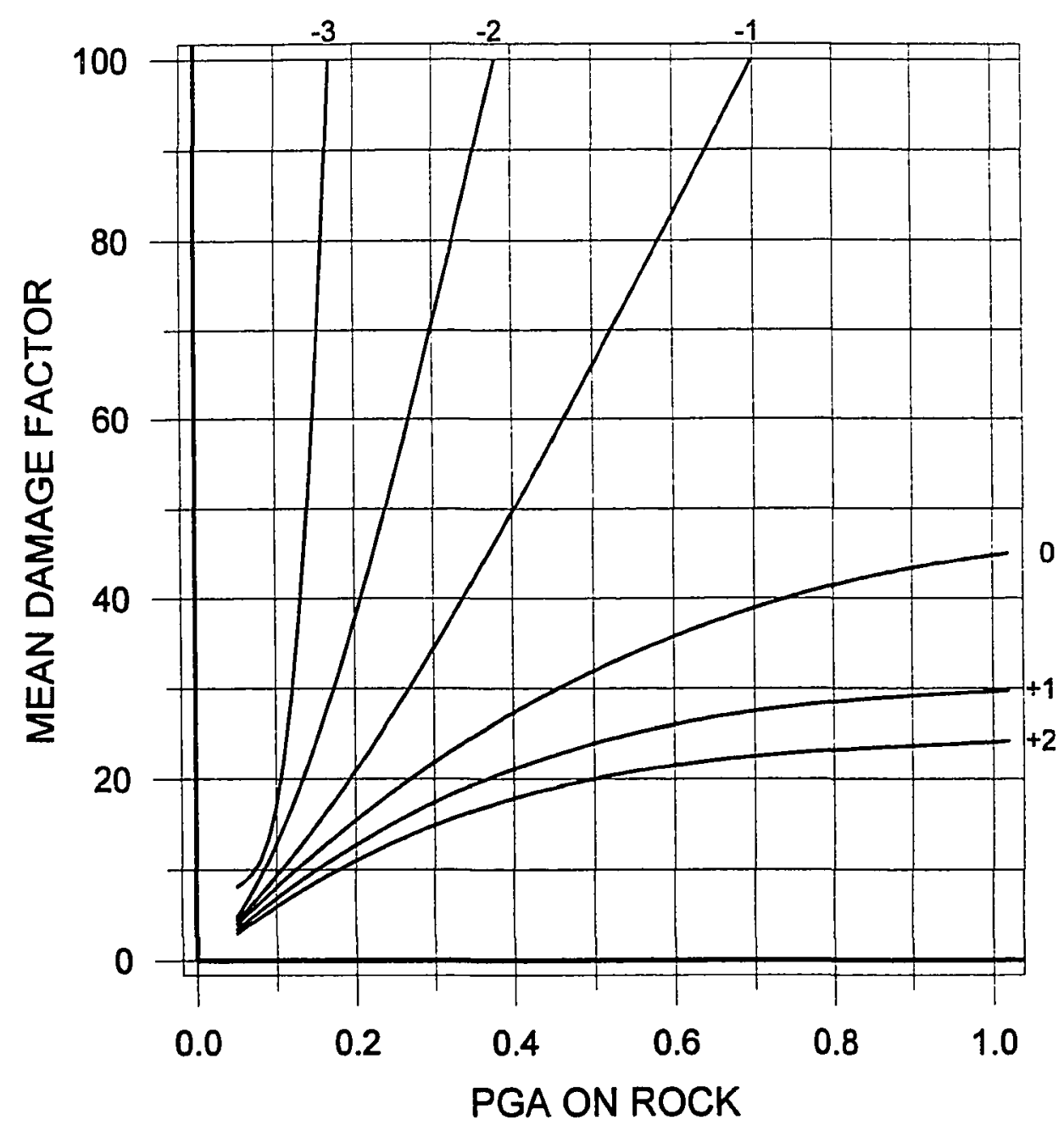

Figure 24. C1 - REINF CONC MRF fragility curves for integer $\Sigma$ (PMF) steps. 


\section{C2 - REINF CONC SHEARWALL NEHRP AREAS 3,4}

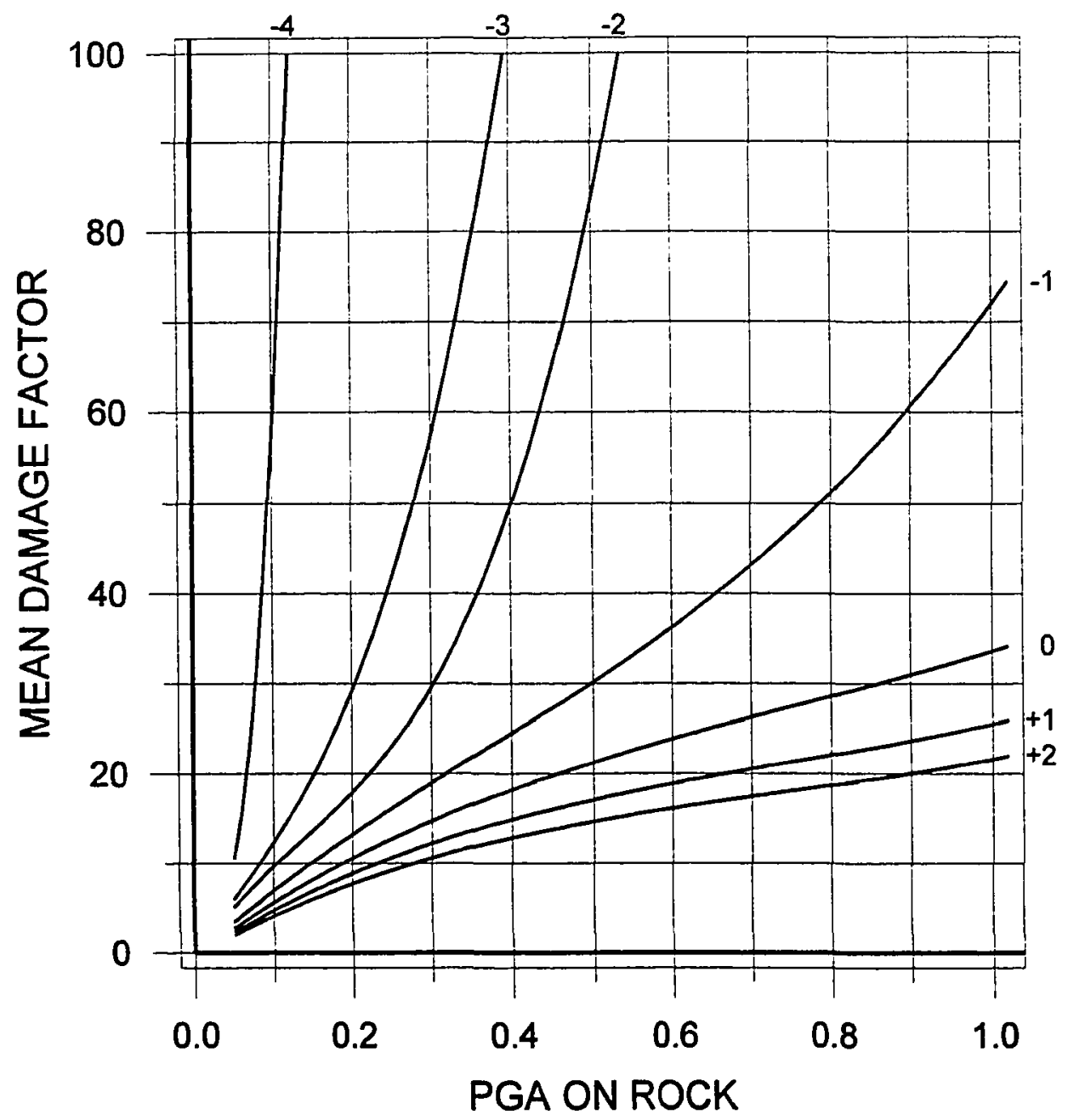

Figure 25. C2 - REINF CONC SHEARWALL fragility curves for integer $\Sigma$ (PHF) steps. 


\section{C3/S5 - URM INFILL \\ NEHRP AREAS 3,4}

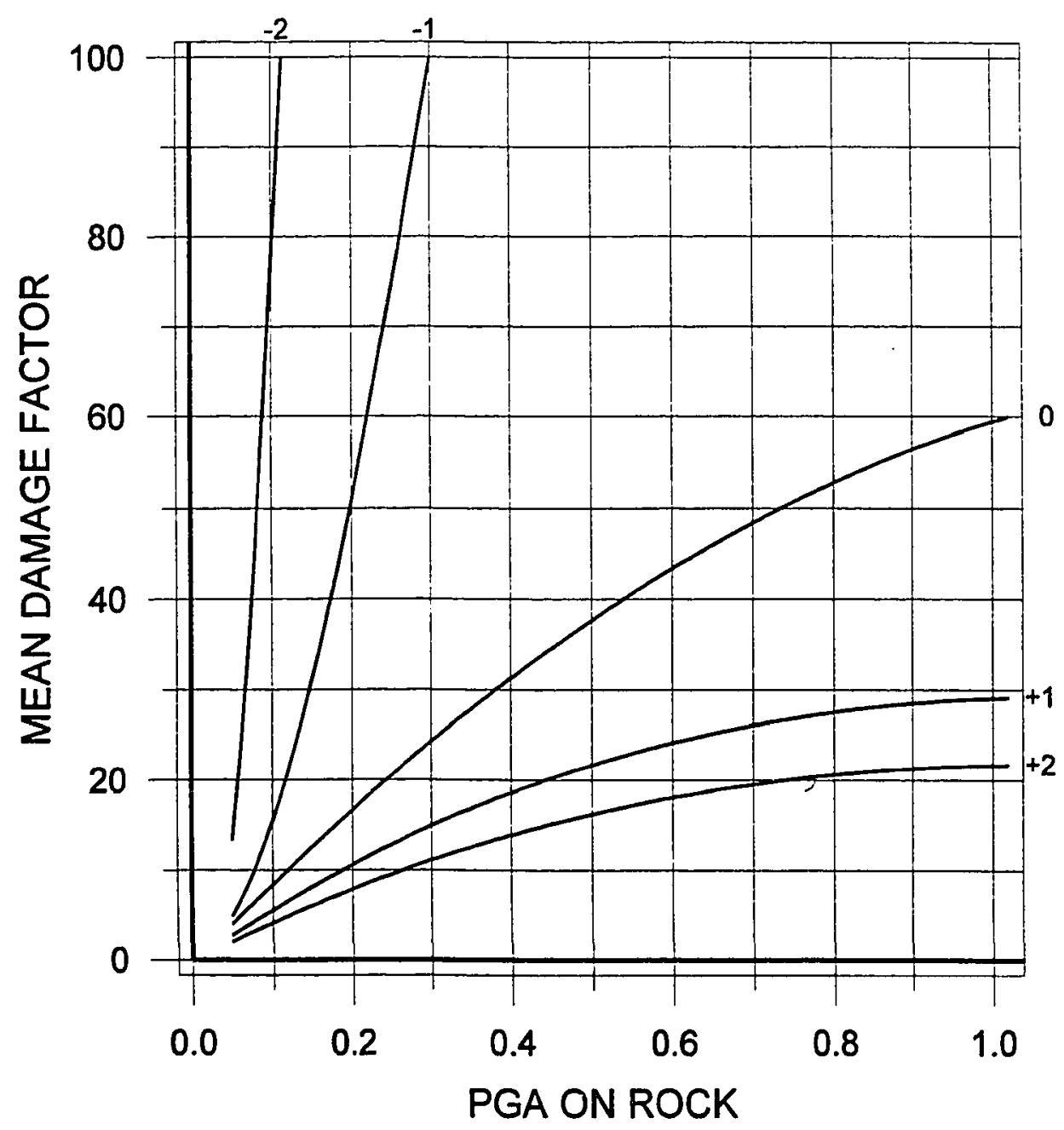

Figure 26. C3/S5 - URH INFILL fragility curves for integer $\Sigma$ (PMF) steps. 


\section{PC2 - PRECAST CONCRETE FRAME NEHRP AREAS 3,4}

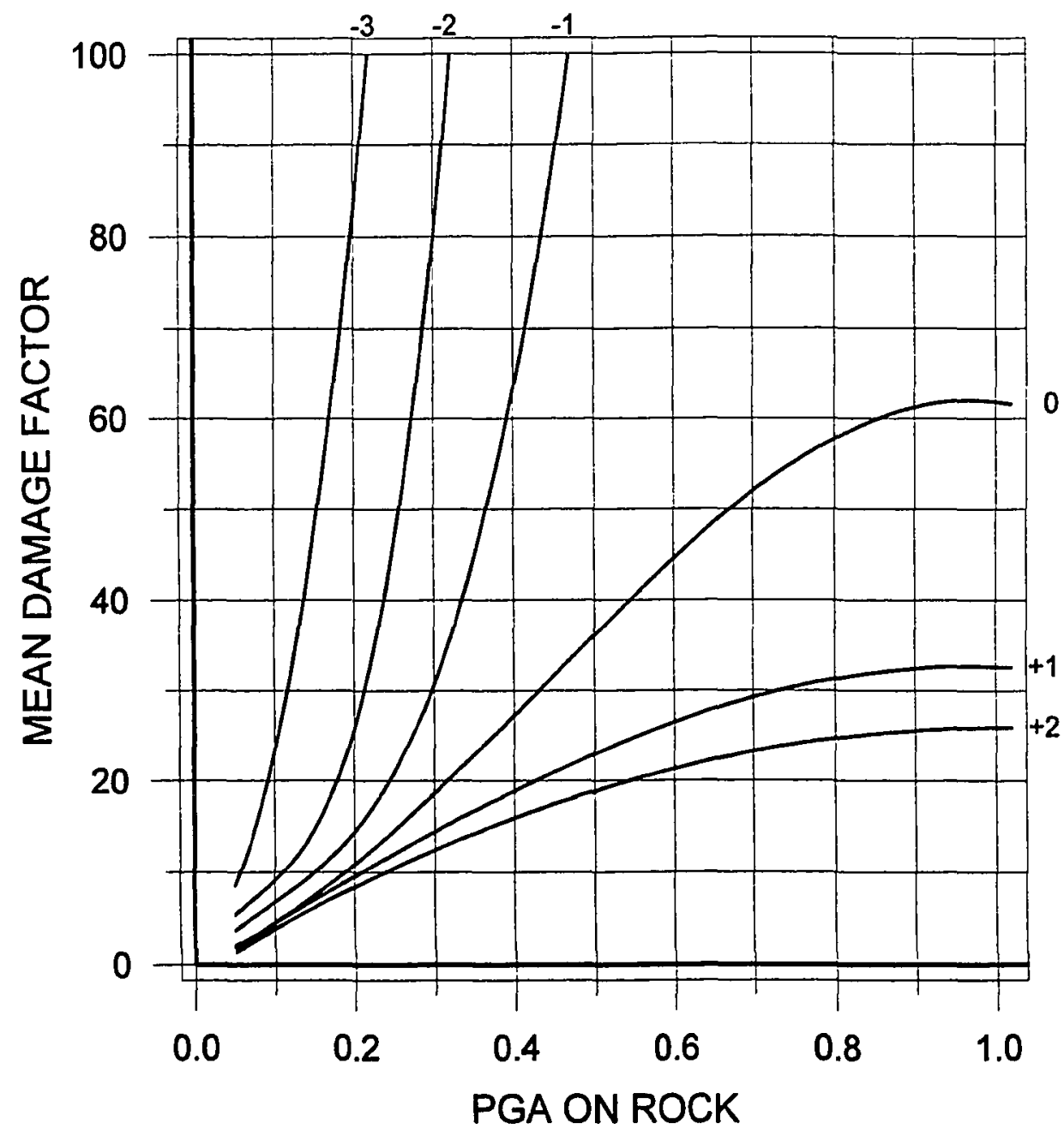

Figure 27. PC2 - PRECAST CONC FRAME fragility curves for integer $\Sigma$ (PMF) steps. 


\section{RM - REINFORCED MASONRY NEHRP AREAS 3,4}

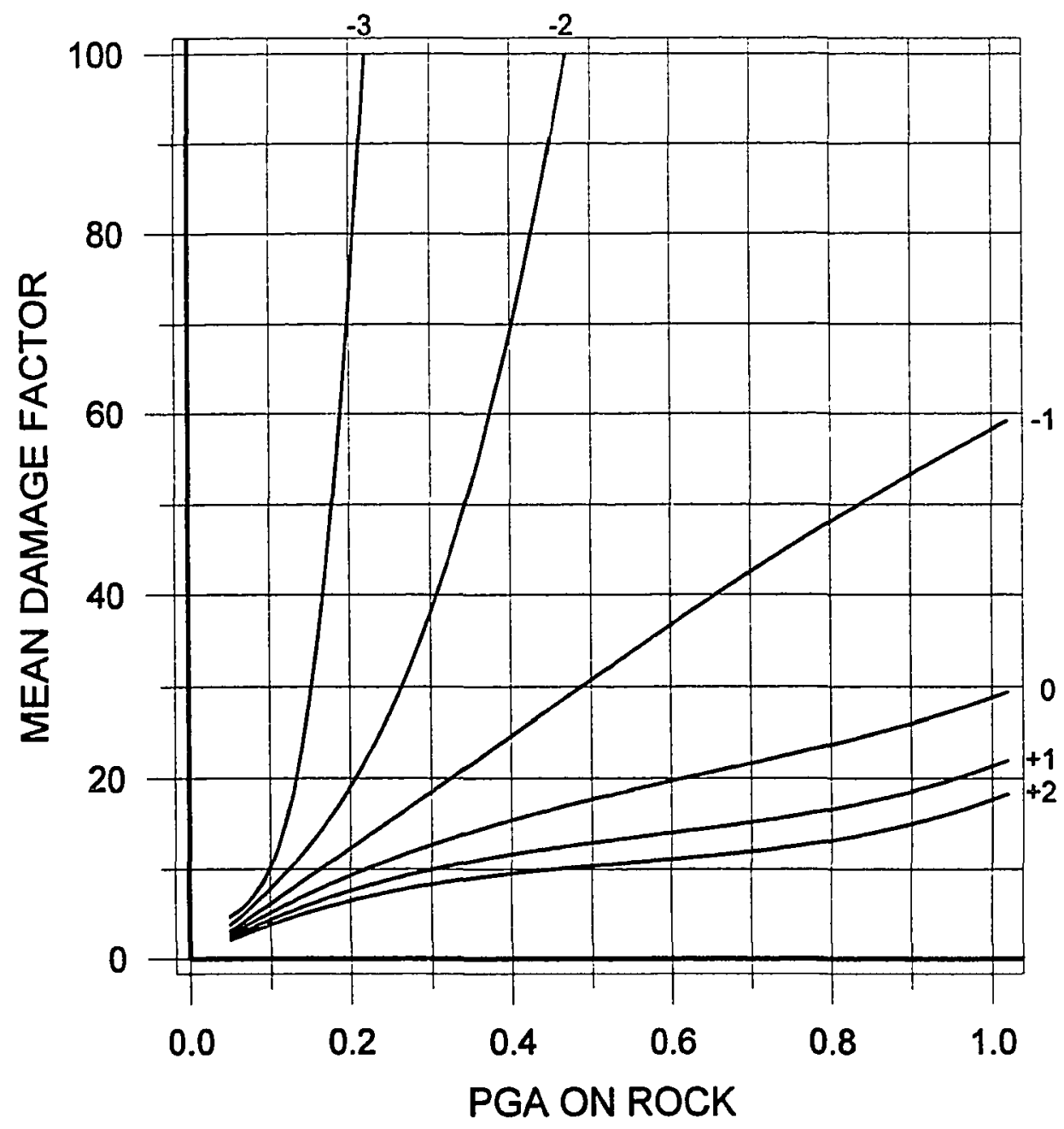

Figure 28. RH - REINF MASONRY fragility curves for integer $\Sigma$ (PMF) steps. 


\section{URM - UNREINFORCED MASONRY \\ NEHRP AREAS 3,4}

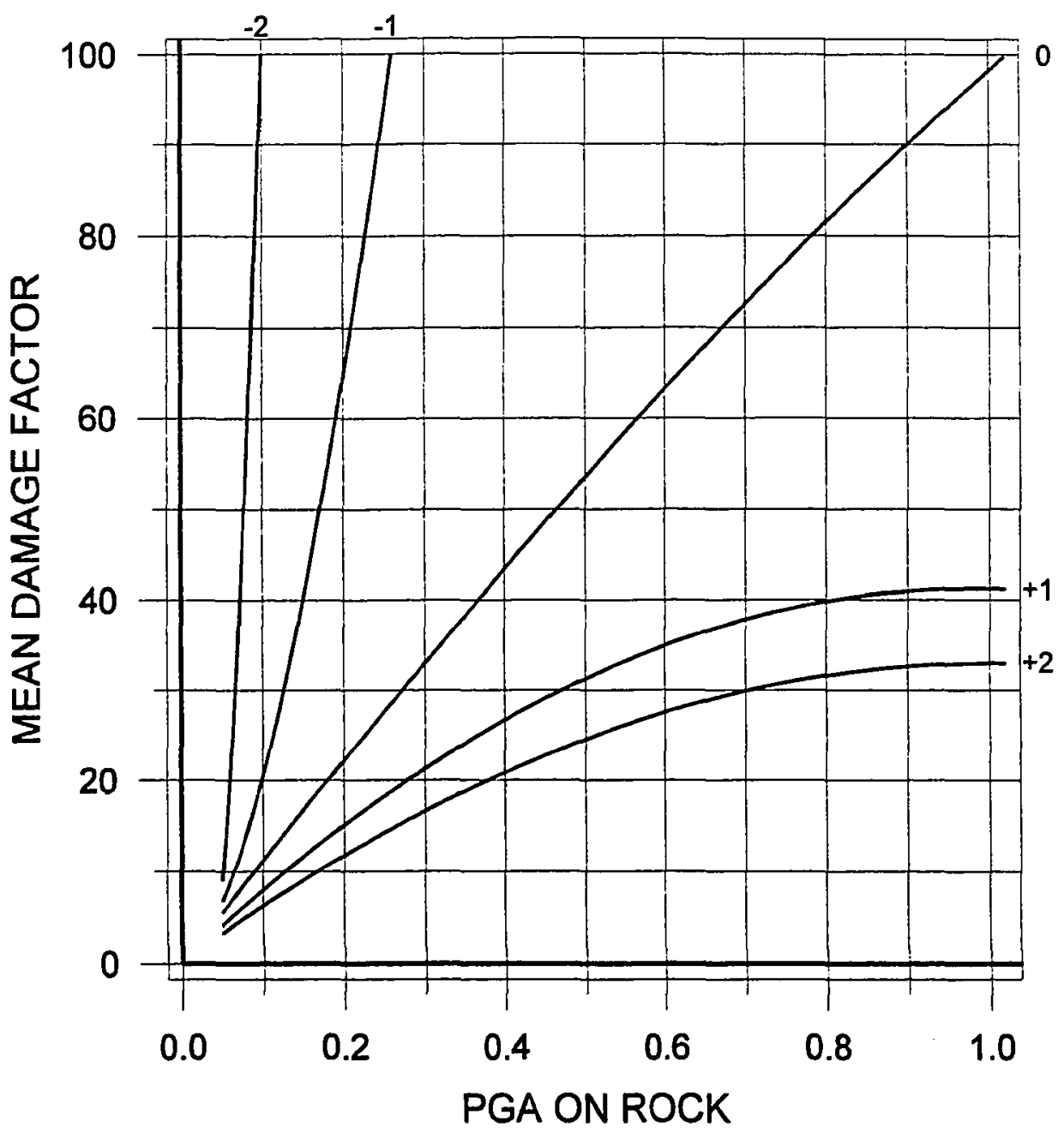

Figure 29. URH - UNREINF MASONRY fragility curves for integer $\Sigma$ (PHF) steps. 
DEVELOPMENT OF A SOIL EFFECTS MODEL

A Soil Effects Model was developed to quantify the effect of the site soil profiles on earthquake damage to buil dings.

Model input is:

1. DOGAMI's Earthquake Hazard Map Series, GMS-79. Model output is:

1. A Soil Modification Factor (SMF) to be included in $\Sigma$ (PMF) in the Earthquake Loss Model.

The soil effects model extends current soil effects modeling by including three types of geologic seismic hazard:

1. Ground Motion Amplification.

2. Soil Liquefaction/Lateral spread.

3. Dynamic slope Instability.

As previously discussed, the Basic Structural Hazard score (BSH) is modifed by adding applicable Performance Modification Factors (PMF) to arrive at the final structural score (S). The PMF's, ranging from -2.5 (detractors, reducing $s)$ to +2.0 (enhancers, increasing $S$ ), modify the BSH score to relect deviations from "average" structural practice or conditions. The PMF values were assigned by the ATC-21 project engineering panel expert opinion, so that the resulting structural score $(\mathrm{S}=\mathrm{BSH}+$ $\Sigma(P M F)$ ) would approximately reflect the probablity of 
major damage for a building, given the presence of the specific PMFs.

ATC-21 includes a Performance Modifier for Soil

Profile, SL. In this way, ATC-21 models soil profile effects in the same manner as structural effects (such as torsion, plan irregularity, etc.): an SL factor for less than ideal soil conditions contributes to reducing the BSH score and increasing the probability of major damage.

In order to provide a consistent approach, the present study follows suit by developing a new soil Modification Factor (SMF), to be applied in a similar manner to the ATC-21 Soil Profile factor, SL. However, the SMF extends ATC-21's SL factor by including additional potential soil hazards.

The ATC-21 Soil Profile Modifier

The ATC-21 SL modifier is based on the UBC and NEHRP classifications of "standard" soil profiles, as follows:

SL1 (PMF $=0)$ : Rock; or sand, gravel, or stiff clay deposits less than 200-feet thick.

SL2 (PMF $=-.3$ ): Sand, grave1, or stiff clay deposits greater than 200-feet thick.

SL3 (PMF $=-.6 ;-.8$ for buildings 8-20 stories): Soft or medium stiff clay deposits greater than 30-feet thick.

The seismic hazard addressed by this modifier is ground motion amplification, wherein the rock PGA is amplified due to the soil column "spring" effect. 
ATC-21 follows building code practice, which is to amplify lateral loads by $20 \%$ for SLe profiles, and $50 \%$ for SL3 profiles. The SL profile, amplification modeled, and PMF assigned are summarized in Table XXXIII, following.

TABLE XXXIII

ATC-21 SOIL PROFILE AND GROUND AMPLIFICATION

\begin{tabular}{ccc}
\hline PROFILE & AMPLIF FACTOR & PMF \\
\hline SL1 & 1.0 & 0 \\
SL2 & 1.2 & -.3 \\
SL3 & 1.5 & $-.6 /-.8$ \\
\hline
\end{tabular}

\section{Amplification Factor}

The Amplification Factor (AF) developed here reflects ground motion amplification (similar to the SL factor in ATC-21), using DOGAMI's GMS-79 Earthquake Hazard Maps. GMS-79/Plate 2 provides a map of the amplification hazard for the Portland Quadrangle, color coding amplifications ranging from 1.0 or less (no amplification) to 2.5 or more $(150 \%)$.

Since the Ground Motion Amplification from GMS-79 Plate 2 is a multiplier of bedrock seismic intensity (Rock PGA), AF was designed to reduce the structural score $S$ at the same rate that the Basic Structural Hazard Score BSH is 
reduced for increasing PGA. An increase in ATC-21

Seismicity of one "level," from Low to Moderate or from Moderate to High, roughly doubles the PGA. The average decrease in BSH from Moderate to High Seismicity is 0.625. Therefore a ground motion amplification of 2 (Yellow on GMS-79, Plate 2) correlates to an AF of -0.6. The AF was stepped down and up for lesser and higher ground motion amplifications than 2. GMS-79/Plate 2 map colors, corresponding amplification, and AF developed herein, are summarized on Table XXXIV, following.

TABLE XXXIV

AMPLIFICATION FACTOR (AF)

\begin{tabular}{llr}
\hline OREGON DOGAMI GMS-79, PLATE 2 & \\
Map Color & Amplification & AF \\
\hline Dark Blue & 1 or less & 0 \\
Dark Green & 1 to 1.4 & -.2 \\
Light Green & 1.4 to 1.8 & -.4 \\
Yellow & 1.8 to 2.2 & -.6 \\
$\begin{array}{l}\text { Orange } \\
\text { Red }\end{array}$ & 2.2 to 2.5 & -.8 \\
\hline
\end{tabular}

It can be seen from Table IV-XIV that the range of AF, from 0 to -1.0 , approximates the analogous ATC-21 SL, which ranges from 0 to -0.8 . 


\section{Liquefaction Factor}

The Liquefaction Factor (LF) developed here was designed to model the contribution to building damage from earthquake induced soil liquefaction and/or lateral spread. It was developed to be used as another Performance Modification Factor.

The DOGAMI GMS-79 maps depict soil liquefaction and lateral spread displacement on Plates 1 and 3 , respectively. Plates 1 and $3 \mathrm{clearly}$ show these two related phenomena occurring together, in the saturated columbia and Willamette River floodplains. Lateral spread displacement from Plate 3 was selected as the index to model the liquefaction hazard. This selection was made because the lateral spread hazard map depicts finer gradations in severity than are shown on the liquefaction map. Additionally, the lateral spread severity is quantified in feet of lateral displacement, an index relevant to building performance.

The values of LF were established from correlations with the ground displacement shown on GMS-79 Plate 3. Severe liquefaction or lateral spread can have a devastating effect on building structures. Therefore, the most severe category of ground displacement was reflected by a modification factor comparable to the most severe PMF 
recommended in ATC-21. In ATC-21, the most severe PMF is Soft Story SS, which for Moderate Seismicity ranges from -1.0 to -2.0 , averaging -1.5. Based on this correlation, -1.5 was selected as the LF for the most severe category (more than 4 feet), and stepped down for less severe ground displacements.

The values of the Liquefaction Factor developed are shown in Table XXXV, following.

TABLE XXXV

LIQUEFACTION FACTOR

OREGON DOGAMI GMS-79, PLATE 3

Map Color Ground Displacement LF

\begin{tabular}{llr}
\hline White & 0 & 0 \\
Light Green & 1 to 2 feet & -.3 \\
Yellow & 2 to 3 feet & -.6 \\
Orange & 3 to 4 feet & -1.0 \\
Red & more than 4 feet & -1.5 \\
\hline
\end{tabular}

\section{Slope Factor}

The slope Factor (SF) developed here was designed to model the contribution to building damage from earthquake induced dynamic slope instability. It was developed to be used as another Performance Modification Factor.

Dynamic slope Instability categories are depicted GMS-79, Plate 3 . The slope Instability was mapped on the 
same plate as Lateral Spread Displacement, since these 2 hazards occur on different types of ground.

The SF was developed using a correlation similar to that used in developing the Liquefaction Factor. The most severe category depicted on the slope instability maps is "existing landslide," which has an effect on building damage comparable in seriousness to severe lateral spread. Therefore, the existing landslide category was assigned an SF of -1.5, and the SF was stepped down for less severe categories.

The values of SF developed are shown in Table XXXVI.

TABLE XXXVI

SLOPE FACTOR

\begin{tabular}{llr}
\hline \multicolumn{2}{c}{ OREGON DOGAMI GMS-79, PLATE 3} \\
Map Color $\quad$ Relative Instability & SF \\
\hline White & None & 0 \\
Dark Green & Slope $>=15 \%$ & -.3 \\
Blue & FS 1.25 to 2 & -.6 \\
Dark Purple & FS less than 1.25 & -1.0 \\
Light Purple & Existing Landside & -1.5 \\
\hline
\end{tabular}

\section{Soil Modification Factor}

The AF, LF, and SF are combined into a single performance modification factor, the Soil Modification Factor (SMF), for inclusion in the Earthquake Loss Model. 
The procedure developed for combining the component factors into the SHF is summarized as follows:

1. Determine the AF and LF for the building site from the GMS-79, Plates 2 and 3 .

2. Use the larger of AF and LF; discara the smaller.

3. Add the SF.

This procedure was developed because liquefaction/ lateral spread and ground motion amplification hazards are unlikely to occur concurrently. If the ground liquefies, its shear strength is lost, and the liquefied soil does not have the ability to amplify shaking. However, slope instability and ground motion amplification could occur simultaneously, hence SF is added to AF (SF will automatically not be added to LF, since the mapping shows these 2 hazards to be mutually exclusive).

COMPARISON TO GOETTEL AND HORNER STUDY

A comparison of the expected damage predicted by the Earthquake Loss Model and the Earthquake Risk Analysis of Portland made by Goettel and Horner (1995) was made.

In G\&H Volume Two, damage functions are presented, in the form of DF vs. discrete values of PGA, for "average" buildings on rock, "firm" soil, and "soft" soil.

Two Structure Types which are expected to suffer high damage in Portland were selected for comparison: 
1. Unreinforced Masonry (URM), and

2. Steel or Concrete Frames with URM infill (C3/S5).

"Average" buildings are represented in the present study by the $\Sigma(P M F)=0$ fragility curve. In Figures 30 and 31, following, fragility curve ranges are shown depicting the increased damage to average buildings for moderate ground motion amplification (1.0 to 1.8$)$, high amplification (1.8 to 2.5), and severe lateral spread or slope instability. Shown on the same graphs are bar-charts depicting the estimated damage factor for "firm" and "soft" soils predicted by G\&H.

It can be observed that the moderate amplification range (1.0 to 1.8$)$ of the present study and the "firm" soils of the G\&H study predict comparable levels of damage, especially in the . 2 to . 3 PGA range. Comparable levels of damage are also predicted for the high amplification range (1.8 to 2.5) of the present study and the "soft" soils of the G\&H study. 


\section{URM - UNREINFORCED MASONRY}
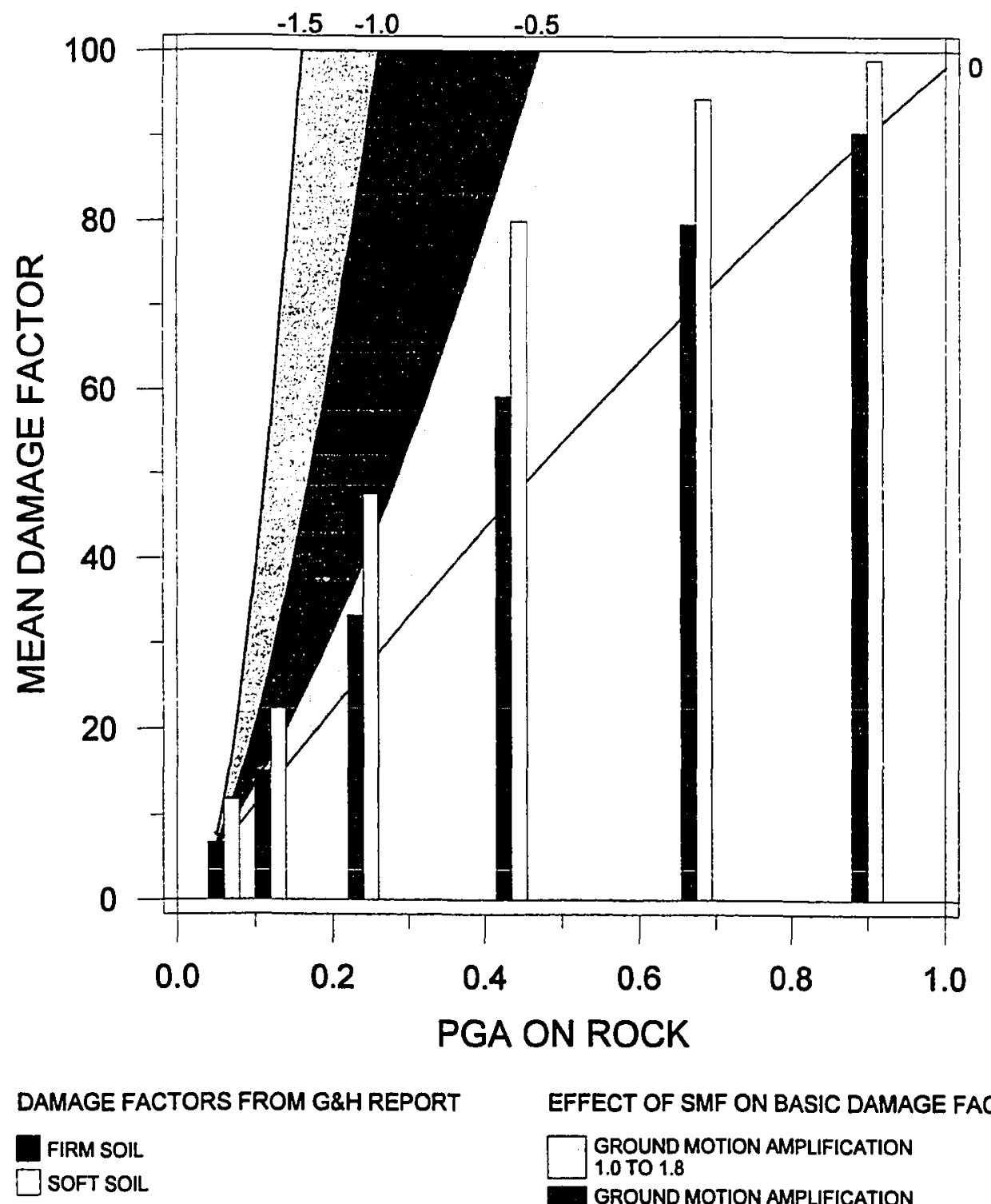

EFFECT OF SMF ON BASIC DAMAGE FACTOR

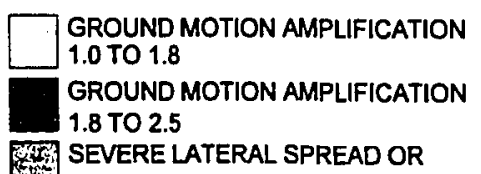

SLOPE INSTABILITY POTENTIAL

Figure 30. Comparison of URH fragility curve for "average" buildings with Goettel \& Horner (1995) Damage Factor estimates. 


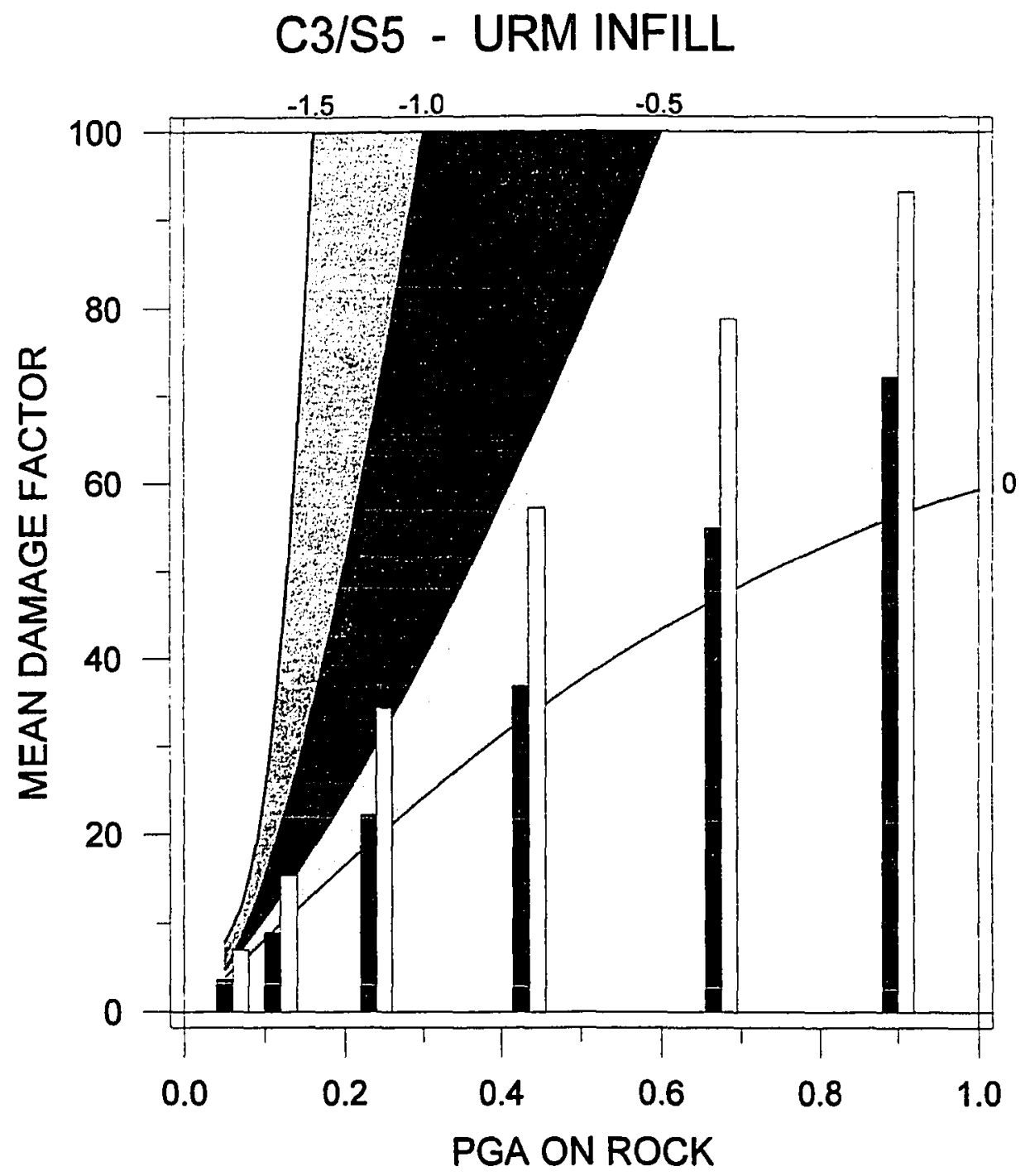

DAMAGE FACTORS FROM G\&H REPORT

FIRM SOIL

$\square$ SOFT SOIL
EFFECT OF SMF ON BASIC DAMAGE FACTOR

$\square$ GROUND MOTION AMPLIFICATION 1.0 TO 1.8

GROUND MOTION AMPLIFICATION

1.8 TO 2.5

XEVERE LATERAL SPREAD OR

SLOPE INSTABILITY POTENTIAL

Figure 31. Comparison of C3/S5 fragility curve for "average" buildings with Goettel \& Horner (1995) Damage Factor estimates. 


\section{EARTHQUAKE LOSSES ESTIMATION}

The result of the preceding sections of the Earthquake Loss Model, (based on selected PGA, ATC-21 survey data, and earthquake hazard maps) is a Damage Factor (DF) for each building in the inventory.

The final phase of the model is to estimate 2 types of loss for each building in the inventory.

1. Dollar value of building damage, and

2. Number of lives lost and serious injuries.

\section{Dollar Value of Building Damage}

Damage Factor has been previously defined as:

$$
\mathrm{DF}=\frac{\text { Dollar Loss }}{\text { Replacement Value }}
$$

The Dollar Loss to buildings is therefore:

Dollar Loss = DF* (Replacement Value) (4.12)

The Replacement Value of a building is not the same thing as the buildings market value. Nor is market value constant in relation to Replacement Value. Market value is affected by lot location, age, and architectural style, and may be below or above Replacement Vvlue. Furthermore, Replacement Value should include additional postearthquake costs including cleanup and demolition. 


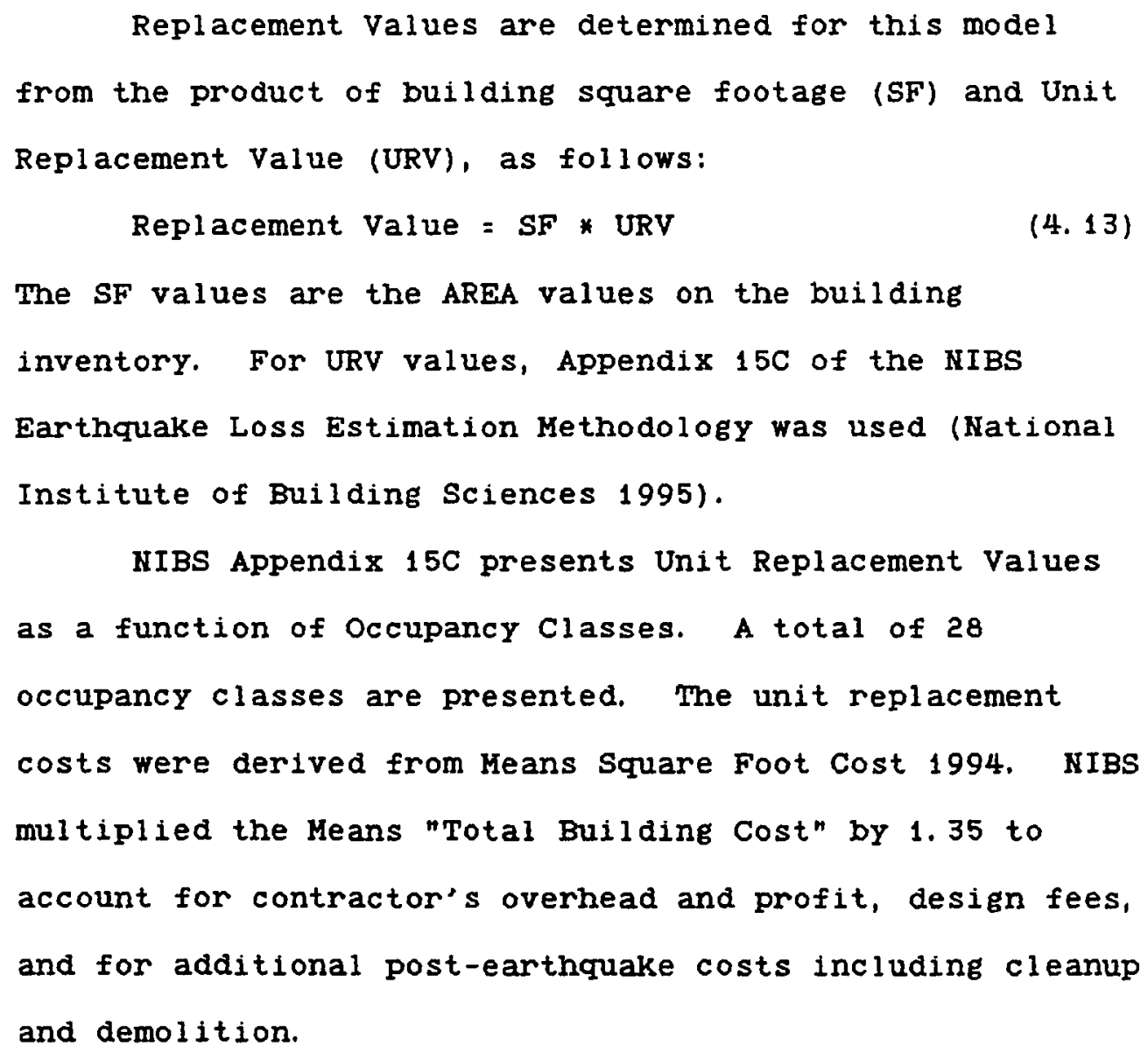

The URV values used herein were determined by grouping the 28 NIBS Occupancy Classes into the 9 ATC-21 Occupancy Types used in the inventory, and averaging each group, then rounding the final value, based on engineering iudgement. The URV values used in the present model are presented in Table XXXVII, following. 
TABLE XXXVII

UNIT REPLACEMENT VALUES (URV)

\begin{tabular}{lc}
\hline ATC-21 OCCUPANCY TYPE & URV $(\$ /$ sq. ft. $)$ \\
\hline & \\
Residential & 80. \\
Commercial & 75. \\
Office & 75. \\
Industrial & 60. \\
Public Assembly & 90. \\
School & 85. \\
Government Building & 75. \\
Emergency Services & 120. \\
Historic Building & 100. \\
\hline
\end{tabular}

The Earthquake Loss Model determines the Dollar Loss for each building in the inventory as follows:

1. Unit Replacement Value is selected from the Occupancy Type in the inventory, and Table XXXVII

2. The Replacement Value is determined from Eq. 4. 13, using the AREA from the inventory.

3. The Dollar Loss is determined from. Eq. 4.12, using the DF previously found in the model.

\section{Loss of Life and Serious Injuries}

As reported in Chapter 2 herein, ATC-13 (1985)

presents in its Table 9.3 a recommended table for estimating casualties, which includes Fraction Dead (FD)

vs. Central Damage Factor (CDF). These values are shown in Table XXXVIII, following. 
TABLE XXXVIII

FRACTION DEAD VS. CENTRAL DAMAGE FACTOR FROM ATC-13 TABLE 9.3

\begin{tabular}{lcl}
\hline $\begin{array}{l}\text { DAMAGE } \\
\text { STATE }\end{array}$ & $\begin{array}{c}\text { CENTRAL } \\
\text { DAMAGE FACTOR }\end{array}$ & $\begin{array}{c}\text { FRACTION } \\
\text { DEAD }\end{array}$ \\
\hline & & \\
1 & 0 & 0 \\
2 & 0.5 & .000001 \\
3 & 5 & .00001 \\
4 & 20 & .0001 \\
5 & 45 & .001 \\
6 & 80 & .01 \\
7 & 100 & .2 \\
\hline
\end{tabular}

A continuous relationship between Damage Factor (DF) and Fraction Dead (FD) was developed in the present research by regressing FD against DF, as shown in Figure 32, resulting in the following exponential equation:

$$
F D=5.94 E-06 * \exp (D F * .104)
$$

Fraction Dead is defined as:

$$
F D=\frac{L L}{N P}
$$

where $L L=1$ ives lost, and NP $=$ No. of People in building. Therefore, the Loss of Life (LL) per building is:

$$
L L=F D * N P
$$

From ATC-13 Table 9, the Serious Injures (SI) are approximately 4 times the number of deaths. Therefore:

$$
S I=4 * L L
$$

The Earthquake Loss Hodel determines the Loss of Life 


\section{FRACTION DEAD vs. DAMAGE FACTOR}

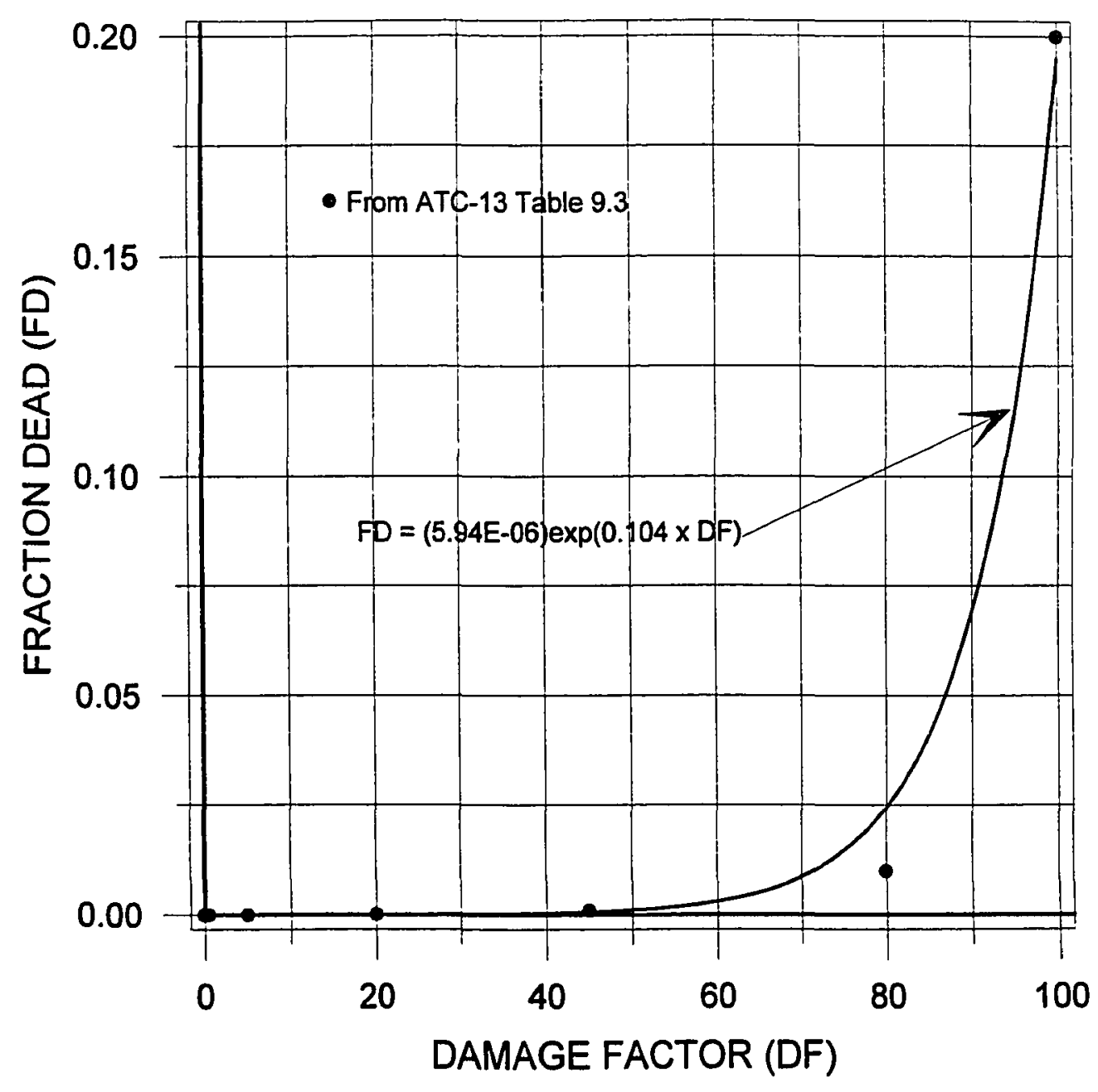

Figure 32. Fraction Dead vs. Damage Factor relationship derived from ATC-13 (1985) Table 9.3 
and Serious Injuries for each inventory in the building as follows:

1. The Fraction Dead is determined from Eq. 4. 14, using the DF previously determined for the building.

2. The Number of People (NP) is taken as the Midpoint of the Range of Number of People from the inventory data (alternatively, LL is determined with the Lowpoint of the range of number of people).

3. Loss of Life is determined from Eq. 4.15

4. Serious Injuries are determined from Eq. 4. 16.

Time of Day. Clearly, the Loss of Life is directly proportional to the Number of People (NP), from Eq. 4.15. The number of people can be expected to vary with the time of day. Generally, two times of day may be considered: during business hours (Monday - Friday, 8:00 to 5:00), and during non-business hours. 


\section{CHAPTER V}

DEVELOPMENT OF A RETROFIT DIRECT BENEFIT AND COST MODEL

A model was developed to estimate the direct benefits and costs resulting from seismic retrofit, for each building in the regional inventory.

Retrofit Direct Benefits are defined as:

1. Dollar value of avoided building damage, and

2. Lives saved and serious injuries avoided.

Indirect benefits are not included in the model. Indirect benefits include various items of economic loss, including rental losses, relocation expenses, personal income loss, business inventory loss, and personal property loss.

Retrofit costs are defined as the total cost to complete a life-safety retrofit, including structural costs, restoration of architectural finishes, "light" non-structural retrofit, design fees, permits, management, insurance, and relocation during retrofit construction.

Retrofit is defined for this study as "life-safety" retrofit, in which the retrofit criteria is designed to reduce bullding collapse or partial collapse, without attempting to strengthen the building to the degree necessary to preserve building serviceability. Guidelines 
for analyzing and retrofitting buildings can be found in FEMA-178 (1992): NEHRP Handbook for the Seismic Evaluation of Existing Buildings, and FEMA-172 (1989): Techniques for Seismically Rehabilitating Existing Buildings.

\section{Retrofit Effectiveness Model}

First, a model was developed to estimate the effectiveness of seismic retrofit for each building in the inventory.

Model inputs are:

1. Input and Output from Earthquake Loss Model. Model output is:

1. A "post-retrofit" Damage Factor (RDF) for each building.

Retrofit Effectiveness is defined as the percentage reduction in expected damages in the post-retrofit facility, compared to expected damages prior to retrofit. FEMA-227 (1992) provides estimated values of Expected Retrofit Effectiveness (ERE) in its Tables 3-6a and 3-6b. These estimates are for 1 ife-safety retrofit, based on engineering experience and judgement. The estimates are tabulated in FEMA-227 by ATC-13 Facility Class and MMI intensity.

For use in the Retrofit Effectiveness Model herein, facility classes in FEMA-227 Table 3-6b have been combined to ATC-21 Structure Types, and MMI intensities converted 
to PGA. Tables XXXIX through XLIII were developed, as follows:

TABLE XXXIX

EXPECTED RETROFIT EFFECTIVENESS (ERE) FOR

W, S3 BUILDINGS

\begin{tabular}{cc}
\hline PGA & ERE (\%) \\
\hline .05 & 50 \\
.10 & 50 \\
.22 & 43 \\
.47 & 35 \\
1.02 & 28 \\
\hline
\end{tabular}

TABLE XL

EXPECTED RETROFIT EFFECTIVENESS (ERE) FOR $\mathrm{C} 1, \mathrm{~S} 1, \mathrm{S2}, \mathrm{S} 4$ BUILDINGS

\begin{tabular}{rl}
\hline PGA & ERE (\%) \\
\hline .05 & 35 \\
.10 & 35 \\
.22 & 31 \\
.47 & 28 \\
1.02 & 24 \\
\hline
\end{tabular}


TABLE XLI

EXPECTED RETROFIT EFFECTIVENESS (ERE) FOR C3/S5, C2, PC2 BUILDINGS

\begin{tabular}{rl}
\hline PGA & ERE (\%) \\
\hline .05 & 40 \\
.10 & 40 \\
.22 & 36 \\
.47 & 33 \\
1.02 & 29 \\
\hline
\end{tabular}

TABLE XLII

EXPECTED RETROFIT EFFECTIVENESS (ERE) FOR RM BUILDINGS

\begin{tabular}{ll}
\hline PGA & ERE(\%) \\
\hline .05 & 30 \\
.10 & 30 \\
.22 & 26 \\
.47 & 23 \\
1.02 & 19 \\
\hline
\end{tabular}


TABLE XIIII

EXPECTED RETROFIT EFFECTIVENESS (ERE) FOR URH, PC1 BUILDINGS

\begin{tabular}{cc}
\hline PGA & ERE (\%) \\
\hline .05 & 50 \\
.10 & 50 \\
.22 & 45 \\
.47 & 40 \\
1.02 & 35 \\
\hline
\end{tabular}

According to FEMA-227, these estimates for reduction in damage correspond to the minimum retrofit needed to address the life safety criteria in each facility class. These values would not be appropriate for retrofits designed to preserve the function of the buildings.

It can be seen from the preceding Tables that the effectiveness of retrofit gradually decreases with increasing seismic intensity, because stronger shaking begins to exceed the strength of the retrofit.

The ERE values were regressed against PGA for each of Tables XXXIX through XLIII. The result was a quadratic relationship between ERE and PGA, of the form:

$E R E=b_{0}+b_{1}(P G A)+b_{2}(P G A)^{2}$

where $b_{0}, b_{1}$, and $b_{2}$ are the regression coefficients. The five regression curves and coefficients are shown in Figs. 33 through 37, following. 


\section{RETROFIT EFFECTIVENESS}

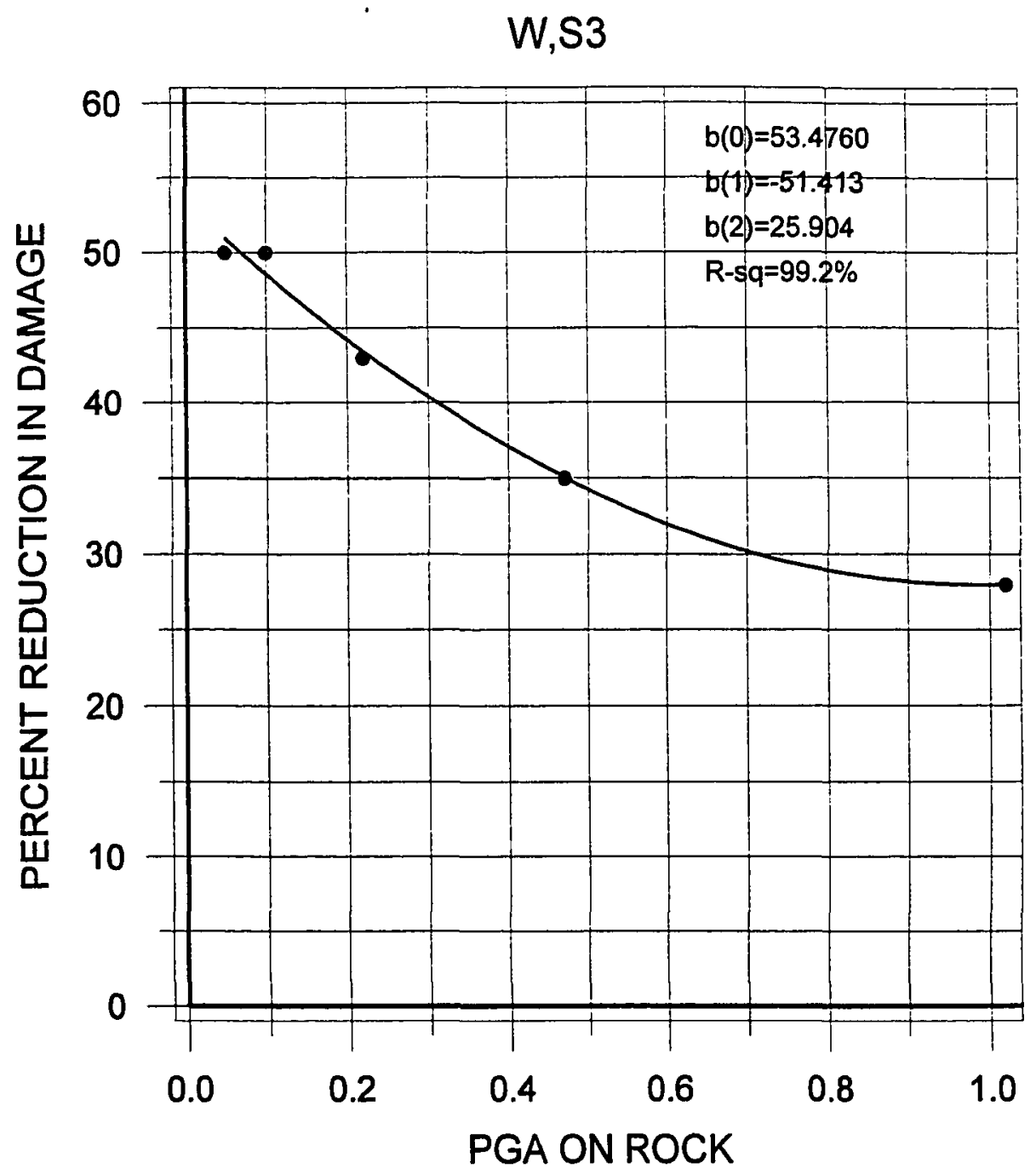

Figure 33, Retrofit Effectiveness for $W$ and $S 3$ buildings. 


\section{RETROFIT EFFECTIVENESS}

\section{$\mathrm{C} 1, \mathrm{~S} 1, \mathrm{~S} 2, \mathrm{~S} 4$}

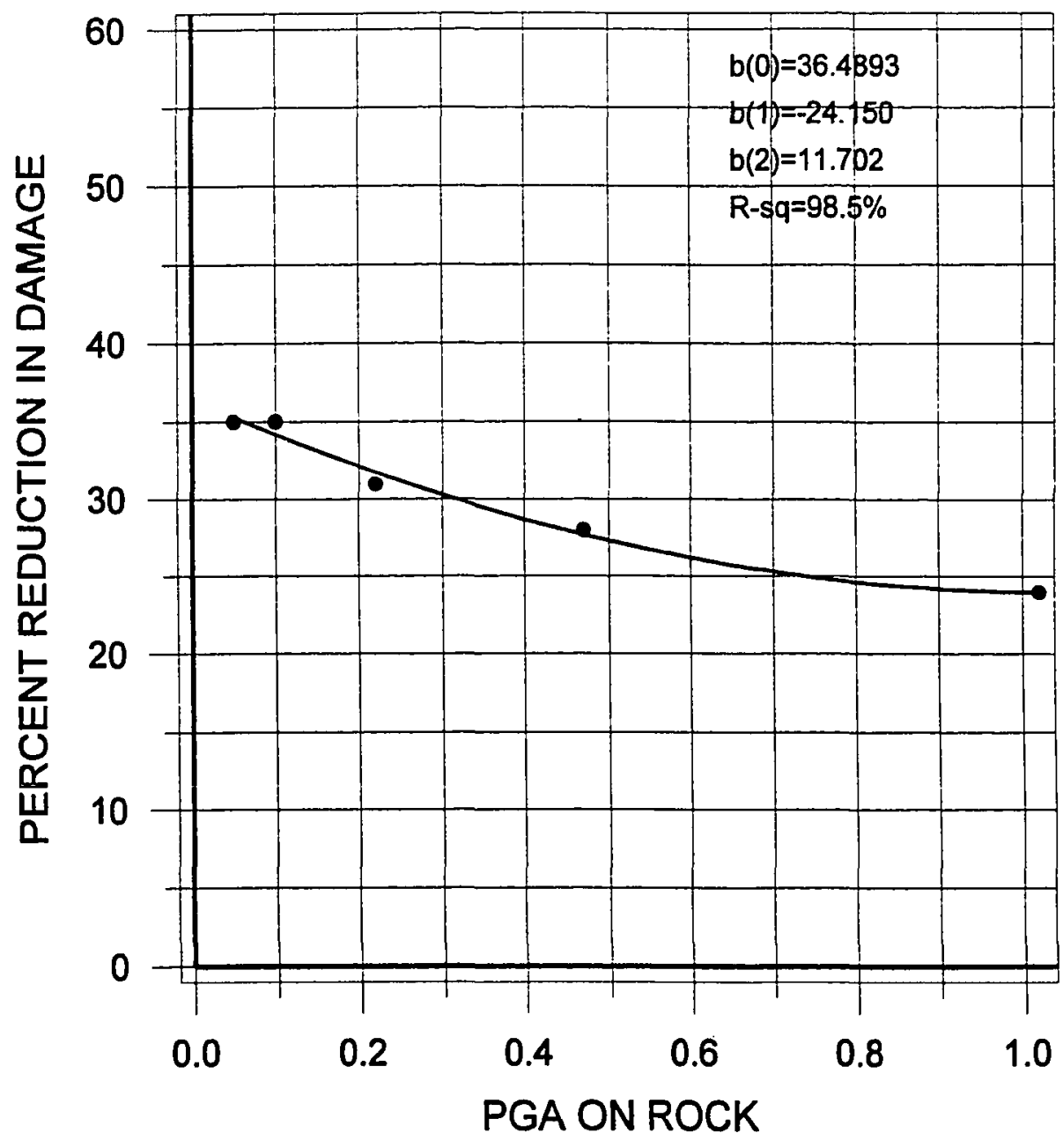

Figure 34. Retrofit Effectiveness for C1, S1, S2, and 54 buildings. 


\section{RETROFIT EFFECTIVENESS $\mathrm{C} 3 / \mathrm{S} 5, \mathrm{C} 2, \mathrm{PC} 2$}

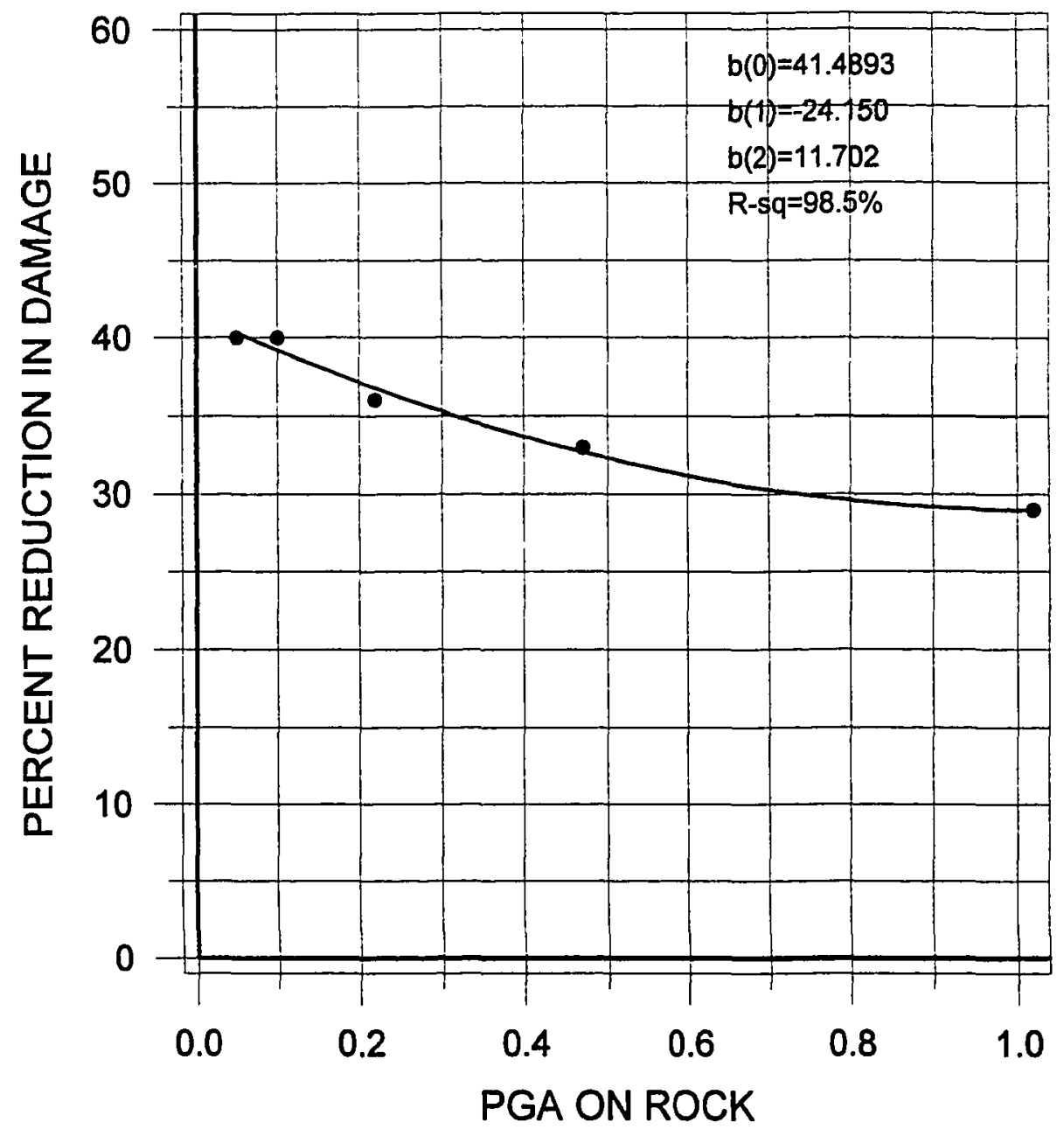

Figure 35. Retrofit Effectiveness for C3/S5, C2, and PC2 buildings 


\section{RETROFIT EFFECTIVENESS}

\section{RM}

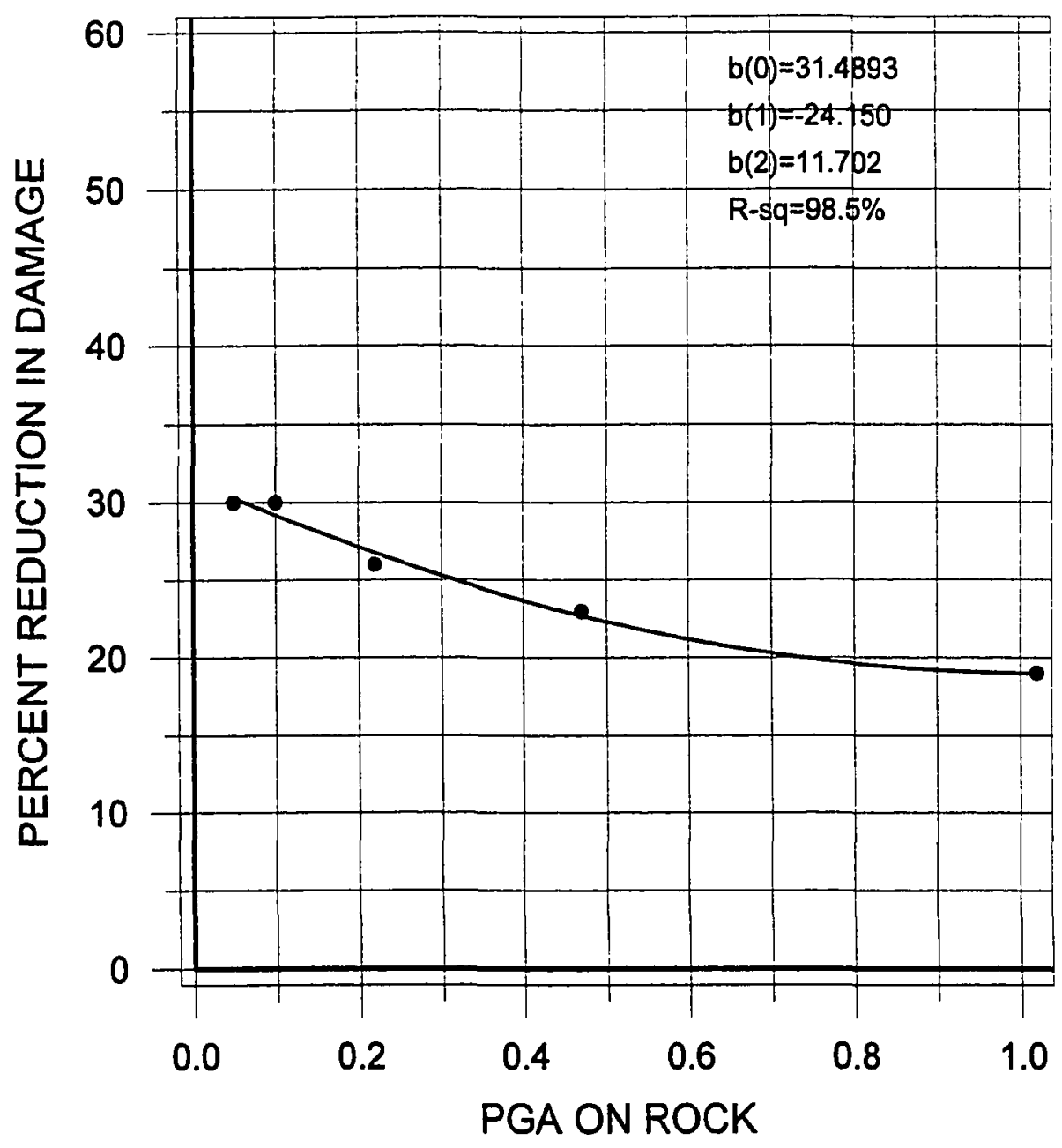

Figure 36. Retrofit Effectiveness for RM buildings. 


\section{RETROFIT EFFECTIVENESS \\ URM,PC1}

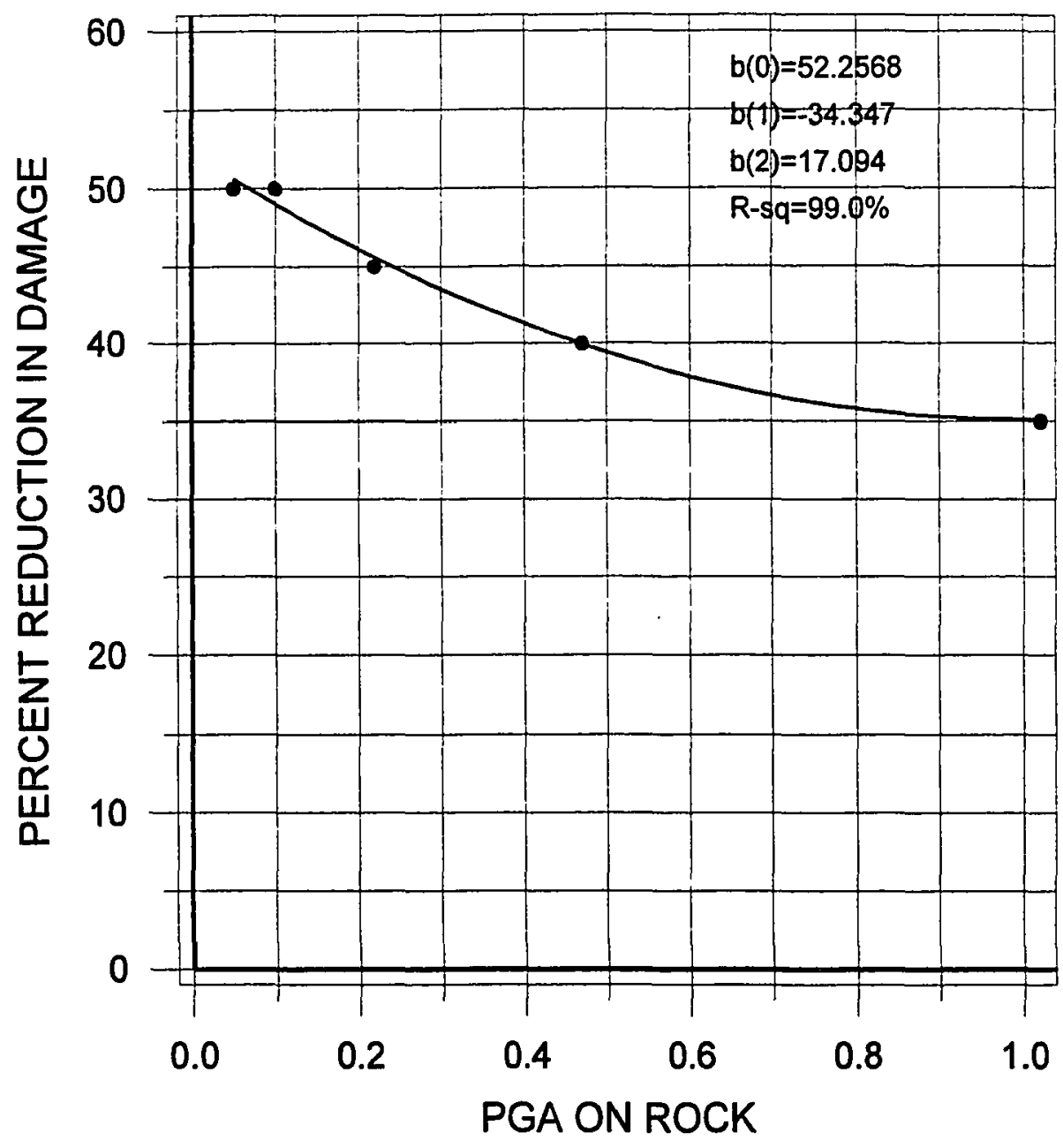

Figure 37. Retrofit Effectiveness for URM and PC1 buildings. 
The RDF from the regressions is checked against a Minimum Damage Factor (RDF-MIN), wherein RDF is limited so that the Damage Factor in the post-retrofit building is not less than the DF for a building with $\Sigma$ (PMF) equal to +2. A $\Sigma$ (PMF) of +2 corresponds to a modern (Post Benchmark) building without any detracting Performance Modifiers; judgement dictates that a building post-retrofit to life-safety standards should not be considered "fitter" than this.

The Damage Factor for post-retrofit buildings (RDF) was determined with the following steps:

1. Determine the Damage Factor (DF) for the building prior to retrofit, based on earthquake $P G A, \Sigma(P M F)$, and the fragility curves presented in the Earthquake Loss Model.

2. Based on Structure Type and earthquake PGA, calculate the Expected Retrofit Effectiveness (ERE) from the appropriate regression equation.

3. Calculate RDF $=\mathrm{DF} *(1-\mathrm{ERE})$.

4. Determine a Minimum Damage Factor (RDF-MIN) equal to the DF from the fragility curves corresponding to $\Sigma(P M F)=+2$.

5. RDF equals the greater of RDF from Step 3, or RDF-MIN from step 4. 


\section{Retrofit Direct Benefit Model}

Model inputs are:

1. Input and output from the retrofit effectiveness model.

Model outputs are:

1. Dollar value of avoided building damage.

2. Number of lives saved and injuries avoided.

The dollar value of avoided building damage is determined for each building in the inventory as follows:

1. The Replacement Value of the building is determined as described in chapter IV.

2. The dollar loss of the post-retrofit building is determined by multiplying the Replacement Value by RDF.

3. The dollar value of avolded building damage equals the difference between the dollar loss of the existing building (determined in the Earthquake Loss Model) and the dollar loss of the post-retrofit building.

The number of lives saved is determined for each building in the inventory as follows:

1. The Fraction Dead is determined from Eq. 4. 14, using RDF in place of DF.

2. Loss of life in the post-retrofit building is determined from Eq. 4. 15. 
3. Number of Lives saved equals the difference between Loss of Life in the existing building (determined in the Earthquake Loss Model) and the loss of 1 ife in the post-retrofit building.

\section{Retrofit Cost Model}

A dollar value of retrofit cost was determined for each building in the inventory. This was determined from the building AREA (square feet) from the inventory, multiplied by total unit cost of retrofit (dollars per square foot).

The unit structural retrofit costs are determined from the published values in FEMA-156 (1994), as presented in Chapter II herein. The values used were for the high seismicity and life-safety performance objective categories (Goettel and Horner (1995) recommends lower values for west-coast RM and PC1 buildings, and their recommendations were followed). The structural costs vary with Structure Type and Building Area, as described in Chapter II.

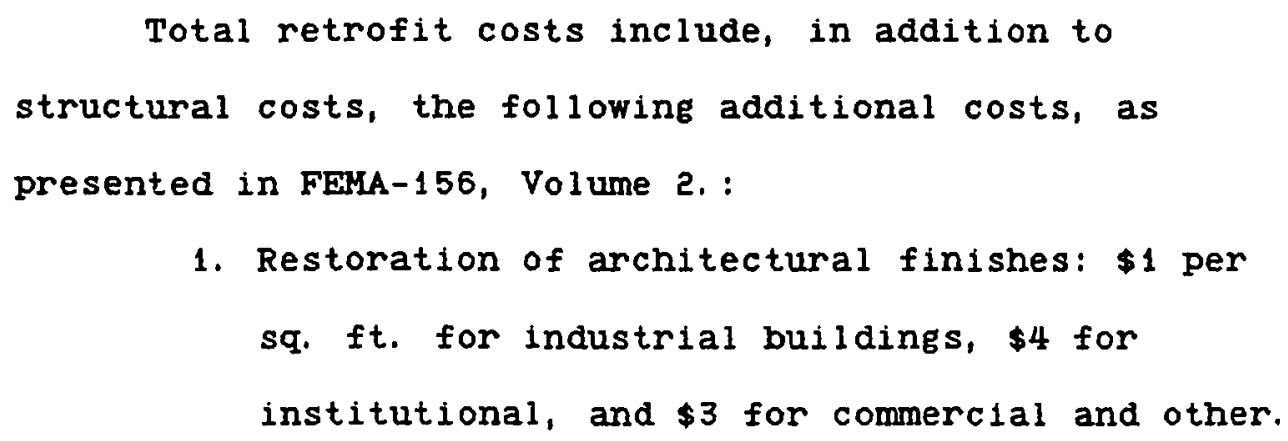


2. Non-structural retrofit costs: $\$ 2$ per sq. ft. for industrial buildings, $\$ 4$ for institutional buildings, and $\$ 3$ for commercial and other buildings.

3. Other costs, including design fees, permits, management, and insurance, were taken as $30 \%$ of the subtotal of the structural, restoration, and non-structural costs.

4. Occupant relocation costs of $\$ 9$ per sq. ft., except $\$ 1.50$ for RH and PC1 buildings, and Industrial occupancies.

Because the restoration and non-structural costs depend on the 3 broad occupancy groups of industrial, institutional, and commercial/other, it was necessary to group the nine ATC-21 occupancy types into one of the three, in order to assign retrofit costs to the building inventory. This assignment was made as follows:

1. INDUSTRIAL: Industrial

2. INSTITUTIONAL: Public Assembly, School, Emergency Services, Historic.

3. COMMERCIAL/OTHER: Residential, Commercial, Office, Government Bldg.

The total unit cost of retrofit values used are shown in Tables XLIV through XLVI, following. 
TABLE XLIV

TOTAL UNIT RETROFIT COSTS FOR

COMMERCIAL BUILDINGS, $\$ / \mathrm{SF}$

\begin{tabular}{lllll}
\hline STR. TYP. & SMALL & MEDIUM & LARGE & V. LARGE \\
\hline URM & & & & \\
W & 34.66 & 34.49 & 33.61 & 30.96 \\
PC1, RM & 30.59 & 31.31 & 35.00 & 40.12 \\
C1, C3/S5 & 16.45 & 14.83 & 12,55 & 11.25 \\
S1 & 42.05 & 41.36 & 40.20 & 36.26 \\
S2, S3 & 42.11 & 41.68 & 40.59 & 34.91 \\
S4, C2, PC2 & 26.67 & 26.17 & 24.33 & 21.06 \\
& 41.73 & 41.13 & 39.92 & 36.13 \\
\hline
\end{tabular}

TABLE XLV

TOTAL UNIT RETROFIT COSTS FOR

INSTITUTIONAL BUILDINGS, \$/SF

\begin{tabular}{lllll}
\hline STR. TYP. & SMALL & MEDIUM & LARGE & V. LARGE \\
\hline URM & & & & \\
W & 37.26 & 37.09 & 36.21 & 33.56 \\
PC1, RM & 33.19 & 33.91 & 37.60 & 42.72 \\
C1, C3/S5 & 19.05 & 17.43 & 15.15 & 13.85 \\
S1 & 44.65 & 43.96 & 42.80 & 38.86 \\
S2, S3 & 44.71 & 44.28 & 43.19 & 37.51 \\
S4, C2, PC2 & 29.27 & 28.77 & 26.93 & 23.66 \\
& 44.33 & 43.73 & 42.52 & 38.73 \\
\hline
\end{tabular}


TABLE XLVI

TOTAL UNIT RETROFIT COSTS FOR

INDUSTRIAL BUILDINGS, \$/SF

\begin{tabular}{lrrrr}
\hline STR. TYP. & SMALL & MEDIUM & LARGE & V. LARGE \\
\hline URH & & & & \\
W & 23.26 & 23.09 & 22.21 & 19.56 \\
PC1, RM & 19.19 & 19.91 & 23.60 & 28.72 \\
C1, C3/S5 & 12.55 & 10.93 & 8.65 & 7.35 \\
S1 & 30.65 & 29.96 & 28.80 & 24.86 \\
S2, S3 & 30.71 & 30.28 & 29.19 & 23.51 \\
S4, C2, PC2 & 15.27 & 14.77 & 12.93 & 9.66 \\
& 30.33 & 29.73 & 28.52 & 24.73 \\
\hline
\end{tabular}


CHAPTER VI

DEVELOPMENT OF A REGIONAL RETROFIT PLANNING METHODOLOGY BUILDING CLASSIFICATION SYSTEM

A system was developed to classify buildings, based on the results of the Earthquake Loss Model and Retrofit Direct Benefit and Cost Model. The objective of this Building Classification System (BCS) was to prioritize classes of buildings in a region for a cost-effective retrofit program.

Current methods used to classify buildings for earthquake retrofit priority are based only on structure type (Goettel and Horner 1995). In addition to structure type, other indices which may be useful are: site-specific soil conditions, individual characteristics of design and construction, occupancy type, and building size. How important any one of these indices becomes is dependent on the specific regional building inventory being classified, but clearly any or all may be important. The BCS was designed with the dual objectives of sufficient detail to capture buildings with similar magnitudes of retrofit benefits, while being simple enough for practical implementation in a real-world retrofit program. 
The BCS is based on 5 indices:

1. Structural Type Group (STG)

2. Soil Hazard Zone (SHZ)

3. Structural Score Range (SSR)

4. Occupancy Type Group (OTG)

5. Building Size Group (BSG)

Nine indices of Structural Type Group are used, based on similarities in ATC-21 structural types, earthquake risk, and unit retrofit costs.

Two indices of Soil Hazard Zonee are used, based on the range of the Soil Modification Factor (SMF), to correlate roughly with the "firm" soils and "soft" soil categories used in Goettel \& Horner (1995), and others. Two indices of Structural Score Range are used. Structural Score $(S=B S H+\Sigma(P M F)+$ SMF) captures the effect of structure type, characteristics of design and construction, and soil profile effects, and provides a measure of their aggregate effect. The index was designed to separate buildings with a significant collapse (and life-safety) risk from those with a lower risk.

Five indices of Occupancy Type Group are used, combining ATC-21 Occupancy Types based on similarities in occupant density, importance, and retrofit cost.

Finally, three indices of Building Size Group are used, based on FEMA-156 (1994) categories, to help group 
similar occupant loads, bldg values, and retrofit cost.

The Building Classification system (BCS) indices are as follows:

STRUCTURAL TYPE GROUP (STG):

1) $\mathrm{S1}, \mathrm{S2}, \mathrm{S} 4$ (Steel frame buildings)

2) C1 (Concrete moment frame)

3) C2 (Concrete shearwall)

4) C3/S5 (Steel or Conc frame with URM infill)

5) PC1 (Tilt-up concrete)

6) PC2 (Precast concrete frame)

7) RM (Reinforced masonry)

8) URM (Unreinforced masonry)

9) W, S3 (Wood \& light metal; low-risk bldgs.) SOIL HAZARD ZONE (SHZ):

1) SMF lower than -.6 (Higher soil hazard)

2) SMF equal to -.6 or higher (Lower hazard) STRUCTURAL SCORE RANGE (SSR):

1) Less than +1.0 (higher risk)

2) Equal to +1.0 or greater (lower risk) OCCUPANCY TYPE GROUP (OTG):

1) Schoo1, Public Assembly

2) Government, Emergency Service

3) Office, Commercial, Historical

4) Residential

5) Industrial 
BUILDING SIZE GROUP (BSG):

1) Small, less than 10,000 sq. ft.

2) Medium, 10,000 to 50,000 sq. ft.

3) Large and Very Large, more than 50,000 sq. ft.

In the Building Classification System, each building in the regional inventory will fall into a Bullding Class (BC) specified by five indices. For example: $\{2,1,1,4,3\}$ is a concrete moment frame (C1) building type, in the higher soil hazard zone, with a structural score less than 1. 0 , residential occupancy, large or very large.

The total number of possible Building Classes is: $9 \times 2 \times 2 \times 5 \times 3=540$

However, because not all combinations of indices occur, the number of indices used in an actual regional classification will be less (as one example, there is really no such thing as a light metal residence, and a wood building in the higher risk score range is unlikely).

\section{RETROFIT COST-BENEFIT ALALYSIS}

Two approaches to a retrofit cost-benefit analysis for a regional building inventory were taken.

First, a "Scenario Earthquake Event" was analyzed, wherein the benefits from retrofitting that would be realized against the full damage from a single earthquake PGA magnitude, the Design Basis Earthquake (DBE), 
were determined.

Second, an Expected Value analysis was made, wherein the expected present value of retrofit benefit against the probability of damages for a range of earthquake magnitudes was determined over a planning horizon.

In both approaches, the results were determined by Building Class, utilizing the outputs from the Retrofit Direct Benefit and Retrofit Cost Models, as presented in Chapter V.

\section{Dollar Value of Life-Safety Benefits}

In order to make a cost-benefit analysis, it is necessary to assign a dollar value to loss of life and serious injuries sustained.

For this study, we have used the values recommended by Goettel \& Horner (these values have also been adopted by FEMA for valuing casualties avoided by FEMA-funded hazard mitigation projects), as follows:

Value of Human Life: \$2, 200,000. Value of Serious Injury: \$12,500.

since, from Eq. 4.16, the number of serious injuries is modeled as 4 times the loss of life, the dollar value of serious injuries are combined with loss of life, as fol lows :

$$
\begin{aligned}
\text { VOL } & =\$ 2,200,000 .+4(12,500 .) \\
& =\$ 2,250,000 .
\end{aligned}
$$


The dollar value of lives saved and serious injuries avoided is determined by multiplying the number of lives saved (from the Retrofit Direct Benefit Model) by VOL, from Eq. 6. 1 .

\section{Scenario Earthquake Event Analysis}

In making a cost-benefit analysis of a scenario Earthquake Event, $100 \%$ of the retrofit benefits and costs are used from a selected earthquake PGA. The scenario earthquake event used was a Design Basis Earthquake (DBE), defined as a PGA with a 10\% probability of occurring within 50 years (500 year return). From the Geomatrix (1995) report, for Portland this is a PGA of 0.20 on rock.

From the Retrofit Direct Benefit Model and Retrofit Cost Model, the following were determined, and summed by Building Class:

1. The dollar value of avoided building damage.

2. The number of lives saved.

3. The dollar value of retrofit Benefit (B), equal to the dollar value of avoided building damage plus the dollar value of lives saved.

4. The dollar value of the Net Benefit (NB) of retrofit, equal to the retrofit Benefit minus the Retrofit Cost (NB = B - C).

5. The $B / C$ ratio. 


\section{Expected Value Analysis}

In making a cost-benefit analysis using an Expected Value approach, the expected Net Present Value (NPV) of retrofit benefit was determined from the sum of the present value of benefits expected to accrue each year over a selected planning horizon (PV), minus the initial cost (C) of retrofit (NPV = PV - C).

The annual value of retrofit benefits are taken as the dollar value of Benefit (B) of a scenario earthquake (PGA), multiplied by the annual exceedance probability of that earthquake $(P(P G A))$, summed over a range of possible earthquakes. The range of earthquake scenarios and annual exceedance probabilities used were as follows:

$\begin{array}{ll}\text { PGA } & P \text { (PGA) } \\ .08 & .01 \\ .20 & .002 \\ .27 & .001 \\ .39 & .0004\end{array}$

To determine the PV of the retrofit benefit, the annual benefits are multiplied by a Uniform Series/Present Worth Factor (PWF), based on a selected discount rate and planning horizon. The economic parameters used were:

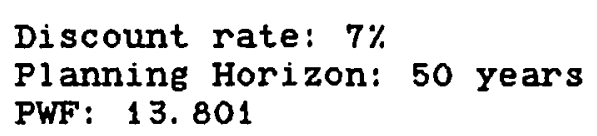

These earthquake scenarios, exceedance probablities, and economic parameters, were applied to the results of the Retrofit Direct Benefit Model and Retrofit Cost Model. The 
following were determined, and summed by Building Class:

1. Net Present Value (NPV = PV - C) of dollar value of total retrofit benefit.

2. PV/C ratio.

RETROFIT PRIORITIZATION AND SYSTEM OPTIMIZATION

Each Building Class forms an alternative solution set of buildings for retrofit. When considering a group of more than one Building Class for a retrofit program, that group of Building Classes becomes a retrofit "system." This phase of the methodology determined:

1. Building Class retrofit priority.

2. The point of maximum system efficiency for a retrofit program.

3. The optimum retrofit budget, where Net System Benefit is maximized in a retrofit program.

Using the results of the cost-benefit analysis, the Building Classes were prioritized for retrofit by sorting them from highest to lowest $B / C$ ratios. Thereby, any retrofit program performed in priority order will attain the maximum net system benefit per dollar spent.

A key decision making principle in allocating resources is the "principle of diminishing returns", which states that eventually a point is encountered where the return from additional resources invested begins to 
decline. This is the point of "maximum system efficiency", beyond which additional resource investment causes a decrease in system net benefit. once the Building Classes were prioritized from highest to lowest $B / C$ ratio, the first $B / C$ ratio encountered less than 1.0 marked the point of maximum system efficiency (this coincides with the first negative value of Net Benefit).

A "running sum" of Retrofit Cost (C) was made of the prioritized Building Classes. This sum is a budget for a retrofit program consisting of all preceding Building Classes. The optimum retrofit budget --- where system Net Benefit is maximized -.- is the sum of all Retrofit Cost up to the point of maximum system efficiency.

A running sum of Direct Benefits -.. dollar value of building damage avoided and lives saved -.- was also made of the prioritized Building Class sequence. This may be used to determine the direct benefits attained for various retrofit budgets. 
DEVELOPMENT OF REGIONAL EARTHQUAKE LOSS AND RETROFIT ANALYSIS SOFTWARE

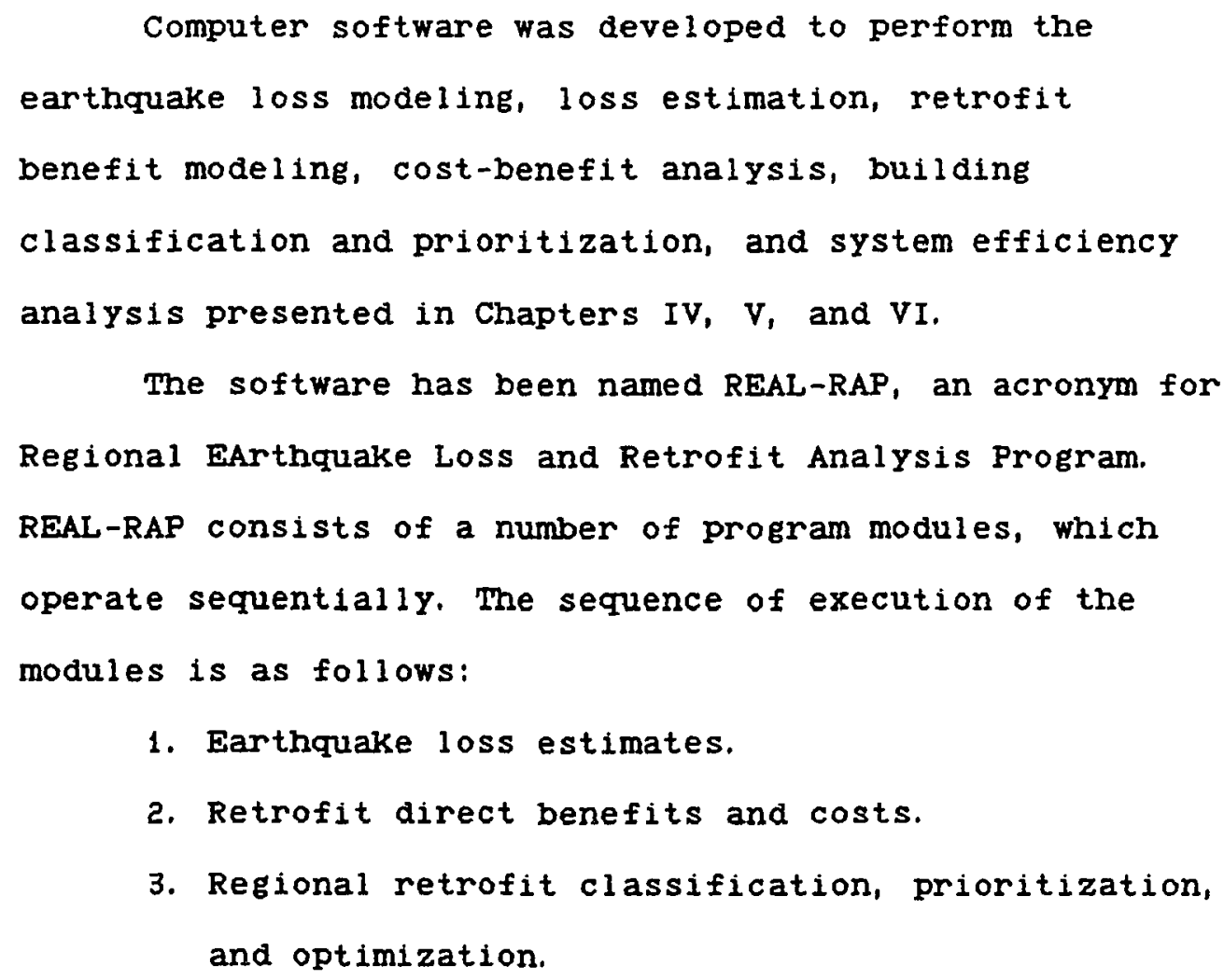

1. Earthquake loss estimates.

2. Retrofit direct benefits and costs.

3. Regional retrofit classification, prioritization, and optimization.

EARTHQUARE LOSS ESTIMATATION MODULES

\section{DAM-FACT Module}

Input: The ATC-21 Rapid Survey data. An example from the input database may be found in Figure 2. The input 
format is a comma-delimited text file, which permits the use of exported data from any spreadsheet or database software. For the Portland Quad, the survey data was grouped into files by survey section (square mile).

Processing: The DAM-FACT module calculates the damage factor for each building in the inventory. The module contains twelve subroutines, one for each ATC-21 Bullding Type. Based on the Performance Modifiers and Soll Modifiers for each building, a value of $\Sigma$ (PMF) is determined, and the $\mathrm{DF}$ is calculated from the regression equations of the fragility curves presented in Chapter IV. This is done for a range of six PGA values, which may adjusted by the user.

Output: A data file, by section, of one line for each inventory building, consisting of sequence number, building type, structural score, soil modification factor, and the Damage Factor for six PGA values. A sample of the output is shown on Figure 38.

\section{DAMAGE- $\$$ Module}

Input: Two data files are input: the Rapid Survey data and the output from the DAM-FACT module, by section. Processing: Based on the Occupancy Type and building area, a replacement value is determined for each bullding, as described in Chapter IV. The dollar value of damage is determined from the damage factor, for six PGA values. 
Output: A data file, by section, of one line for each building, consisting of sequence number, building type, area, occupancy type, and the dollar loss for six PGA values. A sample of the output is shown on Figure 39.

\section{LIFELOSS Module}

Input: Two data files are input: the Rapid Survey data and the output from the DAM-FACT module, by section.

Processing: Based on the range of estimated Number of People and the Damage Factor, the probabilistic loss of life is determined for six PGA values for each building, in accordance with the model presented in Chapter IV. The Midpoint of the range of the number of people is used (this module may be adjusted to compute the loss of life based on other points, such as lowpoint, in the range). Output: A data file, by section, of one line for each inventory building, consisting of sequence number, building type, range of number of people, occupancy type, and the loss of life for six PGA values. A sample of the output is shown on Figure 40.

\section{DAM-SUM Module}

Input: The input is the output from the DAM-FACT, DAMAGE-\$, and LIFELOSS modules, for one section.

Processing: The loss estimation results, which were made previously building-by-building, are summed to 


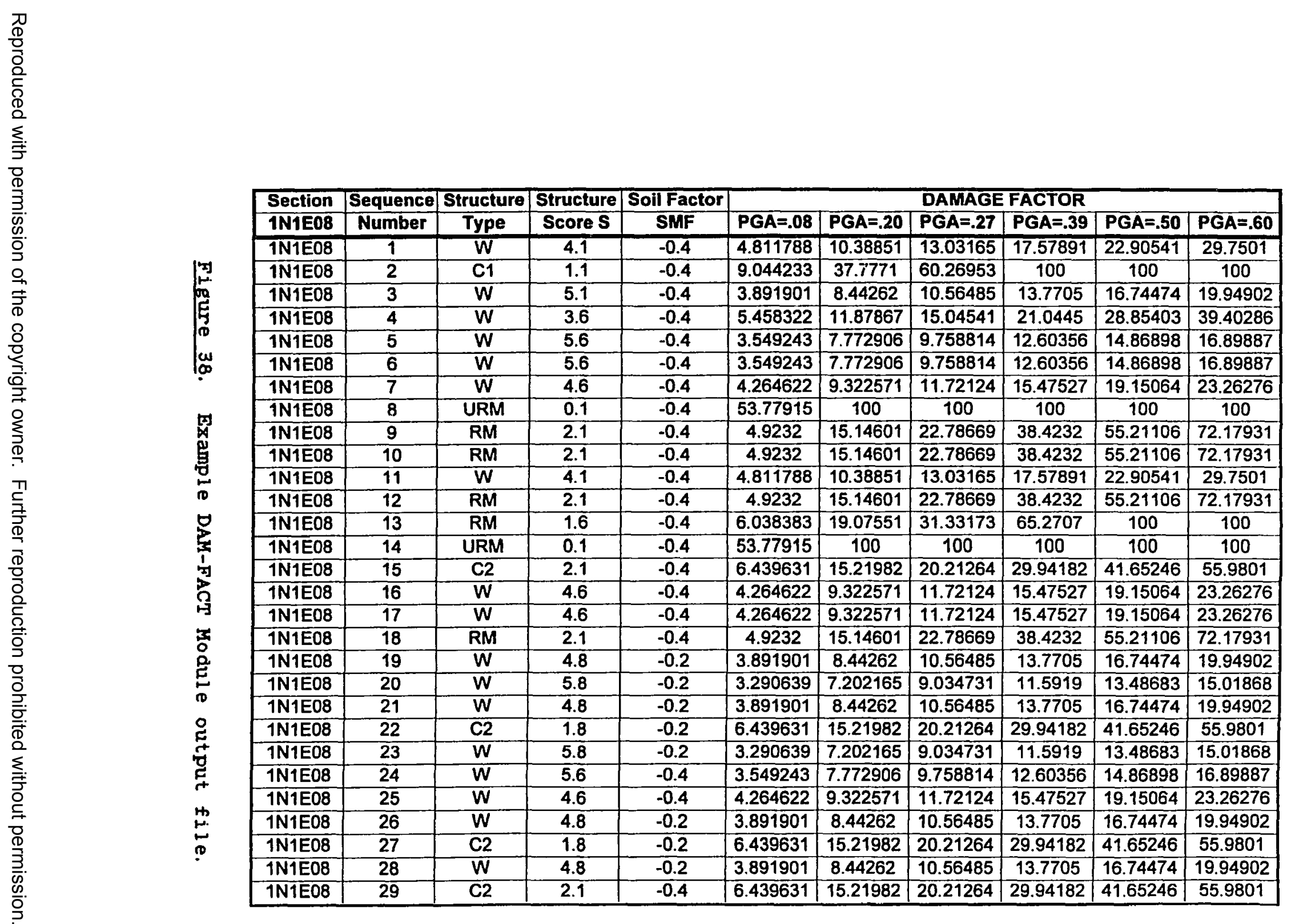




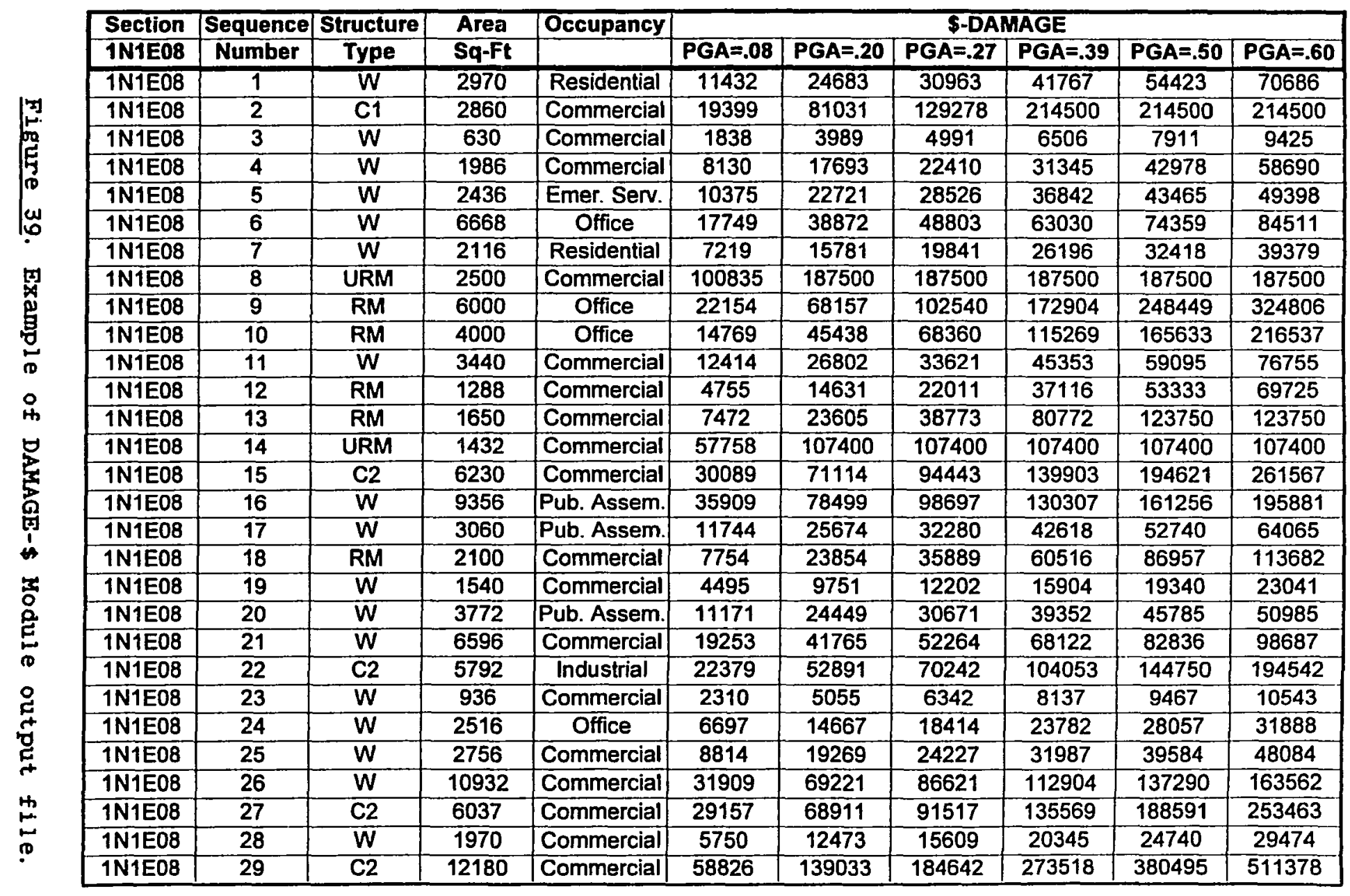




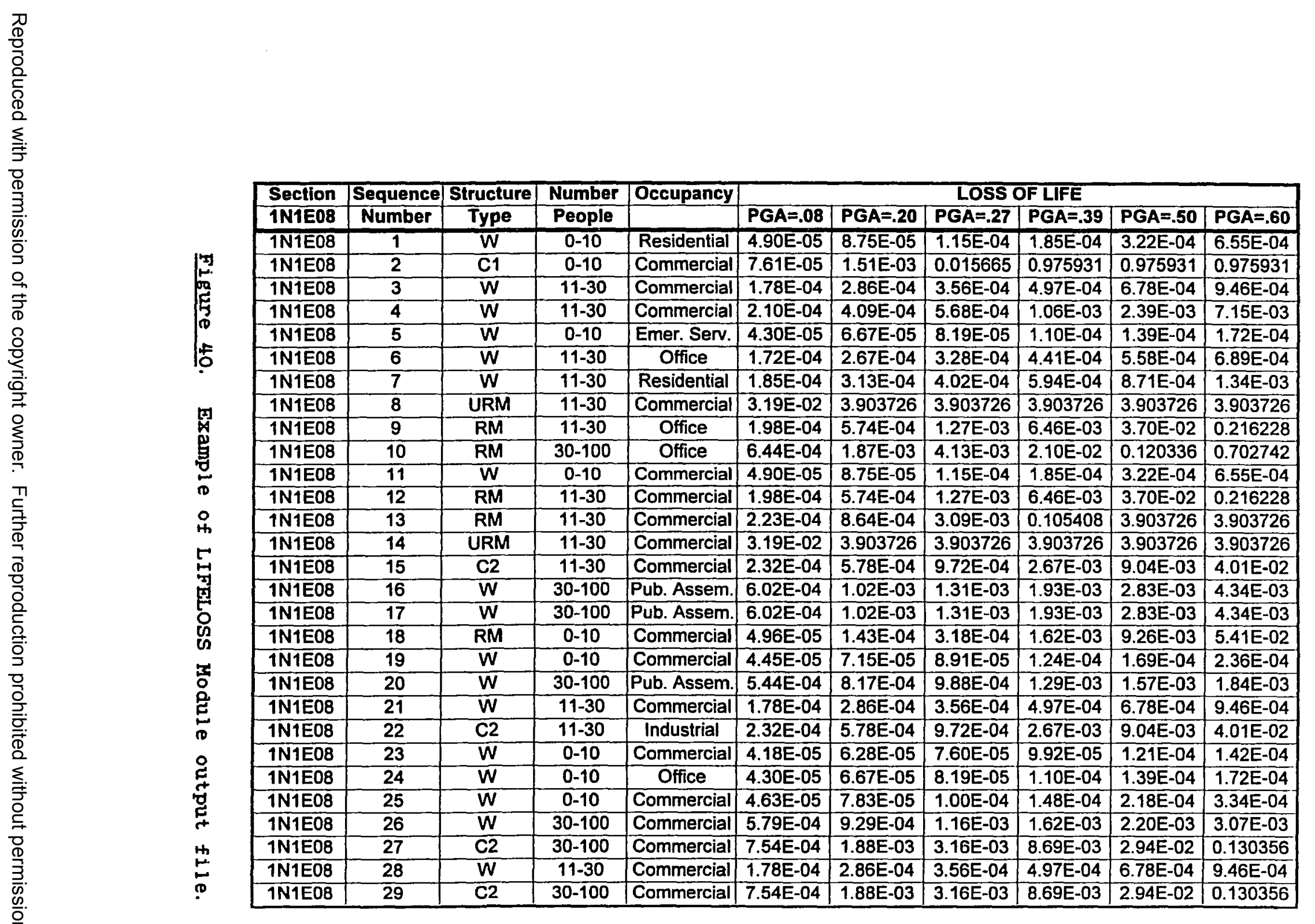


determine the total losses for one section by Building Type. Structural Scores and Damage Factors are averaged by Building Type and for the section.

Output: A data file where each line gives the section totals for each Building Type: number of buildings, area, average structural score, average damage factor, total dollar value of damage, and total loss of life. The TABLE-1 sub-module writes this output file in table form.

\section{REGION-L Modules}

Input: The inputs are the outputs from the DAM-SUM modules, for a number of sections comprising a region.

Processing: The loss estimation results, which were summed by section in DAM-SUM, are summed for the region, by Building Type. Structural Scores and Damage Factors are averaged by Building Type and for the region.

Output: A data file where each line shows the region totals for each Building Type: number of buildings, area, average structural score, average damage factor, total dollar value of damage, and total loss of life. The TABLE-2 sub-module writes this output in table form; Tables XIVII and LI were derived from the TABLE-2 output. Six tables are output, for six PGA values. 
RETROFIT DIRECT BENEFIT AND COST MODULES

\section{RETRO-DF Module}

Input: The ATC-21 Rapid Survey data, by section.

Processing: The RETRO-DF module calculates the post-retrofit damage factor for each building in the inventory. The module first calculates the damage factor for the building, in a procedure identical to the DAM-FACT module. The RETRO-DF module then calculates the retrofit effectiveness and reduces the damage factor, in accordance with the model presented in Chapter $V$. This is done for a range of six PGA values, which may adjusted by the user. Output: A data file, by section, of one line for each inventory building, consisting of sequence number, building type, structural score, soil modification factor, and the post-retrofit Damage Factor for six PGA values. A sample of the output is shown in Figure 41.

\section{RETRO-\$D Module}

Input: Two data files are input: the Rapid Survey data and the output from the RETRO-DF module, by section.

Processing: Based on the Occupancy Type and building area, a replacement value is determined for each building, as described in Chapter IV. The dollar value of damage is then determined from the post-retrofit damage factor, for six PGA values. 
Output: A data file, by section, of one line for each inventory builaing, consisting of sequence number, building type, area, occupancy type, and the post-retrofit dollar loss for six PGA values. A sample of the output is shown in Figure 42.

\section{RETRO-LL Module}

Input: Two data files are input: the Rapid Survey data and the output from the RETRO-LL module, by section.

Processing: The post-retrofit loss of life is determined for each building in the inventory using the same procedure as the LIFELOSS module, except that the post-retrofit damage factor is used. This is done of six PGA values.

Output: A data file, by section, of one line for each inventory building, consisting of sequence number, building type, range of number of people, occupancy type, and the post-retrofit loss of life for six PGA values. A sample of the output is shown on Figure 43. 


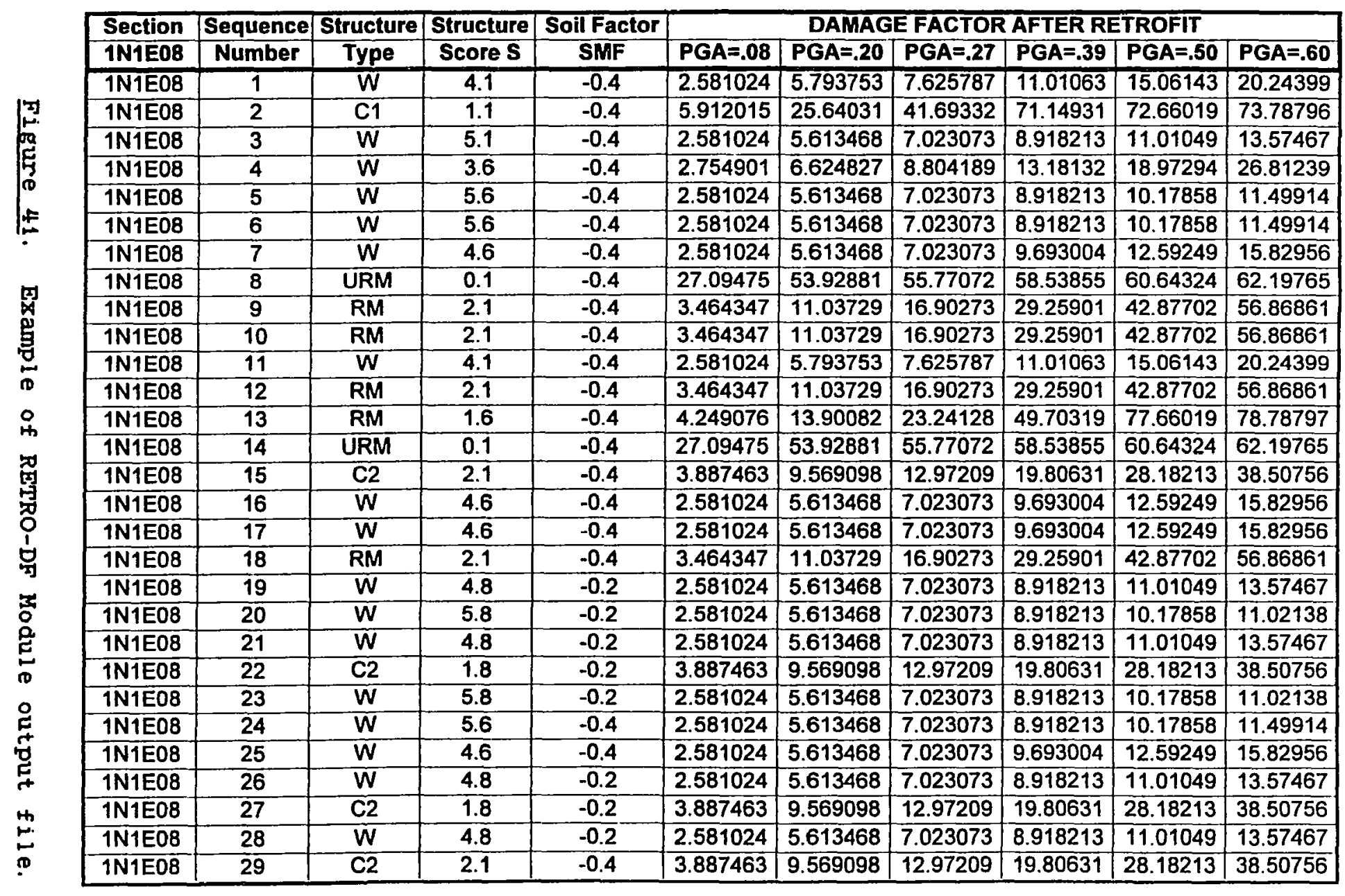




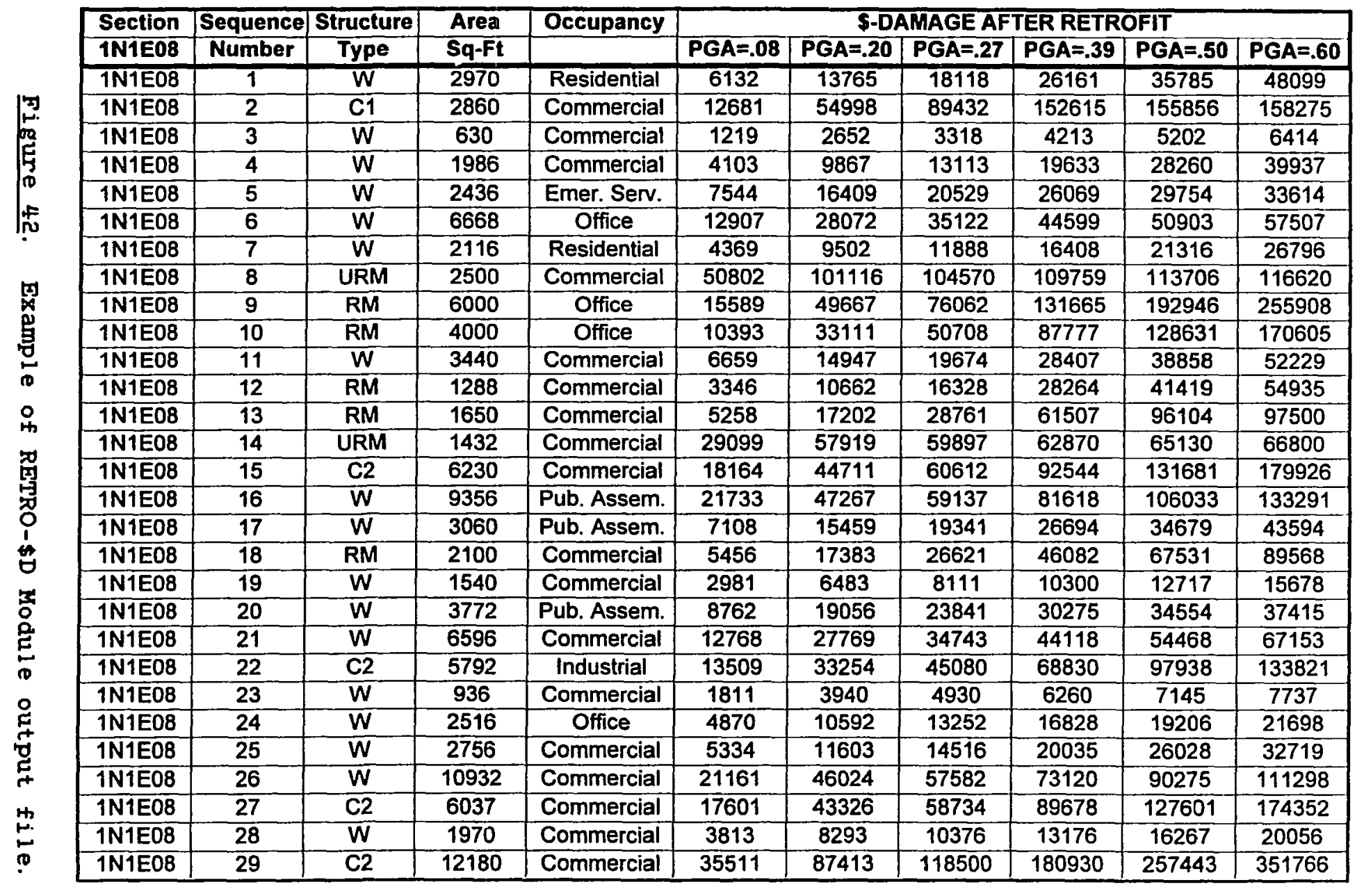




\begin{tabular}{|c|c|c|c|c|c|c|c|c|c|c|}
\hline Section & Sequence & Structure & Number & Occupancy & & LOSS & OF LIFE & FTER RE & ROF & \\
\hline 1N1E08 & Number & Type & People & & $\overline{P G A}=.08$ & $\overline{P G A}=.20$ & $P G A=.27$ & $P G A=.39$ & PGA $=.50$ & $\overline{P G A}=.60$ \\
\hline 1N1E08 & 1 & $w$ & $0-10$ & Residential & $3.88 \mathrm{E}-05$ & 5.43E-05 & 6.56E-05 & $9.33 \mathrm{E}-05$ & $1.42 \mathrm{E}-04$ & $2.44 \mathrm{E}-04$ \\
\hline 1N1E08 & 2 & C1 & $0-10$ & Commercial & 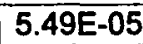 & $4.27 \mathrm{E}-04$ & 2.27E-03 & $4.86 \mathrm{E}-02$ & $5.68 \mathrm{E}-02$ & $6.39 \mathrm{E}-02$ \\
\hline 1N1E08 & 3 & $\mathbf{W}$ & $11-30$ & Commercial & $1.55 \mathrm{E}-04$ & $2.13 \mathrm{E}-04$ & $2.47 \mathrm{E}-04$ & $3.00 \mathrm{E}-04$ & $3.73 \mathrm{E}-04$ & $4.87 \mathrm{E}-04$ \\
\hline 1N1E08 & 4 & $\bar{W}$ & $11-30$ & Commercial & $1.58 \mathrm{E}-04$ & 2.37E-04 & \begin{tabular}{|l|}
$2.97 E-04$ \\
\end{tabular} & $4.68 E-04$ & \begin{tabular}{|l|}
$8.55 E-04$ \\
\end{tabular} & $1.93 \mathrm{E}-03$ \\
\hline IN1E08 & 5 & $\bar{w}$ & $0-10$ & Emer. Senv. & \begin{tabular}{|c|}
$3.88 \mathrm{E}-05$ \\
\end{tabular} & 5.32E-05 & 6.17E-05 & $7.51 \mathrm{E}-05$ & $8.56 \mathrm{E}-05$ & $9.82 \mathrm{E}-05$ \\
\hline 1N1E08 & 6 & $\bar{W}$ & $11-30$ & Office & \begin{tabular}{|c|c|}
$1.55 \mathrm{E}-04$ \\
\end{tabular} & $2.1 \overline{\mathrm{E}}-04$ & \begin{tabular}{|l|}
$2.47 \mathrm{E}-04$ \\
\end{tabular} & $3.00 \mathrm{E}-04$ & $3.42 E-04$ & 3.93E-04 \\
\hline 1N1E08 & 7 & $\bar{W}$ & $11-30$ & Residential & $1.55 \mathrm{E}-04$ & $2.13 \bar{E}-04$ & 2.47E-04 & $3.26 \mathrm{E}-04$ & $4.40 \mathrm{E}-04$ & \begin{tabular}{|c|}
$6.16 \mathrm{E}-04$ \\
\end{tabular} \\
\hline 1N1E08 & 8 & URM & $11-30$ & Commercial & $1.99 \mathrm{E}-03$ & \begin{tabular}{|l|}
$3.24 \mathrm{E}-02$ \\
\end{tabular} & $3.92 \mathrm{E}-02$ & \begin{tabular}{|l|}
$5.23 \mathrm{E}-02$ \\
\end{tabular} & 0.065143 & 0.076573 \\
\hline TN1E08 & 9 & $\overline{R M}$ & $11-30$ & Office & $1.70 \mathrm{E}-04$ & $3.74 \mathrm{E}-04$ & $6.89 \mathrm{E}-04$ & \begin{tabular}{|l|}
$2.49 \mathrm{E}-03$ \\
\end{tabular} & 0.010267 & 0.043993 \\
\hline 1N1E08 & 10 & RM & $30-100$ & Office & 5.54E-04 & 1.22E-03 & $2.24 \mathrm{E}-03$ & $8.10 \mathrm{E}-03$ & 3.34E-02 & 0.142976 \\
\hline 1N1E08 & 11 & $w$ & -10 & Commercial & 3.88E-05 & $5.43 \mathrm{E}-05$ & $6.56 \mathrm{E}-05$ & \begin{tabular}{|l}
$9.33 E-05$ \\
\end{tabular} & \begin{tabular}{|l|}
$1.42 \mathrm{E}-04$ \\
\end{tabular} & $2.44 E-04$ \\
\hline 1N1E08 & 12 & RM & -30 & Commercial & $1.70 \mathrm{E}-04$ & 3.74E-04 & $6.89 \mathrm{E}-04$ & \begin{tabular}{|c|}
$2.49 \mathrm{E}-03$ \\
\end{tabular} & 10267 & 0.043993 \\
\hline 1N1E08 & 13 & RM & $11-30$ & Commercial & $1.85 \mathrm{E}-04$ & \begin{tabular}{|l|}
$5.04 \mathrm{E}-04$ \\
\end{tabular} & $1.33 \mathrm{E}-03$ & \begin{tabular}{|l|}
$2.09 \mathrm{E}-02$ \\
\end{tabular} & 0.382353 & 0.429935 \\
\hline 1N1E08 & 14 & URM & $11-30$ & Commercial & 1.99E-03 & $3.24 \mathrm{E}-02$ & \begin{tabular}{|c|}
$3.92 \mathrm{E}-02$ \\
\end{tabular} & \begin{tabular}{|l}
$5.23 \mathrm{E}-02$ \\
\end{tabular} & 0.065143 & 0.076573 \\
\hline 1N1E08 & 15 & $\mathrm{C} 2$ & $11-30$ & Commercial & $1.78 \mathrm{E}-04$ & 3.21E-04 & \begin{tabular}{|c|}
$4.58 \mathrm{E}-04$ \\
\end{tabular} & \begin{tabular}{|c|}
$9.32 \mathrm{E}-04$ \\
\end{tabular} & $2.23 \mathrm{E}-03$ & $6.52 \mathrm{E}-03$ \\
\hline 1N1E08 & 16 & $\mathbf{W}$ & $30-100$ & Pub. Assem. & 5.05E-04 & \begin{tabular}{|c|}
$6.92 E-04$ \\
\end{tabular} & $8.02 E-04$ & $1.06 \mathrm{E}-03$ & $1.43 \mathrm{E}-03$ & 2.00E-03 \\
\hline 1N1E08 & 17 & $W$ & $30-100$ & Pub. Assem. & 5.05E-04 & $6.92 \mathrm{E}-04$ & 8.02E-04 & 1.06E-03 & 1.43E-03 & $2.00 \mathrm{E}-03$ \\
\hline 1N1E08 & 18 & RM & 0.10 & Commercial & $4.26 \mathrm{E}-05$ & \begin{tabular}{|l|}
$9.36 \mathrm{E}-05$ \\
\end{tabular} & $1.72 \mathrm{E}-04$ & $6.23 \mathrm{E}-04$ & $2.57 \mathrm{E}-03$ & \begin{tabular}{|l|}
$1.10 \mathrm{E}-02$ \\
\end{tabular} \\
\hline 1N1E08 & 19 & $\mathbf{W}$ & $0-10$ & Commercial & $3.88 \mathrm{E}-05$ & \begin{tabular}{|l|}
$5.32 \mathrm{E}-05$ \\
\end{tabular} & $6.17 \mathrm{E}-05$ & \begin{tabular}{|l|}
$7.51 \mathrm{E}-05$ \\
\end{tabular} & \begin{tabular}{|l|}
$9.33 \mathrm{E}-05$ \\
\end{tabular} & $1.22 \mathrm{E}-04$ \\
\hline 1N1E08 & 20 & $W$ & $30-100$ & Pub. Assem. & 5.05E-04 & $6.92 \mathrm{E}-04$ & $8.02 E-04$ & $9.76 \mathrm{E}-04$ & $1.11 \mathrm{E}-03$ & $1.21 \mathrm{E}-03$ \\
\hline 1N1E08 & 21 & $\mathbf{W}$ & $11-30$ & Commercial & $1.55 \mathrm{E}-04$ & \begin{tabular}{|l|}
$2.13 \mathrm{E}-04$ \\
\end{tabular} & \begin{tabular}{|c|}
$2.47 \mathrm{E}-04$ \\
\end{tabular} & \begin{tabular}{|c|}
$3.00 \mathrm{E}-04$ \\
\end{tabular} & $3.73 E-04$ & $4.87 \mathrm{E}-04$ \\
\hline 1N1E08 & 22 & $\overline{C 2}$ & $11-30$ & & $1.78 \mathrm{E}-04$ & 3.21E-04 & $4.58 \mathrm{E}-04$ & E-04 & $2.23 \mathrm{E}-03$ & $6.52 \mathrm{E}-03$ \\
\hline 1N1E08 & 23 & $w$ & & Commercial & 3.88E-05 & $5.32 \mathrm{E}-05$ & $6.17 \mathrm{E}-05$ & 7.51E-05 & $8.56 \mathrm{E}-05$ & 9.34E-05 \\
\hline 1N1E08 & 24 & $\bar{W}$ & 10 & Office & $3.88 \mathrm{E}-05$ & $5.32 \mathrm{E}-05$ & $6.17 \mathrm{E}-05$ & \begin{tabular}{|l|}
$7.51 \mathrm{E}-05$ \\
\end{tabular} & $8.56 \mathrm{E}-05$ & $9.82 \mathrm{E}-05$ \\
\hline 1N1E08 & 25 & $\mathbf{W}$ & $0-10$ & Commercial & 3.88E-05 & \begin{tabular}{|l|}
$5.32 \mathrm{E}-05$ \\
\end{tabular} & $6.17 \mathrm{E}-05$ & \begin{tabular}{|c|}
$8.14 \mathrm{E}-05$ \\
\end{tabular} & $1.10 \mathrm{E}-04$ & $1.54 \mathrm{E}-04$ \\
\hline 1N1E0B & 26 & $\bar{W}$ & $30-100$ & Commercial & $5.05 \mathrm{E}-04$ & $6.92 \mathrm{E}-04$ & $8.02 \mathrm{E}-04$ & \begin{tabular}{|c|}
$9.76 \mathrm{E}-04$ \\
\end{tabular} & $1.21 \mathrm{E}-03$ & $1.58 \mathrm{E}-03$ \\
\hline 1N1E0 & 27 & $\mathrm{C} 2$ & $30-100$ & Commercial & $5.78 \mathrm{E}-04$ & $1.04 \mathrm{E}-03$ & 1.49E-03 & $3.03 \mathrm{E}-03$ & $7.24 \mathrm{E}-03$ & 2.12E-02 \\
\hline 1N1E08 & 28 & $W$ & & Commercial & $1.55 E-04$ & $2.13 \mathrm{E}-04$ & 2.47E-04 & $3.00 \mathrm{E}-04$ & $3.73 E-04$ & $4.87 \mathrm{E}-04$ \\
\hline 1N1EOB & 29 & C2 & $30-100$ & Commercial & $5.78 \mathrm{E}-04$ & $1.04 \mathrm{E}-03$ & $1.49 \mathrm{E}-03$ & $3.03 \mathrm{E}-03$ & $7.24 \mathrm{E}-03$ & $\mid 2.12 \mathrm{E}-02$ \\
\hline
\end{tabular}


RFBEN $-* *$ Modules

Input: The ouput from the DAM-FACT, DAMAGE-\$, LIFELOSS, RETRO- $\$ D$, and RETRO-LL modules, by section.

Processing: The dollar value of building damage avoided and lives saved are determined in accordance with the Retrofit Direct Benefit Model presented in Chapter $v$, for each building in the inventory. The retrofit cost is determined for each building in accordance with the Retrofit Cost Model presented in chapter $v$. There is a separate RFBEN-** module for each PGA value.

Output: A data file, by section, of one line for each building, consisting of sequence number, building type, soil modification factor, structural score, occupancy type, area, retrofit cost, value of damage avoided, and lives saved. This output file contains all the information needed to "stuff" the retrofit data of each building into the regional Building Classification System, the next step.

REGIONAL KETROFIT CLASSIFICATION, PRIORITIZATION, AND OPTIMIZATION MODULES

\section{BCS-RBEN Module}

Input: The output from RFBEN-**, by section.

Processing: The retrofit direct benefits and costs for each building from the RFBEN-** output are summed into a regional Building Classification System (BCS), in 
accordance with the BCS model presented in Chapter VI. The minimum number of building classes required to classify all the buildings in the region are used.

Output: A data file cotaining one line for each building class in the region, with the five BCS indices, total retrofit cost, total value of building damage avoided, and total number of lives saved for each class.

\section{RETRO-BC Module}

Input: The output file from the BCS-RBEN module.

Processing: Total dollar value of retrofit benefit and net benefit values are determined for each building class, in accordance with the scenario earthquake cost-benefit model presented in Chapter VI.

Output: A data file with one line for each building class, with the five BCS indices, total retrofit cost, net benefit, and $B / C$ ratio for each building class. There is a separate run and output file for each scenario PGA event.

\section{EXP-VAL Module}

Input: The output files from RETRO-BC, for a range of scenario PGA values; annual exceedance probabilities for each PGA; discount rate; planning horizon in years.

Processing: The PV, NPV, and $P V / C$ ratios are determined for the range of PGA event values, according to the expected value analysis procedure presented in Ch. VI. 
Output: A data file containing one line for each building class, with the five BCS indices, total retrofit cost, net present value (NPV) of benefit, and PV/C ratio for each building class.

\section{SORT-BC Module}

Input: The output file from the RETRO-BC or EXP-VAL modules.

Processing: The Bullding Classes are prioritized for retrofit by sorting from high to low B/C (or $\mathrm{PV} / \mathrm{C}$ ) ratio, using a selection-sort algorithm.

Output: A file containing one line for each building class, sorted from high to low B/C (or PV/C) ratio, consisting of a retrofit rank number, the five BCS indices, total retrofit cost, net benefit (or NPV), and $B / C$ (or PV/C) ratio for each prioritized building class. There is a separate table for each PGA value in the scenario earthquake event analysis, and one table for the expected value analysis. The TABLE-BC sub-module writes this output file in table form; the tables in Appendix $C$ are examples of the TABLE-BC output.

\section{SYST-EFF Module}

Input: The output file from the SORT-BC module.

Processing: This module calculates a running sum of the retrofit cost and net benefit (or NPV) for each 
prioritized building class.

Output: A file containing one line for each

prioritized building class, consisting of a retrofit rank

number, the five BCS indices, running sum of retrofit cost

and net benefit (or NPV), and aggregate B/C (or PV/C)

ratio. System Efficiency curves in Chapter IX were

plotted from this file. The TABLE-BC Module will write

this output file in Table form. 


\section{EARTHQUAKE LOSS ESTIMATE OF THE PORTLAND, OREGON QUADRANGLE}

The Regional Earthquake Loss and Retrofit Analysis Program (REAL-RAP) Software, which was presented in Chapter VII, was utilized to conduct an earthquake loss estimate of 7,690 non-residential buildings in the Portland, Oregon Quadrangle.

As previously discussed, REAL-RAP and its underlying models are designed to analyze a regional ATC-21 building survey. Therefore, a "test-run" of the methodology and program on an actual survey database is an important part of this research.

$$
\text { NON-RESIDENTIAL BUILDING STOCK DATA }
$$

The test-run of REAL-RAP was made on data taken from the 1993 Portland Seismic Hazards Survey (PSHS-93), conducted by the PSU Civil Engineering Department and the City of Portland Bureau of Buildings. The survey database was discussed in detail in Chapter II.

The number of buildings from the survey used for the analysis are: 


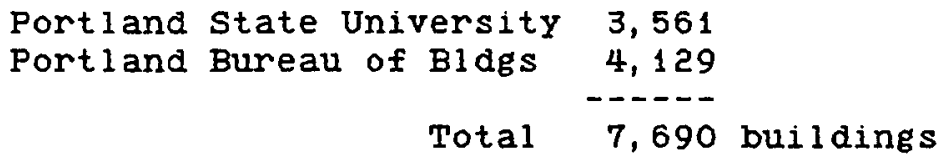

\section{Building Type, Area, and Structural Score}

A summary of the building stock by structure type, including the number of buildings, square footage, and average Structural Score $(S=B S H+E(P M F)+S M F$, using the ATC-21 Moderate Seismicity Scoring system) is shown in Table XLVII, following.

TABLE XLVII

NUMBER OF BUILDINGS, AREA, AND AVERAGE SCORE BY BUILDING TYPE

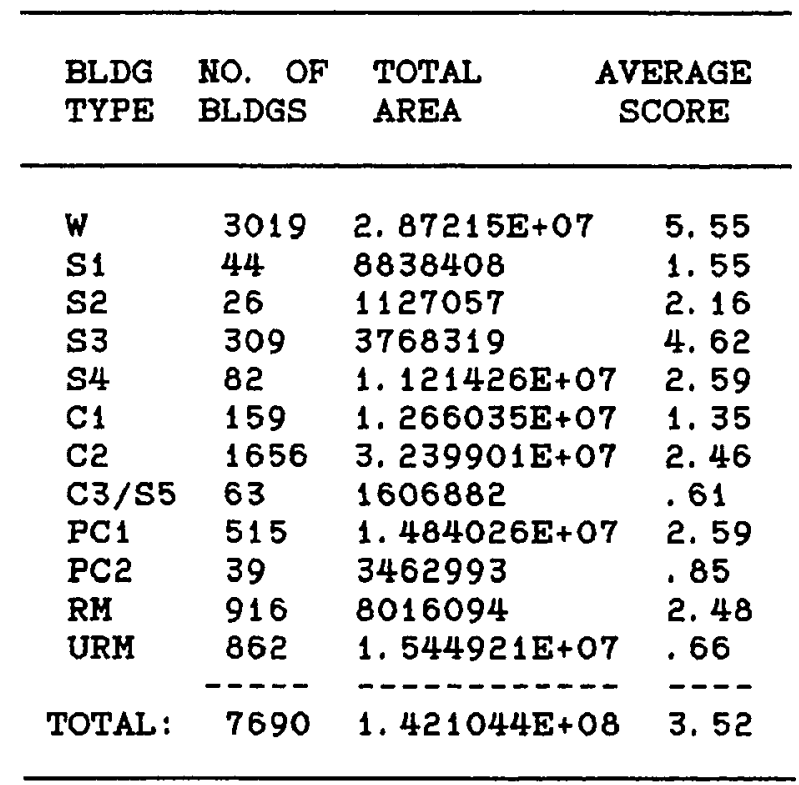

About 12\% of the buildings are URM and C3/S5, which are generally known to be high risk buildings in 
earthquakes. Since very few of these buildings have been retrofit, clearly there is a large hazard in Portland.

The number of buildings in each of five ranges of

structural score are shown in Table XLVIII, following.

\section{TABLE XLVIII}

NUMBER OF BUILDINGS BY RANGE OF STRUCTURAL SCORE (S)

\begin{tabular}{|c|c|c|c|}
\hline SCORE & RANGE & NO. BLDGS & DAMAGE RISK \\
\hline $\begin{array}{ll}0 & t \\
1 & t \\
2 & t\end{array}$ & $\begin{array}{ll}< & 0 \\
\text { to } & 1 \\
\text { to } & 2 \\
\text { to } & 3 \\
> & 3\end{array}$ & $\begin{array}{r}282 \\
725 \\
1,054 \\
1,314 \\
4,315\end{array}$ & $\begin{array}{l}\text { VERY HIGH } \\
\text { HIGH } \\
\text { MODERATE } \\
\text { LOW } \\
\text { VERY LOW }\end{array}$ \\
\hline
\end{tabular}

\section{Soil Modification Factor}

The number of buildings occurring in four ranges of Soil Modification Factor are shown in Table XLIX.

\section{TABLE XLIX}

NUMBER OF BUILDINGS BY RANGE OF SOIL MODIFICATION FACTOR (SMF)

\begin{tabular}{rcl}
\hline SHF RANGE & NO. BLDGS & SOIL HAZARD \\
\hline 0 to -.1 & 9 & LOW \\
-.2 to -.5 & 5,623 & MODERATE \\
-.6 to -.9 & 1,070 & HIGH \\
$<=-1.0$ & 988 & VERY HIGH \\
\hline
\end{tabular}


Table XLIX shows that $27 \%$ of the inventory buildings are in hazardous soil areas.

\section{Occupancy Type and Number of Occupants}

The Lowpoint and Midpoint of the range of number of people in the buildings have been summed by occupancy Type, and presented in Table $L$, following.

TABLE L

LOWPOINT AND MIDPOINT OF RANGE OF NUMBER OF PEOPLE AND NUMBER OF BUILDINGS BY OCCUPANCY TYPE

\begin{tabular}{lrrr}
\hline & & \multicolumn{2}{c}{ RANGE OF NO. PEOPLE } \\
$\begin{array}{l}\text { OCCUPANCY } \\
\text { TYPE }\end{array}$ & $\begin{array}{l}\text { NO. OF } \\
\text { BLDGS }\end{array}$ & $\begin{array}{c}- \\
\text { LOWPOINT }\end{array}$ & MIDPOINT \\
\hline Residential & 1,859 & 42,904 & 107,575 \\
Commercial & 2,229 & 41,263 & 96,595 \\
Office & 1,049 & 56,340 & 131,085 \\
Industrial & 1,899 & 26,384 & 60,965 \\
Pub. Assem. & 281 & 51,714 & 94,970 \\
School & 156 & 27,240 & 69,850 \\
Govt. Bldg. & 150 & 11,090 & 25,125 \\
Emer. Serv. & 36 & 4,927 & 11,125 \\
Historic Bl dg & 31 & 11,462 & 17,960 \\
& ---- & ----- & ----- \\
TOTAL: & 7,690 & 273,324 & 615,250 \\
\hline
\end{tabular}

The number of people range Midpoint, from the field survey data, represents the field inspectors judgement on the number of people that are likely to be in a building when it is in "full use." Since it is not probable that all the buildings in the inventory will at full use at the 
same time, the Lowpoint is useful in studying an aggregate value of occupancy at a lower level.

Judgement points in the direction of looking at a number of people ranging, at "full use," somewhere between the Lowpoint and Midpoint values.

LOSS ESTIMATES FOR FOUR SCENARIO EARTHQUAKE EVENTS

Losses for the 7,690 non-residential buildings in the Portland Quadrangle were determined by REAL-RAP for six values of PGA, four of which are presented in Tables LI through LIV, following. The PGA values input and corresponding return periods are:

PGA RETURN

$\begin{array}{ll}.08 & 100 \text { year } \\ .20 & 500 \text { year } \\ .27 & 1,000 \text { year } \\ .39 & 2,500 \text { year }\end{array}$

"Scenario Earthquake Event" means that the losses shown are the full losses from the model for that PGA. The return times are not used in this estimate, and are shown here for reference only.

The average damage factor, dollar value of building damage, and loss of 1 ife is shown by Building Type for each PGA event. The loss of life shown was determined from the Midpoint of the range of Number of People from the inventory. 
TABLE LI

SUMMARY OF LOSSES FOR THE PORTLAND QUAD
AT PGA $=.08$ (100 YEAR RETURN)

\begin{tabular}{lllc}
\hline $\begin{array}{l}\text { BLDG } \\
\text { TYFE }\end{array}$ & $\begin{array}{c}\text { AVERAGE } \\
\text { DF }\end{array}$ & $\begin{array}{l}\text { TOTAL } \\
\text { DAMAGE }\end{array}$ & $\begin{array}{c}\text { TOT LOSS } \\
\text { OF LIFE }\end{array}$ \\
\hline W & 3.59 & $\$ 8.612823 \mathrm{E}+07$ & 1.0 \\
S1 & 4.99 & $\$ 3.687408 \mathrm{E}+07$ & .6 \\
S2 & 2.97 & $\$ 2325002$ & .1 \\
S3 & 2.2 & $\$ 5219876$ & .1 \\
S4 & 6.11 & $\$ 5.246866 \mathrm{E}+07$ & .9 \\
C1 & 14.6 & $\$ 1.577566 \mathrm{E}+08$ & 1480.3 \\
C2 & 5.74 & $\$ 1.447749 \mathrm{E}+08$ & 14.3 \\
C3/S5 & 23.5 & $\$ 4.725515 \mathrm{E}+07$ & 748.1 \\
PC1 & 10.62 & $\$ 1.164073 \mathrm{E}+08$ & 253.0 \\
PC2 & 7.99 & $\$ 3.070333 \mathrm{E}+07$ & 12.8 \\
RM & 6.73 & $\$ 6.021686 \mathrm{E}+07$ & 324.4 \\
URM & 31 & $\$ 4.58262 \mathrm{E}+08$ & 3009.1 \\
\hline TOTAL: & 8.36 & $\$ 1.198392 \mathrm{E}+09$ & 5844.7 \\
\hline & & &
\end{tabular}




\section{TABLE LII}

SUMMARY OF LOSSES FOR THE PORTLAND QUAD AT PGA $=.20$ (500 YEAR RETURN)

\begin{tabular}{lllc}
\hline $\begin{array}{l}\text { BLDG } \\
\text { TYPE }\end{array}$ & $\begin{array}{c}\text { AVERAGE } \\
\text { DF }\end{array}$ & $\begin{array}{l}\text { TOTAL } \\
\text { DAMAGE }\end{array}$ & $\begin{array}{c}\text { TOT LOSS } \\
\text { OF LIFE }\end{array}$ \\
\hline W & 7.84 & $\$ 1.885347 \mathrm{E}+08$ & 1.7 \\
S1 & 13.69 & $\$ 1.136741 \mathrm{E}+08$ & 245.3 \\
S2 & 6.68 & $\$ 5515891$ & .1 \\
S3 & 5.16 & $\$ 1.221718 \mathrm{E}+07$ & .1 \\
S4 & 14.19 & $\$ 1.212542 \mathrm{E}+08$ & 2.1 \\
C1 & 42.85 & $\$ 4.536644 \mathrm{E}+08$ & 2956.3 \\
C2 & 13.78 & $\$ 3.715052 \mathrm{E}+08$ & 274.5 \\
C3/S5 & 67.05 & $\$ 9.602283 \mathrm{E}+07$ & 1937.5 \\
PC1 & 25.29 & $\$ 2.734362 \mathrm{E}+08$ & 281.7 \\
PC2 & 22.47 & $\$ 7.244 \mathrm{E}+07$ & 16.7 \\
RM & 16.78 & $\$ 1.169726 \mathrm{E}+08$ & 282.1 \\
URM & 69.75 & $\$ 8.686221 \mathrm{E}+08$ & 6998.4 \\
\hline TOTAL: & 19.57 & $\$ 2.693859 \mathrm{E}+09$ & 12996.5 \\
\hline
\end{tabular}




\section{TABLE LIII}

SUMMARY OF LOSSES FOR THE PORTLAND QUAD AT PGA $=.27(1,000$ YEAR RETURN)

\begin{tabular}{lllc}
\hline $\begin{array}{l}\text { BLDG } \\
\text { TYPE }\end{array}$ & $\begin{array}{c}\text { AVERAGE } \\
\text { DF }\end{array}$ & $\begin{array}{l}\text { TOTAL } \\
\text { DAMAGE }\end{array}$ & $\begin{array}{l}\text { TOT LOSS } \\
\text { OF LIFE }\end{array}$ \\
\hline W & 9.859999 & $\$ 2.373614 \mathrm{E}+08$ & 2.9 \\
S1 & 24.91 & $\$ 2.159162 \mathrm{E}+08$ & 562.3 \\
S2 & 8.399999 & $\$ 7023393$ & .1 \\
S3 & 6.74 & $\$ 1.59657 \mathrm{E}+07$ & .1 \\
S4 & 17.05 & $\$ 1.441428 \mathrm{E}+08$ & 3.0 \\
C1 & 56.23 & $\$ 6.180308 \mathrm{E}+08$ & 4995.8 \\
C2 & 18.43 & $\$ 4.986351 \mathrm{E}+08$ & 312.1 \\
C3/S5 & 74.61 & $\$ 1.005628 \mathrm{E}+08$ & 1457.3 \\
PC1 & 33.22 & $\$ 3.620145 \mathrm{E}+08$ & 630.6 \\
PC2 & 40.14 & $\$ 1.392571 \mathrm{E}+08$ & 137.6 \\
RM & 24.02 & $\$ 1.677315 \mathrm{E}+08$ & 600.8 \\
URM & 79.84 & $\$ 9.71185 \mathrm{E}+08$ & 9279.2 \\
\hline TOTAL: & 24.48 & $\$ 3.477826 \mathrm{E}+09$ & 17981.8 \\
\hline
\end{tabular}




\section{TABLE LIV}

SUMMARY OF LOSSES FOR THE PORTLAND QUAD AT PGA $=.39 \quad(2,500$ YEAR RETURN)

\begin{tabular}{lllc}
\hline $\begin{array}{l}\text { BLDG } \\
\text { TYPE }\end{array}$ & $\begin{array}{c}\text { AVERAGE } \\
\text { DF }\end{array}$ & $\begin{array}{l}\text { TOTAL } \\
\text { DAMAGE }\end{array}$ & $\begin{array}{c}\text { TOT LOSS } \\
\text { OF LIFE }\end{array}$ \\
\hline W & 12.91 & $\$ 3.116605 \mathrm{E}+08$ & 142.7 \\
S1 & 31.66 & $\$ 2.827823 \mathrm{E}+08$ & 808.8 \\
S2 & 10.66 & $\$ 9112080$ & .1 \\
S3 & 9.310001 & $\$ 2.207283 \mathrm{E}+07$ & .1 \\
S4 & 22.7 & $\$ 1.892474 \mathrm{E}+08$ & 8.6 \\
C1 & 71.75 & $\$ 7.405977 \mathrm{E}+08$ & 6361.9 \\
C2 & 27.58 & $\$ 7.669451 \mathrm{E}+08$ & 918.6 \\
C3/S5 & 84.61 & $\$ 1.106024 \mathrm{E}+08$ & 2124.8 \\
PC1 & 42.91 & $\$ 4.678059 \mathrm{E}+08$ & 931.0 \\
PC2 & 61.93 & $\$ 1.763162 \mathrm{E}+08$ & 375.6 \\
RH & 36.44 & $\$ 2.435513 \mathrm{E}+08$ & 1624.9 \\
URM & 87.14 & $\$ 1.037381 \mathrm{E}+09$ & 9460.2 \\
\hline TOTAL: & 31.31 & $\$ 4.358074 \mathrm{E}+09$ & 22757.3 \\
\hline
\end{tabular}


LOSS ESTIMATES FOR THE DESIGN BASIS EARTHQUAKE

The Design Basis Earthquake (DBE) is defined as the PGA with a $10 \%$ chance of exceedance in 50 years. This definition has become the national standard for establishing design criteria for new structures (Building Seismic Safety Council 1988). Therefore, the losses found for the DBE are the most important of the earthquake losses determined in this study.

\section{Damage and Loss of Life by Structure Type}

The loss summary by structure type for the DBE, of $P G A=.20$ (Table LII), is repeated below for the convenience of the reader.

As previously discussed, these losses were determined using the Midpoint of the Number of People range, considering all the buildings being in "full use." For this inventory, "full use" would be during regular business hours, Monday - Friday, 8:00 to 5:00. 
TABLE LII

SUMMARY OF LOSSES FOR THE PORTLAND QUAD

$A T$ PGA $=.20$ (500 YEAR RETURN)

\begin{tabular}{lllr}
\hline $\begin{array}{l}\text { BLDG } \\
\text { TYPE }\end{array}$ & $\begin{array}{c}\text { AVERAGE } \\
\text { DF }\end{array}$ & $\begin{array}{l}\text { TOTAL } \\
\text { DAMAGE }\end{array}$ & $\begin{array}{r}\text { TOT LOSS } \\
\text { OF LIFE }\end{array}$ \\
\hline W & 7.84 & $\$ 1.885347 \mathrm{E}+08$ & 1.7 \\
S1 & 13.69 & $\$ 1.136741 \mathrm{E}+08$ & 245.3 \\
S2 & 6.68 & $\$ 5515891$ & .1 \\
S3 & 5.16 & $\$ 1.221718 \mathrm{E}+07$ & .1 \\
S4 & 14.19 & $\$ 1.212542 E+08$ & 2.1 \\
C1 & 42.85 & $\$ 4.536644 E+08$ & 2956.3 \\
C2 & 13.78 & $\$ 3.715052 E+08$ & 274.5 \\
C3/S5 & 67.05 & $\$ 9.602283 E+07$ & 1937.5 \\
PC1 & 25.29 & $\$ 2.734362 E+08$ & 281.7 \\
PC2 & 22.47 & $\$ 7.244 E+07$ & 16.7 \\
RM & 16.78 & $\$ 1.169726 E+08$ & 282.1 \\
URM & 69.75 & $\$ 8.686221 E+08$ & 6998.4 \\
\hline & & & \\
TOTAL: & 19.57 & $\$ 2.693859 E+09$ & 12996.5 \\
\hline
\end{tabular}

Table LII shows that most of the loss of life is attributable to three building types, as follows:

$$
\begin{array}{ll}
\text { LOSS OF } & \text { \% OF } \\
\text { LIFE } & \text { TOTAL }
\end{array}
$$

$\begin{array}{lrr}\text { URM } & 6,998 & 53.8 \% \\ \text { C1 } & 2,956 & 22.7 \% \\ \text { C3/S5 } & 1,937 & 14.9 \% \\ & -11,891 & 91.4 \%\end{array}$




\section{Total Dollar Value of Loss}

The Value of Life (VOL) adopted for use in Chapter VI, which also accounts for accompanying serious injuries, was $\$ 2,250,000$. Based on this, the total dollar value of building damage, loss of 1 ife, and serious injury for the DBE is:

$$
\begin{aligned}
& \text { Damage, from Table VIII-VI }=\$ 2.69 \mathrm{G}(8.4 \%) \\
& \text { Casualties: } 12,996 * \$ 2.25 \mathrm{M}=\$ 29.24 \mathrm{G}(91.6 \%) \\
& \$ 31.93 \mathrm{G} \quad(100 \%)
\end{aligned}
$$

Since more than $90 \%$ of the value of the loss is from the loss of life, loss of 31 fe can be expected to be the critical factor in retrofit planning.

\section{Loss of Life by Structural Score}

The loss of life by Structural score range is shown in Table LV, following:

TABLE LV

\begin{tabular}{|c|c|c|}
\hline $\begin{array}{l}\text { STRUCTURAL } \\
\text { SCORE RANGE }\end{array}$ & $\begin{array}{l}\text { LOSS OF LIFE } \\
\text { (MIDPOINT) }\end{array}$ & DAMLAGE RISK \\
\hline $\begin{array}{rrr} & < & 0 \\
0 & \text { to } & 1 \\
1 & \text { to } & 2 \\
2 & \text { to } & 3 \\
& > & 3\end{array}$ & $\begin{array}{r}7,973 \\
5,006 \\
10 \\
3 \\
3\end{array}$ & $\begin{array}{l}\text { VERY HIGH } \\
\text { HIGH } \\
\text { MODERATE } \\
\text { LOW } \\
\text { VERY LOW }\end{array}$ \\
\hline
\end{tabular}

LOSS OF LIFE BY RANGE OF STRUCTURAL SCORE (S) 
Table LV shows clearly that virtually $100 \%$ of the loss of life occurs in buildings with a structural Score of 1 or less.

Loss of Life by Soil Modification Factor

The loss of life occurring in four ranges of Soil Modification Factor are shown in Table LVI, following:

TABLE LVI

LOSS OF LIFE BY RANGE OF SOIL MODIFICATION FACTOR (SMF)

\begin{tabular}{rcl}
\hline SMF RANGE & $\begin{array}{c}\text { LOSS OF LIFE } \\
\text { (MIDPOINT) }\end{array}$ & $\begin{array}{c}\text { SOIL } \\
\text { HAZARD }\end{array}$ \\
\hline 0 to -.1 & 0 & LOW \\
-.2 to -.5 & 7,542 & LOW \\
-.6 to -.9 & 3,651 & HIGH \\
$<=-1.0$ & 1,802 & HIGH \\
\hline
\end{tabular}

Table LVI appears to show that soil conditions do not have a statisticaliy large impact on the distribution of loss of life in the Portland Quad.

\section{Loss of Life by Number of People}

As previously mentioned, the loss of life in Table LII was determined using the Midpoint of the Number of People Range.

To study the effect on the loss of life of the surveyed range of number of people, REAL-RAP was re-run 
for the inventory using the Lowpoint Number of the range. The loss of life for both the Lowpoint and Midpoint is shown by Occupancy Type in Table LVII, following.

\section{TABLE LVII}

LOSS OF LIFE BY LOWPOINT AND MIDPOINT OF NUMBER OF PEOPLE RANGE, BY OCCUPANCY TYPE

\begin{tabular}{lcc}
\hline & LOSS OF LIFE FOR \\
$\begin{array}{l}\text { OCCUPANCY } \\
\text { TYPE }\end{array}$ & LOWPOINT & MIDPOINT \\
\hline & & \\
Residential & 661 & 1,734 \\
Commercial & 1,306 & 2,902 \\
Office & 1,264 & 3,229 \\
Industrial & 384 & 898 \\
Pub. Assem. & 412 & 1,042 \\
Schoo1 & 760 & 1,914 \\
Govt. Bldg. & 178 & 467 \\
Emer. Serv. & 104 & 257 \\
Historic Bldg & 225 & 552 \\
TOTAL: & $--1,--$ & $---1--$ \\
& 5,294 & 12,995 \\
\hline
\end{tabular}

Comparison of Tables LII and LVII shows that the loss of life is proportionate to the number of people occupying the buildings.

Based on the preceding discussion on the range of the total number of people, it is concluded that the methodology estimates a range of loss of life: from 5, 294 to 12,995 . 


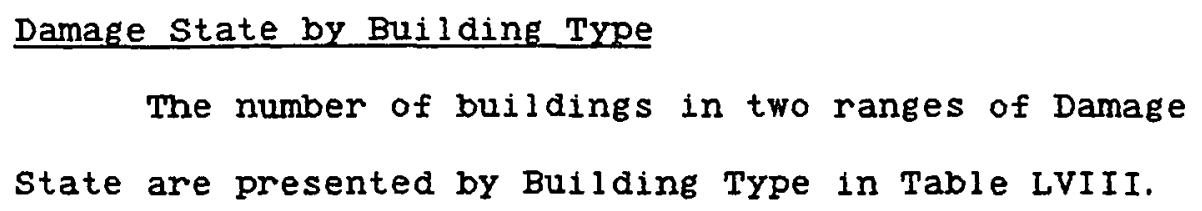

\begin{tabular}{lrr} 
& \multicolumn{2}{c}{ DAMAGE FACTOR $(\mathrm{DF})$} \\
BLDG & $100 \%$ & $50 \%$ TO $99 \%$ \\
TYPE & & \\
& & 0 \\
S1 & 0 & 0 \\
S2 & 1 & 0 \\
S3 & 0 & 0 \\
S4 & 0 & 0 \\
C1 & 0 & 21 \\
C2 & 25 & 4 \\
C3/S5 & 3 & 15 \\
PC1 & 20 & 40 \\
PC2 & 1 & 4 \\
RH & 17 & 26 \\
URM & 410 & 182 \\
TOTAL: & --- & -- \\
& 508 & 292 \\
\hline
\end{tabular}

The percentage of buildings in the inventory in these two damage states is:

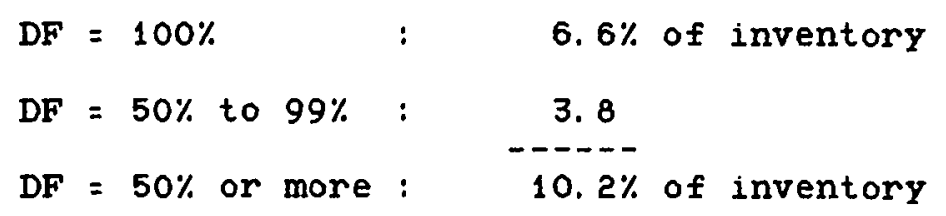


major damage states, near DF $=100$ ) in the Portland Quad inventory is taking place in about $10 \%$ of the buildings.

\section{Comparison to Kobe City Earthquake of 1995}

The 1995 Kobe City earthquake has potential for comparison to a DBE earthquake in Portland, owing to the following similarities:

1. Kobe and Portland are cities of comparable size.

2. The 1995 event was considered a "moderate" earthquake, Richter Magnitude 6.8

3. Both Kobe and Portland are "modern" cities, but historically lacking in stringent seismic design requirements for buildings such as would be found in California.

A comparison of buildings in major damage states from the present study, with that reported by Comartin et al (1995) for Kobe, is summarized in Table LIX, following.

TABLE LIX

DAMAGE STATE COMPARISON TO KOBE CITY 1995 EARTHQUAKE

\begin{tabular}{|c|c|c|}
\hline $\begin{array}{l}\text { DAMAGE } \\
\text { STATE }\end{array}$ & \% OF BLDGS IN & $\begin{array}{c}\text { DAMAGE STATE } \\
\text { Kobe City }\end{array}$ \\
\hline $\begin{array}{l}100 \% \\
50 \% \text { to } 99 \%\end{array}$ & $\begin{array}{l}6.6 \% \\
3.8 \%\end{array}$ & $\begin{array}{l}\text { 4. } 9 \% \\
7.7 \%\end{array}$ \\
\hline $50 \%$ or more & 10. $2 \%$ & 12. $6 \%$ \\
\hline
\end{tabular}


Table LIX indicates that the percentage of buildings shown by REAL-RAP to be in major damage states is comparable to the Kobe City earthquake.

\section{Losses Attributable to the Performance Modifiers}

In order to study the effect of the Performance Modifiers, a version of REAL-RAP was run which used the SMF as usual, but set $\Sigma(P M F)=0$ for all buildings in the inventory. The effect of the Performance Modifiers is shown in Table LX, following.

TABLE LX

BUILDING DAMAGE AND LOSS OF LIFE ATTRIBUTABLE TO PERFORMANCE MODIFIERS

\begin{tabular}{lccr}
\hline & $\begin{array}{c}\text { AVERAGE } \\
\text { DF }\end{array}$ & $\begin{array}{c}\text { TOT BLDG } \\
\text { DAMAGE }\end{array}$ & $\begin{array}{c}\text { LOSS OF } \\
\text { LIFE }\end{array}$ \\
\hline From Table VIII-VI & 19.57 & $\$ 2.69 \mathrm{G}$ & 12,996 \\
With $\Sigma($ PMF) $=0$ & 11.85 & $\$ 1.39 \mathrm{G}$ & 477 \\
\hdashline Attributed to $\Sigma($ PMF) & 7.72 & $\$ 1.30 \mathrm{G}$ & \begin{tabular}{c}
$\$ 2,519$ \\
\hline
\end{tabular} \\
\hline
\end{tabular}

Table LX shows that loss estimates which are based on "average" structures only, without Performance Modifiers taken into account, seriously underestimate the losses, especially the loss of life. 


\section{CHAPTER IX}

RETROFIT ANALYSIS OF THE PORTLAND, OREGON QUADRANGLE

The Regional Earthquake Loss and Retrofit Analysis Program (REAL-RAP) was utilized to conduct a retrofit analysis of the 7,690 buildings in the Portland, Oregon Quadrangle. The building inventory used and losses to be mitigated are the same as those presented previously in Chapter VIII, using the midpoint of the number of people range (except as noted in the following).

Five retrofit analyses were made in this study:

1. For four Scenario Earthquake Events, the reduced losses resulting from a Full Retrofit (where all buildings in the inventory are retrofit) are analyzed and presented.

2. For a Design Basis Earthquake, a cost-benefit and system efficiency analysis was made, to determine an Optimal Retrofit Program. This is then compared to the Full Retrofit.

3. The sensitivity of the optimal retrofit program to the number of people and to the dollar value of life was analyzed. This was done by determining two alternate optimal retrofit. programs: 1) using the lowpoint of the number 
of people range, and 2) using about $25 \%$ of the dollar value of life.

4. An Expected Value cost-benefit and system efficiency analysis was made, as an alternate determination of an Optimal Retrofit Program. This program is compared to the DBE-based Optimal Retrofit Program.

\title{
POST-RETROFIT EARTHQUAKE LOSS ESTIMATES FOR FOUR SCENARIO EARTHQUARE EVENTS FOLLOWING FULL RETROFIT
}

\begin{abstract}
Post-retrofit losses were determined for the Portland Quad inventory, based on $100 \%$ of the buildings having been retrofit. This is not an "efficient" retrofit program, but is an excercise to determine the maximum mitigation attainable, according to the retrofit model. The same four PGA scenarios run in Chapter VIII are presented for the post-retrofit buildings, in Tables LXI through LXIV, following. The average damage factor, dollar value of building damage, and loss of life is shown by building type for each PGA event. The loss of life shown was determined from the Midpoint of the range of Number of People from the inventory.
\end{abstract}


TABLE LXI

SUMMARY OF LOSSES FOR THE PORTLAND QUAD IF ALL BLDGS ARE RETROFIT AT PGA $=.08$ (100 YEAR RETURN)

\begin{tabular}{llll}
\hline $\begin{array}{l}\text { BLDG } \\
\text { TYPE }\end{array}$ & $\begin{array}{c}\text { AVERAGE } \\
\text { DF }\end{array}$ & $\begin{array}{l}\text { TOTAL } \\
\text { DAMAGE }\end{array}$ & $\begin{array}{l}\text { TOT LOSS } \\
\text { OF LIFE }\end{array}$ \\
\hline W & 2.59 & $\$ 6.096544 \mathrm{E}+07$ & .9 \\
S1 & 3.3 & $\$ 2.430852 \mathrm{E}+07$ & .5 \\
S2 & 1.96 & $\$ 1581728$ & .0 \\
S3 & 1.66 & $\$ 3910518$ & .1 \\
S4 & 4.38 & $\$ 3.848339 \mathrm{E}+07$ & .8 \\
C1 & 9.7 & $\$ 1.052362 \mathrm{E}+08$ & 40.9 \\
C2 & 3.67 & $\$ 9.203788 \mathrm{E}+07$ & 1.5 \\
C3/S5 & 14.19 & $\$ 2.852689 \mathrm{E}+07$ & 12.4 \\
PC1 & 6.4 & $\$ 6.690674 \mathrm{E}+07$ & 1.7 \\
PC2 & 5.13 & $\$ 1.924749 \mathrm{E}+07$ & .3 \\
RM & 4.86 & $\$ 4.307256 \mathrm{E}+07$ & 15.2 \\
URH & 15.7 & $\$ 2.316 \mathrm{E}+08$ & 18.5 \\
\hline TOTAL: & 5.06 & $\$ 7.158775 \mathrm{E}+08$ & 92.8 \\
\hline
\end{tabular}


TABLE LXII

SUMMARY OF LOSSES FOR THE PORTLAND QUAD IF ALL BLDGS ARE RETROFIT AT PGA $=.20$ (500 YEAR RETURN)

\begin{tabular}{lllc}
\hline $\begin{array}{l}\text { BLDG } \\
\text { TYPE }\end{array}$ & $\begin{array}{c}\text { AVERAGE } \\
\text { DF }\end{array}$ & $\begin{array}{l}\text { TOTAL } \\
\text { DAMAGE }\end{array}$ & $\begin{array}{c}\text { TOT LOSS } \\
\text { OF LIFE }\end{array}$ \\
\hline W & 5.68 & $\$ 1.337343 \mathrm{E}+08$ & 1.2 \\
S1 & 9.399999 & $\$ 7.760756 \mathrm{E}+07$ & 9.4 \\
S2 & 4.62 & $\$ 4027448$ & .1 \\
S3 & 3.74 & $\$ 8810041$ & .1 \\
S4 & 10.21 & $\$ 8.830522 \mathrm{E}+07$ & 1.4 \\
C1 & 29.29 & $\$ 3.1122 \mathrm{E}+08$ & 111.4 \\
C2 & 9 & $\$ 2.408885 \mathrm{E}+08$ & 8.1 \\
C3/S5 & 42.16 & $\$ 6.037205 \mathrm{E}+07$ & 40.9 \\
PC1 & 15.21 & $\$ 1.591369 \mathrm{E}+08$ & 3.3 \\
PC2 & 14.62 & $\$ 4.671833 \mathrm{E}+07$ & .6 \\
RH & 12.36 & $\$ 8.614131 \mathrm{E}+07$ & 18.6 \\
URM & 37.61 & $\$ 4.684373 \mathrm{E}+08$ & 61.4 \\
\hline TOTAL: & 12.23 & $\$ 1.685399 \mathrm{E}+09$ & 256.5 \\
\hline
\end{tabular}


TABLE LXI I I

SUMMARY OF LOSSES FOR THE PORTLAND QUAD IF ALL BLDGS

ARE RETROFIT AT PGA $=.27(1,000$ YEAR RETURN)

\begin{tabular}{llll}
\hline $\begin{array}{l}\text { BLDG } \\
\text { TYPE }\end{array}$ & $\begin{array}{c}\text { AVERAGE } \\
\text { DF }\end{array}$ & $\begin{array}{l}\text { TOTAL } \\
\text { DAMAGE }\end{array}$ & $\begin{array}{l}\text { TOT LOSS } \\
\text { OF LIFE }\end{array}$ \\
\hline W & 7.16 & $\$ 1.686144 E+08$ & 1.5 \\
S1 & 17.37 & $\$ 1.497794 \mathrm{E}+08$ & 25.9 \\
S2 & 5.93 & $\$ 5263660$ & .1 \\
S3 & 4.77 & $\$ 1.123457 \mathrm{E}+07$ & .1 \\
S4 & 12.49 & $\$ 1.077262 \mathrm{E}+08$ & 1.8 \\
C1 & 39.08 & $\$ 4.304779 \mathrm{E}+08$ & 206.0 \\
C2 & 12.13 & $\$ 3.265227 \mathrm{E}+08$ & 11.3 \\
C3/S5 & 47.88 & $\$ 6.45393 \mathrm{E}+07$ & 38.2 \\
PC1 & 20.13 & $\$ 2.136936 \mathrm{E}+08$ & 7.1 \\
PC2 & 26.09 & $\$ 9.021271 \mathrm{E}+07$ & 3.7 \\
RH & 17.96 & $\$ 1.25342 \mathrm{E}+08$ & 43.2 \\
URM & 44.53 & $\$ 5.416366 \mathrm{E}+08$ & 94.4 \\
\hline TOTAL: & 15.68 & $\$ 2.235043 \mathrm{E}+09$ & 433.3 \\
\hline
\end{tabular}


TABLE LXIV

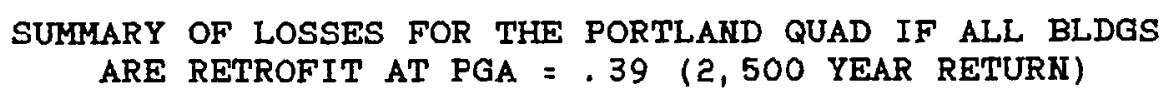

\begin{tabular}{lllc}
\hline $\begin{array}{l}\text { BLDG } \\
\text { TYPE }\end{array}$ & $\begin{array}{c}\text { AVERAGE } \\
\text { DF }\end{array}$ & $\begin{array}{l}\text { TOTAL } \\
\text { DAMAGE }\end{array}$ & $\begin{array}{l}\text { TOT LOSS } \\
\text { OF LIFE }\end{array}$ \\
\hline W & 9.359999 & $\$ 2.205176 \mathrm{E}+08$ & 5.4 \\
S1 & 22.74 & $\$ 2.019095 \mathrm{E}+08$ & 54.7 \\
S2 & 7.82 & $\$ 7105022$ & .1 \\
S3 & 6.4 & $\$ 1.512223 \mathrm{E}+07$ & .1 \\
S4 & 16.86 & $\$ 1.428168 \mathrm{E}+08$ & 3.2 \\
C1 & 51.24 & $\$ 5.299333 \mathrm{E}+08$ & 323.7 \\
C2 & 18.49 & $\$ 5.129665 \mathrm{E}+08$ & 38.2 \\
C3/S5 & 55.97 & $\$ 7.316269 \mathrm{E}+07$ & 63.0 \\
PC1 & 26.65 & $\$ 2.84768 \mathrm{E}+08$ & 13.7 \\
PC2 & 41.19 & $\$ 1.172277 \mathrm{E}+08$ & 12.3 \\
RH & 27.89 & $\$ 1.863266 \mathrm{E}+08$ & 139.7 \\
URY & 51.01 & $\$ 6.072673 \mathrm{E}+08$ & 131.6 \\
\hline TOTAL: & 20.8 & $\$ 2.899124 \mathrm{E}+09$ & 785.7 \\
\hline
\end{tabular}


DEVELOPMENT OF AN OPTIMAL RETROFIT PROGRAM FOR THE DESIGN BASIS EARTHQUAKE

The Design Basis Earthquake (DBE) is defined as the PGA with a $10 \%$ chance of exceedance in 50 years. This is the same as a return of 500 years, which is $\mathrm{PGA}=.20$. The sumnary of losses at $P G A=.20$ if all the buildings are retrofit (Table LXII) is repeated below.

TABLE LXII

SUMMARY OF LOSSES FOR THE PORTLAND QUAD IF ALL BLDGS ARE RETROFIT AT PGA $=.20$ (500 YEAR RETURN)

\begin{tabular}{lllr}
\hline $\begin{array}{l}\text { BLDG } \\
\text { TYPE }\end{array}$ & $\begin{array}{l}\text { AVERAGE } \\
\text { DF }\end{array}$ & $\begin{array}{l}\text { TOTAL } \\
\text { DAMAGE }\end{array}$ & $\begin{array}{l}\text { TOT LOSS } \\
\text { OF LIFE }\end{array}$ \\
\hline W & 5.68 & $\$ 1.337343 E+08$ & 1.2 \\
S1 & $9.399999 \$ 7.760756 E+07$ & 9.4 \\
S2 & 4.62 & $\$ 4027448$ & .1 \\
S3 & 3.74 & $\$ 8810041$ & .1 \\
S4 & 10.21 & $\$ 8.830522 E+07$ & 1.4 \\
C1 & 29.29 & $\$ 3.1122 E+08$ & 111.4 \\
C2 & 9 & $\$ 2.408885 E+08$ & 8.1 \\
C3/S5 & 42.16 & $\$ 6.037205 E+07$ & 40.9 \\
PC1 & 15.21 & $\$ 1.591369 E+08$ & 3.3 \\
PC2 & 14.62 & $\$ 4.671833 E+07$ & .6 \\
RH & 12.36 & $\$ 8.614131 E+07$ & 18.6 \\
URH & 37.61 & $\$ 4.684373 E+08$ & 61.4 \\
& & & \\
\hline & & & \\
TOTAL: & 12.23 & $\$ 1.685399 E+09$ & 256.4 \\
\hline
\end{tabular}

Total Value of Retrofit Benefits

The effectiveness of retrofitting all buildings is summarized in Table LxV, following. 
TABLE LXV

EFFECT OF RETROFITTING ALL BUILDINGS

\begin{tabular}{lll}
\hline & $\begin{array}{l}\text { BEFORE } \\
\text { RETROFIT }\end{array}$ & $\begin{array}{l}\text { ALL BLDGS } \\
\text { RETROFIT }\end{array}$ \\
\hline Average DF & $\begin{array}{l}19.57 \\
2.69 \mathrm{G}\end{array}$ & $\begin{array}{l}12.23 \\
1.69 \mathrm{G} \\
256\end{array}$ \\
$\begin{array}{l}\text { Tot Bldg Damage } \\
\text { Tot Loss of Life }\end{array}$ & 12,996 & \begin{tabular}{l}
$\$ 2.996$ \\
\hline
\end{tabular} \\
\hline
\end{tabular}

Table LXV shows that $98 \%$ of the loss of 1 ife and $37 \%$ of the building damage is mitigated by retrofitting all the buildings.

The total benefit of retrofitting all the buildings, based on the Value of Life (VOL) used previously, is:

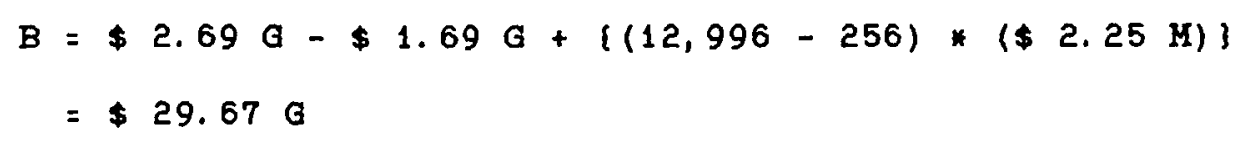

\section{Retrofit Prioritization by Building Class}

The Retrofit Group of program modules in REAL-RAP was used to place all the buildings in the inventory in a Bullding Class, determine the direct benefits and costs of retrofit for each Bullding Class, and prioritize the Bullding $\mathrm{Classes}$ by $\mathrm{B} / \mathrm{C}$ ratio.

The prioritized list of Building Classes is shown in Appendix $C$. In Appendix $C$, the first column is the ranking of the Bullding $C l a s s$ by $B / C$ ratio. The next five columns are the indices which identify the Building 
Class (STG, SHZ, SSR, OTG, and BSG). The last three columns are the total retrofit fit cost and net benefit of all the buildings in that class, and the $B / C$ ratio for that class.

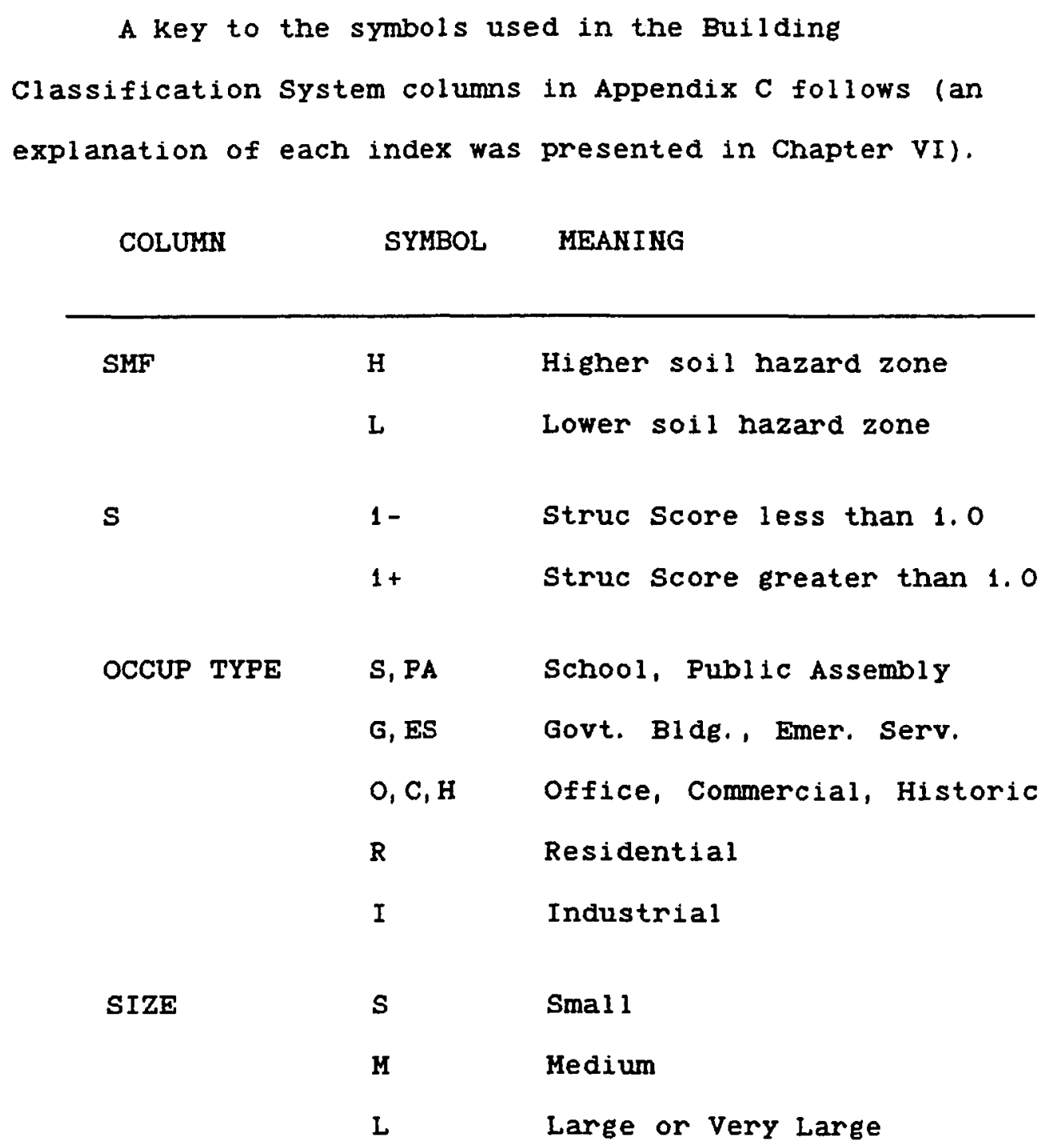


From Appendix $C$, it can be seen that 284 Building Classes (of a possible 540) are used to classify all the buildings in the inventory.

\section{System Efficiency}

The maximum $B / C$ ratio is 982 . The first $B / C$ less than 1.0 occurs at R/F Rank number 86. This is also where the Net Benefit becomes negative.

Therefore, the point of maximum efficiency, where system net benefit is maximized, occurs at retrofit Rank number 85. This marks the point of Optimum Retrofit Investment, and is identified in the retrofit prioritization of Appendix C.

A running sum of the costs and benefits was made from Appendix C. From the running sum, a System Efficiency Curve was made (Fig. 44). The System Efficiency Curve shows Benefit (B) and Net Benefit (NB = B - C) vs. Retrofit Investment (C). From Fig. 44, the Optimal Retrofit Investment can be seen as the point of maximum Net Benefit on the NB curve.

\section{Parameters of the Optimal Retrofit Program}

System parameters of the Optimal Retrofit were derived from the running sum of the costs and benefits, and are presented in Table LXVI, following. 


\section{SYSTEM EFFICIENCY CURVES \\ Retrofit for DBE (PGA=.20) \\ Portland Quadrangle - 7,690 Buildings}

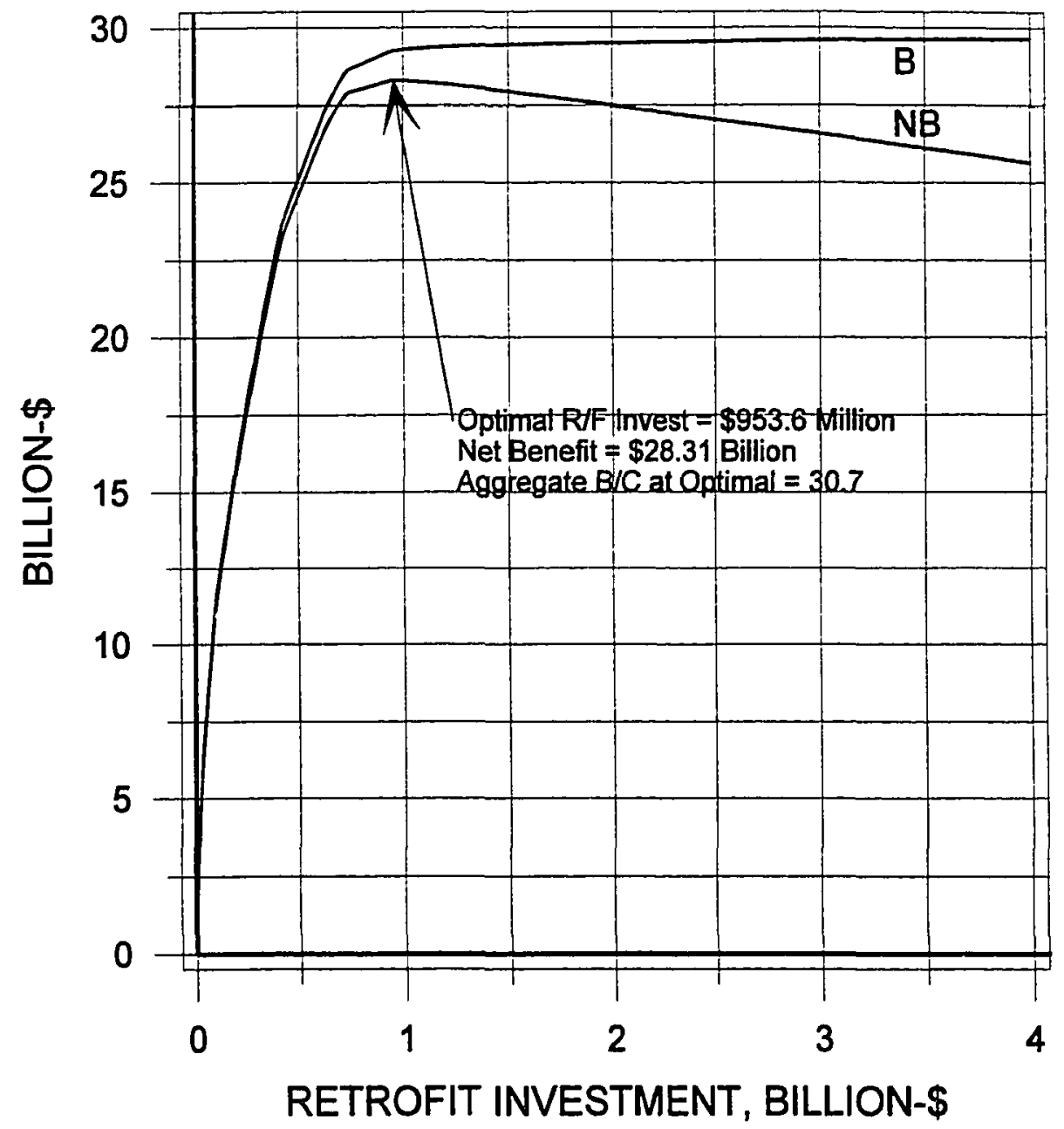

Figure 44. System Efficiency Curves for Retrofit for DBE (PGA $=.20$ ) for the Portland Quad. 
TABLE LXVI

SYSTEM PARAMETERS OF OPTIMAL RETROFIT INVESTMENT

FOR A SCENARIO EARTHQUAKE EVENT OF PGA $=.20$

\begin{tabular}{lc}
\hline Total Retrofit cost & $\$ 953.6$ Million \\
Net System Benefit & $\$ 28.31$ Billion \\
Aggregate B/C & 30.7 \\
No. Bldgs. Retrofit & 903 bldgs \\
Bldg Damage Avoided & $\$ 646$. Million \\
Lives Saved & 12,717 lives \\
\hline
\end{tabular}

Running sums were also made of Direct Benefits by Building Class (see Appendix). Figs. 45 and 46 present curves of lives saved and building damage avoided, respectively, vs. retrofit investment. From these curves, the Direct Benefit / Retrofit Cost ratios for an optimal retrofit investment ( $\$ 953.6 \mathrm{Million}$ ) are:
a) 13.3 lives saved / \$1-Million invested, and
b) $\$ .68$ damage aroided / \$1.00 invested.

\section{Comparison of Optimal Retrofit to Full Retrofit}

Table LXVII, following, compares the amount of loss mitigation provided by the optimal retrofit versus a "complete" retrofit (i.e., all bulldings retrofit). 


\section{LIVES SAVED vs. RETROFIT INVESTMENT Retrofit for DBE (PGA=.20) Portland Quadrangle - 7,690 Buildings}

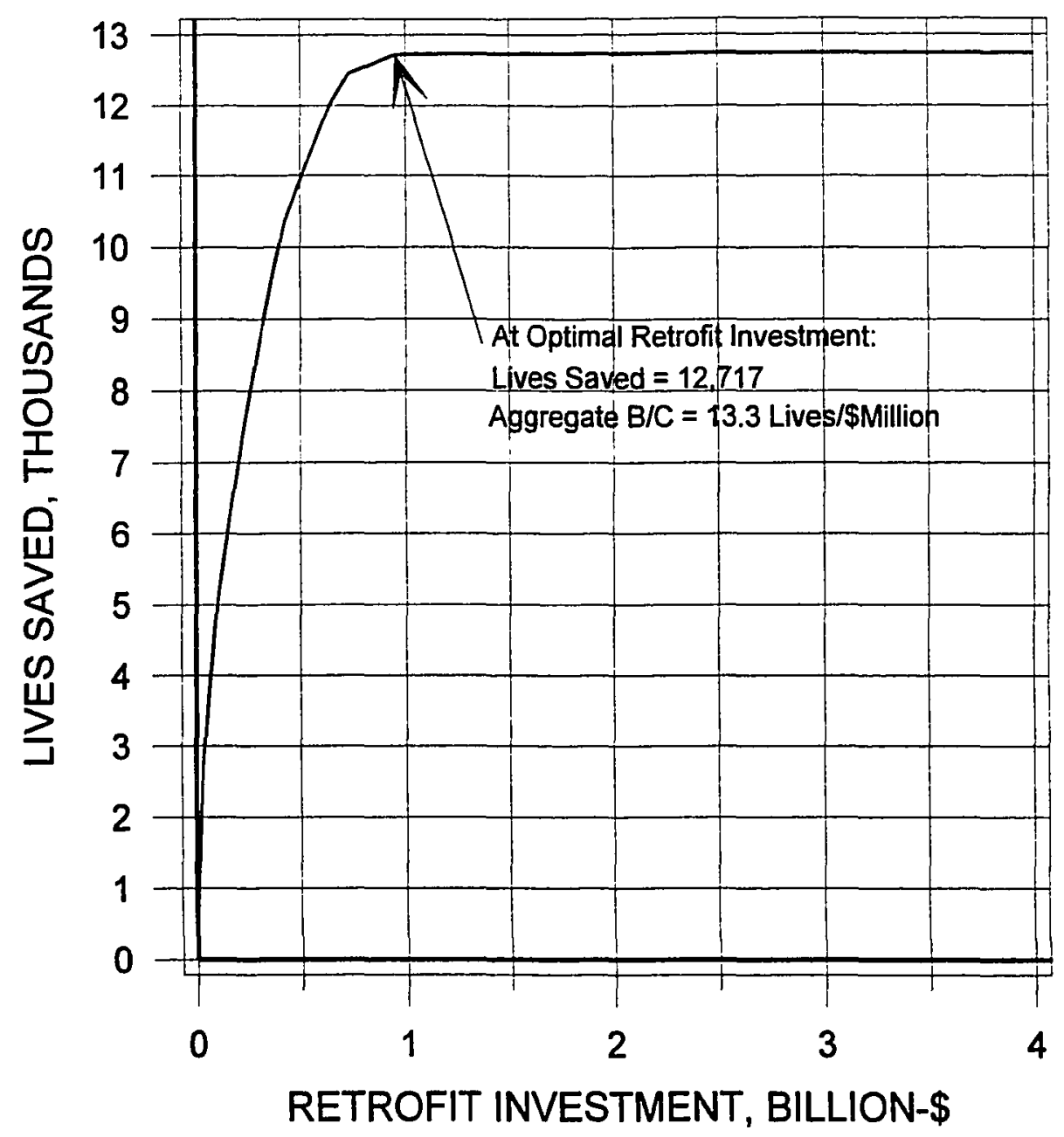

Figure 45. Lives Saved vs. Retrofit Investment for Retrofit for DBE (PGA $=.20)$. 
BLDG DAMAGE AVOIDED vs. RETROFIT INVESTMENT

Retrofit for DBE (PGA $=.20)$

Portland Quadrangle - 7,690 Buildings

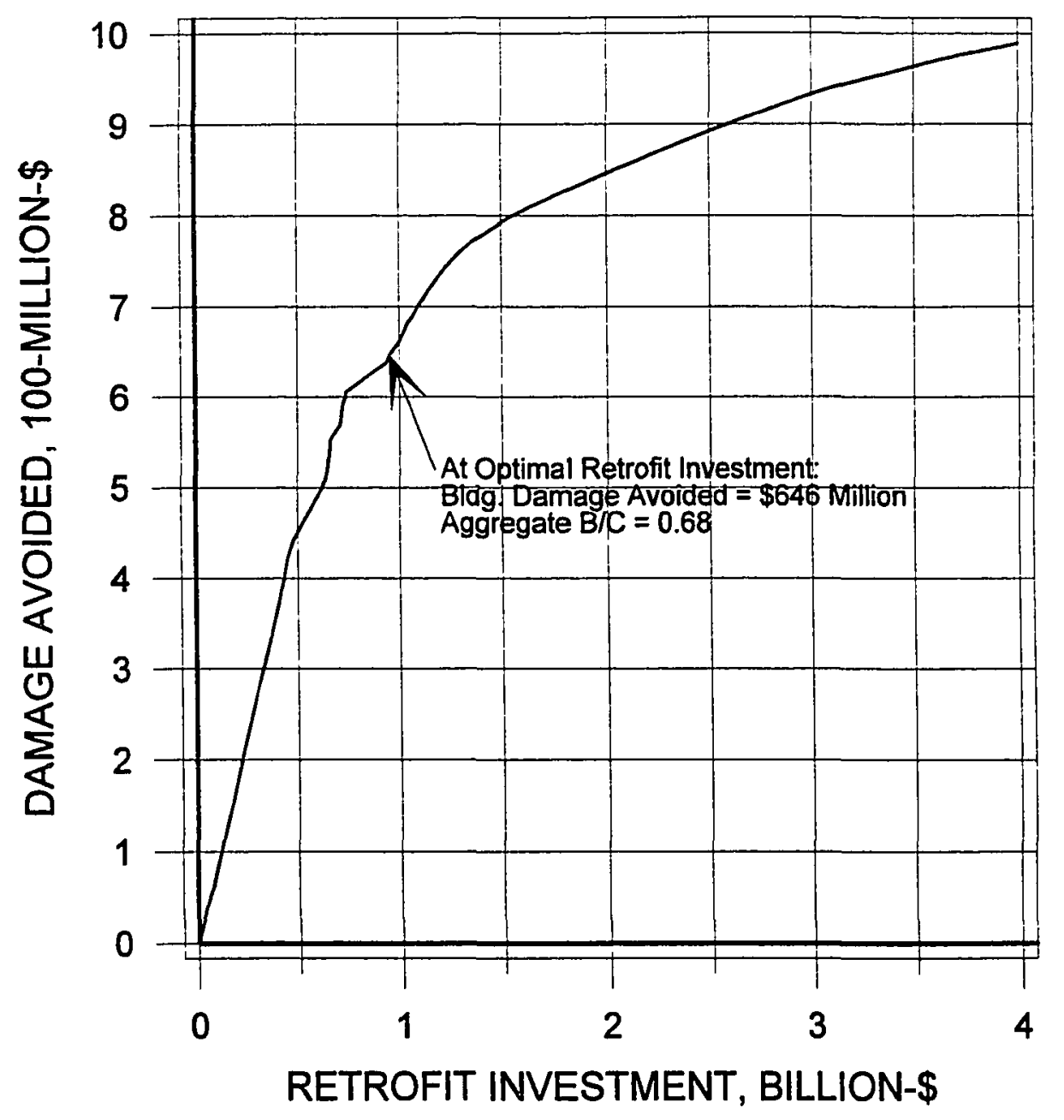

Figure 46. Bldg Damage Avoided vs. Retrofit Investment for Retrofit for DBE (PGA $=.20$ ). 
TABLE LXVII

COMPARISON BETWEEN COMPLETE RETROFIT AND OPTIMAL RETROFIT

\begin{tabular}{lrrr}
\hline & $\begin{array}{l}\text { BEFORE } \\
\text { RETROFIT }\end{array}$ & $\begin{array}{l}\text { ALL BLDGS } \\
\text { RETROFIT }\end{array}$ & $\begin{array}{l}\text { OPTIMAL } \\
\text { RETROFIT }\end{array}$ \\
\hline Tot Bldg Damage & $\$ 2.69 \mathrm{G}$ & $\$ 1.69 \mathrm{G}$ & $\$ 2.05 \mathrm{G}$ \\
Tot Loss of Life & 12,996 & 256 & 279 \\
Retrofit Investment & 0 & $\$ 4.42 \mathrm{G}$ & $\$ .95 \mathrm{G}$ \\
\hline
\end{tabular}

From Table LXVII, it is clear that the optimal retrofit provides essentially the same life-safety benefit as retrofitting all the buildings, but at one-fifth of the cost. Retrofitting past optimal does provide additional avolded building dmage, but at one-sixth the $3 / C$ ratio as optimal.

\section{Building Class Indices in the Optimal Retrofit}

Table LXVIII, following, presents a summary of the Building Types and Occupancy Groups of the 903 buildings included within the optimal retrofit program. 
TABLE LXVIII

SUMMARY OF BUILDING TYPES AND OCCUPANCY GROUPS INCLUDED IN THE OPTIMAL RETROFIT PROGRAM

\begin{tabular}{|c|c|c|c|c|c|c|}
\hline \multirow{2}{*}{$\begin{array}{l}\text { BLDG } \\
\text { TYPE }\end{array}$} & \multicolumn{5}{|c|}{ OCCUPANCY TYPE GROUP } & \multirow[b]{2}{*}{ TOTAL } \\
\hline & $S, P A$ & G, ES & $\mathrm{O}, \mathrm{C}, \mathrm{H}$ & $\mathbf{R}$ & I & \\
\hline $51,2,4$ & 0 & 0 & 22 & 0 & 0 & 22 \\
\hline $\mathrm{Cl}$ & 5 & 6 & 44 & 3 & 4 & 62 \\
\hline$C 2$ & 0 & 1 & 9 & 0 & 3 & 13 \\
\hline $\mathrm{C} 3 / \mathrm{S} 5$ & 5 & 0 & 29 & 3 & 8 & 45 \\
\hline PC1 & 1 & 3 & 11 & 0 & 76 & 91 \\
\hline PC2 & 0 & 0 & 0 & 0 & 1 & 1 \\
\hline RM & 0 & 14 & 30 & 3 & 31 & 78 \\
\hline URM & 38 & 6 & 328 & 116 & 103 & 591 \\
\hline$w, 53$ & 0 & 0 & 0 & 0 & 0 & 0 \\
\hline TOTAL & 49 & 30 & 473 & 125 & 226 & 903 \\
\hline
\end{tabular}

It can be concluded that the number Unreinforced Masonry (URM) bulldings included in the optimal retrofit (591) is an order of magnitude more than any other building type. Of the other building types, Concrete Frame (C1), URM Frame Infi11 (C3/S5), Tilt-up (PC1), and Reinforced Masonry (RM) all have similar numbers of buildings (45 to 91) included in the optimal retrofit.

More than 75-percent of the total number of buildings included in the optimal retrofit are included in the Office-Commercial-Historical and Industrial Occupancies.

Table LXIX, following, presents a summary of the number of Bullding Types in the optimal retrofit program, 
as a percentage of the total number of its type in the inventory.

TABLE LXIX

PERCENTAGE OF BUILDINGS TYPES INCLUDED IN OPTIMAL RETROFIT PROGRAM

\begin{tabular}{lr}
\hline S1, 2,4 & $14.5 \%$ \\
$\mathrm{C} 1$ & $39.0 \%$ \\
$\mathrm{C} 2$ & $0.8 \%$ \\
$\mathrm{C} 3 / \mathrm{S} 5$ & $71.4 \%$ \\
$\mathrm{PC1}$ & $17.7 \%$ \\
$\mathrm{PC2}$ & $2.6 \%$ \\
$\mathrm{RM}$ & $8.5 \%$ \\
URM & $68.6 \%$ \\
W, S3 & $0 \%$ \\
\hline & \\
\hline
\end{tabular}

Unreinforced Masonry (URM) and URM Frame Infill (C3/S5) show a very high percentage of the inventory included in the optimal retrofit. Additionally, Concrete Frame (C1) shows a large percentage of the inventory included.

Table LXX, following, presents a summary of the number of Occupancy Type Groups in the optimal retrofit program, as a percentage of the total number of its type group in the inventory. 
TABLE LXX

\section{PERCENTAGE OF OCCUPANCY TYPE GROUPS INCLUDED IN OPTIMAL RETROFIT PROGRAM}

\begin{tabular}{lr} 
School, Pub. Assem. & $11.2 \%$ \\
Govt. Bldg., Emer, Serv. & $16.1 \%$ \\
Office, Commercial, Historic & $14.3 \%$ \\
Residential & $\begin{array}{r}6.7 \% \\
\text { Industrial }\end{array}$ \\
\hline TOTAL & $11.9 \%$ \\
\hline
\end{tabular}

The percentage of each occupancy type group included in the optimal retrofit is of the same order of magnitude as the percentage of the entire inventory, which is $11.7 \%$ The number of buildings by Soil Hazard Zone (SHZ) range included in the optimal retrofit are as follows:

$\begin{array}{ll}\text { H (high) } & 179 \text { bldgs } \\ \text { L (low) } & 724 \\ & \\ \text { TOTAL } & 903 \text { bldgs }\end{array}$

The fraction of buildings in each soil Hazard zone included in the optimal retrofit roughly matches the fraction of the entire bullaing inventory in each zone. The number of buildings by Building Size Group (SIZE) included in the optimal retrofit are as follows:

$\begin{array}{lr}S \text { (smal 1) } & 325 \text { bldgs } \\ M \text { (medium) } & 433 \\ L \text { (large) } & 145 \\ & -- \\ \text { TOTAL } & 903 \text { bldgs }\end{array}$

Again, it appears that the fraction of buildings in each 
size group roughly matches the fraction of the building inventory in each group.

The number of buildings by Structural Score Range

(SSR) included in the optimal retrofit are as follows:

$$
\begin{array}{cr}
1-(S<+1) & 881 \text { bldgs } \\
1+(S>+1) & 22 \\
& -- \\
\text { TOTAL } & 903 \text { bldgs }
\end{array}
$$

It is clear that 98 -percent of the buildings in the optimal retrofit have a Structural score of less than 1.0.

\section{Sensitivity Analysis}

Clearly, the optimal retrofit program is being driven by the benefit of the dollar value of lives saved by retrofit. Two parameters which affect the dollar value of 1 ives saved and could possibly impact the scope of the optimal retrofit program are the number of people (NP) in the buildings, and the dollar value used for human life (VOL). To study the sensitivity of the optimal retrofit program to these two parameters, the following two alternate optimal retrofit programs were determined:

1. An optimal retrofit program using for NP the Lowpoint (in lieu of Midpoint) of the range of the number of people in each building. A system efficiency curve based on the Lowpoint NP is shown in Figure 47 , following. 
2. An optimal retrofit program using for vol $\$ 500,000$. (in 1 ieu of $\$ 2.25 \mathrm{M}$ ). A system efficiency curve based on VOL $=\$ 500,000$. is shown in Figure 48, following.

A comparison between the optimal retrofit program determined previously (based on $\mathbb{N P}=$ Midpoint, and VOL $=\$ 2.25 \mathrm{M}$ ) and the two alternate programs is made in Table LXXI, following.

TABLE LXXI

SENSITIVITY ANALYSIS RESULTS

\begin{tabular}{lll}
\hline $\begin{array}{l}\text { RETROFIT } \\
\text { PROGRAM }\end{array}$ & $\begin{array}{l}\text { NO. OF } \\
\text { BLDGS }\end{array}$ & $\begin{array}{l}\text { RETROFIT } \\
\text { INVESTMENT }\end{array}$ \\
\hline $\begin{array}{l}\text { DBE Optimal } \\
\text { Retrofit }\end{array}$ & 903 & $\$ 954 . \mathrm{M}$ \\
$\begin{array}{l}\text { DBE Optima } \\
\text { using LOWPOINT }\end{array}$ & 892 & $\$ 947, \mathrm{M}$ \\
$\begin{array}{l}\text { DBE Optimal } \\
\text { using LOW VOL }\end{array}$ & 860 & $\$ 743 . \mathrm{M}$ \\
\hline
\end{tabular}

From Table LXXI, it is clear that the scope of the retrofit program changes only slightly when the Value of Life (VOL) or the Number of People (NP) used in the analysis are varied.

Variations in the Vol or range of number of people in the buildings will not change the decision to retrofit. 


\section{SYSTEM EFFICIENCY CURVES Retrofit for DBE (PGA=.20) at Lowpoint of NP Range Portland Quadrangle - 7,690 Buildings}

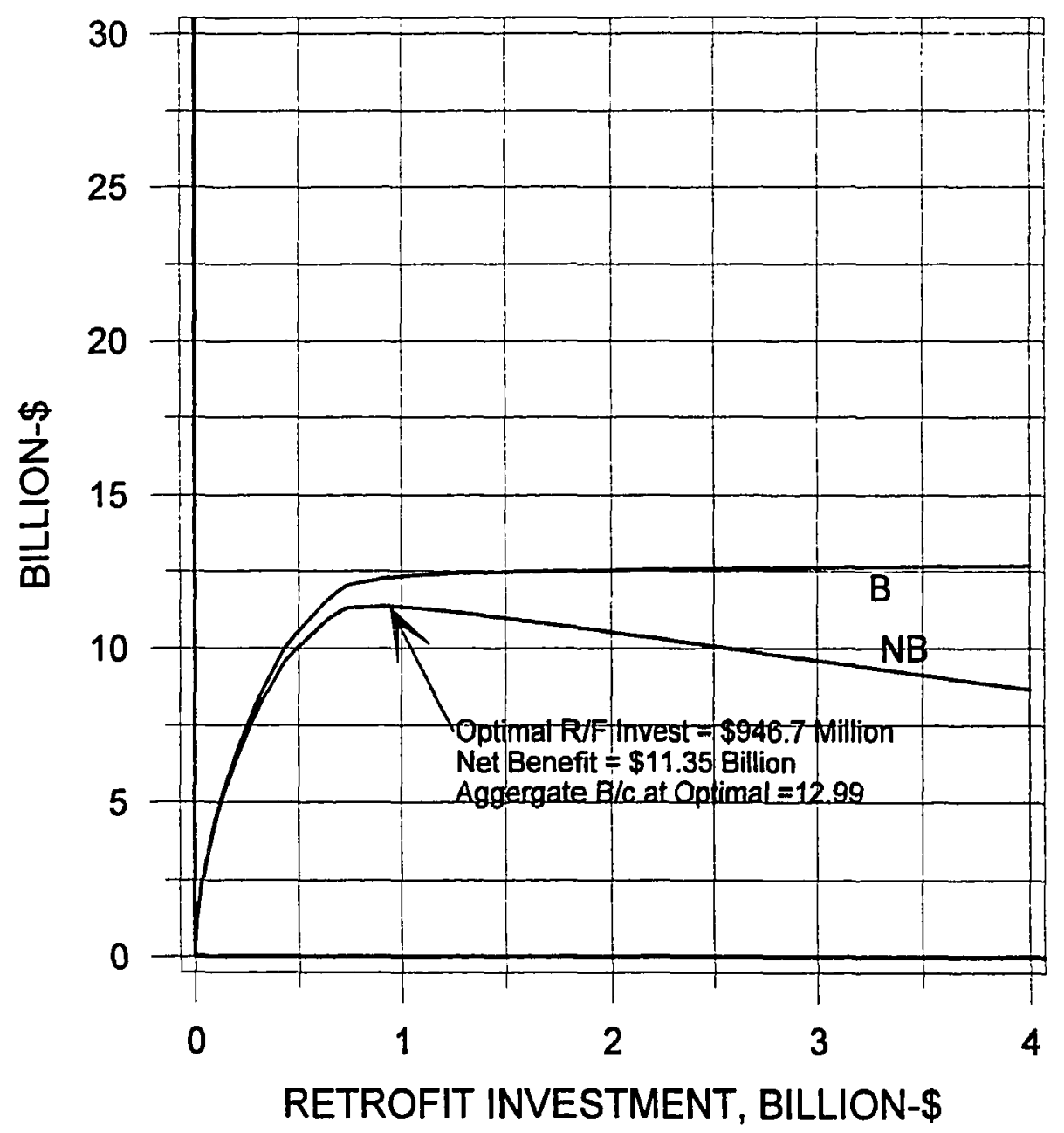

Figure 47. System efficiency curves for retrofit for DBE (PGE = .20) for the Portland Quad, using the Lowpoint of KP range. 


\section{SYSTEM EFFICIENCY CURVES \\ Retrofit for DBE(PGA=.20) with Value \\ of Life $=\$ 500,000$}

Portland Quadrangle - 7,690 Buildings

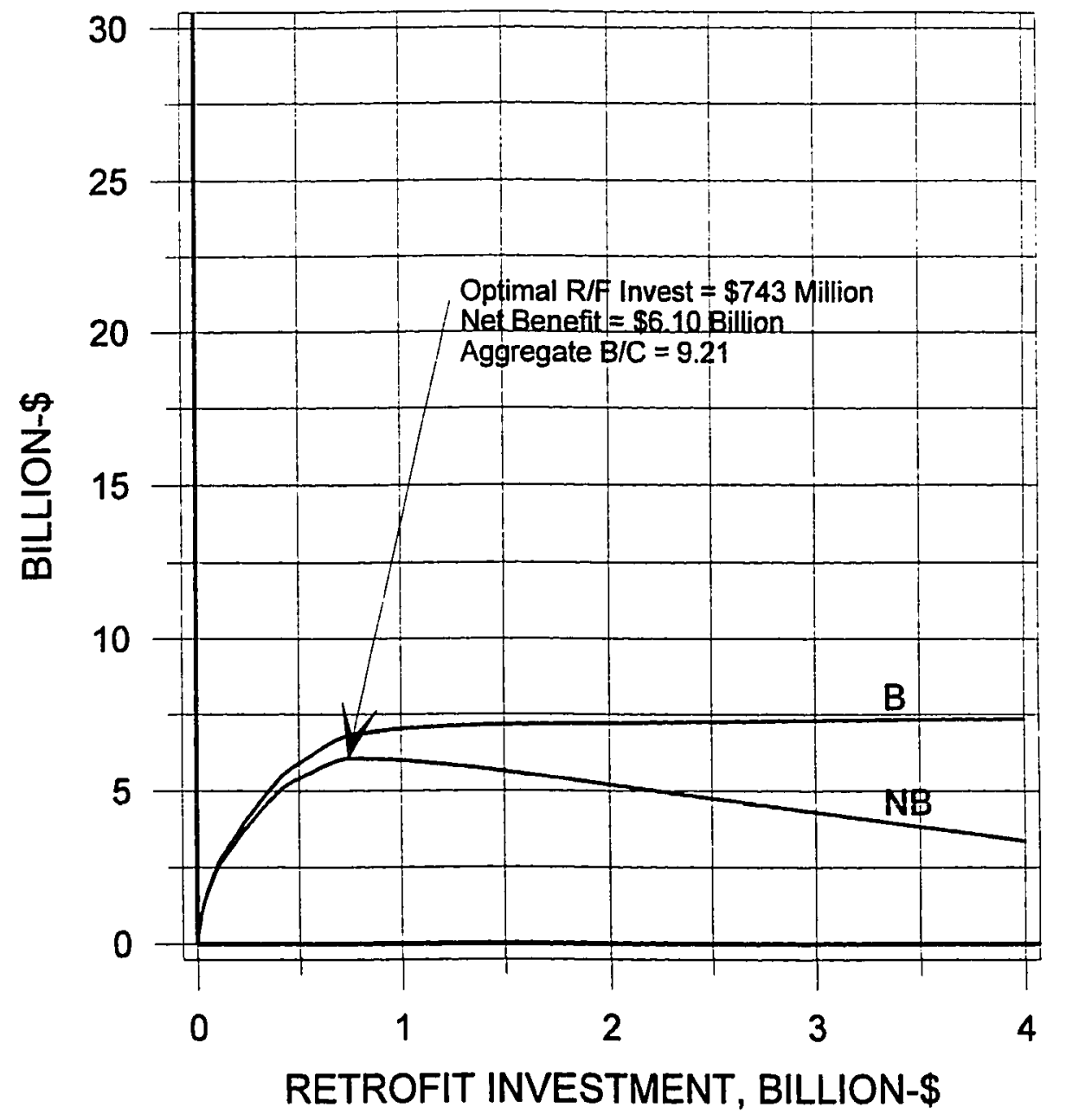

Figure 48. System efficiency curves for retrofit for DBE (PGA $=.20$ ) for the Portland Quad, using VOL $=\$ 500,000$. 
DEVELOPMENT OF AN OPTIMAL RETROFIT PROGRAM

BASED ON AN EXPECTED VALUE ANALYSIS

An expected value analysis of retrofit was made,

using the methodology described in chapter VI. The

resulting optimal retrofit program resulting from this

analysis is compared to the DBE optimal retrofit program.

\section{Present Value of Full Retrofit}

The annual expected value of a "full" retrofit, wherein all the builaings in the inventory are retrofit, is presented in Table LXXI, following. In Table LXXII, the sum of the annual benefits for a range of four PGA scenario events is taken as the total annual expected value of retrofit. The values of Damage Avoided and Lives Saved are the difference between the bottom-line values in Tables LI to LIV, and Tables LXI to LXIV. The Scenario Benefit is taken as the dollar value of avoided damage plus the lives saved times the value of life (Eq. 6.1). EAE is the expected annual number of earthquakes, as presented in Chapter VI. The annual expected value of benefit is taken as EAE times the scenario benefit. 
TABLE LXXII

ANNUAL EXPECTED VALUE OF FULL RETROFIT

\begin{tabular}{lllllll}
\hline PGA & $\begin{array}{l}\text { DAMAGE } \\
\text { AVOID (M\$) }\end{array}$ & $\begin{array}{l}\text { LIVES } \\
\text { SAVED }\end{array}$ & $\begin{array}{l}\text { SCENARIO } \\
\text { BEN (M\$) }\end{array}$ & EAE & \multicolumn{2}{c}{$\begin{array}{l}\text { ANNUAL EXP } \\
\text { BEN (M\$) }\end{array}$} \\
\hline .08 & $\$$ & 482.5 & $5,752$. & $\$ 13,424$. & .01 & $\$ 134.24$ \\
.20 & $\$ 1,008.5$ & $12,740$. & $\$ 29,674$. & .002 & $\$ 59.35$ \\
.27 & $\$ 1,242.8$ & $17,549$. & $\$ 40,727$. & .001 & $\$ 40.73$ \\
.39 & $\$ 1,458.9$ & $21,972$. & $\$ 50,895$. & .0004 & $\$ 20.36$ \\
\hline
\end{tabular}

TOTAL ANNUAL EXPECTED VALUE OF BENEFIT: \$254.67

The Expected Present Value (PV) of the full retrofit is the sum of the annual expected value over a planning horizon, discounted to present value. As described in Chapter VI, a planning horizon of 50 years and discount rate of 7-percent results in a Uniform Series/ Present Worth Factor (PWF) of 13.801.

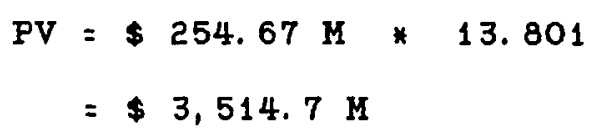

This PV is roughly one-tenth of the Benefit (B) from a full retrofit based on the Design Basis Earthquake, from page 213.

The Net Present Value of full retrofit is the difference between the Present Value and the Retrofit Cost: 


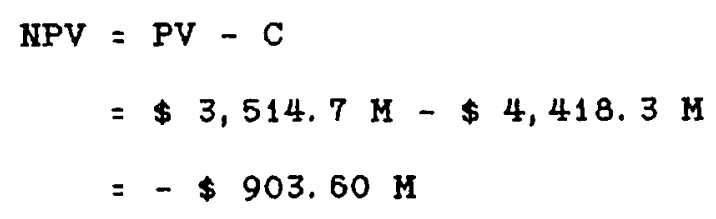

The negative result for NPV clearly indicates that, from an expected value approach, there will be a loss of value to retrofit all the buildings in the inventory (this was not the case with the DBE, where the NB at full retrofit was still a large positive number).

Therefore, from an expected value viewpoint, an optimum retrofit program takes on added significance, in that the optimal retrofit investment is necessary not only to maximum benefit, but also to avoid actual loss.

\section{Retrofit Prioritization by Building Class}

The Retrofit Group of program modules in REAL-RAP was used to place all the buildings in the inventory in a Building Class, determine the PV and NPV of retrofit (as presented above) for each Building Class, and prioritize the Building Classes by PV/C ratio.

The prioritized list of Building Classes is shown in Appendix D. In Appendix $D$, the first column is the ranking of the Building Class by $P V / C$ ratio. The next five columns are the indices which identify the Building Class (STG, SHZ, SSR, OTG, and BSG). The last three columns are the total retrofit cost, NPV of retrofit, and PV/C ratio for all the buildings in that class. 


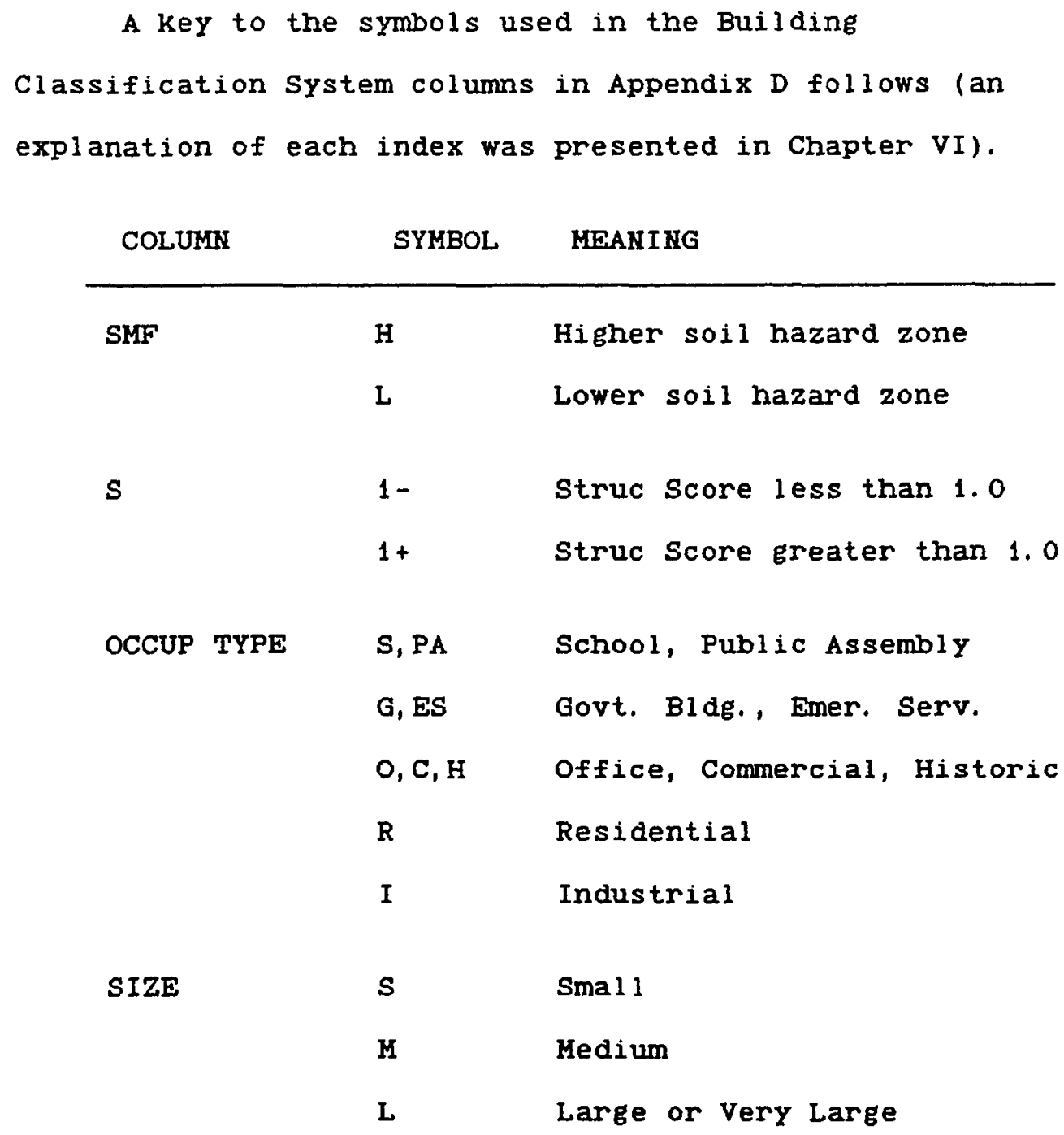

In Appendix $D$, the same 284 Building Classes used in the DBE Optimal Retrofit are used to classify the buildings for the Expected Value Optimal Retrofit (because it is the same building inventory). 


\section{System Efficiency}

The maximum PV/C ratio is 182 . The first $B / C$ less than 1.0 occurs at R/F Rank number 79 . This is also where the Net Present Value becomes negative.

Therefore, the point of naximum efficiency, where system net benefit is maximized, occurs at retrofit Rank number 78. This marks the point of Optimum Retrofit Investment, and is identified in the retrofit prioritization of Appendix D.

A running sum of the costs and benefits was made from Appendix D. From the running sum, a System Efficiency Curve was made (Fig. 49). The System Efficiency Curve shows Present Value of retrofit benefit (PV) and Net Present Value of retrofit benefit (NPV = PV - C) vs. Retrofit Investment (C). From Fig. 49, the Optimal Retrofit Investment can be seen as the point of maximum Net Present Value on the NPV curve.

\section{Parameters of the Optimal Retrofit Program}

System parameters of the Optimal Retrofit were derived from the running sum of the costs and benefits, and are presented in Table LXXII, following. 


\section{SYSTEM EFFICIENCY CURVES}

Retrofit for Expected Value Analysis

\section{Portland Quadrangle - 7,690 Buildings}

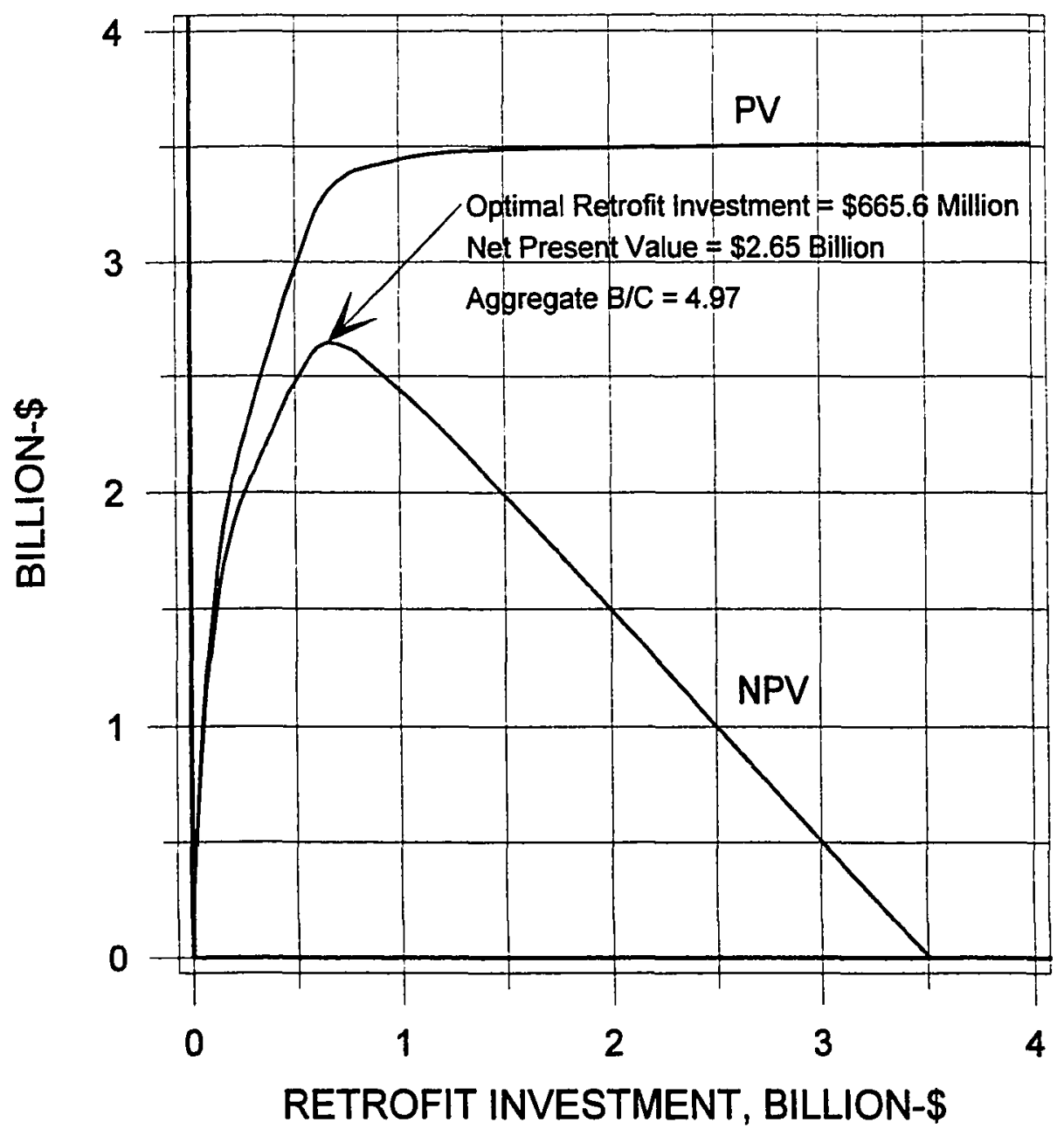

Figure 49. System Efficiency Curves for Retrofit for Expected Value Analysis for the Portland Quad. 
TABLE LXXIII

SYSTEM PARAMETERS OF OPTIMAL RETROFIT INVESTMENT BASED ON AN EXPECTED VALUE ANALYSIS

\begin{tabular}{lc}
\hline Total Retrofit Cost & $\$ 665.6$ Million \\
Net System Benefit & $\$ 2.646$ Billion \\
Aggregate B/C & 4.97 \\
No. Bldgs. Retrofit & 846 bldgs \\
\hline
\end{tabular}

Building Class Indices in the Optimal Retrofit

Table LXXIV summarizes Building Types and Occupancy Groups of the 846 buildings in the optimal retrofit.

TABLE LXXIV

SUMMARY OF BUILDING TYPES AND OCCUPANCY GROUPS INCLUDED IN THE OPTIMAL RETROFIT PROGRAM

BASED ON AN EXPECTED VALUE ANALYSIS

\begin{tabular}{|c|c|c|c|c|c|c|}
\hline \multirow{2}{*}{$\begin{array}{l}\text { BLDG } \\
\text { TYPE }\end{array}$} & \multicolumn{5}{|c|}{ OCCUPAKCY TYPE GROUP } & \multirow[b]{2}{*}{ TOTAL } \\
\hline & $S, P A$ & G, ES & $\mathrm{O}, \mathrm{C}, \mathrm{H}$ & $\mathbf{R}$ & $I$ & \\
\hline$s 1,2,4$ & 0 & 0 & 0 & 1 & 0 & 1 \\
\hline $\mathrm{C} 1$ & 5 & 4 & 37 & 4 & 1 & 51 \\
\hline $\mathrm{C} 2$ & 1 & 0 & 0 & 0 & 3 & 4 \\
\hline $\mathrm{C} 3 / \mathrm{S} 5$ & 5 & 0 & 28 & 3 & 4 & 40 \\
\hline PC1 & 1 & 3 & 5 & 0 & 76 & 85 \\
\hline PC2 & 1 & 0 & 0 & 0 & 1 & 2 \\
\hline RM & 2 & 14 & 30 & 4 & 31 & 81 \\
\hline URM & 38 & 6 & 324 & 114 & 100 & 582 \\
\hline$w, s 3$ & 0 & 0 & 0 & 0 & 0 & 0 \\
\hline TOTAL & 53 & 27 & 424 & 126 & 216 & 846 \\
\hline
\end{tabular}


It can be concluded that the number Unreinforced Masonry (URM) buildings included in the optimal retrofit (582) is an order of magnitude more than any other building type. Of the other building types, Concrete Frame (C1), URM Frame Infill (C3/S5), Tilt-up (PC1), and Reinforced Masonry (RM) all have similar numbers of buildings ( 40 to 85 ) included in the optimal retrofit.

More than 75-percent of the total buildings included in the optimal retrofit are included in the Office-Commerclal-Historical and Industrial Occupancies.

Table LXXV, following, presents a summary of the number of Building Types in the optimal retrofit program, as a percentage of the total number of its type in the inventory.

TABLE LXXV

\section{PERCENTAGE OF BUILDINGS TYPES IHCLUDED III OPTIMAL RETROFIT PROGRAM BASED ON AN EXPECTED VALUE ANALYSIS}

\begin{tabular}{lr}
\hline S1, 2,4 & $0.7 \%$ \\
C1 & $32.1 \%$ \\
C2 & $0.2 \%$ \\
C3/S5 & $63.5 \%$ \\
PC1 & $16.5 \%$ \\
PC2 & $5.1 \%$ \\
RM & $8.8 \%$ \\
URH & $67.5 \%$ \\
W, S3 & $0 \%$ \\
\hline TOTAL & $11.0 \%$ \\
\hline
\end{tabular}


Unreinforced Masonry (URM) and URM Frame Infill (C3/S5) show a very high percentage of the inventory included in the optimal retrofit. Additionally, Concrete Frame (C1) shows a large percentage of the inventory included.

Table LXXVI, following, presents a summary of the number of Occupancy Type Groups in the optimal retrofit program, as a percentage of the total number of its type group in the inventory.

TABLE LXXVI

PERCENTAGE OF OCCUPANCY TYPE GROUPS INCLUDED IN OPTIMAL RETROFIT PROGRAM BASED ON AN EXPECTED VALUE AKALYSIS

\begin{tabular}{lr}
\hline & \\
School, Pub. Assem. & $12.1 \%$ \\
Govt. Bldg., Emer. Serv. & $14.5 \%$ \\
Office, Commercial, Historic & $12.8 \%$ \\
Residential & $6.8 \%$ \\
Industrial & $11.4 \%$ \\
\hline TOTAL & $11.0 \%$ \\
\hline
\end{tabular}

The percentage of each occupancy type group included in the optimal retrofit is of the same order of magnitude as the percentage of the entire inventory, which is $11.0 \%$ The number of buildings by Soil Hazard Zone (SHZ) range included in the optimal retrofit are as follows: 


$$
\begin{array}{lr}
\text { H (high) } & 161 \text { bldgs } \\
\text { L (low) } & 685 \\
& \\
\text { TOTAL } & 846 \text { bldgs }
\end{array}
$$

The fraction of buildings in each Soil Hazard Zone included in the optimal retrofit roughly matches the fraction of the entire building inventory in each zone.

The number of buildings by Building Size Group (SIZE) included in the optimal retrofit are as follows:

$\begin{array}{lr}S \text { (small) } & 321 \text { bldgs } \\ M \text { (medium) } & 416 \\ L \text { (large) } & 109 \\ & --- \\ \text { TOTAL } & 846 \text { bldgs }\end{array}$

Again, it appears that the fraction of buildings in each size group roughly matches the fraction of the building inventory in each group.

The number of buildings by structural score Range (SSR) included in the optimal retrofit are as follows:

$$
\begin{aligned}
& 1-(s<+1) \quad 829 \text { b1 dgs } \\
& 1+(S>+1) \quad 17 \\
& \text { TOTAL } 846 \mathrm{blags}
\end{aligned}
$$

It is clear that 98 -percent of the buildings in the optimal retrofit have a structural score of less than 1.0.

\section{Comparison of Expected Value and Design Basis Retrofits}

A comparison of the Building Indices in the expected value optimal retrofit with those presented previously for the design basis optimal retrofit show that there is little difference betweeen the buildings captured for 
retrofit in both programs.

In order to compare the Direct Benefits of the Expected Value Optimal Retrofit with the Design Basis Optimal Retrofit, the Direct Benefits corresponding to an earthquake scenario of $P G A=.20$ were compiled from the Expected Value Optimal Retrofit Building Classes, and running sums were made of Direct Benefits by Building Class (see Appendix). A comparison of system parameters is presented in Table LXXVII, following.

\section{TABLE LXXVII}

COMPARISON OF SYSTEM PARAMETERS OF EXPECTED VALUE VS. DESIGI BASIS OPTIMAL RETROFIT PROGRAMS

\begin{tabular}{lll} 
& $\begin{array}{c}\text { EXPECTED VALUE } \\
\text { RETROFIT }\end{array}$ & $\begin{array}{c}\text { DESIGN BASIS } \\
\text { RETROFIT }\end{array}$ \\
\hline Total Retrofit Cost & $\$ 665.6 \mathrm{M}$ & $\$ 953.6 \mathrm{M}$ \\
NPV and NB & $\$ 2,646 . \mathrm{M}$ & $\$ 28,306 . \mathrm{M}$ \\
Aggregate B/C & 4.97 & 30.68 \\
No. Bldgs, Retrofit & $846 \mathrm{bldgS}$ & $903 \mathrm{bldgs}$ \\
Dam. Avoid. (PGA=.2) & $\$ 559.6 \mathrm{M}$ & $\$ 646 . \mathrm{M}$ \\
Lives Saved (PGA=.2) & 11,943 lives & 12,717 lives \\
\hline
\end{tabular}

As can be seen from Table LXXVII, there is not a large difference between these two retrofit programs. 
The high value of life "penetrates" the benefit reduction caused by the earthquake probabilities in the expected value approach. The great majority of the live-safety hazardous buildings are captured in both retrofit programs. 
CHAPTER $\mathrm{X}$

SUMMARY AND CONCLUSIONS

EARTHQUAKE LOSS AND RETROFIT MODELING

The "average" building damage estimates provided by ATC-13 (1985) were extended in the present research to include earthquake-sensitive effects of variations in design, construction, and site-specific soil conditions which are commonly found in buildings. The structural scoring system and performance modifiers provided in ATC-21 (1988) were used as the basis of these variations. Probability theory was used to derive a relationship between Structural Score (S) and Damage Factor (DF). This relationship was transformed to fragility curve families, providing a relationship between Peak Ground Acceleration (PGA) and DF, based on the performance modifiers in individual buildings.

Site-specific soil effects were included in the damage model performance modifiers. Local earthquake hazard maps were used as the basis of assigning performance modifiers to account for the effect on damage of ground motion amplification, liquefaction/lateral spread risk, and dynamic slope instability risk. The Damage Factor was used to calculate the 
probabilistic dollar value of building damage, loss of life, and serious injuries in a building, based on the occupancy type and an estimated range of number of persons in the building while in use.

The retrofit effectiveness values provided in FEMA-227 (1992) were extended to estimate the beneficial avoided building damage and lives saved following retrofit of buildings. Retrofit costs were estimated from published values in FEMA-156 (1994) and Goettel and Horner (1995).

\section{REGIONAL RETROFIT PLANNING MODEL}

A system was developed to classify buildings in a region, based on similarities in expected earthquake loss and retrofit cost. Individual buildings from a Rapid Visual screening survey are aggregated into one of 540 possible building classes based on structural type, soil hazards, structural score, occupancy type, and size.

A cost-benefit analysis model was developed for the building classes, including the value of avoided damage, value of lives saved and serious injuries avoided, and cost of structural and non-structural retrofit. The costbenefit model was developed for a scenario earthquake event, and for a range of earthquake events using an expected value approach. 
A technique was developed to prioritize the building classes, so that the most cost-effective buildings are retrofit first in a regional plan.

A system efficiency analysis was developed to determine the optimum retrofit investment for a region.

COMPUTER SOFTWARE DEVELOPMENT

Regional EArthquake Loss and Retrofit Analysis Program (REAL-RAP) was developed to conduct the loss estimates and retrofit analysis for a regional ATC-21 (1988) survey inventory.

The REAL-RAP program is composed of modules, which operate sequentialiy. Data files of intermediate results are made at each module step, to enable thorough checking of results, and processing of large amounts of data on micro-computers. The modular design philosophy also permits additions or adjustments to the program to be more easily integrated.

EARTHQUAKE LOSS ESTIMATE OF THE PORTLAND QUADRANGLE ATC-21 survey inventory data collected from more than 7,500 buildings in the Portland Quadrangle during the 1993 Portland Seismic Hazards Survey was analyzed with REAL-RAP. 
The loss estimate focused on the Design Basis Earthquake Scenario, $P G A=0.2 \mathrm{~g}$. The results of this estimate were:

$$
\begin{aligned}
\text { Building Damage: } \$ 2.7 \text { Billion } \\
\text { Loss of Life: } 5,294 \text { to } 12,995
\end{aligned}
$$

The loss of life varies directly with the building occupant load. The range of loss of 1 ife shown above derives from the lowpoint to the midpoint of the range of the estimated number of occupants, from the field survey.

Over two-thirds of the loss of life was in unreinforced masonry or unreinforced masonry infill buildings (URM and C3/S5). Nearly one quarter of the loss of 1 ife was in concrete frame buildings (C1).

The total dollar value of loss, including the value of life, was \$31.9 Billion. Over ninety-percent of the total dollar value of loss is attributable to the value of lost human life.

Nearly all of the loss of life occurred in buildings with a Structural Score of less than 1.0. Over half of the loss of life occurred in the commercial, office, and Industrial occupancies. Nearly one quarter of the loss of life occurred in the School and Public Assembly occupancies. There was not a significant correlation between loss of 1 ife and Soil Modification Factor. Ten-percent of the buildings in the inventory have a 
damage factor above 50 (major damage or collapse). For comparison to a similar earthquake in a modern city, the 1994 Kobe earthquake had 12.6-percent of the buildings at damage factor 50 or greater.

When REAL-RAP was run without any performance modifiers in the model (corresponding to the $\Sigma$ (PMF) $=0$ line on the fragility curves), the midpoint loss of life dropped from 12,995 to 477. This indicates that more than 95-percent of the loss of 11 fe derives from the variations in design and construction as modeled in the performance modifiers.

\section{RETROFIT ANALYSIS OF THE PORTLAND QUADRANGLE}

The REAL-RAP software was first used to determine the result of a "full" retrofit -.. retrofitting every building in the inventory. For the design basis earthquake (DBE, $P G A=.20)$, the value of damage was reduced to $\$ 1.69$ Billion and loss of life was reduced to 256 lives lost, at a retrofit cost of $\$ 4.42$ Billion. (a $37 \%$ reduction in damage and a $98 \%$ reduction in loss of life).

Next, the retrofit benefits and costs were classified and prioritized from high to low B/C ratio for the Design BAsis Earthquake (DBE). A system efficiency analysis was made, resulting in an optimal retrofit program as follows. 


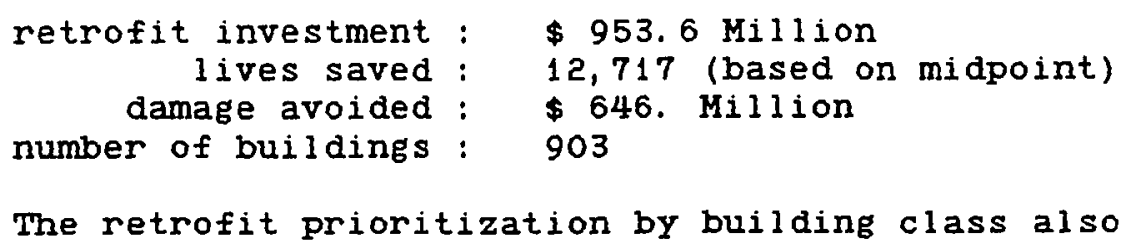


reducing the retrofit investment from the full retrofit program. The choice of an ATC-21 structural score of +1.0 as a classification index was successful in ldentifying the important buildings for retrofit.

The REAL-RAP software was also used to make an expected value analysis of retrofit. Although the present values of retrofit benefit are only one-tenth those of the Design Basis Earthquake, the PV/C (present value to cost) ratios are still high enough to capture most of the life-safety critical bulldings in the optimal retrofit program. The optimal retrofit program based on the expected value analysis is as follows:

The categories of buildings in the expected value optimal retrofit are roughly the same as the DBE program. It is concluded that seismic retrofit for Portland has a very high $B / C$ ratio, and it makes sense to retrofit. Variations in the number of building occupants and dollar value of human life do not change this conclusion. The same conclusion is reached whether a scenario earthquake event or an expected value anaysis of retrofit benefit are used.

The initial B/C ratios, at the "top" of the prioritized building classes, approach 1,000 (for the DBE 
retrofit). The aggregate $B / C$ ratio for the optimal DBE is about 30 . With such high initial B/C ratios, the question is not whether to retrofit, but where to "cut-off" a retrofit program. The optimal retrofit program is one answer to that question.

\section{LIMITATIONS IN APPLYING THIS RESEARCH}

In applying the results of this research, it is important to understand the probabilistic roots of the loss estimation techniques developed.

This methodology is intended to evaluate hundreds or thousands of buildings in a region, and is applicable only to categories or groups of buildings. This methodology is definitely not intended to fully determine the seismic safety of individual buildings.

The methodology developed herein is intended to be the first step of a several step process in identifying those buildings that require additional, more detailed investigation by qualified engineers. The goal is to broadly identify most of the potentially seismically hazardous buildings, and to eliminate most of the relatively adequate buildings from further review.

The utility of this methodology in taking this first step in an actual retrofit program is dependent upon the qualifications of the responsible building officials, and 
the quality of the input information. Field survey crews must be qualified, well trained, and adequately supervised and checked by professional engineering personnel. The soil hazard mapping information is approximate in nature; its detail and quality can be expected to vary greatly from community to community, and should be scrutinized by professional engineering personnel qualified to judge its value. The building officials in responsible charge of implementing this information should have the technical background to fully understand these limitations. The loss estimates and retrofit analyses made in this research consider the buildings in "full use" during regular business hours. Additionally, the effect of foundation type (deep vs. shallow) are not considered in the ATC-21 inventory nor the loss/retrofit models.

\section{RECOMMENDATIONS FOR FURTHER RESEARCH}

This methodology bases its loss estimates and retrofit recommendations on a "far-field" seismic source, wherein every building in the region is considered to subject to the same PGA.

For a local earthquake source, near-field attenuation effects would result in different values of PGA for different buildings, depending upon their individual proximity to the fault rupture. In Portland, 
for example, a west-hills fault rupture would likely cause buildings downtown to have PGA values higher than the DBE, while buildings in east Portland may be at or below the DBE level of PGA. The resulting loss estimates and retrofit programs may be different, depending upon where the hazardous buildings are relative to damaging levels of PGA.

A recommended next step in this model will be to "map" near-field PGA values to the individual buildings. An attenuation model could be linked to the building inventory via parcel numbers and GIS technology.

The present model would be adjusted so that a PGA value individual to each building will be used to determine that building's damage factor. This would require the addition of modules preceding the DAM-FACT module, plus adjustments in the DAM-FACT module. The remaining REAL-RAP modules would require little if any additional work.

Further research also needs to be done on the estimated damage from long-duration subduction zone earthquakes. The damage estimates used (ATC-13 1985) are based on experince with short-duration crustal events. Very little information is available on the effect of the long-duration shaking, which can be up to 3 -minutes long. Research also needs to be done on the synergistic 
effects of building losses and lifeline-utility losses, as discussed in Chapter I, realizing that building losses are one part of the larger puzzle.

The loss estimation methodology developed in the present research has potential as a "pre-processor" to other regional loss estimation methodologies which still look only at "average" buildings, such as the recently developed HAZUS program (NIBS 1995).

The methodology developed herein is not experimentally verifiable without monumental cost. However, the loss estimating and retrofit effectiveness factors could be adjusted and refined based on detailed reconnaissance information from actual earthquakes. Therefore, reconnaissance data gathering from future earthquakes should be more detailed to aid this type of refinement. 
Aki, K., 1988, "Local Site Effects on Strong Ground Motion, " Earthquake Engineering and Soil Dynamics II: Recent Advances in Ground Motion Evaluation, ASCE Geotechnical Special Publication 20, pp. $103-155$.

Applied Technology Council (ATC-13), 1985, Earthquake Damage Evaluation Data for Cal ifornia, FEMA Contract No. EMW-C-0912, Redwood City, California.

Applied Technology Council (ATC-21), 1988, Rapid Visual Screening of Buildings for Potential Seismic Hazards: A Handbook, FEMA-154, Redwood City, California.

Applied Technology Council (ATC-21-1), 1988, Rapid Visual Screening of Buildings for Potential Seismic Hazards: Supporting Documentation, FEMA-155, Redwood City, California.

Atwater, B.F., 1987, "Evidence for Great Holocene Earthquakes Along the Outer coast of Washington State," Science, V. 236, pp. 942-944.

Bartlett, S.F., and Youd, T.L., 1992, "Empirical prediction of lateral spread displacement", US-Japan Workshop on Earthquake Resistant Design Lifeline Facilities and Countermeasures for Soll Liquefaction, 4th, Honolulu, Hawaii, Proceedings, National Center for Earthquake Engineering Research Technical Report NCEER-92-0019, v. 2 , p. $351-366$.

Benuska, L. , 1990, Earthquake Spectra Supplement to Volume 6: Loma Prieta Earthquake Reconnaissance Report, Earthquake Engineering Research Institute, El Cerrito, California.

Building Seismic Safety Council, 1988, NEHRP Recommended Provisions for the Development of Seismic Regulations for Hew Buildings, Washington, D. C.

Comartin, C. D. , Greene, M. , and Tubbesing, S. K. , 1995, The Hyogo-Ken Nanbu Earthquake: Prel iminary Reconnaissance Report, Earthquake Eng ineering Research Institue, Oakl and, California. 
Federal Emergency Management Agency (FEMA-172), 1989, Techniques for Seismically Rehabilitating Existing Buildings (Preliminary), URS/John A. Blume \& Associates, Washington, D. C.

Federal Emergency Management Agency (FEMA-178), 1992, NEHRP Handbook for the Seismic Evaluation of Existing Buildings, Building Seismic Safety Council, Washington, D.C.

Federal Emergency Management Agency (FEMA-227 \& 228), 1992, A Benefit-Cost Model for the Seismic Rehabilitation of Buildings, VSP Associates, Vol. I \& II, Washington, D. C.

Federal Emergency Management Agency (FEMA-156), 1994, Typical Costs for Seismic Rehabilitation of Existing Buildings, Second Edition, Vols. 1 and 2, Hart Consultant Group, Washington, D.C.

Goettel \& Horner Inc., 1995, Earthquake Risk Analysis, Final Report, Vol. 1 \& 2 , Submitted to the City of Portland, Sacramento, California.

Geomatrix Consultants, 1995 Seismic Design Mapping, State of Oregon, Final Report, ODOT Contract 11688, San Francisco, California.

International Conference of Building Officials, 1991, Uniform Building Code, Whittier, California.

Oregon Department of Geology \& Mineral Industries (GMS-79), 1993, Earthquake Hazard Maps of the Portland Quadrangle, Portland, Oregon.

National Bureau of Standards (NBS 55), 1964, Handbook of Mathematical Functions, Applied Mathematics Series 55, Washington, D. C.

National Institue of Building Sciences, 1995, Development of a Standardized Earthquake Loss Estimation Methodology, Volume I, Draft Technical Manual $100 \%$ Submittal, Risk Management Solutions, Inc., Menlo Park, California.

Rad, F. N. , \& McCormack, T. C. , 1994, Rapid Visual Screening of 4500 Buildings in Portland, submitted to Metro, Portland, Oregon. 
Richter, C. F., 1958, Elementary Seismology, W. H. Freeman and Co., San Francisco, California.

Robertshaw, J. E. , Mecca, S. J., and Rerick, M. N., 1978, Problem Solving: A Systems Approach, Petrocelli Books Inc., New York, N. Y.

Schnable, P. B. , Lysmer, J., and Seed, H. B., 1972, SHAKE - A computer program for earthquake analysis of horizontally layered sites, Earthquake Engineering Research Center Report EERC 72-12, Berkeley, California, University of California.

Tri-Ket, 1993, Line Section 5A Geotechnical Interpretive Report, Westside Corridor Project, Tri-County Metropolitan Transportation District of Oregon, Portland, Oregon.

Wood, H. O., and Newmann, F., 1931, "Modifed Mercalli Intensity Scale of 1931," Seismological Society of America Bulletin, Vol. 21, No. 4, pp. 277-283.

Wyllie, L. A., and Filson, J.R., 1989, Earthquake Spectra Special Supplement: Armenia Earthquake Reconnaissance Report, Earthquake Engineering Research Institute, El Cerrito, California. 


\begin{abstract}
APPENDIX A
POWER CURVE COEFFICIENTS FROM MEAN DAMAGE FACTOR
\end{abstract}

VS. STRUCTURAL SCORE REGRESSIONS

Reproduced with permission of the copyright owner. Further reproduction prohibited without permission. 
W - WOOD FRAME

\begin{tabular}{lllll}
\hline MMI & PGA & BSH & $b(0)$ & $b(1)$ \\
\hline VI & .05 & 7.08 & 18.20052 & -1.10604 \\
VII & .10 & 8.46 & 24.51270 & -0.82999 \\
VIII & .22 & 4.76 & 25.86136 & -0.78016 \\
IX & .47 & 3.75 & 30.20206 & -0.63640 \\
X & 1.02 & 1.48 & 29.77830 & -0.64946 \\
\hline
\end{tabular}

S1 - STEEL MRF

\begin{tabular}{lllll}
\hline MIMI & PGA & BSH & $b(0)$ & \multicolumn{1}{c}{$b(1)$} \\
\hline VI & .05 & 2.24 & 4.80857 & -2.33550 \\
VII & .10 & 5.42 & 19.47400 & -1.04302 \\
VIII & .22 & 6.12 & 27.30582 & -0.72981 \\
IX & .47 & 5.42 & 31.92183 & -0.58500 \\
X & 1.02 & 3.43 & 34.13045 & -0.52297 \\
\hline
\end{tabular}


S2 - BRACED STL FRAME

\begin{tabular}{lllll}
\hline MMI & PGA & BSH & $b(0)$ & $b(1)$ \\
\hline VI & .05 & 2.33 & 4.80857 & -2.33550 \\
VII & .10 & 3.76 & 14.11023 & -1.34190 \\
VIII & .22 & 5.30 & 24.92447 & -0.81451 \\
IX & .47 & 5.04 & 29.81674 & -0.64834 \\
X & 1.02 & 3.36 & 32.00781 & -0.58252 \\
\hline
\end{tabular}

S3 - LIGHT METAL

\begin{tabular}{lcccc}
\hline MMI & PGA & BSH & $b(0)$ & $b(1)$ \\
\hline VIII & .22 & 8.08 & 25.43586 & -0.79565 \\
IX & .47 & 5.40 & 28.38696 & -0.69388 \\
X & 1.02 & 3.24 & 31.80362 & -0.58847 \\
\hline
\end{tabular}




\begin{tabular}{lllll}
\multicolumn{5}{c}{ S4 - STL FRAME W/ CONC SHEARWALLS } \\
\hline MMI & PGA & BSH & $\mathrm{b}(0)$ & $\mathrm{b}(1)$ \\
\hline VI & .05 & 9.61 & 24.69128 & -0.82320 \\
VII & .10 & 6.17 & 25.13170 & -0.80662 \\
VIII & .22 & 4.73 & 30.47236 & -0.62809 \\
IX & .47 & 3.49 & 34.70487 & -0.50750 \\
$X$ & 1.02 & 1.80 & 34.47071 & -0.51382 \\
\hline
\end{tabular}

C1 - REINF CONC MRF

\begin{tabular}{lllll}
\hline MMI & PGA & BSH & $b(0)$ & $b(1)$ \\
\hline VI & .05 & 5.12 & 18.43037 & -1.09442 \\
VII & .10 & 4.86 & 26.75175 & -0.74878 \\
VIII & .22 & 2.56 & 30.61683 & -0.62376 \\
IX & .47 & 1.33 & 35.18993 & -0.49472 \\
X & 1.02 & 0.65 & 37.23838 & -0.44221 \\
\hline
\end{tabular}


C2 - REINF CONC SHEARWALL

\begin{tabular}{lllll}
\hline MMI & PGA & BSH & $b(0)$ & $b(1)$ \\
\hline VI & .05 & 7.18 & 18.89713 & -1.07089 \\
VII & .10 & 3.85 & 20.43563 & -0.99845 \\
VIII & .22 & 3.80 & 29.02565 & -0.67320 \\
IX & .47 & 2.25 & 32.27684 & -0.57477 \\
$X$ & 1.02 & 1.21 & 37.07823 & -0.44649 \\
\hline
\end{tabular}

C3/S5 - URM INFILL

\begin{tabular}{lllll}
\hline MMI & PGA & BSH & $b(0)$ & $b(1)$ \\
\hline VI & .05 & 3.06 & 14.40824 & -1.32260 \\
VII & .10 & 2.27 & 19.10022 & -1.06120 \\
VIII & .22 & 1.34 & 24.07250 & -0.84667 \\
IX & .47 & 0.76 & 29.89975 & -0.64564 \\
$X$ & 1.02 & 0.34 & 34.03400 & -0.52571 \\
\hline
\end{tabular}


PC1 - TILT UP

\begin{tabular}{lllll}
\hline MMI & PGA & BSH & $b(0)$ & $b(1)$ \\
\hline VI & .05 & 5.98 & 20.10624 & -1.01358 \\
VII & .10 & 5.70 & 27.55186 & -0.72151 \\
VIII & .22 & 3.02 & 29.66477 & -0.65295 \\
IX & .47 & 1.97 & 33.63610 & -0.53654 \\
X & 1.02 & 0.95 & 34.75106 & -0.50629 \\
\hline
\end{tabular}

PC2 - PRECAST FRAME

\begin{tabular}{lllll}
\hline MMI & PGA & BSH & $b(0)$ & $b(1)$ \\
\hline VI & .05 & 3.02 & 10.11581 & -1.65050 \\
VII & .10 & 4.15 & 21.27473 & -0.96109 \\
VIII & .22 & 2.75 & 25.78235 & -0.78297 \\
IX & .47 & 1.05 & 34.34272 & -0.51727 \\
X & 1.02 & 0.33 & 37.34354 & -0.43962 \\
\hline
\end{tabular}


RM - REINF MASONRY

\begin{tabular}{lllll}
\hline MIMI & PGA & BSH & $b(0)$ & $b(1)$ \\
\hline VI & .05 & 6.23 & 17.58770 & -1.13773 \\
VII & .10 & 6.03 & 24.83763 & -0.81770 \\
VIII & .22 & 3.16 & 24.92447 & -0.81451 \\
IX & .47 & 1.93 & 27.49434 & -0.72342 \\
X & 1.02 & 1.35 & 34.36127 & -0.51679 \\
\hline
\end{tabular}

URM - UNREINF MASONRY

\begin{tabular}{lllll}
\hline MMI & PGA & BSH & $b(0)$ & $b(1)$ \\
\hline VI & .05 & 4.69 & 22.35209 & -0.91548 \\
VII & .10 & 2.03 & 20.92972 & -0.97639 \\
VIII & .22 & 1.24 & 28.94623 & -0.67583 \\
IX & .47 & 0.49 & 36.89790 & -0.47127 \\
X & 1.02 & 0.07 & 42.07165 & -0.32905 \\
\hline
\end{tabular}


APPENDIX B

HALF-STEP FRAGILITY CURVES

Reproduced with permission of the copyright owner. Further reproduction prohibited without permission. 


\section{WOOD - WOOD FRAME}

NEHRP AREAS 3,4

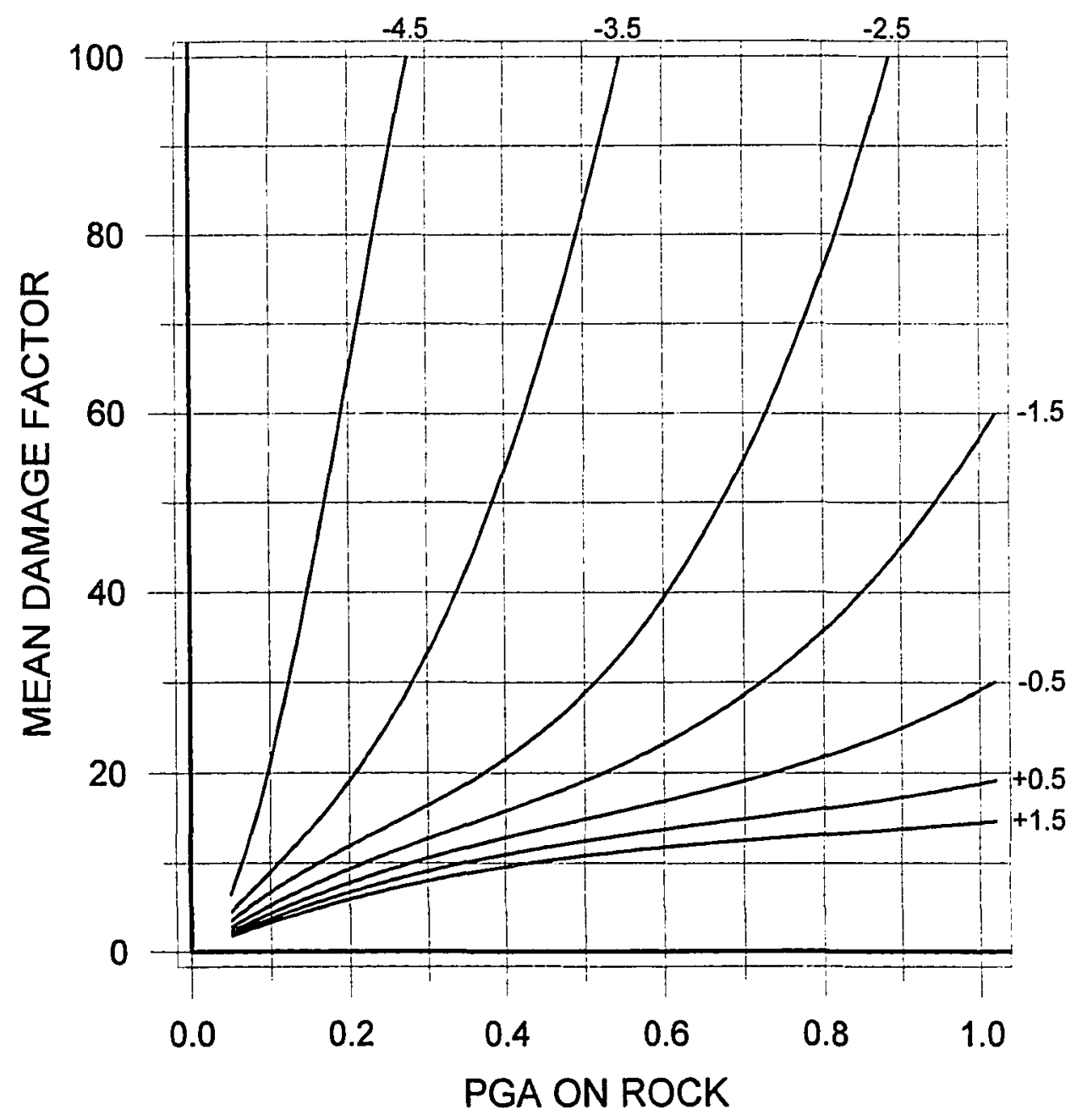




\section{S1 - STEEL MRF}

\section{NEHRP AREAS 3,4}

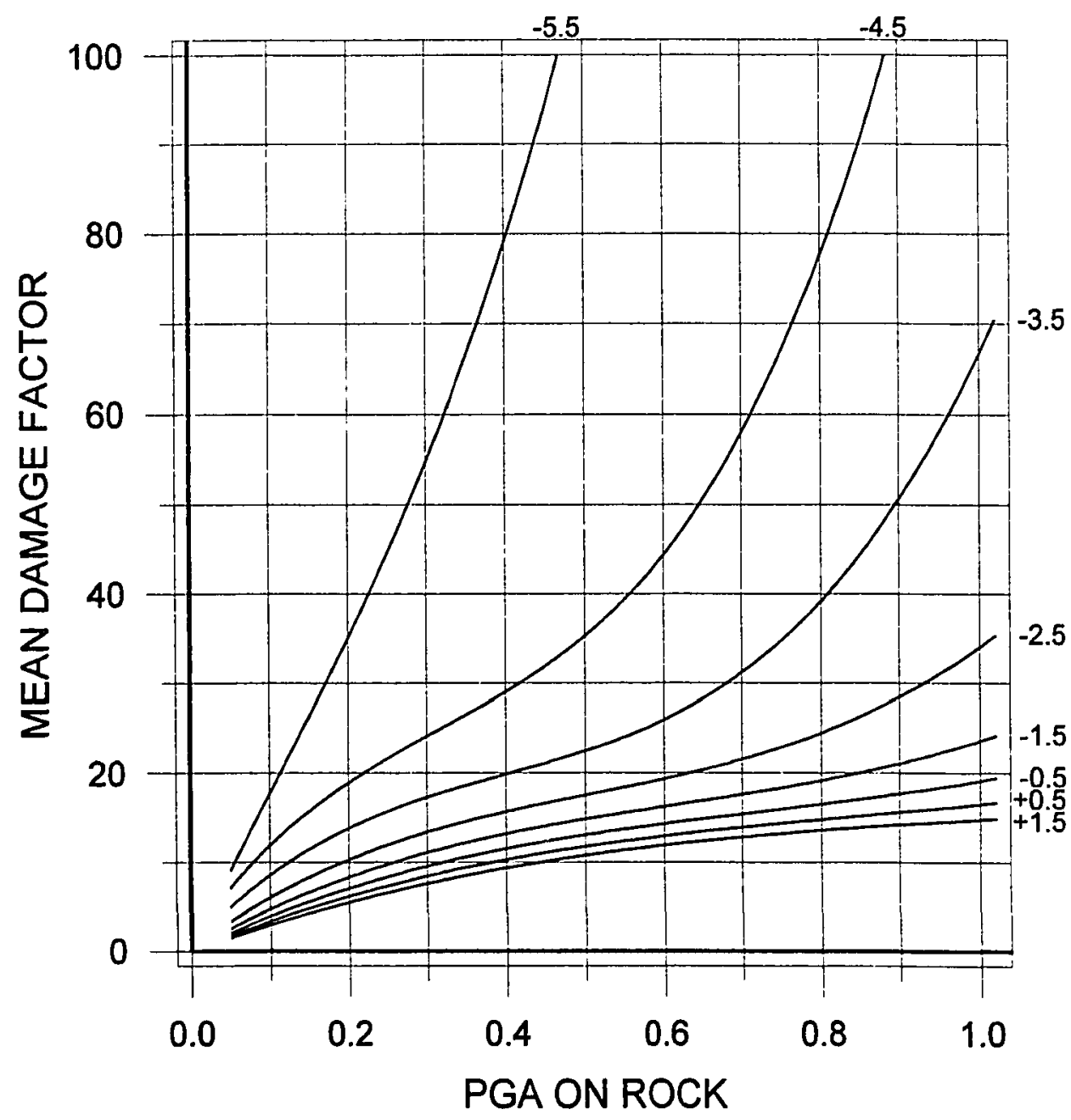




\section{S2 - BRACED STEEL FRAME NEHRP AREAS 3,4}

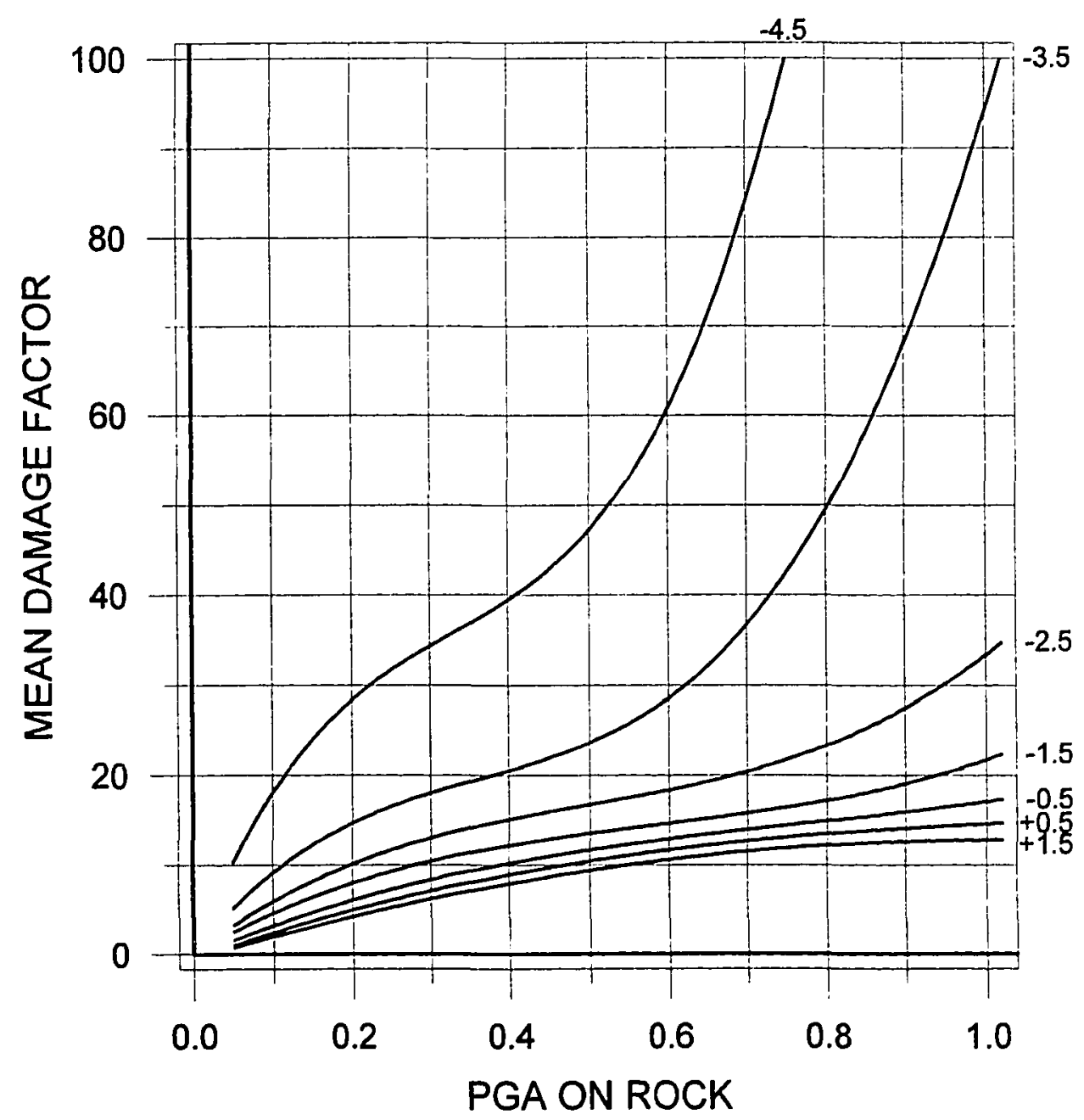




\section{S3 - LIGHT METAL}

NEHRP AREAS 3,4

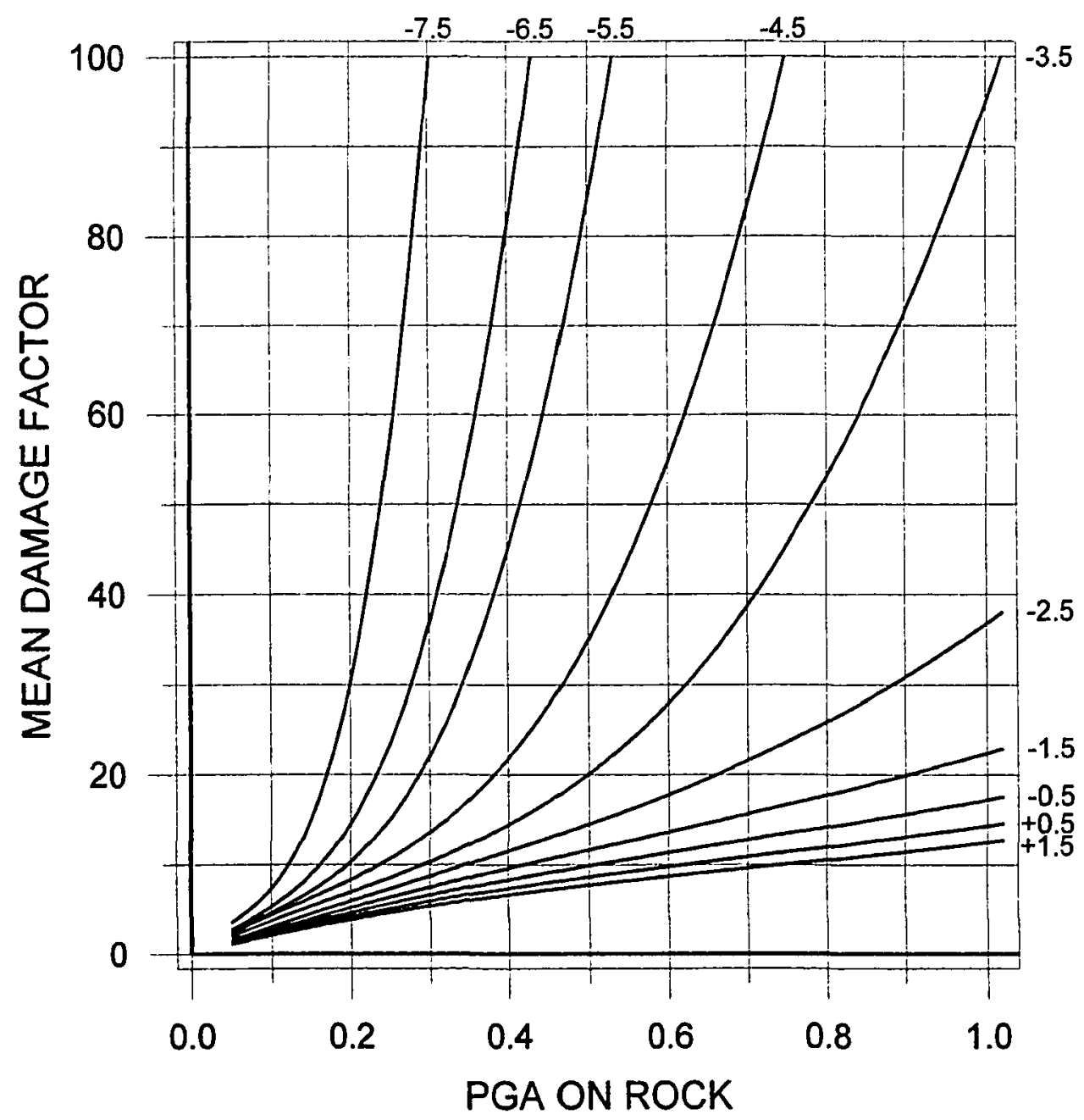




\section{S4 - STEEL FRAME W/ CONC SHEARWALLS NEHRP AREAS 3,4}

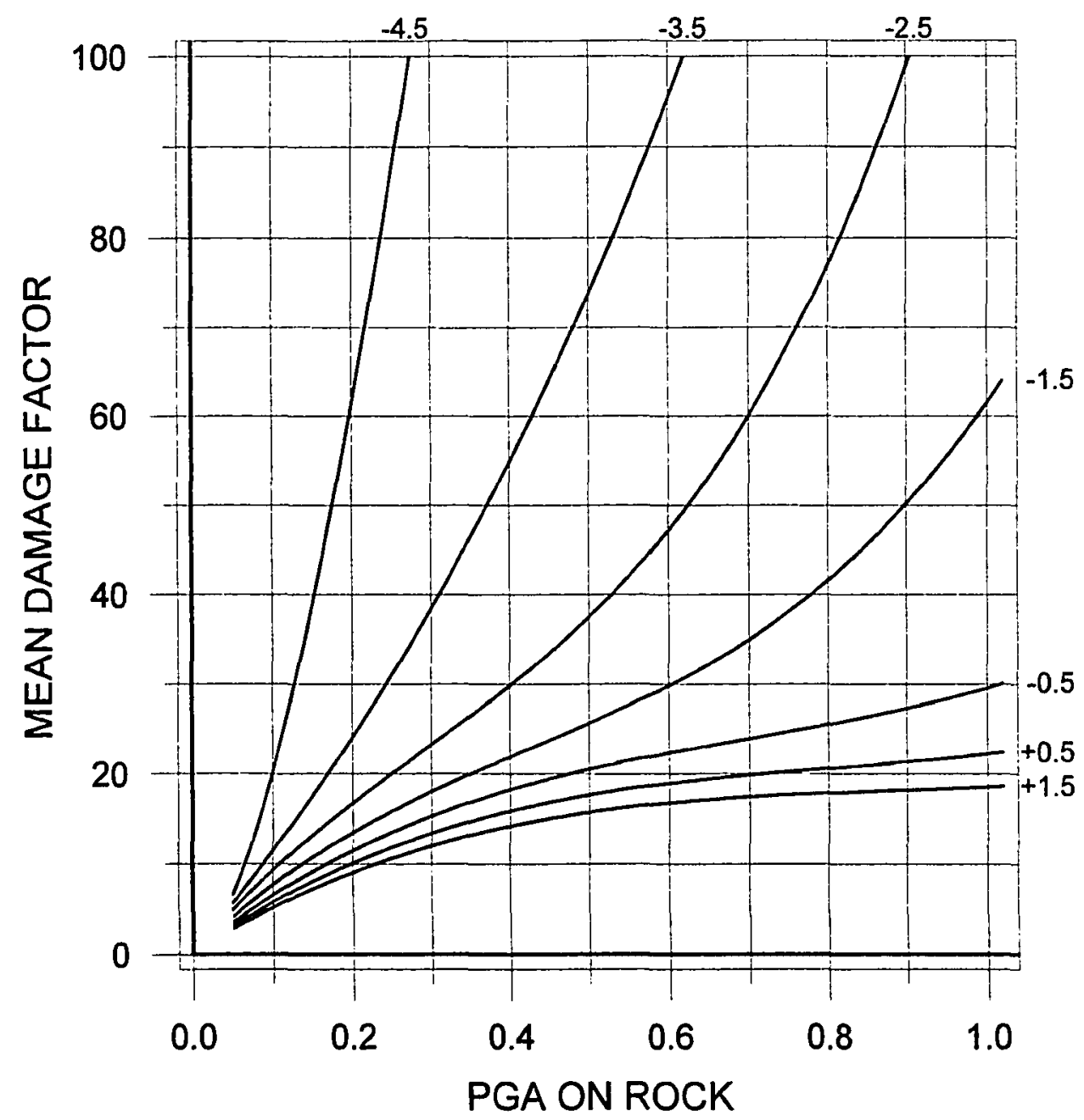


C1 - REINF CONC MRF NEHRP AREAS 3,4

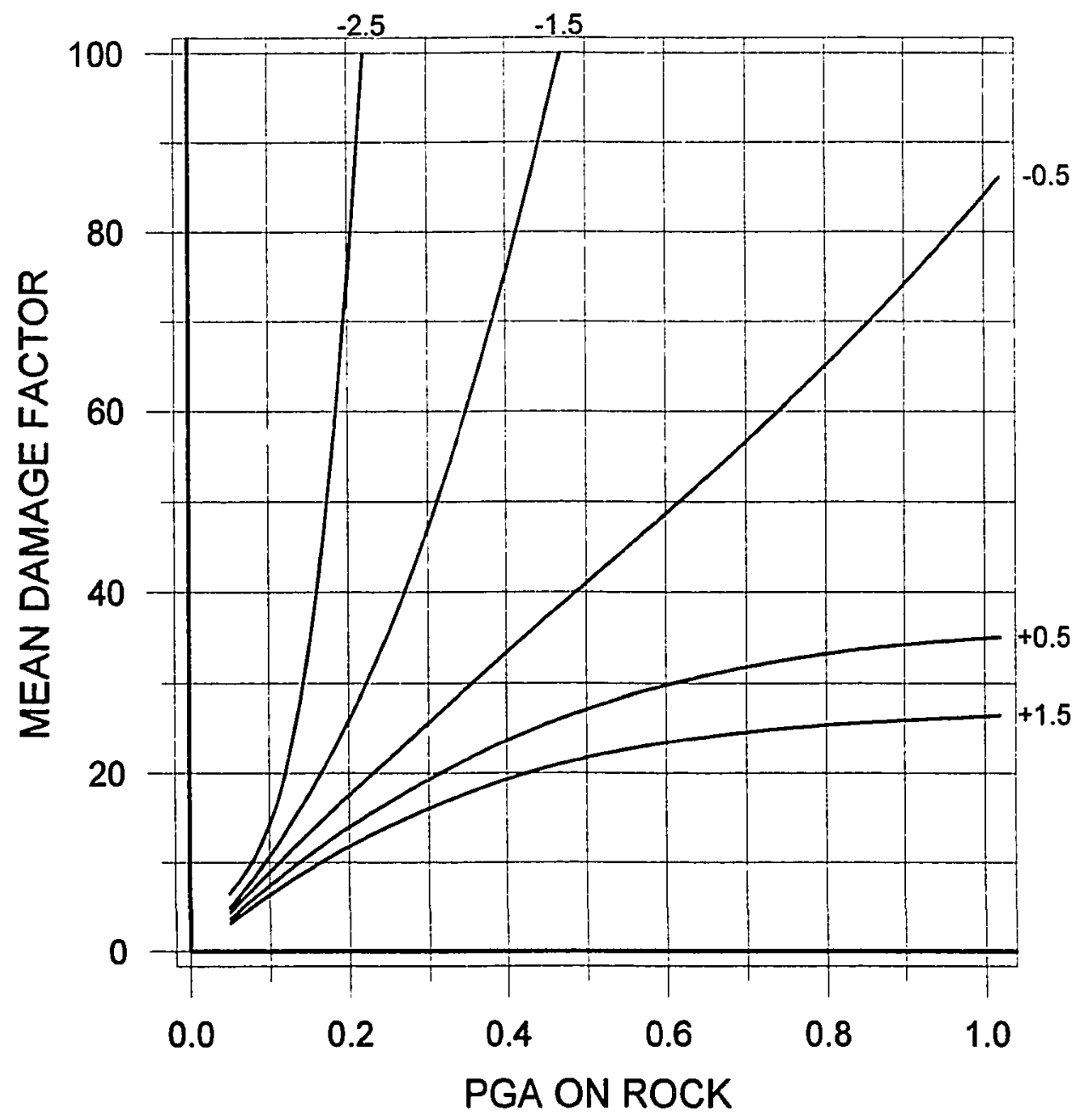




\section{C2 - REINF CONC SHEARWALL NEHRP AREAS 3,4}

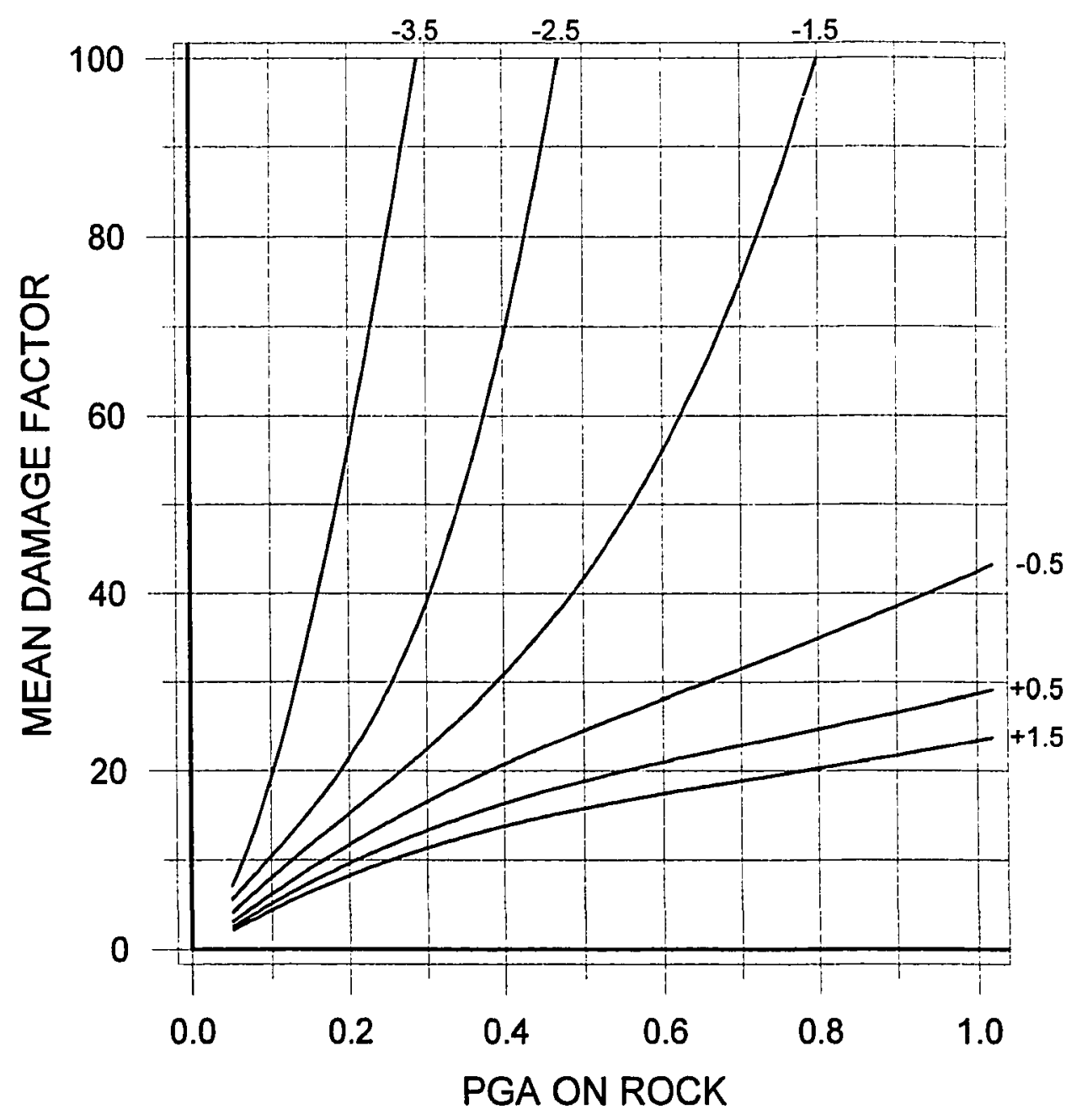




\section{C3/S5 - URM INFILL \\ NEHRP AREAS 3,4}

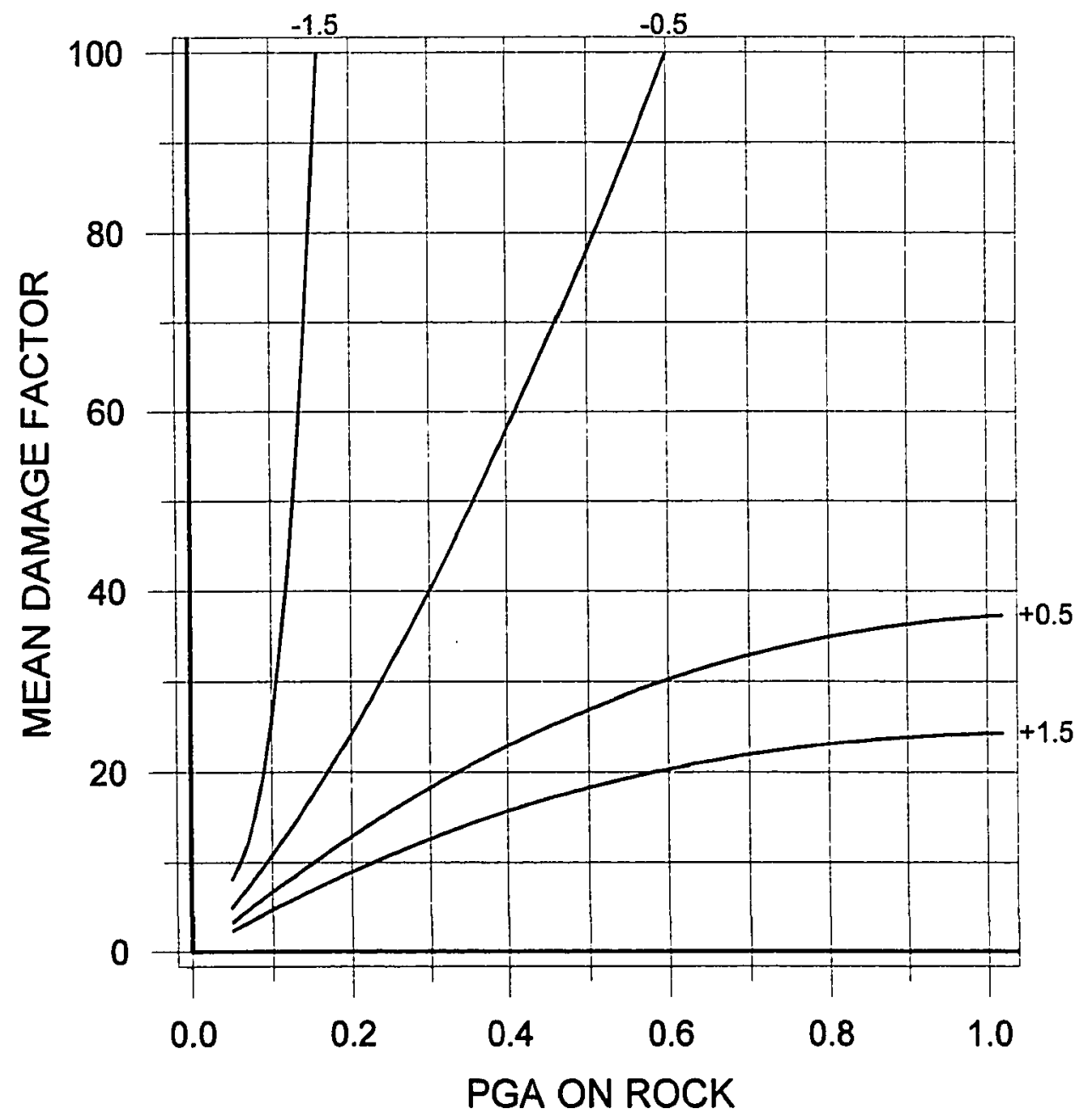




\section{PC1 - TILT UP}

\section{NEHRP AREAS 3,4}

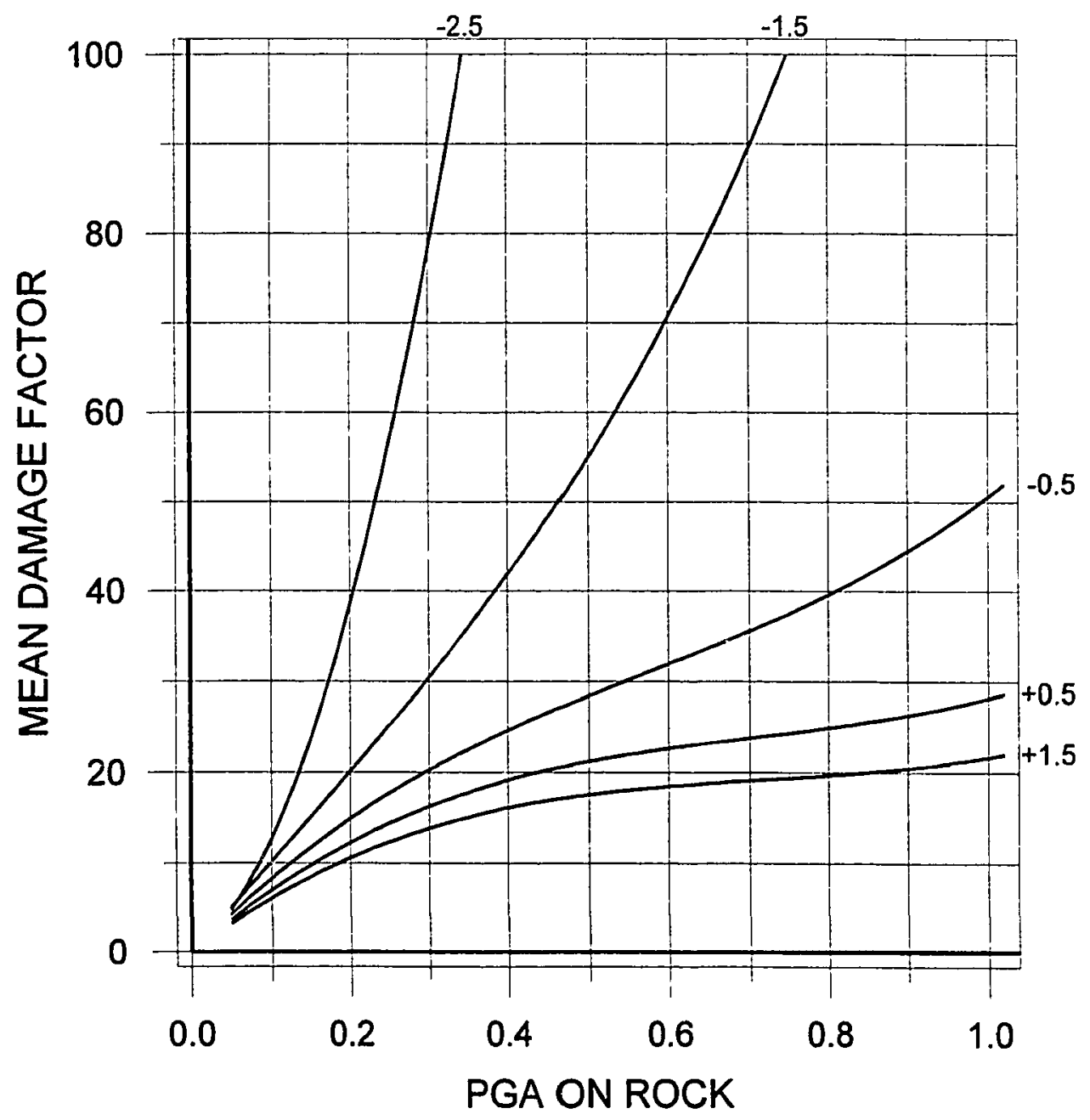




\section{PC2 - PRECAST CONCRETE FRAME NEHRP AREAS 3,4}

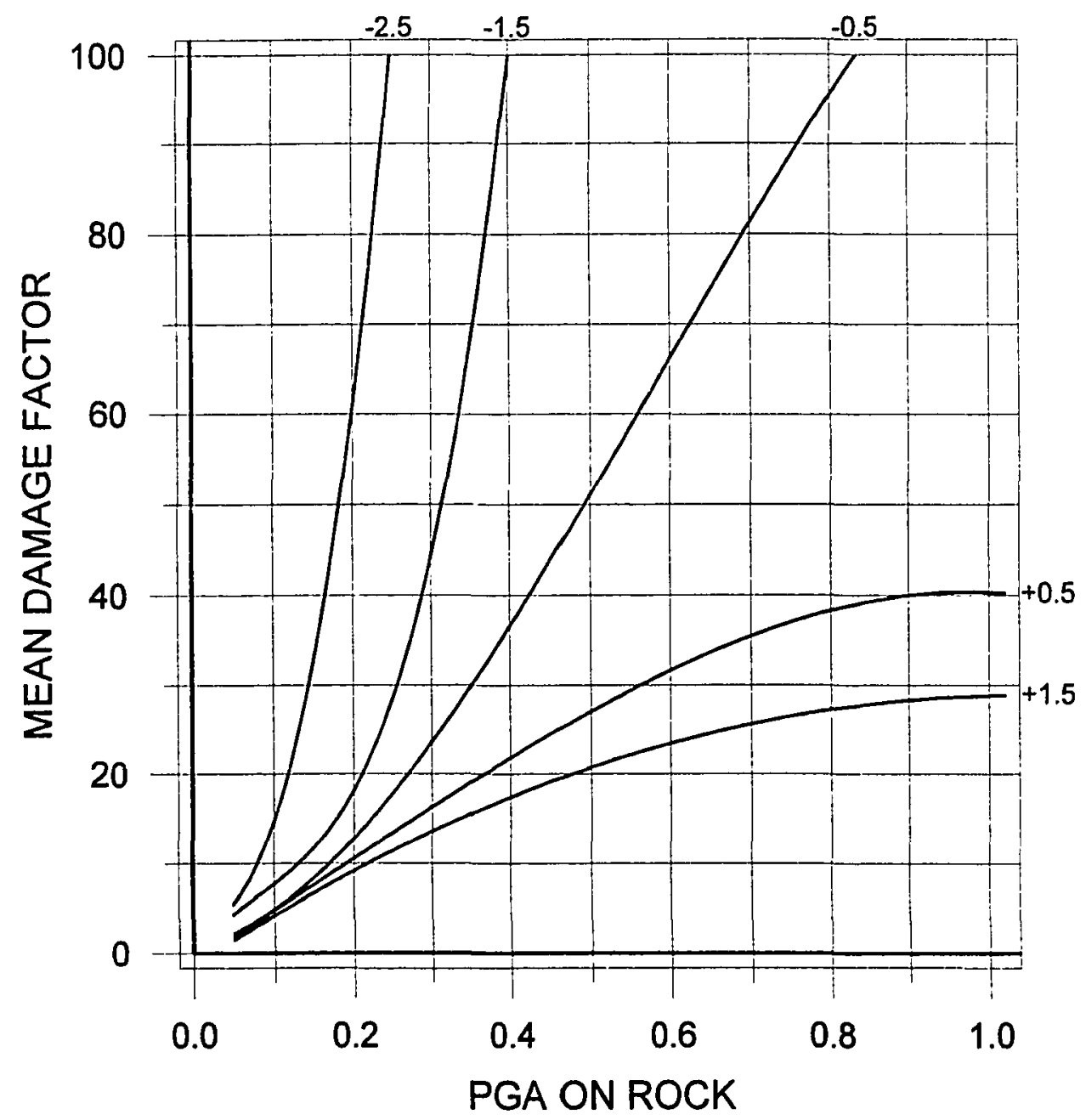




\section{RM - REINFORCED MASONRY NEHRP AREAS 3,4}

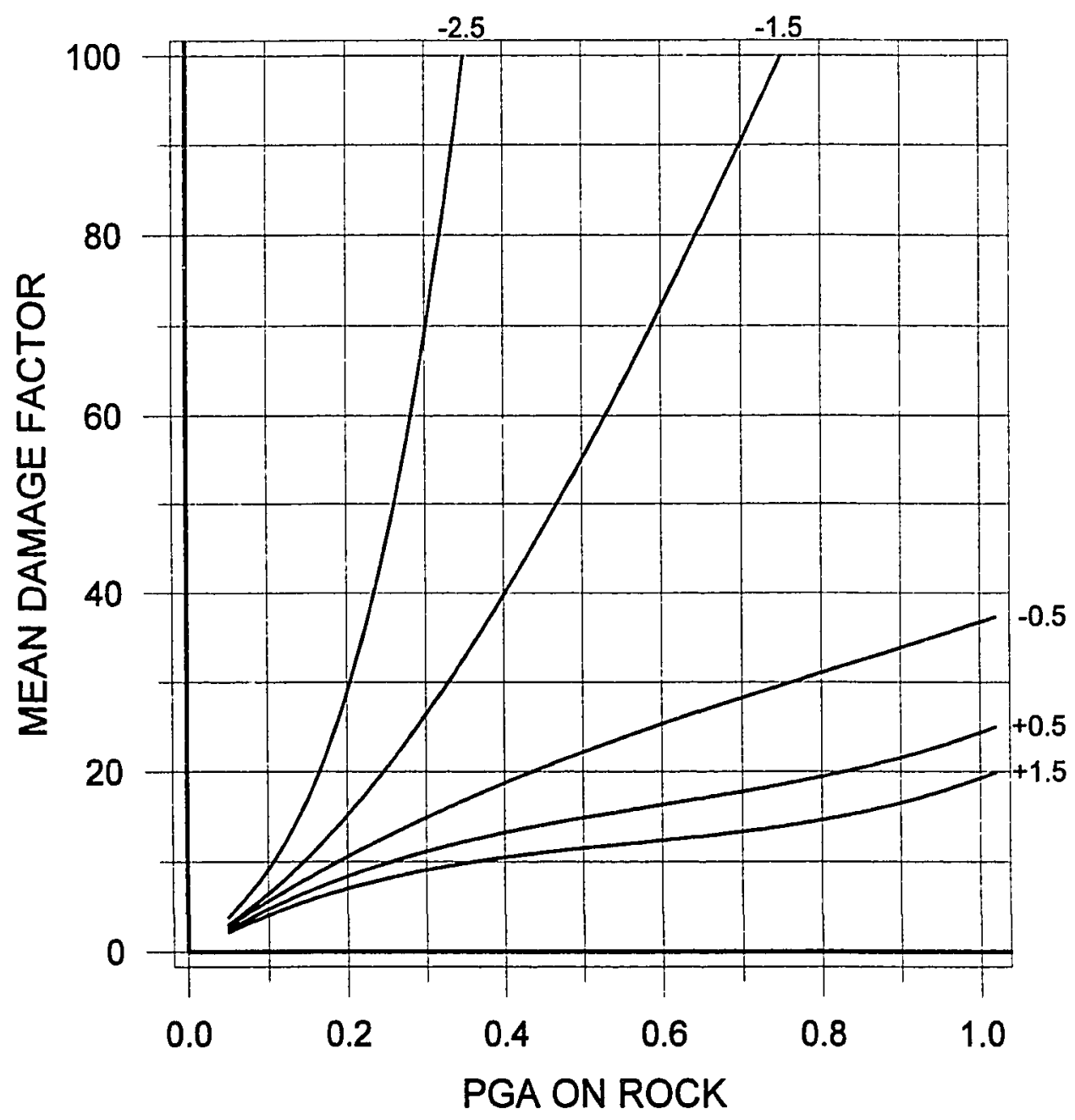




\section{URM - UNREINFORCED MASONRY NEHRP AREAS 3,4}

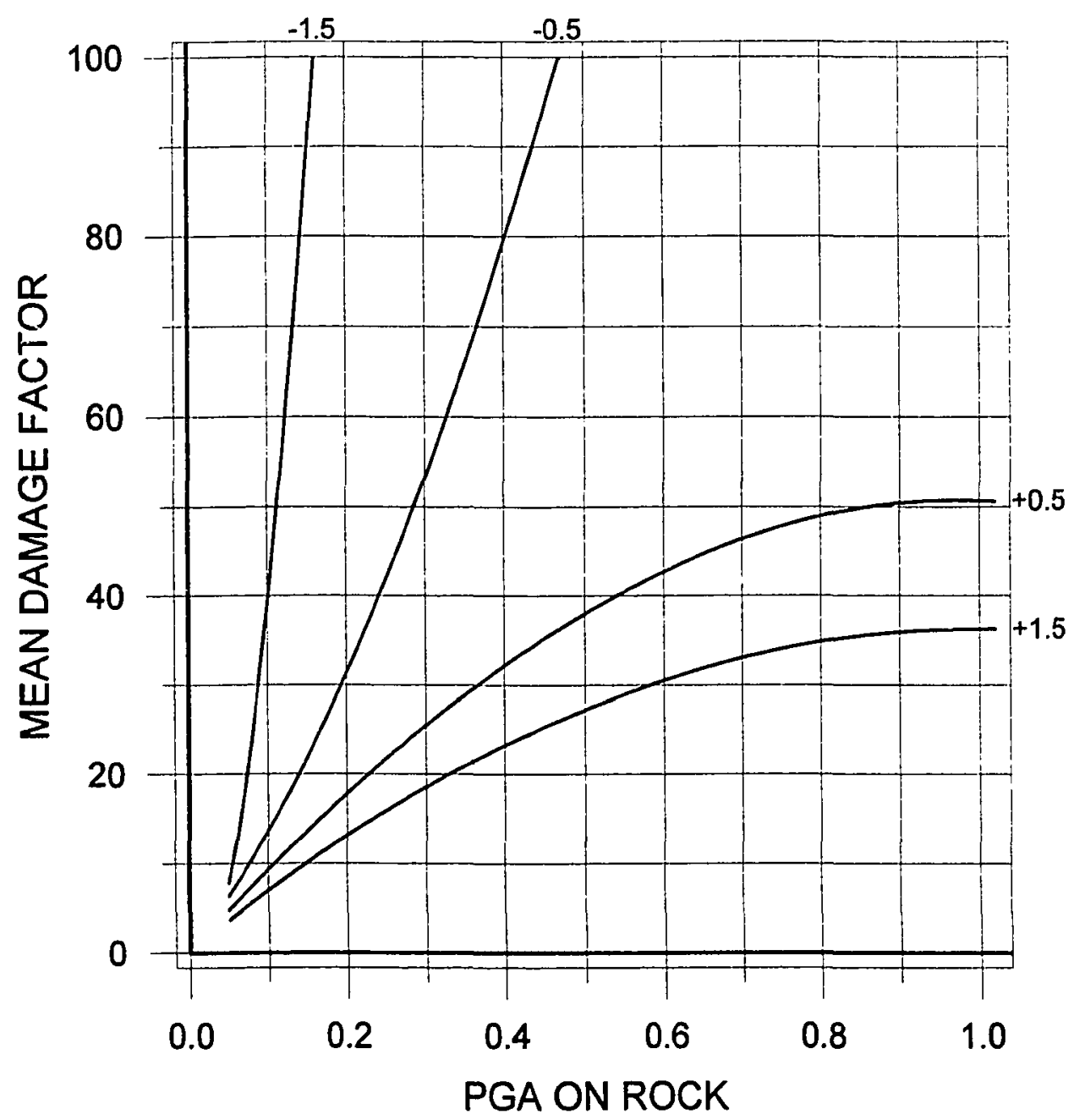


APPENDIX C

BUILDING CLASSES PRIORITIZED FOR OPTIMAL RETROFIT FOR A DESIGN BASIS EARTHQUAKE 
BUILDING CLASSES PRIORITIZED FOR OPTIMAL RETROFIT FOR A DESIGN BASIS EARTHQUAKE (PGA $=.20$ )

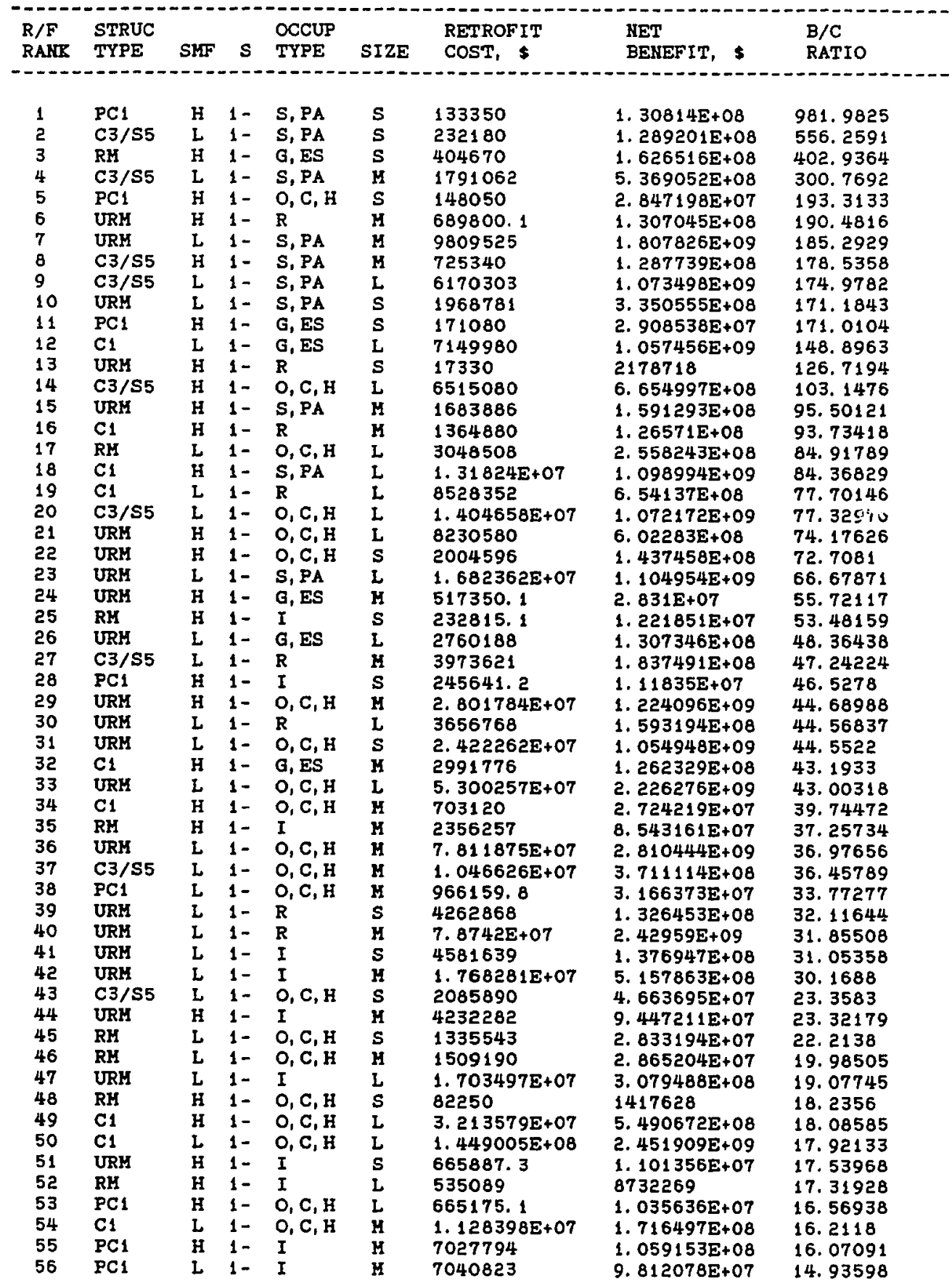




\begin{tabular}{|c|c|c|c|c|c|c|c|c|}
\hline $\begin{array}{l}\text { R/F } \\
\text { RANLS }\end{array}$ & $\begin{array}{l}\text { STRUC } \\
\text { TYPE }\end{array}$ & SMF & $\mathbf{S}$ & $\begin{array}{l}\text { OCCUP } \\
\text { TYPE }\end{array}$ & SIZE & $\begin{array}{l}\text { RETROFIT } \\
\text { COST, \$ }\end{array}$ & $\begin{array}{l}\text { NET } \\
\text { BENEFIT, \$ }\end{array}$ & $\begin{array}{l}\text { B/C } \\
\text { RATIO }\end{array}$ \\
\hline $\begin{array}{l}57 \\
58 \\
59 \\
60 \\
61 \\
62 \\
63 \\
64 \\
65 \\
66 \\
67 \\
68 \\
69 \\
70 \\
71 \\
72 \\
73 \\
74 \\
75 \\
76 \\
77 \\
78 \\
79 \\
80 \\
81 \\
82 \\
83 \\
84 \\
85\end{array}$ & $\begin{array}{l}\text { C3/S5 } \\
\text { C2 } \\
\text { PC1 } \\
\text { PC2 } \\
\text { CL } \\
\text { PC1 } \\
\text { URH } \\
\text { C3/S5 } \\
\text { C1 } \\
\text { PC1 } \\
\text { C2 } \\
\text { RH } \\
\text { URH } \\
\text { C3/S5 } \\
\text { RH } \\
\text { C1 } \\
\text { PC1 } \\
\text { PC1 } \\
\text { RH } \\
\text { URH } \\
\text { S1, 2, } 4 \\
\text { C1 } \\
\text { URH } \\
\text { URH } \\
\text { URH } \\
\text { URH } \\
\text { C1 } \\
\text { C1 } \\
\text { C1 }\end{array}$ & $\begin{array}{l}\text { L } \\
H \\
H \\
H \\
L \\
L \\
H \\
L \\
H \\
L \\
H \\
L \\
L \\
H \\
L \\
L \\
H \\
L \\
L \\
L \\
L \\
L \\
H \\
H \\
H \\
H \\
H \\
L \\
\text { L }\end{array}$ & $\begin{array}{l}1- \\
1- \\
1- \\
1- \\
1- \\
1- \\
1- \\
1- \\
1- \\
1- \\
1- \\
1- \\
1- \\
1- \\
1- \\
1- \\
1- \\
1- \\
1- \\
1+ \\
1- \\
1- \\
1+ \\
1+ \\
1+ \\
1+ \\
1- \\
1- \\
1-\end{array}$ & $\begin{array}{l}\text { I } \\
\text { G, ES } \\
\text { I } \\
\text { I } \\
\text { O, C, H } \\
\text { I } \\
\text { I } \\
\text { I } \\
\text { I } \\
\text { G, ES } \\
\text { I } \\
\text { I } \\
\text { G, ES } \\
\text { O, C, H } \\
\text { R } \\
\text { S, PA } \\
\text { O, C, H } \\
\text { I } \\
\text { I } \\
\text { S, PA } \\
\text { O, C, H } \\
\text { O, C, H } \\
\text { O, C, H } \\
\text { I } \\
\text { I } \\
\text { O, C, H } \\
\text { I } \\
\text { I } \\
\text { G, ES }\end{array}$ & $\begin{array}{l}S \\
L \\
L \\
H \\
L \\
L \\
L \\
H \\
S \\
S \\
H \\
H \\
S \\
H \\
S \\
H \\
H \\
S \\
S \\
S \\
L \\
S \\
S \\
S \\
H \\
H \\
L \\
H \\
H\end{array}$ & $\begin{array}{l}916618.9 \\
2143008 \\
6305523 \\
445950 \\
4.817625 E+07 \\
1.191433 E+07 \\
3220450 \\
3193137 \\
211791.5 \\
96347.66 \\
3549821 \\
945936.9 \\
655163.6 \\
413600 \\
295590.1 \\
1913755 \\
2962663 \\
271845.6 \\
790650 \\
1345049 \\
1.959992 E+08 \\
1166888 \\
968920.5 \\
58150 \\
692700 \\
5380440 \\
1474445 \\
2152566 \\
3047144\end{array}$ & $\begin{array}{l}\text { 1. } 255845 E+07 \\
2.804779 E+07 \\
8.044111 E+07 \\
4888704 \\
5.055421 E+08 \\
1.2236 E+08 \\
3.127442 E+07 \\
2.8928 E+07 \\
1806800 \\
698739.1 \\
2.573751 E+07 \\
6291938 \\
4191031 \\
2014498 \\
1256503 \\
7832591 \\
1.042215 E+07 \\
907450.6 \\
2104964 \\
2565293 \\
3.671397 E+08 \\
218312 B \\
1693279 \\
96603.09 \\
560151.1 \\
4328500 \\
1183235 \\
535646 \\
180924.3\end{array}$ & $\begin{array}{l}14.70084 \\
14.08805 \\
13.75724 \\
11.96245 \\
11.4936 \\
11.26998 \\
10.71119 \\
10.05943 \\
9.531032 \\
8.252269 \\
8.250367 \\
7.651541 \\
7.396923 \\
5.870642 \\
5.250831 \\
5.092787 \\
4.51783 \\
4.338111 \\
\text { 3. } 66232 \\
2.907211 \\
2.873169 \\
2.870898 \\
2.747594 \\
2.661274 \\
1.808649 \\
1.804488 \\
1.802495 \\
1.248841 \\
1.059375\end{array}$ \\
\hline
\end{tabular}

RANK HO. 85 = POINT OF MAXIMUM EFFICIENCY (OPTIMAL RETROFIT)

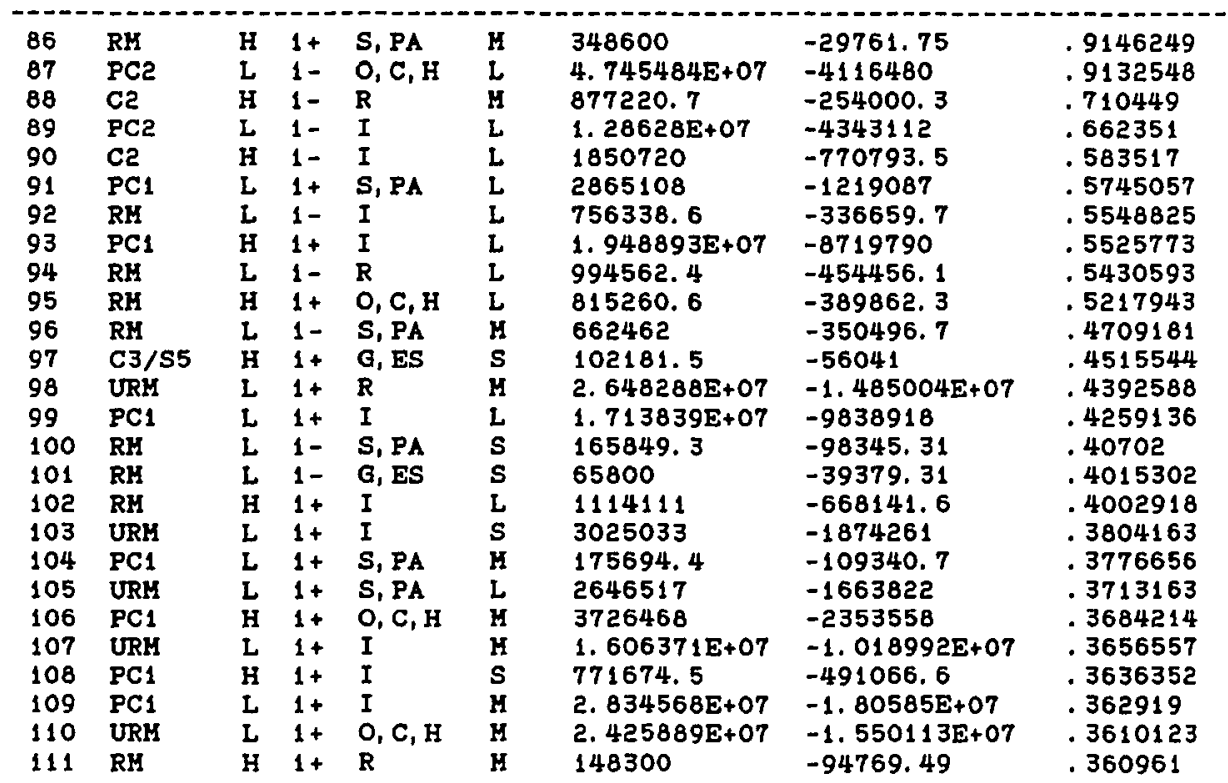




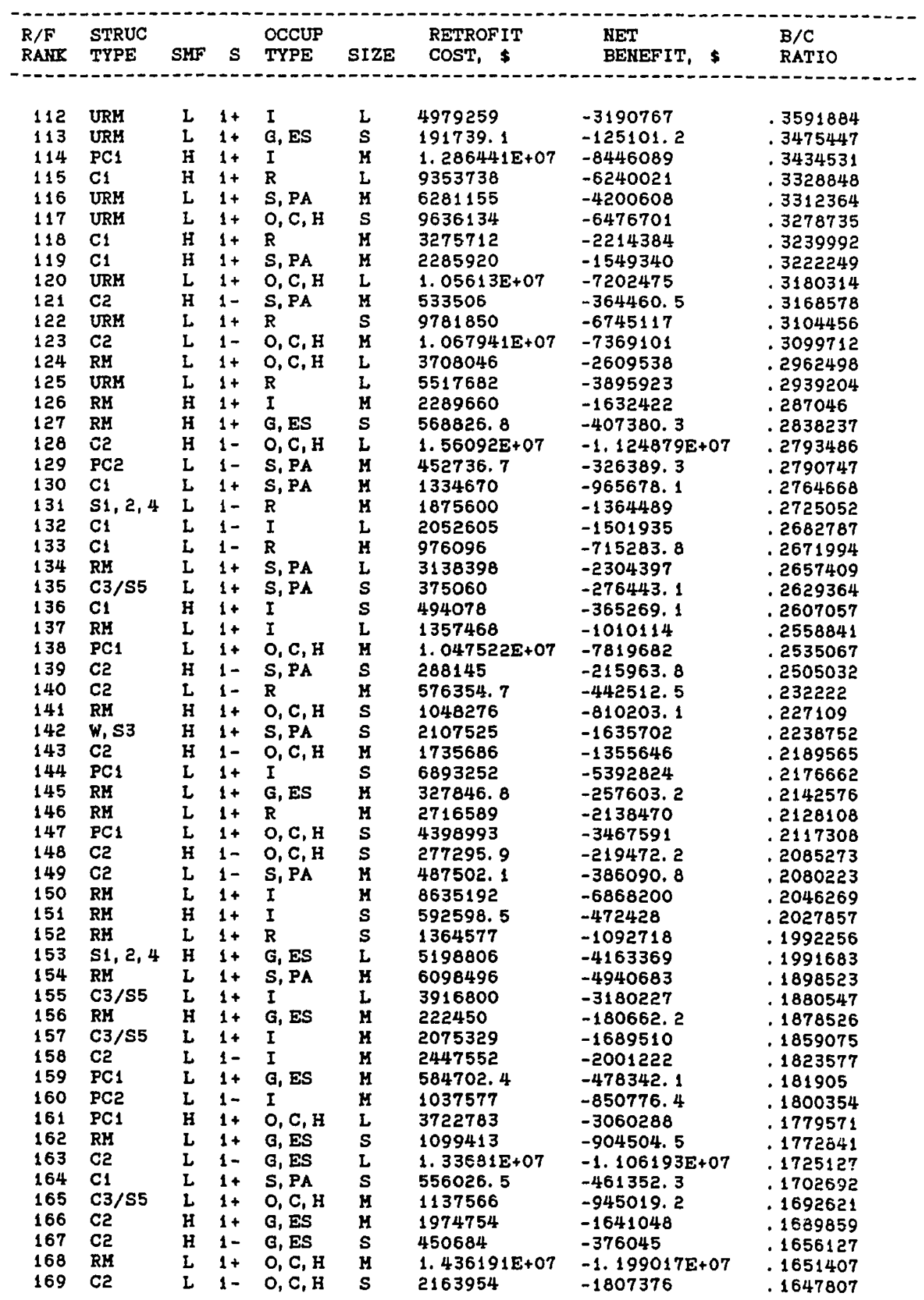




\begin{tabular}{|c|c|c|c|c|c|c|c|c|}
\hline $\begin{array}{l}R / F \\
\text { RANK }\end{array}$ & $\begin{array}{l}\text { STRUC } \\
\text { TYPE }\end{array}$ & SMF & $\mathbf{s}$ & $\begin{array}{l}\text { OCCUP } \\
\text { TYPE }\end{array}$ & SIZE & $\begin{array}{l}\text { RETROFIT } \\
\text { COST, } \$\end{array}$ & $\begin{array}{l}\text { NET } \\
\text { BENEFIT, }\end{array}$ & $\begin{array}{l}\text { B/C } \\
\text { RATIO }\end{array}$ \\
\hline 170 & C2 & L & $1-$ & I & $\mathbf{s}$ & 241881.8 & -202225.5 & .163949 \\
\hline 171 & PC1 & $\mathrm{H}$ & $1+$ & $\mathrm{O}, \mathrm{C}, \mathrm{H}$ & $\mathbf{s}$ & 159828.2 & -133817.3 & .1627428 \\
\hline 172 & C1 & L & $1+$ & $I$ & $\mathbf{s}$ & 353823.6 & -296295.4 & .1625902 \\
\hline 173 & C1 & L & $1+$ & S, PA & L & 2. $77972 E+07$ & $-2.33449 E+07$ & .1601708 \\
\hline 174 & c2 & $\mathrm{H}$ & $1+$ & G, ES & L & 5116480 & -4302497 & .1590904 \\
\hline 175 & RH & L & $1+$ & $\mathrm{O}, \mathrm{C}, \mathrm{H}$ & $\mathbf{s}$ & 2. $611807 \mathrm{E}+07$ & -2. 197621E+07 & .1585822 \\
\hline 176 & C1 & $\mathrm{H}$ & $1+$ & I & $\boldsymbol{H}$ & 1078560 & -909767.1 & .1564984 \\
\hline 177 & $51,2,4$ & I & $1-$ & $\mathrm{O}, \mathrm{C}, \mathrm{H}$ & $\mathbf{s}$ & 333840 & -281653.2 & .1563228 \\
\hline 178 & $\mathrm{Cl}_{1}$ & L & $1+$ & $\mathbf{R}$ & L & 2. $103142 E+07$ & $-1.778067 E+07$ & .1545664 \\
\hline 179 & RH & H & $1+$ & $\mathrm{O}, \mathrm{C}, \mathrm{H}$ & $\mathbf{M}$ & 1852890 & -1568529 & .153469 \\
\hline 180 & RH & L & $1+$ & $I$ & $s$ & 8932788 & -7564231 & .1532061 \\
\hline 181 & $\mathrm{C} 2$ & $\mathbf{H}$ & $1+$ & I & L & 2. $700477 \mathrm{E}+07$ & $-2.297141 E+07$ & .1493573 \\
\hline 182 & C1 & L & $1+$ & $\mathrm{O}, \mathrm{C}, \mathrm{H}$ & $\mathbf{s}$ & 2957125 & -2531031 & .1440906 \\
\hline 183 & $\mathrm{Cl}$ & H & $1+$ & $O, C, H$ & L & 1. $192852 E+07$ & $-1.022711 E+07$ & .1426338 \\
\hline 184 & $\mathrm{Cl}$ & L & $1+$ & $\mathrm{O}, \mathrm{C}, \mathrm{H}$ & M & 1. $306418 \mathrm{E}+07$ & $-1.123243 E+07$ & .1402118 \\
\hline 185 & $\mathrm{C} 2$ & H & $1+$ & $\mathbf{S}, \mathbf{P A}$ & M & 1486820 & -1278662 & .140002 \\
\hline 186 & $\mathrm{C} 2$ & H & $1+$ & & H & 1386287 & -1193822 & .1388351 \\
\hline 187 & C3/S5 & L & $1+$ & $\mathrm{O}, \mathrm{C}, \mathrm{H}$ & $\mathbf{s}$ & 976821.5 & -841894.3 & .1381288 \\
\hline 188 & $51,2,4$ & H & $1+$ & S, PA & $\mathbf{H}$ & 1093250 & -943597.5 & .1368878 \\
\hline 189 & $\mathrm{C} 2$ & H & $1+$ & $I$ & $\boldsymbol{H}$ & 1. $787947 \mathrm{E}+07$ & $-1.550706 \mathrm{E}+07$ & .1326889 \\
\hline 190 & $c_{1}$ & L & $1+$ & $\mathbf{R}$ & $\mathbf{s}$ & 245992.5 & -213450.8 & .1322876 \\
\hline 191 & C1 & $\mathbf{H}$ & $1+$ & $\mathrm{O}, \mathrm{C}, \mathrm{H}$ & $\boldsymbol{M}$ & 5629096 & -4901586 & .129241 \\
\hline 192 & RM & L & $1+$ & S, PA & $\mathbf{s}$ & 1822780 & -1589642 & .1279026 \\
\hline 193 & C2 & L & $1+$ & G, ES & $\mathbf{s}$ & 2238572 & -1952776 & .1276687 \\
\hline 194 & C1 & $L$ & $1+$ & $\mathbf{R}$ & $\boldsymbol{H}$ & 2746304 & -2400145 & .1260454 \\
\hline 195 & W. S3 & $\mathrm{H}$ & $1+$ & S, PA & $\mathbf{M}$ & 4007506 & -3512770 & .1234524 \\
\hline 196 & $\mathrm{C}_{1}$ & L & $1+$ & $I$ & $\mathbf{M}$ & 3808845 & -3338784 & .1234131 \\
\hline 197 & $C 3 / 55$ & $L$ & $1+$ & I & $s$ & 678866.9 & -595737.6 & .122453 \\
\hline 198 & PC2 & L & $1-$ & S, PA & L & 7433443 & -6523476 & .1224154 \\
\hline 199 & $\mathrm{C}_{1}$ & H & $1+$ & $O, C, H$ & $\mathbf{s}$ & 122996.3 & -107999.6 & .121928 \\
\hline 200 & $\mathrm{C2}$ & $\mathrm{H}$ & $1+$ & $\mathrm{O}, \mathrm{C}, \mathrm{H}$ & L & 2. $568632 \mathrm{E}+07$ & $-2.262906 \mathrm{E}+07$ & .1190231 \\
\hline 201 & C2 & H & $1+$ & I & $\mathbf{s}$ & 4354812 & -3839912 & .1182371 \\
\hline 202 & PC1 & L & $1+$ & S, PA & $\mathbf{s}$ & 247650 & -218392 & .1181425 \\
\hline 203 & C2 & н & $1+$ & $O, C, H$ & H & 1. $453975 E+07$ & $-1.284915 E+07$ & .1162746 \\
\hline 204 & C1 & L & $1+$ & $0, \mathrm{C}, \mathrm{H}$ & L & $6.616771 E+07$ & $-5.873827 \mathrm{E}+07$ & .1122821 \\
\hline 205 & $\mathrm{C} 2$ & L & $1+$ & G, ES & L & 1. $719561 \mathrm{E}+07$ & $-1.530423 E+07$ & .1099923 \\
\hline 206 & c2 & $\mathrm{H}$ & $1+$ & G, ES & $\mathbf{s}$ & 1112813 & -990558 & .1098612 \\
\hline 207 & $51,2,4$ & L & $1-$ & G, ES & 2 & 4. $368387 E+07$ & $-3.889677 \mathrm{E}+07$ & .1095852 \\
\hline 208 & $\mathrm{C2}$ & $\mathbf{L}$ & $1+$ & S, PA & L & 5. $609033 \mathrm{E}+07$ & $-5.004423 E+07$ & .1077923 \\
\hline 209 & PC2 & L & $1-$ & $\mathrm{O}, \mathrm{C}, \mathrm{H}$ & $\mathbf{s}$ & 1149912 & -1026848 & .1070208 \\
\hline 210 & PC2 & L & $1-$ & $\mathbf{R}$ & H & 1225345 & -1096359 & .105265 \\
\hline 211 & RH & L & $1+$ & $\mathbf{R}$ & L & 6041498 & -5407977 & .1048616 \\
\hline 212 & $\mathrm{C2}$ & $\mathbf{H}$ & $1+$ & $\mathrm{O}, \mathrm{C}, \mathrm{H}$ & $\mathbf{s}$ & 3741178 & -3352773 & .1038189 \\
\hline 213 & PC1 & $\mathbf{L}$ & $1+$ & $\mathrm{O}, \mathrm{C}, \mathrm{H}$ & L & 2160909 & -1937929 & .1031882 \\
\hline 214 & & L & $1+$ & G, ES & L & $7.014597 \mathrm{E}+07$ & $-6.298104 E+07$ & .1021432 \\
\hline 215 & $51,2,4$ & H & $1+$ & S, PA & $L$ & 2608251 & -2341911 & .1021144 \\
\hline 216 & $\mathbf{w}, \mathbf{s 3}$ & $\mathbf{H}$ & $1+$ & I & s & 1. $034847 E+07$ & -9293048 & .1019882 \\
\hline 217 & $\mathrm{c} 2$ & L & $1+$ & I & L & 6. $602995 E+07$ & $-5.936998 E+07$ & .1008629 \\
\hline 218 & PC2 & L & $1-$ & $\mathrm{O}, \mathrm{C}, \mathrm{H}$ & M & 3234423 & -2909910 & .1003309 \\
\hline 219 & $\mathrm{C2}$ & L & $1+$ & & L & 9. $428126 \mathrm{E}+07$ & $-8.495198 E+07$ & $9.895168 \mathrm{E}-02$ \\
\hline 220 & PC2 & L & $1-$ & G, ES & $\boldsymbol{M}$ & 1236368 & -1114267 & $9.875776 \mathrm{E}-02$ \\
\hline 221 & $\mathrm{C2}$ & L & $1+$ & $\mathrm{O}, \mathrm{C}, \mathrm{H}$ & L & 1. $206058 E+08$ & $-1.08745 E+08$ & 9. $834338 \mathrm{E}-02$ \\
\hline 222 & w, s3 & $\mathbf{H}$ & $1+$ & I & L & 2. $1951 \mathrm{BE}+07$ & $-1.981781 E+07$ & 9. $721232 \mathrm{E}-02$ \\
\hline 223 & $\mathrm{C2}$ & L & $1+$ & S, PA & $\boldsymbol{H}$ & 5. $161151 E+07$ & $-4.666639 E+07$ & 9. $581443 \mathrm{E}-02$ \\
\hline 224 & C2 & L & $1+$ & $I$ & $\ddot{M}$ & 1. $213618 E+08$ & $-1.097387 E+08$ & $9.577276 \mathrm{E}-02$ \\
\hline 225 & $51,2,4$ & $\mathbf{H}$ & $1-$ & I & s & 156621 & -141745.1 & $9.498048 \mathrm{E}-02$ \\
\hline 226 & W, s3 & H & $1+$ & & $\mathbf{M}$ & 1. $728747 E+07$ & $-1.564554 E+07$ & $9.497826 \mathrm{E}-02$ \\
\hline 227 & w, s3 & $\mathbf{L}$ & $1+$ & S, PA & M & 1. $801923 E+07$ & $-1.631851 E+07$ & 9. $438358 \mathrm{E}-02$ \\
\hline
\end{tabular}




\begin{tabular}{|c|c|c|c|c|c|c|c|c|}
\hline $\begin{array}{l}\mathrm{R} / \mathrm{F} \\
\text { RANK }\end{array}$ & $\begin{array}{l}\text { STRUC } \\
\text { TYPE }\end{array}$ & SHF & $\mathbf{S}$ & $\begin{array}{l}\text { OCCUP } \\
\text { TYPE }\end{array}$ & SIZE & $\begin{array}{l}\text { RETROFIT } \\
\text { COST, }\end{array}$ & $\begin{array}{l}\text { NET } \\
\text { BENEFIT, \$ }\end{array}$ & $\begin{array}{l}\text { B/C } \\
\text { RATIO }\end{array}$ \\
\hline $\begin{array}{l}228 \\
229 \\
230 \\
231 \\
232 \\
233 \\
234 \\
235 \\
236 \\
237 \\
238 \\
239 \\
240 \\
241 \\
242 \\
243 \\
244 \\
245 \\
246 \\
247 \\
248 \\
249 \\
250 \\
251 \\
252 \\
253 \\
254 \\
255 \\
256 \\
257 \\
258 \\
259 \\
260 \\
261 \\
262 \\
263 \\
264 \\
265 \\
266 \\
267 \\
268 \\
269 \\
270 \\
271 \\
272 \\
273 \\
274 \\
275 \\
276 \\
277 \\
278 \\
279 \\
280 \\
281 \\
282 \\
283 \\
284\end{array}$ & 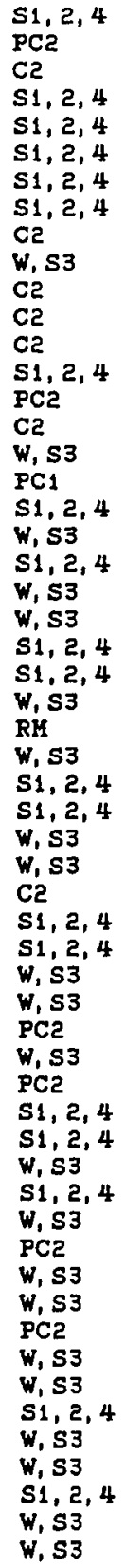 & $\begin{array}{l}\text { L } \\
L \\
L \\
H \\
L \\
H \\
L \\
L \\
L \\
H \\
L \\
L \\
L \\
L \\
L \\
L \\
H \\
L \\
L \\
L \\
H \\
H \\
L \\
L \\
L \\
L \\
L \\
H \\
L \\
H \\
L \\
L \\
L \\
L \\
L \\
H \\
L \\
L \\
H \\
L \\
L \\
H \\
H \\
L \\
L \\
L \\
Z \\
L \\
H \\
L \\
L \\
L \\
L \\
L \\
H\end{array}$ & $\begin{array}{l}1+ \\
1+ \\
1+ \\
1+ \\
1+ \\
1+ \\
1- \\
1- \\
1+ \\
1+ \\
1+ \\
1+ \\
1+ \\
1+ \\
1+ \\
1+ \\
1+ \\
1+ \\
1+ \\
1+ \\
1+ \\
1+ \\
1+ \\
1+ \\
1+ \\
1+ \\
1+ \\
1+ \\
1+ \\
1+ \\
1+ \\
1+ \\
1+ \\
1+ \\
1+ \\
1+ \\
1+ \\
1+ \\
1+ \\
1+ \\
1+ \\
1+ \\
1+ \\
1+ \\
1+ \\
1+ \\
1+ \\
1+ \\
1+ \\
1+ \\
1+ \\
1+ \\
1+ \\
1+ \\
1+ \\
1+ \\
1+\end{array}$ & $\begin{array}{l}\text { R } \\
\text { S, PA } \\
\text { G, ES } \\
\text { O, C, H } \\
\text { I } \\
\text { I } \\
\text { I } \\
\text { G, ES } \\
\text { O, C, H } \\
\text { O, C, H } \\
\text { S, PA } \\
\text { I } \\
\text { R } \\
\text { G, ES } \\
\text { O, C, H } \\
\text { O, C, H } \\
\text { O, C, H } \\
\text { G, ES } \\
\text { I } \\
\text { S, PA } \\
\text { O, C, H } \\
\text { S, PA } \\
\text { I } \\
\text { S, PA } \\
\text { O, C, H } \\
\text { I } \\
\text { G, ES } \\
\text { O, C, H } \\
\text { G, ES } \\
\text { G, ES } \\
\text { G, ES } \\
\text { I } \\
\text { R } \\
\text { S, PA } \\
\text { O, C, H } \\
\text { G, ES } \\
\text { O, C, H } \\
\text { O, C, H } \\
\text { R } \\
\text { O, C, H } \\
\text { O, C, H } \\
\text { R } \\
\text { R } \\
\text { G, ES } \\
\text { R } \\
\text { I } \\
\text { O, C, H } \\
\text { S, PA } \\
\text { O, C, H } \\
\text { R } \\
\text { O, C, H } \\
\text { R } \\
\text { R } \\
\text { G, ES } \\
\text { S, PA } \\
\text { R } \\
\text { G, ES }\end{array}$ & 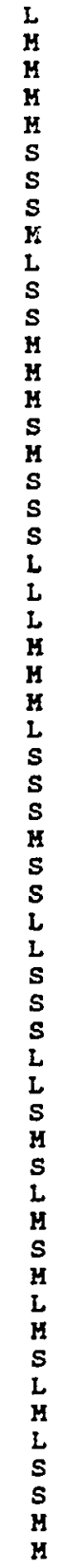 & 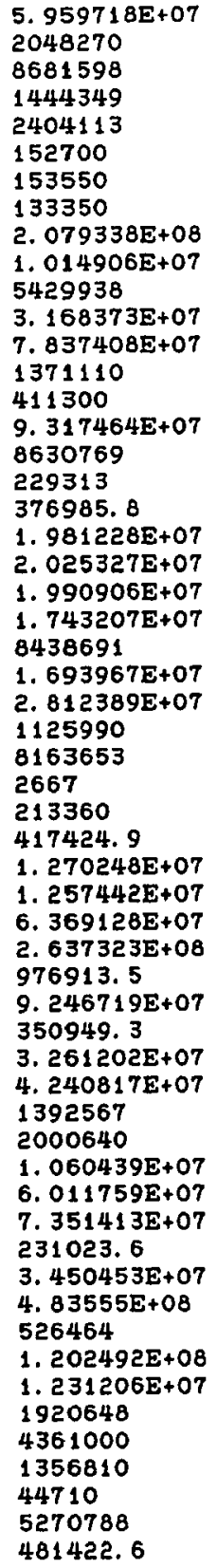 & 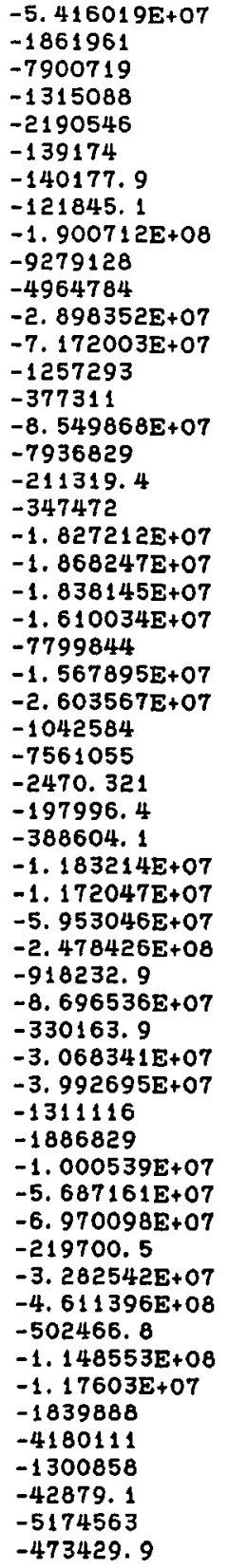 & 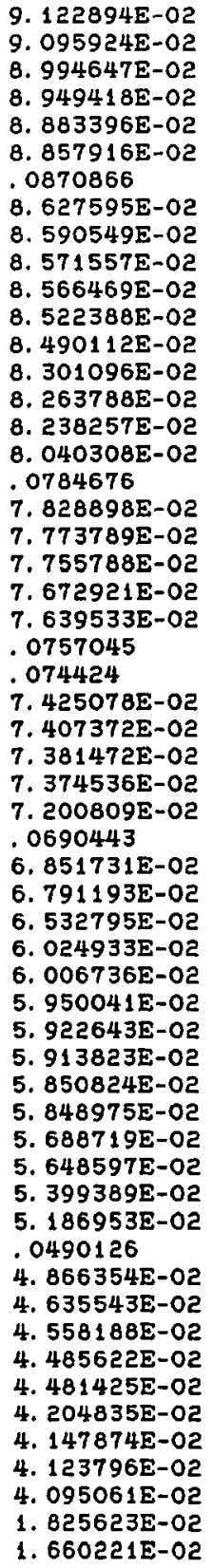 \\
\hline
\end{tabular}




\section{APPENDIX D}

\section{BUILDING CLASSES PRIORITIZED FOR OPTIMAL RETROFIT}

BASED ON AN EXPECTED VALUE ANALYSIS 
BUILDIMG CLASSES PRIORITIZED FOR OPTIHAL RETROFIT BASED ON AN EXPECTED VALUE ANALYSIS

\begin{tabular}{|c|c|c|c|c|c|c|c|c|}
\hline $\begin{array}{l}\text { R/F } \\
\text { RAKK }\end{array}$ & $\begin{array}{l}\text { STRUC } \\
\text { TYPE }\end{array}$ & SHF & $\mathbf{S}$ & $\begin{array}{l}\text { OCCUP } \\
\text { TYPE }\end{array}$ & SIZE & $\begin{array}{l}\text { RETROFIT } \\
\text { COST, \$ }\end{array}$ & $\begin{array}{l}\text { NPV OF } \\
\text { BENEFIT, } \$\end{array}$ & $\begin{array}{l}\text { PV/C } \\
\text { RATIO }\end{array}$ \\
\hline- & & & -- & -7 & & $=-$ & 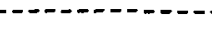 & $-\ldots$ \\
\hline 1 & PC1 & $\mathrm{H}$ & $1-$ & S, PA & $\mathbf{S}$ & 133350 & 2. $412518 E+07$ & 181.9162 \\
\hline 2 & RH & $\mathrm{H}$ & $1-$ & G, ES & $\mathrm{S}$ & 404670 & 3. 111164E+07 & 77.8815 \\
\hline 3 & PC1 & $\mathrm{H}$ & $1-$ & $\mathrm{O}, \mathrm{C}, \mathrm{H}$ & $s$ & 148050 & 5156207 & 35.82747 \\
\hline 4 & URH & $\mathrm{H}$ & $1-$ & $\mathbf{R}$ & $\mathbf{M}$ & 689800.1 & 2. $365563 E+07$ & 35. 29345 \\
\hline 5 & PC1 & $\mathrm{H}$ & $1-$ & G, ES & $S$ & 171080 & 5296898 & 31.96153 \\
\hline 6 & $\mathrm{C}_{1}$ & L & $1-$ & G, ES & L & 7149980 & 1. $908457 \mathrm{E}+08$ & 27.69178 \\
\hline 7 & URM & L & $1-$ & $\mathbf{S}, \mathbf{P A}$ & $\mathbf{s}$ & 1968781 & 3. $844657 \mathrm{E}+07$ & 20.52811 \\
\hline 8 & RH & I & $1-$ & $\mathbf{R}$ & L & 994562.4 & 1. $901965 \mathrm{E}+07$ & 20.12364 \\
\hline 9 & C3/S5 & L & $1-$ & S, PA & $\mathbf{S}$ & 232180 & 4369893 & 19.82114 \\
\hline 10 & URM & L & $1-$ & S, PA & $\mathbf{H}$ & 9809525 & 1. $654148 E+08$ & 17.86267 \\
\hline 11 & $\mathrm{C3} / \mathrm{S5}$ & $\mathrm{H}$ & $1-$ & $\mathrm{O}, \mathrm{C}, \mathrm{H}$ & $L$ & 6515080 & 1. $002391 \mathrm{E}+08$ & 16. 3857 \\
\hline 12 & RH & L & $1-$ & $\mathrm{O}, \mathrm{C}, \mathrm{H}$ & $\mathrm{L}$ & 3048508 & 4. $647194 \mathrm{E}+07$ & 16. 24416 \\
\hline 13 & C3/S5 & L & $1-$ & $\mathrm{O}, \mathrm{C}, \mathrm{H}$ & L & 1. $404658 \mathrm{E}+07$ & 1. $87053 E+08$ & 14.31662 \\
\hline 14 & URM & $\mathrm{H}$ & $1-$ & $\mathrm{O}, \mathrm{C}, \mathrm{H}$ & L & 8230580 & 1. $049445 E+08$ & 13. 75056 \\
\hline 15 & URH & L & $1-$ & S, PA & L & 1. $682362 E+07$ & 1. $989876 E+08$ & 12. 82787 \\
\hline 16 & RH & $H$ & $1-$ & I & $\mathbf{S}$ & 232815.1 & 2452166 & 11.53268 \\
\hline 17 & $c 3 / 55$ & L & $1-$ & S, PA & $\mathbf{H}$ & 1791062 & 1. $742152 E+07$ & 10. 72692 \\
\hline 18 & PC1 & $\mathbf{H}$ & $1-$ & $I$ & $\mathbf{S}$ & 245641.2 & 1876408 & 8. 638814 \\
\hline 19 & C3/S5 & $\mathrm{H}$ & $1-$ & S, PA & $\mathbf{H}$ & 725340 & 5351829 & 8.378373 \\
\hline 20 & $\mathrm{RM}$ & $\mathrm{H}$ & $1+$ & $S, P A$ & $\mathbf{H}$ & 348600 & 2498188 & 8. 166346 \\
\hline 21 & $\mathrm{Cl}_{1}$ & $\mathrm{H}$ & $1-$ & G, ES & $\mathbf{M}$ & 2991776 & 2. $104633 \mathrm{E}+07$ & 8.034729 \\
\hline 22 & URH & L & $1-$ & $\mathrm{O}, \mathrm{C}, \mathrm{H}$ & L & 5. $300257 \mathrm{E}+07$ & 3. $497782 E+08$ & 7. 599269 \\
\hline 23 & $\mathrm{Cl}$ & $H$ & $1-$ & $\mathrm{O}, \mathrm{C}, \mathrm{H}$ & $\mathbf{H}$ & 703120 & 4496438 & 7. 39498 \\
\hline 24 & C3/S5 & L & $2-$ & $S_{1} \mathbf{P A}$ & L & 6170303 & 3. $882024 E+07$ & 7.291465 \\
\hline 25 & RH & $\mathrm{H}$ & $1-$ & $\mathbf{I}$ & $\mathbf{H}$ & 2356257 & 1. $474596 E+07$ & 7. 258214 \\
\hline 26 & URH & L & $1-$ & $\hat{\mathbf{R}}$ & L & 3656768 & 2. $255551 \mathrm{E}+07$ & 7.168155 \\
\hline 27 & RH & H & $1-$ & $\mathrm{O}, \mathrm{C}, \mathrm{H}$ & $\mathbf{S}$ & 82250 & 473583.5 & 6.757854 \\
\hline 28 & PC1 & L & $1-$ & $\mathrm{O}, \mathrm{C}, \mathrm{H}$ & $\mathbf{H}$ & 966159.8 & 5262047 & 6.446353 \\
\hline 29 & URH & $\mathrm{H}$ & $1-$ & $\mathrm{O}, \mathrm{c}, \mathrm{H}$ & $\mathbf{s}$ & 2004596 & 1. $059906 \mathrm{E}+07$ & 6.287379 \\
\hline 30 & URH & $\mathrm{H}$ & $1-$ & $\mathbf{R}$ & $\mathbf{S}$ & 17330 & 89374.12 & 6.157192 \\
\hline 31 & $\mathrm{Cl}_{1}$ & $\mathrm{~L}$ & $1-$ & $\mathbf{R}$ & $L$ & 8528352 & 4. $058413 E+07$ & 5. 758731 \\
\hline 32 & C1 & $H$ & $1-$ & S, PA & L & 1. $31824 \mathrm{E}+07$ & 5. $068889 E+07$ & 4. 845195 \\
\hline 33 & RH & L & $1-$ & $\mathrm{O}, \mathrm{C}, \mathrm{H}$ & $\mathbf{S}$ & 1335543 & 4965930 & 4. 718285 \\
\hline 34 & URH & $\mathrm{H}$ & $1-$ & $\mathbf{S}, \mathbf{P A}$ & $\mathbf{H}$ & 1683886 & 6007278 & 4. 567509 \\
\hline 35 & C1 & $\mathrm{H}$ & $1-$ & $\mathbf{R}$ & $\mathbf{H}$ & 1364880 & 4631747 & 4.39352 \\
\hline 36 & URH & $\mathbf{H}$ & $1-$ & $\mathrm{O}, \mathrm{C}, \mathrm{H}$ & $\mathbf{H}$ & 2. $801784 E+07$ & $9.485271 \mathrm{E}+07$ & 4. 38544 \\
\hline 37 & PC1 & $H$ & $1-$ & $\mathrm{O}, \mathrm{C}, \mathrm{H}$ & $\mathbf{L}$ & 665175.1 & 2215990 & 4. 331438 \\
\hline 38 & RH & $\mathbf{L}$ & $1-$ & $\mathrm{O}, \mathrm{C}, \mathrm{H}$ & $\mathbf{H}$ & 1509190 & 4530426 & 4.001893 \\
\hline 39 & URH & $\mathbf{L}$ & $1-$ & $\mathbf{R}$ & $\mathbf{S}$ & 4262868 & 1. $267594 \mathrm{E}+07$ & 3.973571 \\
\hline 40 & URM & L & $1-$ & $\mathrm{O}, \mathrm{C}, \mathrm{H}$ & $\mathbf{s}$ & 2. $422262 E+07$ & $7.056948 E+07$ & 3. 913371 \\
\hline 41 & URH & $\mathbf{L}$ & $1-$ & G, ES & $\mathbf{S}$ & 655163.6 & 1500557 & 3. 290354 \\
\hline 42 & $\mathbf{R H}$ & HI & $1-$ & I & L & 535089 & 1204542 & 3. 251105 \\
\hline 43 & PC1 & $\mathbf{H}$ & $1-$ & I & $\mathbf{H}$ & 7027794 & 1. $52248 \mathrm{E}+07$ & 3. 16637 \\
\hline 44 & RM & $\mathbf{L}$ & $1-$ & I & $\mathbf{H}$ & 945936.9 & 1988497 & 3. 102146 \\
\hline 45 & URH & $\mathbf{L}$ & $1-$ & $\mathrm{O}, \mathrm{C}, \mathrm{H}$ & $\mathbf{H}$ & 7. $811875 E+07$ & 1. $638732 E+08$ & 3. 097745 \\
\hline 46 & C1 & $\mathbf{L}$ & $1-$ & $\mathrm{O}, \mathrm{C}, \mathrm{H}$ & L & 1. $449005 E+08$ & 2. $943038 \mathrm{E}+08$ & 3.031075 \\
\hline 47 & PC1 & L. & $1-$ & $I$ & $\mathrm{H}$ & 7040823 & 1. $384212 \mathrm{E}+07$ & 2. 965981 \\
\hline 48 & $\mathrm{C}_{1}$ & $\mathrm{H}$ & $1-$ & I & $\mathbf{S}$ & 211791.5 & 376199.5 & 2. 776273 \\
\hline 49 & URH & H & $1-$ & G, ES & H & 517350.1 & 904854.2 & 2. 749017 \\
\hline 50 & RH & L & $1-$ & $\mathbf{R}$ & $S$ & 295590.1 & 459673.2 & 2. 555103 \\
\hline 51 & PC1 & $\mathbf{H}$ & $1-$ & $I$ & L & 6305523 & 9721785 & 2. 541789 \\
\hline 52 & URH & $\mathbf{L}$ & $1-$ & $\bar{R}$ & $\mathbf{H}$ & 7. $8742 E+07$ & 1. $183907 \mathrm{E}+08$ & 2. 503526 \\
\hline 53 & URM & L & $1-$ & $I$ & $S$ & 4581639 & 6845443 & 2. 494104 \\
\hline 54 & URH & L & $1-$ & G, ES & L & 2760188 & 3859853 & 2. 398402 \\
\hline 55 & URH & L & $1-$ & $I$ & $\mathbf{H}$ & 1. $768281 \mathrm{E}+07$ & 2. $422209 E+07$ & 2. 36981 \\
\hline 56 & C3/S5 & L & $1-$ & $\mathbf{R}$ & $\mathbf{H}$ & 3973621 & 4661814 & 2. 17319 \\
\hline
\end{tabular}




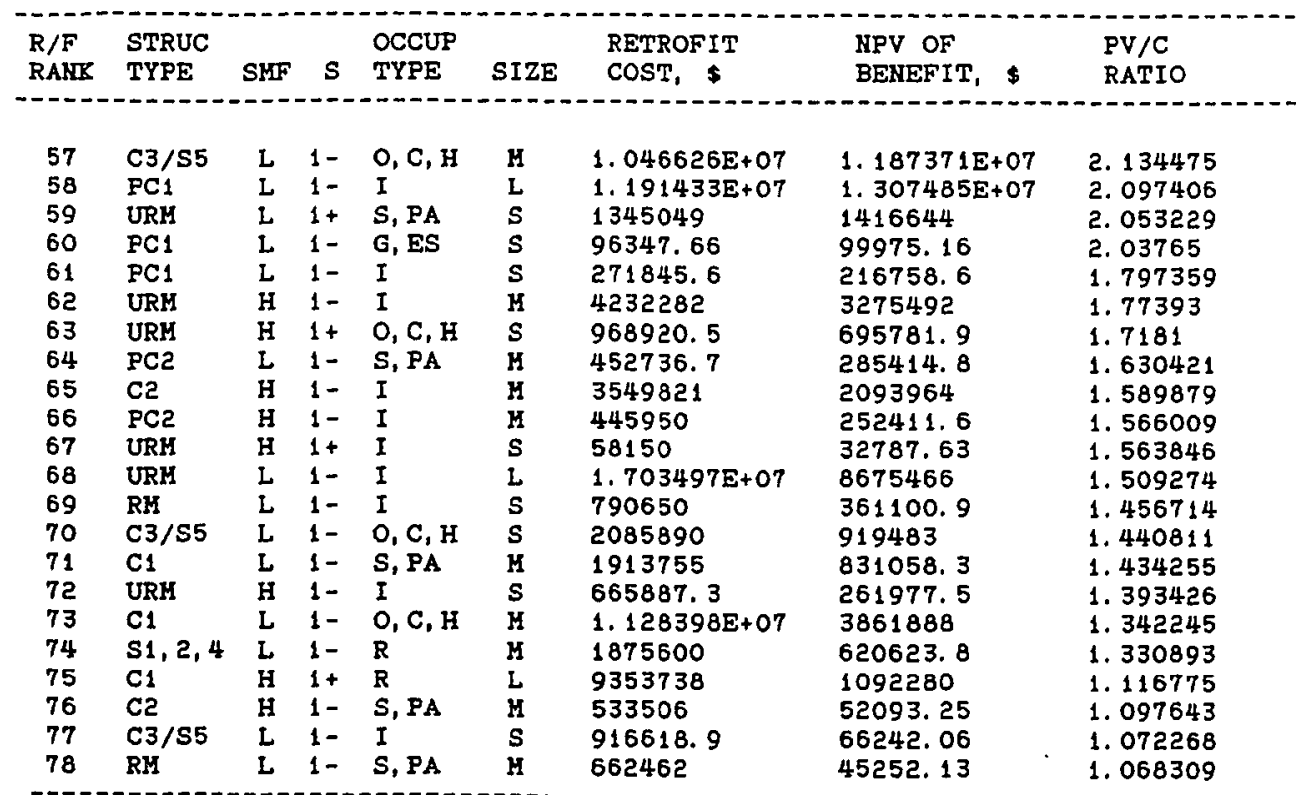

RANE NO. 78 = POINT OF MAXIMUM EFFICIENCY (OPTIKAL RETROFIT)

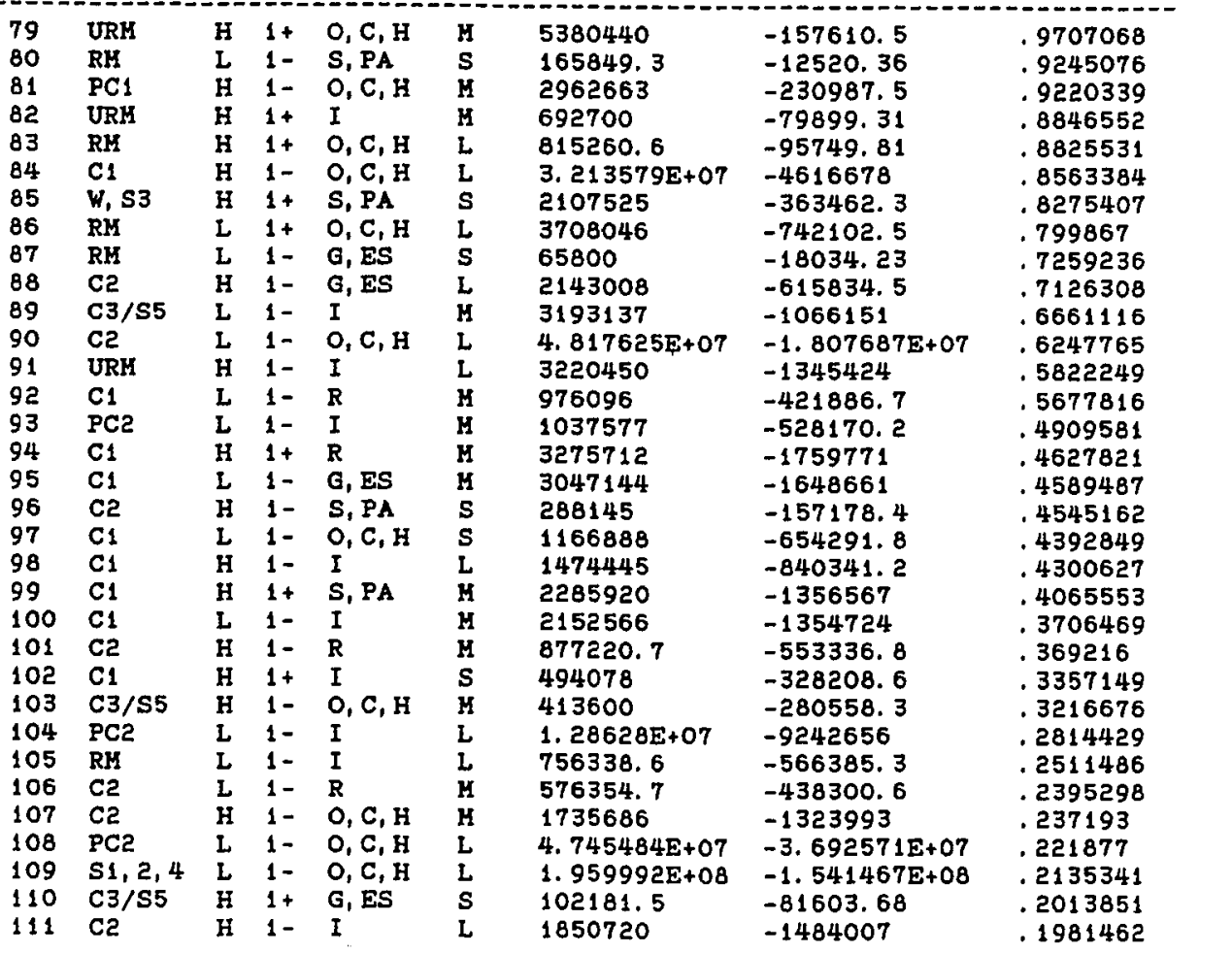




\begin{tabular}{|c|c|c|c|c|c|c|c|c|}
\hline $\begin{array}{l}\text { R/F } \\
\text { RANKR }\end{array}$ & $\begin{array}{l}\text { STRUC } \\
\text { TYPE }\end{array}$ & SMF & $\mathbf{s}$ & $\begin{array}{l}\text { OCCUP } \\
\text { TYPE }\end{array}$ & SIZE & $\begin{array}{l}\text { RETROFIT } \\
\text { COST, } \$\end{array}$ & $\begin{array}{l}\text { NPV OF } \\
\text { BENEFIT, \$ }\end{array}$ & $\begin{array}{l}\text { PV/C } \\
\text { RATIO }\end{array}$ \\
\hline 112 & RM & $\mathrm{H}$ & $1+$ & I & L & 1114111 & -920081.1 & 1741568 \\
\hline 113 & C1 & L & $1+$ & $\mathbf{R}$ & L & 2. $103142 E+07$ & $-1.75178 E+07$ & .1670651 \\
\hline 114 & $\mathrm{C} 2$ & L & $1-$ & $O, C, H$ & $\mathbf{M}$ & 1. $067941 E+07$ & -8944096 & .1624915 \\
\hline 115 & $\mathrm{C} 2$ & H & $1-$ & $0, \mathrm{C}, \mathrm{H}$ & $s$ & 277295.9 & -232904.9 & .1600853 \\
\hline 116 & RM & H & $1+$ & $\mathbf{R}$ & MI & 148300 & -126523 & .1468442 \\
\hline 117 & URM & L & $1+$ & $\mathbf{R}$ & M & 2. $648288 E+07$ & $-2.271378 E+07$ & .1423222 \\
\hline 118 & RH & $\mathbf{H}$ & $1+$ & $I$ & $\mathbf{s}$ & 592598.5 & -509018.8 & .1410394 \\
\hline 119 & $C_{1}$ & L & $1+$ & S, PA & H & 1334670 & -1147447 & .1402766 \\
\hline 120 & RH & L & $1+$ & S, PA & $\mathbf{H}$ & 6098496 & -5293188 & . 1320502 \\
\hline 121 & RMI & H & $1+$ & I & $\boldsymbol{H}$ & 2289660 & -2023354 & .116308 \\
\hline 122 & $\mathrm{C}_{1}$ & L & $1+$ & $O, C, H$ & L & $6.616771 \mathrm{E}+07$ & $-5.932476 E+07$ & 1034183 \\
\hline 123 & $C_{1}$ & $\mathbf{L}$ & $1-$ & I & L & 2052605 & -1845914 & .100697 \\
\hline 124 & $\mathrm{C2}$ & H & $1-$ & $\mathrm{O}, \mathrm{C}, \mathrm{H}$ & $\bar{L}$ & 1. $56092 E+07$ & $-1.409464 E+07$ & 9. $702982 E-02$ \\
\hline 125 & $R \mathbf{R}$ & $\mathbf{H}$ & $1+$ & $\mathrm{O}, \mathrm{C}, \mathrm{H}$ & s & 1048276 & -953639.1 & 9. $027858 E-02$ \\
\hline 126 & URH & L & $1+$ & $0, \mathrm{C}, \mathrm{H}$ & $\mathbf{M}$ & 2. $425889 E+07$ & $-2.245963 E+07$ & 7. $416923 \mathrm{E}-02$ \\
\hline 127 & RH & H & $1+$ & G, ES & $\mathrm{s}$ & 568826.8 & -528801.2 & 7. $036521 \mathrm{E}-02$ \\
\hline 128 & $\mathrm{Cl}_{1}$ & $\mathbf{L}$ & $1+$ & $O, C, H$ & $\mathbf{M}$ & 1. $306418 E+07$ & $-1.214815 E+07$ & $7.011772 E-02$ \\
\hline 129 & URH & $\mathbf{L}$ & $1+$ & $\mathbf{S}, \mathbf{P A}$ & $\boldsymbol{H}$ & 6281155 & -5856220 & $6.765241 \mathrm{E}-02$ \\
\hline 130 & URH & L & $1+$ & $O, C, H$ & 5 & 9636134 & -8991664 & 6. $688053 \mathrm{E}-02$ \\
\hline 131 & PC2 & L & $1-$ & $O, C, H$ & $\boldsymbol{H}$ & 3234423 & -3022644 & 6. $547671 E-02$ \\
\hline 132 & URH & L & $1+$ & G, ES & $s$ & 191739.1 & -179332.6 & 6. $470521 E-02$ \\
\hline 133 & URH & L & $1+$ & S, PA & L & 2646517 & -2477762 & 6. $376482 E-02$ \\
\hline 134 & PC1 & $H$ & $1+$ & I & L & 1. $948893 \mathrm{E}+07$ & $-1.826058 E+07$ & 6. 302792E-02 \\
\hline 135 & URM & L & $1+$ & $\mathbf{I}$ & $\bar{s}$ & 3025033 & -2835107 & 6. $278468 \mathrm{E}-02$ \\
\hline 136 & PC1 & $\bar{L}$ & $1+$ & S, PA & L & 2865108 & -2689581 & 6. $126357 \mathrm{E}-02$ \\
\hline 137 & $\mathrm{C} 2$ & $\mathbf{L}$ & $1-$ & S, PA & $\mathbf{M}$ & 487502.1 & -458262.1 & 5. $997935 \mathrm{E}-02$ \\
\hline 138 & URM & L & $1+$ & $\mathbf{R}$ & s & 9781850 & -9228940 & 5. $652404 E-02$ \\
\hline 139 & PC1 & L & $1+$ & I & L & 1. $713839 \mathrm{E}+07$ & $-1.618202 \mathrm{E}+07$ & 5. $5802632-02$ \\
\hline 140 & $\mathrm{c} 2$ & L & $1-$ & I & $\mathbf{M}$ & 2447552 & -2316456 & 5. $356226 \mathrm{E}-02$ \\
\hline 141 & PC1 & H & $1+$ & I & $s$ & 771674.5 & -730517.8 & 5. $333436 \mathrm{E}-02$ \\
\hline 142 & PC1 & H & $1+$ & $\mathrm{O}, \mathrm{C}, \mathrm{H}$ & MI & 3726468 & -3531132 & 5. $241871 E-02$ \\
\hline 143 & PC1 & L & $1+$ & I & $\mathbf{H}$ & 2. $834568 E+07$ & $-2.688545 E+07$ & 5. $151503 \mathrm{E}-02$ \\
\hline 144 & RH & L & $1+$ & $S, P A$ & L & 3138398 & -2977256 & 5. $134522 E-02$ \\
\hline 145 & $\mathrm{C} 2$ & L & $1-$ & $0, C, H$ & $s$ & 2163954 & -2053431 & 5. $107446 E-02$ \\
\hline 146 & C1 & L & $1+$ & $I$ & $\mathbf{s}$ & 353823.6 & -336107.5 & 5. $007033 E-02$ \\
\hline 147 & URM & $\mathbf{L}$ & $1+$ & I & $\mathbf{H}$ & 1. $606371 E+07$ & $-1.526656 E+07$ & 4. $962434 E-02$ \\
\hline 148 & $\mathbf{R M}$ & L & $1+$ & $\mathrm{O}, \mathrm{C}, \mathrm{H}$ & $\mathbf{s}$ & 2. $611807 \mathrm{E}+07$ & -2. $488121 E+07$ & .0473566 \\
\hline 149 & RH & L & $1+$ & $I$ & M & 8635192 & -8235773 & 4. $625474 \mathrm{E}-02$ \\
\hline 150 & C3/S5 & L & $1+$ & S, PA & $\mathbf{s}$ & 375060 & -358407.7 & 4. $439913 \mathrm{E}-02$ \\
\hline 151 & URH & $\mathbf{L}$ & $1+$ & I & L & 4979259 & -4758497 & .0443363 \\
\hline 152 & PC1 & $\mathbf{H}$ & $1+$ & I & $\mathbf{M}$ & 1. $286441 E+07$ & $-1.23252 E+07$ & .0419151 \\
\hline 153 & PC1 & L & $1+$ & S, PA & $\mathbf{M}$ & 175694.4 & -168400.3 & 4. $151579 \mathrm{E}-02$ \\
\hline 154 & $\mathbf{R H}$ & L & $1+$ & $I$ & $\mathbf{s}$ & 8932788 & -8583598 & 3. $909085 \mathrm{E}-02$ \\
\hline 155 & $\mathrm{C2}$ & H & $1-$ & G, ES & $\mathbf{s}$ & 450684 & -433729.3 & $3.762005 \mathrm{E}-02$ \\
\hline 156 & URH & L & $1+$ & $O, C_{1} \mathrm{H}$ & L & 1. $05613 E+07$ & $-1.0181 B 1 E+07$ & 3. $593181 \mathrm{E}-02$ \\
\hline 157 & PC2 & $\bar{L}$ & $1-$ & $\mathrm{O}, \mathrm{C}, \mathrm{H}$ & $\mathrm{s}$ & 1149912 & -1109673 & 3. $499306 \mathrm{E}-02$ \\
\hline 158 & URM & $\bar{L}$ & $1+$ & $\mathbf{R}$ & L & 5517682 & -5329728 & 3. $406392 \mathrm{E}-02$ \\
\hline 159 & $\mathbf{R} \mathbf{M}$ & $\mathrm{L}$ & $1+$ & G, ES & $\mathbf{s}$ & 1099413 & -1064926 & 3. $136867 \mathrm{E}-02$ \\
\hline 160 & RH & L & $1+$ & $\mathbf{R}$ & $\mathbf{s}$ & 1364577 & -1322320 & 3. $0966825-02$ \\
\hline 161 & RH & $\bar{L}$ & $1+$ & $\mathbf{R}$ & $\mathbf{H}$ & 2716589 & -2635097 & $2.9997995-02$ \\
\hline 162 & PCI & L & $1+$ & $\mathrm{O}, \mathrm{C}, \mathrm{H}$ & $\boldsymbol{H}$ & 1. $047522 E+07$ & $-1.016644 E+07$ & 2. $947706 \mathrm{E}-02$ \\
\hline 163 & RH & $\mathbf{L}$ & $1+$ & I & L & 1357468 & -1318046 & 2. $904081 E-02$ \\
\hline 164 & $\mathrm{Cl}_{1}$ & L & $1+$ & S, PA & L & 2. $77972 E+07$ & $-2.700563 E+07$ & .0284767 \\
\hline 165 & $C_{1}$ & $L$ & $1+$ & $\mathrm{O}, \mathrm{C}, \mathrm{H}$ & $\mathbf{s}$ & 2957125 & -2874005 & 2. $810835 \mathrm{E}-02$ \\
\hline 166 & $\mathrm{C}_{1}$ & $\mathbf{H}$ & $1+$ & $\mathrm{O}, \mathrm{C}, \mathrm{H}$ & $\mathbf{H}$ & 5629096 & -5478707 & 2. $671644 \mathrm{E}-02$ \\
\hline 167 & $\mathrm{C} 2$ & L & $1-$ & G, ES & L & 1. $33681 \mathrm{E}+07$ & $-1.301806 E+07$ & 2. $618502 \mathrm{E}-02$ \\
\hline 168 & PC1 & L & $1+$ & & $\mathbf{s}$ & 6893252 & -6717085 & 2. $555646 \mathrm{E}-02$ \\
\hline 169 & PC2 & L & $1-$ & S, PA & L & 7433443 & -7243628 & 2. $553528 \mathrm{E}-02$ \\
\hline
\end{tabular}




\begin{tabular}{|c|c|c|c|c|c|c|c|c|}
\hline $\begin{array}{l}\text { R/F } \\
\text { RANK }\end{array}$ & $\begin{array}{l}\text { STRUC } \\
\text { TYPE }\end{array}$ & SMF & $\mathbf{S}$ & $\begin{array}{l}\text { OCCUP } \\
\text { TYPE }\end{array}$ & SIZE & $\begin{array}{l}\text { RETROFIT } \\
\text { COST, } \$\end{array}$ & $\begin{array}{l}\text { KPV OF } \\
\text { BENEFIT, }\end{array}$ & $\begin{array}{l}\text { PV/C } \\
\text { RATIO }\end{array}$ \\
\hline $\begin{array}{l}170 \\
171 \\
172 \\
173 \\
174 \\
175 \\
176 \\
177 \\
178 \\
179 \\
180 \\
181 \\
182 \\
183 \\
184 \\
185 \\
185 \\
187 \\
188 \\
189 \\
190 \\
191 \\
192 \\
193 \\
194 \\
195 \\
196 \\
197 \\
198 \\
199 \\
200 \\
201 \\
202 \\
203 \\
204 \\
205 \\
206 \\
207 \\
208 \\
209 \\
210 \\
211 \\
212 \\
213 \\
214 \\
215 \\
216 \\
217 \\
218 \\
219 \\
220 \\
221 \\
222 \\
223 \\
224 \\
225 \\
226 \\
227\end{array}$ & 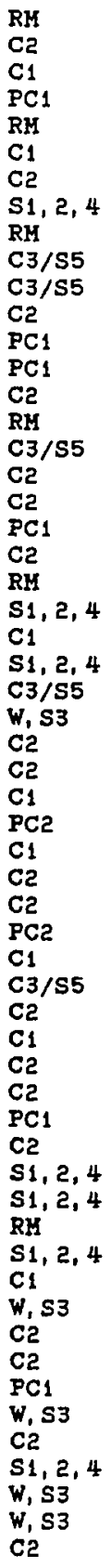 & 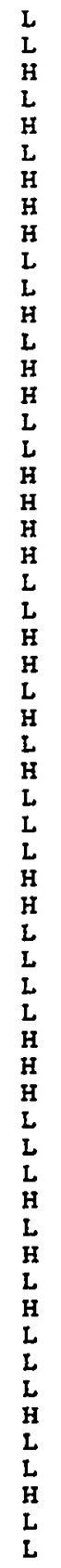 & $\begin{array}{l}1+ \\
1- \\
1+ \\
1+ \\
1+ \\
1+ \\
1+ \\
1+ \\
1+ \\
1+ \\
1+ \\
1+ \\
1+ \\
1+ \\
1+ \\
1+ \\
1+ \\
1+ \\
1+ \\
1+ \\
1+ \\
1+ \\
1- \\
1+ \\
1+ \\
1+ \\
1+ \\
1+ \\
1+ \\
1+ \\
1- \\
1+ \\
1+ \\
1+ \\
1- \\
1+ \\
1+ \\
1+ \\
1+ \\
1+ \\
1+ \\
1+ \\
1+ \\
1- \\
1+ \\
1+ \\
1- \\
1+ \\
1+ \\
1+ \\
1+ \\
1+ \\
1+ \\
1+ \\
1- \\
1+ \\
1+ \\
1+\end{array}$ & $\begin{array}{l}\text { G, ES } \\
\text { I } \\
\text { I } \\
\text { O, C, H } \\
\text { O, C, H } \\
\text { S, PA } \\
\text { G, ES } \\
\text { G, ES } \\
\text { G, ES } \\
\text { I } \\
\text { I } \\
\text { I } \\
\text { G, ES } \\
\text { O, C, H } \\
\text { G, ES } \\
\text { O, C, H } \\
\text { O, C, H } \\
\text { S, PA } \\
\text { R } \\
\text { O, C, H } \\
\text { I } \\
\text { S, PA } \\
\text { O, C, H } \\
\text { O, C, H } \\
\text { S, PA } \\
\text { O, C, H } \\
\text { S, PA } \\
\text { G, ES } \\
\text { I } \\
\text { I } \\
\text { R } \\
\text { R } \\
\text { O, C, H } \\
\text { O, C, H } \\
\text { G, ES } \\
\text { R } \\
\text { I } \\
\text { S, PA } \\
\text { O, C, H } \\
\text { O, C, H } \\
\text { G, ES } \\
\text { S, PA } \\
\text { G, ES } \\
\text { G, ES } \\
\text { S, PA } \\
\text { R } \\
\text { I } \\
\text { G, ES } \\
\text { I } \\
\text { O, C, H } \\
\text { I } \\
\text { O, C, H } \\
\text { I } \\
\text { I } \\
\text { I } \\
\text { I } \\
\text { S, PA } \\
\text { S, PA }\end{array}$ & 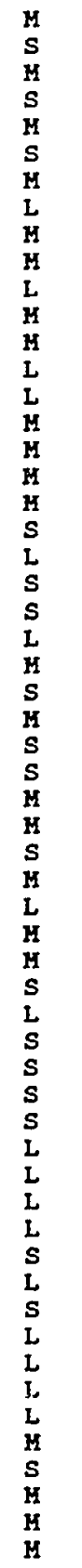 & $\begin{array}{l}327846.8 \\
241881.8 \\
1078560 \\
4398993 \\
1852890 \\
556026.5 \\
1974754 \\
5198806 \\
222450 \\
2075329 \\
3916800 \\
1.787947 \mathrm{E}+07 \\
584702.4 \\
3722783 \\
5116480 \\
1.436191 \mathrm{E}+07 \\
1137566 \\
1486820 \\
1386287 \\
159828.2 \\
2.700477 \mathrm{E}+07 \\
1822780 \\
333840 \\
1.192852 \mathrm{E}+07 \\
1093250 \\
976821.5 \\
4007506 \\
2238572 \\
4354812 \\
3808845 \\
1225345 \\
245992.5 \\
1.453975 \mathrm{E}+07 \\
2.568632 \mathrm{E}+07 \\
1236368 \\
2746304 \\
678866.9 \\
5.609033 \mathrm{E}+07 \\
122996.3 \\
3741178 \\
1112813 \\
247650 \\
1.719561 \mathrm{E}+07 \\
4.368387 \mathrm{E}+07 \\
2608251 \\
6041498 \\
156621 \\
7.014597 \mathrm{E}+07 \\
1.034847 \mathrm{E}+07 \\
1.206058 \mathrm{E}+08 \\
6.602995 \mathrm{E}+07 \\
2160909 \\
2.19518 \mathrm{E}+07 \\
1.213618 \mathrm{E}+08 \\
153550 \\
1.728747 \mathrm{E}+07 \\
1.801923 \mathrm{E}+07 \\
5.161151 \mathrm{E}+07\end{array}$ & $\begin{array}{l}-319579 \\
-235947.1 \\
-1052614 \\
-4293696 \\
-1809095 \\
-543256.1 \\
-1931619 \\
-5086394 \\
-217666.4 \\
-2031170 \\
-3836442 \\
-1.751315 E+07 \\
-572807.1 \\
-3648593 \\
-5014731 \\
-1.407635 E+07 \\
-1115329 \\
-1458509 \\
-1360358 \\
-156916.9 \\
-2.651528 E+07 \\
-1792370 \\
-328326.6 \\
-1.173194 E+07 \\
-1075450 \\
-961385.6 \\
-3945158 \\
-2203829 \\
-4287400 \\
-3749892 \\
-1207020 \\
-242350.3 \\
-1.432891 E+07 \\
-2.532229 E+07 \\
-1218919 \\
-2708181 \\
-669469 \\
-5.531548 E+07 \\
-121347.7 \\
-3691677 \\
-1098271 \\
-244432.8 \\
-1.697262 E+07 \\
-4.312204 E+07 \\
-2574769 \\
-5964656 \\
-154667.3 \\
-6.928248 E+07 \\
-1.022357 E+07 \\
-1.191556 E+08 \\
-6.525954 E+07 \\
-2135715 \\
-2.170104 E+07 \\
-1.200064 E+08 \\
-151846.8 \\
-1.709605 E+07 \\
-1.781979 E+07 \\
-5.104175 E+07\end{array}$ & 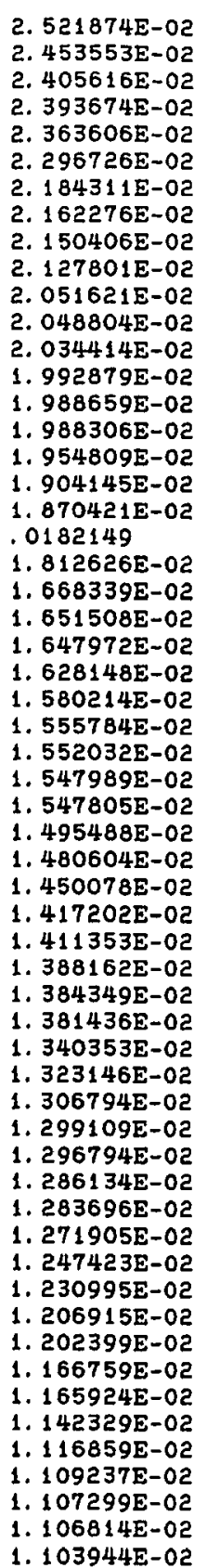 \\
\hline
\end{tabular}




\begin{tabular}{|c|c|c|c|c|c|c|c|c|}
\hline $\begin{array}{l}\text { R/F } \\
\text { RANK }\end{array}$ & $\begin{array}{l}\text { STRUC } \\
\text { TYPE }\end{array}$ & SMF & $\mathbf{S}$ & $\begin{array}{l}\text { OCCUP } \\
\text { TYPE }\end{array}$ & SIZE & $\begin{array}{l}\text { RETROFIT } \\
\text { COST, \$ }\end{array}$ & $\begin{array}{l}\text { NPV OF } \\
\text { BENEFIT, }\end{array}$ & $\begin{array}{l}\text { PV/C } \\
\text { RATIO }\end{array}$ \\
\hline $\begin{array}{l}228 \\
229 \\
230 \\
231 \\
232 \\
233 \\
234 \\
235 \\
236 \\
237 \\
238 \\
239 \\
240 \\
241 \\
242 \\
243 \\
244 \\
245 \\
246 \\
247 \\
248 \\
249 \\
250 \\
251 \\
252 \\
253 \\
254 \\
255 \\
256 \\
257 \\
258 \\
259 \\
260 \\
261 \\
262 \\
263 \\
264 \\
265 \\
266 \\
267 \\
268 \\
269 \\
270 \\
271 \\
272 \\
273 \\
274 \\
275 \\
276 \\
277 \\
278 \\
279 \\
280 \\
281 \\
282 \\
283 \\
284\end{array}$ & 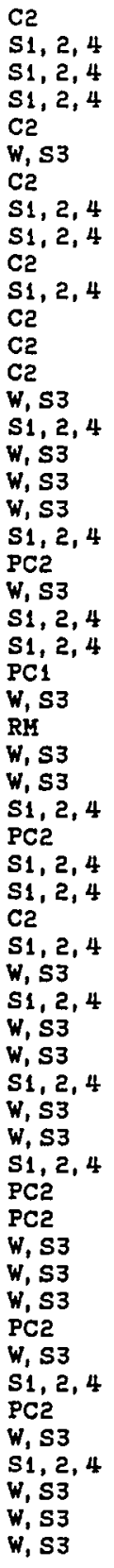 & $\begin{array}{l}L \\
L \\
H \\
L \\
L \\
H \\
L \\
L \\
H \\
L \\
L \\
L \\
L \\
L \\
H \\
L \\
H \\
L \\
L \\
L \\
L \\
H \\
H \\
L \\
L \\
L \\
L \\
L \\
L \\
L \\
L \\
H \\
L \\
L \\
L \\
L \\
H \\
H \\
H \\
L \\
H \\
L \\
L \\
L \\
H \\
H\end{array}$ & $\begin{array}{l}1+ \\
1- \\
1+ \\
1+ \\
1+ \\
1+ \\
1+ \\
1+ \\
1+ \\
1+ \\
1+ \\
1+ \\
1+ \\
1+ \\
1+ \\
1+ \\
1+ \\
1+ \\
1+ \\
1+ \\
1+ \\
1+ \\
1+ \\
1+ \\
1+ \\
1+ \\
1+ \\
1+ \\
1+ \\
1+ \\
1+ \\
1+ \\
1+ \\
1+ \\
1+ \\
1+ \\
1+ \\
1+ \\
1+ \\
1+ \\
1+ \\
1+ \\
1+ \\
1+ \\
1+ \\
1+ \\
1+ \\
1+ \\
1+ \\
1+ \\
1+ \\
1+ \\
1+ \\
1+ \\
1+ \\
1+ \\
1+\end{array}$ & $\begin{array}{l}\text { R } \\
\text { G, ES } \\
\text { I } \\
\text { I } \\
\text { G, ES } \\
\text { O, C, H } \\
\text { O, C, H } \\
\text { R } \\
\text { O, C, H } \\
\text { I } \\
\text { G, ES } \\
\text { S, PA } \\
\text { R } \\
\text { O, C, H } \\
\text { O, C, H } \\
\text { I } \\
\text { S, PA } \\
\text { S, PA } \\
\text { I } \\
\text { O, C, H } \\
\text { S, PA } \\
\text { O, C, H } \\
\text { G, ES } \\
\text { S, PA } \\
\text { G, ES } \\
\text { I } \\
\text { G, ES } \\
\text { G, ES } \\
\text { I } \\
\text { G, ES } \\
\text { O, C, H } \\
\text { O, C, H } \\
\text { S, PA } \\
\text { R } \\
\text { O, C, H } \\
\text { O, C, H } \\
\text { R } \\
\text { G, ES } \\
\text { R } \\
\text { O, C, H } \\
\text { R } \\
\text { R } \\
\text { G, ES } \\
\text { O, C, H } \\
\text { O, C, H } \\
\text { O, C, H } \\
\text { S, PA } \\
\text { O, C, H } \\
\text { I } \\
\text { R } \\
\text { S, PA } \\
\text { O, C, H } \\
\text { R } \\
\text { R } \\
\text { G, ES } \\
R \\
\text { G, ES }\end{array}$ & 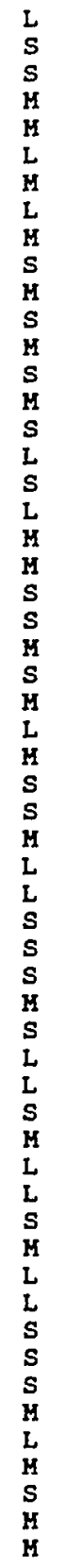 & $\begin{array}{l}9.428126 \mathrm{E}+07 \\
133350 \\
152700 \\
2404113 \\
8681598 \\
1.014906 \mathrm{E}+07 \\
2.079338 \mathrm{E}+08 \\
5.959718 \mathrm{E}+07 \\
1444349 \\
3.168373 \mathrm{E}+07 \\
1371110 \\
5429938 \\
7.837408 \mathrm{E}+07 \\
9.317464 \mathrm{E}+07 \\
8630769 \\
376985.8 \\
1.990906 \mathrm{E}+07 \\
1.981228 \mathrm{E}+07 \\
1.743207 \mathrm{E}+07 \\
1.693967 \mathrm{E}+07 \\
2048270 \\
8163653 \\
213360 \\
8438691 \\
229313 \\
2.812389 \mathrm{E}+07 \\
1125990 \\
417424.9 \\
1.270248 \mathrm{E}+07 \\
2667 \\
411300 \\
2.025327 \mathrm{E}+07 \\
6.369128 \mathrm{E}+07 \\
1.257442 \mathrm{E}+07 \\
1392567 \\
9.246719 \mathrm{E}+07 \\
2000640 \\
976913.5 \\
3.261202 \mathrm{E}+07 \\
2.637323 \mathrm{E}+08 \\
1.060439 \mathrm{E}+07 \\
7.351413 \mathrm{E}+07 \\
6.011759 \mathrm{E}+07 \\
4.240817 \mathrm{E}+07 \\
350949.3 \\
3.450453 \mathrm{E}+07 \\
4.83555 \mathrm{~B}+08 \\
1.231206 \mathrm{E}+07 \\
231023.6 \\
1.202492 \mathrm{E}+08 \\
44710 \\
526464 \\
4361000 \\
1920648 \\
1356810 \\
5270788 \\
481422.6 \\
1.69\end{array}$ & $\begin{array}{l}-9.324702 E+07 \\
-131904.6 \\
-151061.2 \\
-2378768 \\
-8591495 \\
-1.004421 E+07 \\
-2.058241 E+08 \\
-5.900395 E+07 \\
-1430011 \\
-3.137139 E+07 \\
-1357651 \\
-5376961 \\
-7.761121 E+07 \\
-9.227369 E+07 \\
-8549126 \\
-373439.9 \\
-1.972482 E+07 \\
-1.963356 E+07 \\
-1.727625 E+07 \\
-1.678864 E+07 \\
-2030132 \\
-8091793 \\
-211486.5 \\
-8364737 \\
-227309.1 \\
-2.788167 E+07 \\
-1116727 \\
-414021.9 \\
-1.260081 E+07 \\
-2645.788 \\
-408096.7 \\
-2.009616 E+07 \\
-6.319993 E+07 \\
-1.247753 E+07 \\
-1382840 \\
-9.182174 E+07 \\
-1986803 \\
-970166.2 \\
-3.238819 E+07 \\
-2.619612 E+08 \\
-1.053457 E+07 \\
-7.306749 E+07 \\
-5.976824 E+07 \\
-4.216523 E+07 \\
-348942.4 \\
-3.430761 E+07 \\
-4.809422 E+08 \\
-1.224564 E+07 \\
-229797.4 \\
-1.1962 E+08 \\
-44483.59 \\
-523854.1 \\
-4339714 \\
-1911295 \\
-1350353 \\
-5259647 \\
-480497.9 \\
-145\end{array}$ & 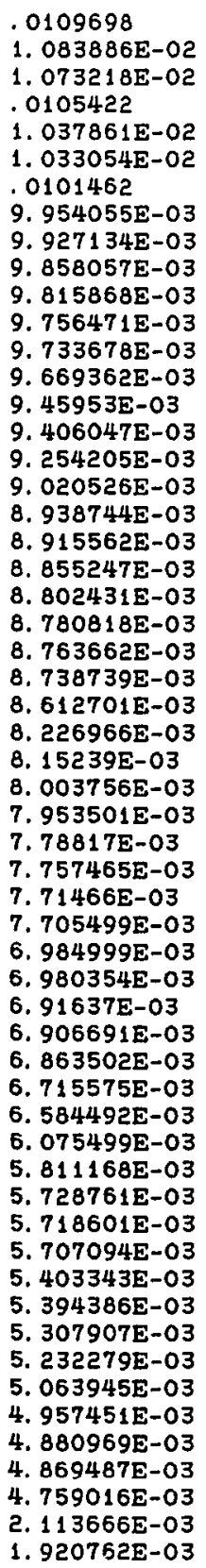 \\
\hline
\end{tabular}

